Fabiane dos Santos

(Organizadora)

\section{Meio Ambiente em Foco Volume 11}

1a Edição

Belo Horizonte

Poisson

2020 
Editor Chefe: Dr. Darly Fernando Andrade

\section{Conselho Editorial}

Dr. Antônio Artur de Souza - Universidade Federal de Minas Gerais Msc. Davilson Eduardo Andrade

Dra. Elizângela de Jesus Oliveira - Universidade Federal do Amazonas

Msc. Fabiane dos Santos

Dr. José Eduardo Ferreira Lopes - Universidade Federal de Uberlândia

Dr. Otaviano Francisco Neves - Pontifícia Universidade Católica de Minas Gerais

Dr. Luiz Cláudio de Lima - Universidade FUMEC

Dr. Nelson Ferreira Filho - Faculdades Kennedy

Msc. Valdiney Alves de Oliveira - Universidade Federal de Uberlândia

\begin{tabular}{|l} 
Dados Internacionais de Catalogação na Publicação (CIP) \\
Meio Ambiente em Foco - Volume 11/ \\
Organização: Fabiane dos Santos \\
Belo Horizonte - MG: Poisson, 2020 \\
Formato: PDF \\
ISBN: $978-85-7042-214-9$ \\
DOI: 10.36229/978-85-7042-214-9 \\
Modo de acesso: World Wide Web \\
Inclui bibliografia \\
1. Meio ambiente 2. Gestão. I. dos Santos, \\
Fabiane \\
CDD-577
\end{tabular}

O conteúdo dos artigos e seus dados em sua forma, correção e confiabilidade são de responsabilidade exclusiva dos seus respectivos autores.

Baixe outros títulos gratuitamente em www.poisson.com.br

contato@poisson.com.br 


\section{APRESENTAÇÃO}

Há uma exigência imperiosa em ligarmos as relações humanas com as bases da sustentabilidade para a vida em nosso planeta. Ressignificar, no sentido de atribuir o que se conhece à nossa visão sobre o meio do qual somos integrantes, é um dos caminhos para a percepção ambiental mais eficiente e ativa em prol da educação e da qualidade de vida que constitui a essência de qualquer ser vivo. Para tal, requer-se mudar as perspectivas e alterar os resultados, além das escolhas e dos comportamentos.

Formar entendimento e conectar o ser humano com o meio ambiente apazigua e restaura os valores, as escolhas e as atitudes ambientais, transformando a sociedade e a cultura além das necessidades. É com esse viés que se pode chegar à tomada de consciência e às mudanças significativas.

Ao ampliarmos os conhecimentos e levá-los adiante cumprimos com o desafio de coordenar a riqueza ambiental do país de forma mais equitativa e descentralizada, assegurando a reflexão e o debate com justiça socioambiental. Desenvolvendo, portanto, a clareza do papel de cada um nesse processo.

Alinhar ao que o caro leitor espera, surpreendê-lo e estimulá-lo a compartilhar com o maior número de pessoas, desde estudantes, profissionais, a tomadores de decisões, se propaga nas próximas páginas, recheadas de bons conteúdos, comprometimento dos autores e amplas vias de conhecimento.

Aproveite a leitura!

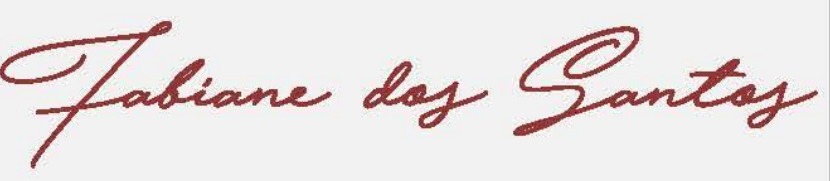




\section{Sumário}

Capítulo 1: Estimativa de vazões máximas no Rio Itapetininga 08

Alice Sales Fabiano de Almeida, Isabela Malospírito Villens, Mariana Barbosa, Stephanie Oliveira Neves, Jorge Luis Rodrigues Pantoja Filho

DOI: 10.36229/978-85-7042-214-9.CAP.01

Capítulo 2: Aplicação de métodos probabilísticos na previsão de enchentes na Bacia Hidrográfica do Rio Piracicaba, no Município de Piracicaba-SP 19

Júlia Rinaldi de Macedo Cortez, Thiago de Oliveira Calsolari, Jorge Luis Rodrigues Pantoja Filho

DOI: $10.36229 / 978-85-7042-214-9 . C A P .02$

Capítulo 3: Avaliação da eficiência de tratamento piloto de filtro ascendente e bloco cerâmico para a água do Rio Paraopeba pós -rompimento da Barragem B1 da Vale, em Brumadinho- MG 29

Tiago Lucas Ferreira, Jessica Cristina de Souza Caetano, Hygor Aristides Victor Rossoni

DOI: 10.36229/978-85-7042-214-9.CAP.03

Capítulo 4: Avaliação do uso de coagulantes naturais no tratamento de águas residuárias do processo de fabricação de fogos de artifício

Sueli Maria dos Santos, Hygor Aristides Victor Rossini

DOI: $10.36229 / 978-85-7042-214-9 . C A P .04$

Capítulo 5: Avaliação da eficiência das sementes de Moringa Oleifera Lam. para remoção de turbidez em afluentes 37

Filipe de Souza Pinto, Ana Claudia Pimentel de Oliveira

DOI: 10.36229/978-85-7042-214-9.CAP.05

Capítulo 6: Estudo da capacidade de adsorção de íons $\mathrm{Mn}^{2+}$ em cabelo 43

Tania Regina Giraldi, Breno Cantadori, Juan Douglas Carvalho Guidio, Luis Henrique Nery

DOI: $10.36229 / 978-85-7042-214-9 . C A P .06$

Capítulo 7: Estudo da viabilidade de utilização de técnicas alternativas para a produção de peças porosas de $\mathrm{ZnO}$ para fotocatálise 47

Paula Guimarães Neves, Rodrigo Amorim Munhoz, Sergio Andres Villalba Morales, Sylma Carvalho Maestrelli

DOI: $10.36229 / 978-85-7042-214-9 . C A P .07$ 


\section{Sumário}

Capítulo 8: Estudo do teor de Enxofre presente na gasolina comercializada no Território Brasileiro 51

Rosana Petinatti da Cruz, Isabella Oliveira da Silva, Tiago Nascimento da Silva Faria, Karine Resende Corrêa Florentino, Domenique Ramalho Corrêa

DOI: $10.36229 / 978-85-7042-214-9 . C A P .08$

Capítulo 9: Analise do desenvolvimento de biossensores com ênfase ambiental nas últimas décadas.

Jocimara Camargo da Silva, Wyllerson Evaristo Gomes, Regina Marcia Longo, Renata Kelly Mendes DOI: 10.36229/978-85-7042-214-9.CAP.09

Capítulo 10: Ruídos: identificação e análise da poluição sonora nas regiões centrais dos Municípios Mineiros de Florestal e Betim. 59

Nicole Júnia Lemos Chaves, Hygor Aristides Victor Rossoni, Laura Bueno Silva

DOI: $10.36229 / 978-85-7042-214-9 . C A P .10$

Capítulo 11: Modelagem ambiental: Simulação de 30 anos do desmatamento no Município de Brasnorte - MT . 66

Marcelo Alvares Tenenwurcel, Adriana Monteiro da Costa, Douglas Felipe Lucas, Lucas Antônio Brasil Gonçalves Lacerda

DOI: $10.36229 / 978-85-7042-214-9 . C A P .11$

Capítulo 12: Adoção do selo verde em uma empresa do setor agrícola: Barreira ou oportunidade estratégica?

Thábata Fernandes Precrimo, Márcia Thelma Rios Donato Marino, Matheus Cordeiro Façanha, Leonardo Holanda Lima, Suellen Galvão Moraes

DOI: $10.36229 / 978-85-7042-214-9 . C A P .12$

Capítulo 13: Telhado verde: Uma proposta de utilização no Colégio Militar do Recife a partir da vivencia do Arco de Charles Maguerez 84

Brenda Silva dos Santos, Bruna Oliveira Bezerra, João Pedro Valuche de Andrade Pereira, José Henrique Nóbrega Albuquerque, Matheus Almeida de Sena, Pedro Soares de Lima Filho, Ana Paula Costa de Abreu e Melo

DOI: $10.36229 / 978-85-7042-214-9 . C A P .13$ 


\section{Sumário}

Capítulo 14: "Aproveitamento alimentar sustentável": 0 uso da sustentabilidade alimentar como instrumento de fortalecimento do Programa Nacional de Alimentação Escolar (PNAE), nas Escolas Estaduais do Município de Barbacena -MG 99

Luiza Gonçalves dos Santos, Flora Liz Doumith Oliveira Sobrinho

DOI: 10.36229/978-85-7042-214-9.CAP.14

Capítulo 15: Fator motivacional para o engajamento dos atores sociais atuarem no contexto da sustentabilidade.

Nathali Vieira da Silva, Ramiro Guedes do Carmo, Bárbara Oliveira de Morais, Adalberto Oliveira Brito

DoI: 10.36229/978-85-7042-214-9.CAP.15

Capítulo 16: 0 método SICOGEA como Cálculo de Sustentabilidade para Condomínios

Lorena Simões do Vale, Juliana Freitas Guedes Rêgo, Karina Lima Oliveira, Zoraia da Silva Assunção DOI: 10.36229/978-85-7042-214-9.CAP.16

Capítulo 17: Sistema de captação de água proveniente dos ares condicionados do IFPI Campus Floriano

Mateus dos Santos Correia, Danyel Lima Matos Granzotti, Lara Denise Alves de Vasconcelos, Isadora Rodrigues Rocha, Uesllei Sousa Reis

DOI: 10.36229/978-85-7042-214-9.CAP.17

Capítulo 18: Potencial de aproveitamento da água condensada das centrais de ar de Campus universitário.

Ana Taís Fernandes de Oliveira, Alisson Gadelha de Medeiros, Êmele Rádna Rodrigues do Vale, Maria Josicleide Felipe Guedes DOI: 10.36229/978-85-7042-214-9.CAP.18

Capítulo 19: Avaliação da relação entre a degradação ambiental e a percepção ambiental da comunidade de alto Rio Possmoser em Santa Maria de Jetibá, ES

Charles Moura Netto, Wanderson de Paula, Heitor Messias Sacht, Mylenna Zibell

DOI: 10.36229/978-85-7042-214-9.CAP.19

Autores: 


\section{Capítulo 1}

\section{Estimativa de vazões máximas no Rio Itapetininga}

\section{Alice Sales Fabiano de Almeida \\ Isabela Malospirito Villens}

Mariana Barbosa

Stephanie Oliveira Neves

Jorge Luis Rodrigues Pantoja Filho

Resumo: As inundações são um dos principais e mais devastadores fenômenos naturais, caracterizadas pela elevação do nível d'água normal a tal magnitude que as águas não se limitam à calha principal do rio, extravasando para áreas marginais, habitualmente não ocupadas pelas águas, em decorrência de uma precipitação intensa, por exemplo. Desta maneira, o presente artigo tem por objetivo estimar as vazões máximas para o rio Itapetininga, afluente da bacia hidrográfica do Alto Paranapanema, a partir de dados de vazões obtidos junto ao posto fluviométrico Porto Velho, visando fornecer subsídios técnicos para formulação de políticas públicas para prevenção e resposta às inundações. Os dados foram extraídos da plataforma Hidroweb, onde obteve-se as vazões máximas anuais a partir de uma série histórica de 10 anos. Os métodos probabilísticos adotados para a realização do estudo foram a distribuição de Gumbel e o Método de Foster (aplicação da distribuição de Pearson do tipo III). Os valores de estimativa de vazão para os diferentes períodos de retorno em estudo $(2,5,10,20$ e 100) variaram entre 66,8 a $141,3 \mathrm{~m}^{3} \cdot \mathrm{s}^{-1}$ para o método de Foster e entre 64,8 a $150,9 \mathrm{~m}^{3} \cdot \mathrm{s}^{-1}$ para a distribuição de Gumbel, respectivamente. 


\section{INTRODUÇÃO}

Enchentes e inundações tratam-se de fenômenos hidrometeorológicos naturais, causados pelo aumento do nível de água do rio devido ao aporte de água concentrada dada a ocorrência de uma precipitação intensa, por exemplo. Quando o rio, no entanto, extravasa para além de sua calha principal atingindo sua planície de inundação e áreas ribeirinhas, descreve-se as inundações (Santana, 2017).

Embora naturais, esses fenômenos podem ser intensificados pelas alterações ambientais e intervenções urbanas de origem antrópica, como por exemplo a impermeabilização das superfícies vertentes da bacia, dada pelo intenso processo de urbanização, que promove a diminuição da infiltração e consequentemente o aumento do escoamento superficial. Outro fator é a ocupação irregular das áreas de várzea pela população marginalizada, configurando inúmeras perdas, seja no âmbito econômico ou até mesmo de vidas (Paz, 2004).

Visto que informações sobre a vazão e precipitações máximas são imprescindíveis para a determinação e prevenção de cheias, faz-se necessário o desenvolvimento de métodos de estimação da vazão máxima. Dentro desse contexto, pode-se destacar os métodos empíricos, métodos baseados no hidrograma unitário e métodos probabilísticos (Martins, Uliana, Reis, 2011).

Os métodos empíricos relacionam a vazão com características físicas e climáticas da bacia, por meio de parâmetros e coeficientes empíricos, ou seja, de caráter experimental. 0 método racional por exemplo, envolve simplificações e coeficientes que não levam em consideração a natureza real e complexa do escoamento superficial (deflúvio), gerando restrições a sua aplicação. Sendo assim, para bacias de grande extensão, superiores a $3 \mathrm{~km}^{2}$, o método torna-se ineficaz, no entanto, trata-se de um método prático, uma vez que os elementos envolvidos podem ser facilmente obtidos (Studart, 2006).

Dispondo-se de dados históricos de precipitação, existem também outras formas de obtenção de valores de vazão a partir das informações pluviométricas, esses métodos são denominados de chuva x deflúvio, podendo-se citar a aplicação de chuvas intensas ao hidrograma unitário, por exemplo. Esse método parte do pressuposto de que a precipitação efetiva e unitária tem intensidade constante ao longo de sua duração e distribui-se uniformemente sobre toda a área de drenagem, ou seja, é a resposta da bacia a uma precipitação unitária com determinada duração (Paz, 2004).

Pode-se citar ainda a análise de frequências das variáveis hidrológicas, dada pelo método estatístico, por meio do cálculo das probabilidades de excelência e o ajuste a distribuição probabilística mais adequada. Essa distribuição de probabilidade relaciona a magnitude dos eventos com sua frequência de ocorrência, descrita por uma função densidade de probabilidade, dessa forma, a probabilidade de ocorrência de uma variável aleatória assumir um valor arbitrário é dada por essa função, ou ainda pela integral da densidade dessa variável, ou seja, a área abaixo da função (Cavalcanti, 2014).

Dentre os métodos probabilísticos pode-se citar o método de Foster, que consiste na aplicação da distribuição de Pearson III, determinando-se primeiramente os parâmetros da distribuição, ou seja, a média, desvio padrão e coeficiente de obliquidade de Pearson. Realiza-se ainda um ajuste desse coeficiente com uma correção proposta por Hazen e então, encontra-se a probabilidade associada ao período de retorno adotado. Em contrapartida, o método utilizado por Gumbel baseia-se em uma distribuição de valores extremos e utilizando-se dos dados históricos, calcula-se a média e o desvio padrão. Este último é de mais fácil aplicação, uma vez que utiliza-se dos parâmetros alfa e beta para a estimativa de vazão ou qualquer outro evento de interesse (Studart, 2006).

Nesse sentido, a aplicação dos métodos anteriormente citados é de suma importância para a determinação do grau de risco a enchentes, minimizando os impactos gerados por esses eventos, especialmente para o planejamento e ordenamento do território de municípios que encontram-se em desenvolvimento como Itapetininga-SP, que segundo dados, é acometida por alagamentos e enchentes do rio Itapetininga dada a ocorrência de precipitações intensas, especialmente durante os meses de janeiro e fevereiro, fenômeno que é agravado pela ocupação dos moradores nas áreas de várzea (Salles, 2019).

\section{OBJETIVOS}

Estimar as vazões máximas para o rio Itapetininga, no município de Itapetininga- SP, com dados de vazões obtidos a partir do posto fluviométrico "vila Sottemo", contidos no portal Hidroweb, utilizando dois métodos probabilísticos. 


\section{METODOLOGIA}

\subsection{DELINEAMENTO MATEMÁTICO}

Foram utilizados dois métodos probabilísticos, sendo Método de Gumbel e o Método de Foster, com aplicação da distribuição de Pearson do tipo III.

A distribuição de Gumbel. Conforme apresentada por Righetto (1998), para a realização dos cálculos de estimativa das vazões em determinados períodos de retorno, inicialmente calculou-se a média das vazões pela seguinte equação:

$$
\mu=\frac{\Sigma x i}{n}(E q .2)
$$

No qual, $\mu$ é a média, xi representa o somatório dos valores e $\mathrm{n}$ a quantidade de elementos.

Em seguida, calculou-se o desvio padrão dado pela seguinte equação:

$$
\mathrm{S}=\sqrt{\frac{\sum(x i-\mu)^{2}}{n-1}}(\text { Eq.3) }
$$

Em que, $S$ é o desvio padrão, xi o somatório dos valores, $\mu$ é a média das vazões e o n representa a quantidade de elementos. Calculou-se o parâmetro $\beta$ pela seguinte equação:

$$
\beta=6^{0,5} \cdot \frac{S}{\pi}(E q \cdot 4)
$$

Por conseguinte, determinou-se o parâmetro $\alpha$ dado pela equação:

$$
\alpha=(\mu-0,577 . \beta)(\text { Eq.5) }
$$

Onde, $\alpha$ é o parâmetro, $\mu$ é a média das vazões e $\beta$ é o parâmetro definido anteriormente.

Em seguida, definiu-se outro parâmetro para assim obter as vazões em diferentes tempos de retorno. Foi utilizada a seguinte equação para determinar o parâmetro:

$$
F=1-\left(\frac{1}{\operatorname{Tr}}\right)(E q \cdot 6)
$$

No qual, F é a frequência e Tr é o tempo de retorno dado em anos.

Por fim, utilizou-se a seguinte equação para determinar a previsão de cheia:

$$
\mathrm{Q}=(-\ln /(\ln .1 /((1-1 / \operatorname{Tr})))) \cdot \beta+\alpha(\mathrm{Eq} \cdot 7)
$$

Onde, Q é vazão estimada $\left(\mathrm{m}^{3} / \mathrm{s}\right)$, Tr é o tempo de retorno (anos) e $\beta$ e $\alpha$ são os parâmetros.

A distribuição Log Pearson do tipo III. 0 método de Foster baseia-se na distribuição de Pearson do tipo III, estando relacionado com a descrição do comportamento das vazões máximas anuais de maneira similar à distribuição de Gumbel (Ferreira; Reis; Mandonça, 2015). A distribuição de Pearson pode ser entendida como um parâmetro de correlação de variáveis. Nesse método são levados em consideração a média, o desvio padrão e coeficiente de obliquidade de Pearson. 
Para a determinação da cheia em diferentes períodos de retorno, calculou-se inicialmente a média das vazões observadas, o qual é explicitado pela equação 2.

Em seguida foi calculado o desvio padrão pela equação 3 e logo após determinou-se o coeficiente de obliquidade de Pearson, dado pela seguinte equação:

$$
C o=\frac{\Sigma(Q i-\bar{x})^{3}}{2 . d p \sum(Q i-\bar{x})^{2}}(E q .8)
$$

Onde, Co é coeficiente de obliquidade de Pearson, x̄ é a média das vazões , Qi é a vazão observado $\left(\mathrm{m}^{3} / \mathrm{s}\right)$ e dp que representa o desvio padrão. Logo após foi calculado o coeficiente de Hazen pela seguinte equação:

$$
C o^{\prime}=\left(1-\frac{8,5}{n}\right) \cdot \operatorname{Co}(E q \cdot 9)
$$

Em que, Co' é o coeficiente e Hazen, Co é o coeficiente de obliquidade de Pearson, calculado anteriormente e $n$ é valor de vazões observadas.

Posteriormente, calculou-se a probabilidade do tempo de retorno, que é dado pela seguinte equação:

$$
P=\frac{1}{\operatorname{Tr}}(E q .10)
$$

Onde P é a probabilidade e Tr é o tempo de retorno adotado (anos).

Tabela 1: Curva de frequência assimétrica - tipo III de Pearson.

\begin{tabular}{|c|c|c|c|c|c|c|c|}
$\begin{array}{c}\text { Valores de } \\
\text { A (\%) }\end{array}$ & 0.0 & \multicolumn{1}{c}{0.1} & \multicolumn{2}{c}{0.2} & \multicolumn{2}{c}{0.3} & \multicolumn{2}{c|}{0.4} & 0.5 & 0.6 \\
\hline 0.01 & -3.73 & -3.32 & -2.92 & -2.53 & -2.18 & -1.88 & -1.63 \\
\hline 0.1 & -3.09 & -2.81 & -2.54 & -2.28 & -2.03 & -1.80 & -1.59 \\
\hline 1.0 & -2.33 & -2.18 & -2.03 & -1.88 & -1.74 & -1.59 & -1.45 \\
\hline 5.0 & -1.65 & -1.58 & -1.51 & -1.45 & -1.38 & -1.31 & -1.25 \\
\hline 10.0 & -1.28 & -1.25 & -1.22 & -1.19 & -1.16 & -1.12 & -1.08 \\
\hline 20.0 & -0.84 & -0.85 & -0.85 & -0.86 & -0.86 & -0.86 & -0.85 \\
\hline 50.0 & 0.00 & -0.03 & -0.06 & -0.09 & -0.13 & -0.16 & -0.19 \\
\hline 80.0 & 0.84 & 0.83 & 0.82 & 0.80 & 0.78 & 0.76 & 0.74 \\
\hline 90.0 & 1.28 & 1.30 & 1.32 & 1.33 & 1.34 & 1.34 & 1.35 \\
\hline 95.0 & 1.65 & 1.69 & 1.74 & 1.79 & 1.83 & 1.87 & 1.90 \\
\hline 99.0 & 2.33 & 2.48 & 2.62 & 2.77 & 2.90 & 3.03 & 3.15 \\
\hline 99.9 & 3.09 & 3.38 & 3.67 & 3.96 & 4.25 & 4.54 & 4.82 \\
\hline 99.99 & 3.73 & 4.16 & 4.60 & 5.04 & 5.48 & 5.92 & 6.37 \\
\hline 99.999 & 4.27 & 4.84 & 5.42 & 6.01 & 6.61 & 7.22 & 2.85 \\
\hline 999.999 & 4.76 & 5.48 & 6.24 & 7.02 & 7.82 & 8.63 & 9.45 \\
\hline
\end{tabular}

Fonte: Vilela, 1975.

Logo em seguida, subtraiu-se o valor de cada probabilidade por um e calculou-se a probabilidade, da seguinte maneira:

$$
\begin{aligned}
A & =1-P(E q .11) \\
P a & =A .100(E q .12)
\end{aligned}
$$

Onde, $\mathrm{P}$ é a probabilidade anteriormente calculada.

Por meio da probabilidade A calculada, utilizou-se o valor obtido para encontrar $\mathrm{x} / \mathrm{dp}$ ( dp representa o desvio padrão) na tabela de curva de frequência assimétrica do tipo III de Pearson. Assim que foi encontrado esse valor, o substitui na expressão x/dp para assim encontrar o valor de $\mathrm{x}$. Com isso, foi possível encontrar as vazões finais pela seguinte equação: 


$$
Q=x+\bar{Q}(E q .13)
$$

Em que, $Q$ é a vazão de projeto obtido $\left(\mathrm{m}^{3} / \mathrm{s}\right)$, x é o valor encontrado através da manipulação realizado e $\bar{Q}$ é a média das vazões $\left(\mathrm{m}^{3} / \mathrm{s}\right)$.

\subsection{DELINEAMENTO EXPERIMENTAL}

A forma mais apropriada de se determinar a vazão de um projeto para um determinado rio é a partir dos seus registros de vazão anteriores, para assim poder aplicá-los nos métodos supracitados. A eficiência deste método dependerá da estabilidade das características do regime do curso d'água estudado, no caso o Rio Itapetininga. Por esta razão, o rio não pode ter sofrido nenhuma modificação hidrológica importante.

Dessa maneira, a partir dos dados de vazão dos anos de 2006 a 2015, obtidos a partir do posto fluviométrico em Porto Velho (Código da estação: 64065000) localizado entre as coordenadas -23,63 e 48,11, pertencente ao município de Itapetininga, estado de São Paulo, pode-se determinar a vazão do projeto pelo Método de Foster (Distribuição Pearson III) e pela distribuição de Gumbel. Para a realização dos cálculos utilizou-se a somatória das maiores vazões mensais para cada ano analisado.

A partir da plataforma hidroweb, localizou-se a estação fluviométrica de interesse. Para tal escolha foi tomado como base dados primários de moradores da cidade, o qual relatam ser recorrente a incidência de enchentes na Vila Sottemo, localizada em Itapetininga-SP. Sendo esta apresentada na Figura 01 a seguir:

Figura 01: Área de estudo.

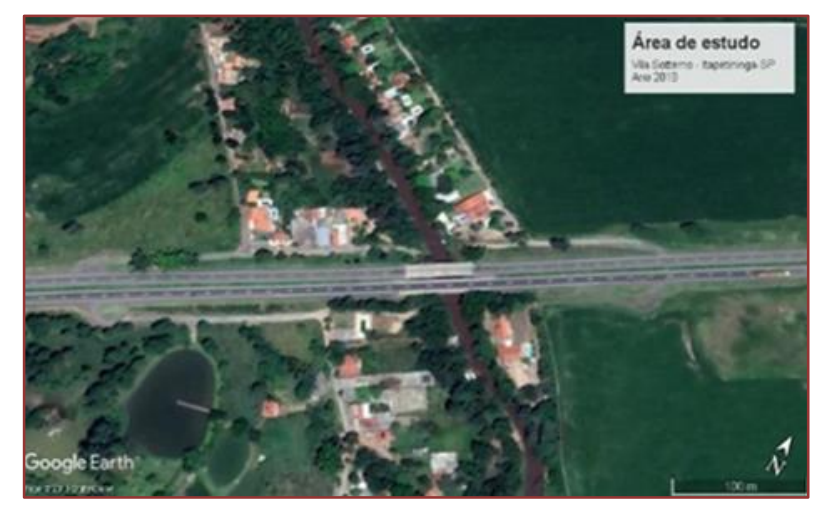

Fonte: Google Earth, 2019.

Nota-se que na região citada encontra-se alguns postos fluviométricos. Sendo assim, a fim de se obter dados mais próximos do cruzamento do Rio Itapetininga com a BR-373, o qual se mostra o local de maior índice de enchentes, adotou-se o seguinte posto:

Figura 02: Posto fluviométrico selecionado.

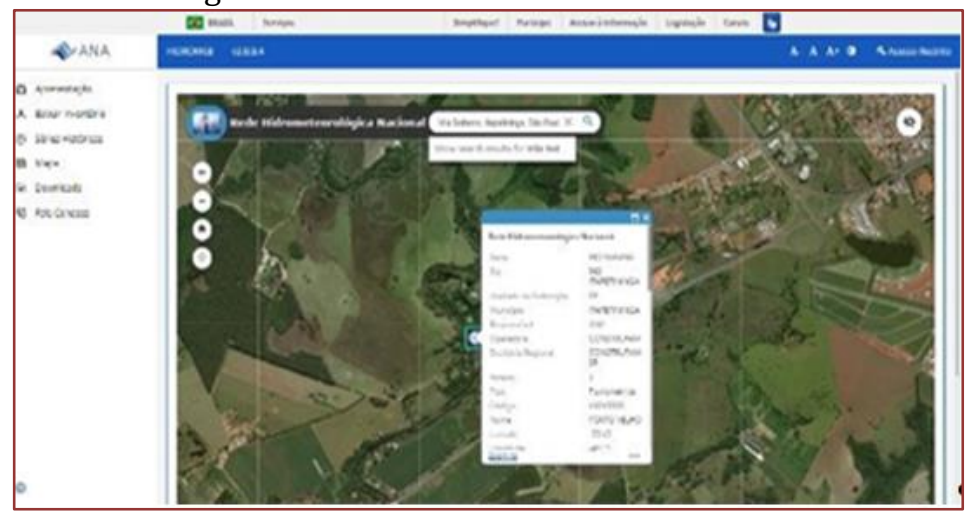

Fonte: Hidroweb, 2019. 
Com o código da estação, buscou-se os dados necessários nas séries históricas mínimas para realização dos métodos probabilísticos. Desta maneira, ao analisar os dados de vazões, notou-se que a estação contém valores de 1947 a 2017. Contudo, sendo necessário apenas dados de no mínimo 10 anos, adotouse o período de 2006 a 2015 por serem mais recentes e não apresentarem falta de dados nos meses dos anos supracitados. Admitiu-se vazões máximas de cada ano para efetuar os cálculos dos métodos probabilísticos de Foster e Gumbel, sendo as vazões:

Tabela 2 : Série temporal para as vazões máximas (Q máx).

\begin{tabular}{|c|c|}
\hline Ano & $\begin{array}{c}\text { Q máx } \\
\left(\mathrm{m}^{3} \mathrm{~s}^{-1}\right)\end{array}$ \\
\hline 2006 & 47,5 \\
\hline 2007 & 88,8 \\
\hline 2008 & 47,3 \\
\hline 2009 & 95,3 \\
\hline 2010 & 107,9 \\
\hline 2011 & 98 \\
\hline 2012 & 51 \\
\hline 2013 & 49,3 \\
\hline 2014 & 36,9 \\
\hline 2015 & 69 \\
\hline
\end{tabular}

Fonte: Autorais, 2019.

\section{RESULTADOS E DISCUSSÃO}

Para a aplicação do método de Foster, partiu-se dos dados históricos de vazões máximas observadas. Então, determinou-se os parâmetros da distribuição, sendo estes a média, o desvio padrão e o coeficiente de obliquidade de Pearson, cujos resultados estão apresentados nas Tabelas 3 e 4.

Tabela 3: Vazão máxima observada.

\begin{tabular}{|c|c|c|c|}
\hline Ano & $\begin{array}{c}\text { Vazão } \\
\text { observada } \\
\text { máxima } \\
\text { (diário) } \\
\left(\mathrm{m}^{3} / \mathrm{s}\right)\end{array}$ & $\begin{array}{c}\text { (Qi- } \\
\text { Qmed) }\end{array}$ & $\begin{array}{c}(\mathrm{Qi}- \\
\mathrm{Qmed}^{3}\end{array}$ \\
\hline 2006 & 47,53 & 466,49 & $-10075,5$ \\
\hline 2007 & 88,81 & 387,48 & 7627,46 \\
\hline 2008 & 47,35 & 474,34 & $-10330,9$ \\
\hline 2009 & 95,32 & 686,26 & 17977,73 \\
\hline 2010 & 107,91 & 1503,94 & 58323,5 \\
\hline 2011 & 98,08 & 838,31 & 24272,12 \\
\hline 2012 & 51,02 & 327,88 & $-5937,02$ \\
\hline 2013 & 49,35 & 391,03 & $-7732,32$ \\
\hline 2014 & 36,89 & 1039,19 & $-33499,6$ \\
\hline 2015 & 69,01 & 0,014 & $-0,002$ \\
\hline \multicolumn{2}{|c|}{ Somatório } & 6114,93 & 40625,52 \\
\hline
\end{tabular}

Fonte: Autorais, 2019. 
Tabela 4: Estatística descritiva e parâmetros para Foster .

\begin{tabular}{|l|c|}
\hline Média & 69,1 \\
\hline Desvio padrão & 26,0 \\
\hline Coeficiente de obliquidade & 0,13 \\
\hline Correção do coeficiente (Hazen) & 0,24 \\
\hline
\end{tabular}

Fonte: Autorais, 2019.

Com relação às vazões máximas observadas, verifica-se valores mínimos e máximos de $47,4 \mathrm{e} 107,9 \mathrm{~m}^{3} \cdot \mathrm{s}^{-1}$ para os anos de 2008 e 2010, respectivamente. A média e o desvio padrão para a série temporal foram, respectivamente, de 69,1 e $26,0 \mathrm{~m}^{3} \cdot \mathrm{s}^{-1}$. 0 coeficiente de obliquidade da distribuição log Pearson III foi de 0,13 e sua correção, de acordo com Hazen, foi de 0,24 .

Tabela 5: Vazões máximas (Q máx) previstas para Tempos de Retorno (Tr) variando entre 2 e 100 anos, para Foster.

\begin{tabular}{|l|c|c|c|c|c|}
\hline $\operatorname{Tr}$ & 2 & 5 & 10 & 20 & 100 \\
\hline $\mathrm{P}=1 / \mathrm{Tr}$ & 0,5 & 0,2 & 0,1 & 0,05 & 0,01 \\
\hline $\mathrm{A}=1-\mathrm{P}$ & 0,5 & 0,8 & 0,9 & 0,95 & 0,99 \\
\hline $\mathrm{A}(\%)$ & 50 & 80 & 90 & 95 & 99 \\
\hline $\mathrm{x} / \delta$ & $-0,09$ & 0,80 & 1,33 & 1,79 & 2,77 \\
\hline $\mathrm{X}$ & $-2,35$ & 20,9 & 34,7 & 46,7 & 72,2 \\
\hline $\mathrm{Q}$ máx & 66,8 & 90,0 & 103,8 & 115,8 & 141,3 \\
\hline
\end{tabular}

Fonte: Autorais, 2019.

Na tabela 5 é possível verificar, dentre outras coisas, os valores das estimativas para as vazões máximas, os quais foram de 66,$8 ; 90,0 ; 103,8 ; 115,8$ e $141,3 \mathrm{~m}^{3} . \mathrm{s}^{-1}$ para os tempos de retorno de 2, 5, 10, 20 e 100 anos, respectivamente. Os valores de vazões estimados pelo Método de Foster apresentaram um comportamento esperado, aumentando de acordo com o aumento do tempo de retorno.

No tocante à obtenção da máxima enchente de um rio a partir da distribuição de Gumbel, procedeu-se, de maneira análoga a Foster, calculando, primeiramente, os valores da média e do desvio padrão calculados anteriormente, encontrou-se os parâmetros $\alpha$ e $\beta$, conforme mostra as relações abaixo, a qual está demonstrada explicitamente, para efeito didático, conforme segue:

$$
\begin{gathered}
\beta=6^{0,5} \cdot \frac{\mathrm{S}}{\pi}(E q \cdot 25) \\
\beta=6^{0,5} \cdot \frac{26,0660}{3,14} \\
\beta=20,33 \\
\alpha=(\bar{Q}-0,577) \cdot \beta(E q \cdot 26) \\
\alpha=(69,1254-0,577) \cdot 20,33 \\
\alpha=57,39
\end{gathered}
$$

Os valores foram tabelados para melhor análise. 
Tabela 6: Estatística descritiva e parâmetros alfa e beta de Gumbel.

\begin{tabular}{|c|c|}
\hline Média & 69,1 \\
\hline Desvio Padrão & 26,1 \\
\hline$B=\left(6^{\wedge} 0,5\right) . \sigma / \mathrm{Pi}$ & 20,3 \\
\hline$\alpha=($ Qmed-0,577.B $)$ & 57,4 \\
\hline
\end{tabular}

Fonte: Autorais, 2019.

Para efeito de simples didatismo, demonstra-se, de maneira explícita, o cálculo da frequência (F) e da vazão máxima (Q máx) para o tempo de retorno de 2 anos. De maneira análoga, pode-se tomar o mesmo algoritmo a seguir para o cálculo dos parâmetros supracitados considerando tempos de retorno de 5, 10, 20 e 100 anos. Sendo assim:

$$
\begin{gathered}
\mathrm{F}(\mathrm{Q}(\text { dia; } \mathrm{T}))=1-1 / \mathrm{T} \text { (Eq.27) } \\
\mathrm{F}(\mathrm{Q}(\text { dia; } \mathrm{T}))=1-1 / 2 \\
\mathrm{~F}(\mathrm{Q}(\text { dia; } \mathrm{T}))=0,5
\end{gathered}
$$

Estabelecido a frequência (F) e os parâmetros $\alpha e \beta$, aplicou-se o modelo matemático da distribuição de Gumbel, conforme Righetto, para a estimativa de vazão:

$$
\begin{gathered}
(\mathrm{Q}(1 \text { dia;Tr })-\alpha) / \beta=-\ln (\ln (1 /(\mathrm{F}(\mathrm{Q}(1 \mathrm{dia} ; \mathrm{Tr})))) \quad(\mathrm{Eq} \cdot 28) \\
(\mathrm{Q}(1 \mathrm{dia} ; \mathrm{Tr})-57,39) / 20,33=-\ln (\ln (1 / 0,5)) \\
Q \operatorname{Qmáx}(1 \text { dia;Tr })=64,845
\end{gathered}
$$

Tabela 7: Vazões máximas (Q máx) previstas para Tempos de Retorno (Tr) variando entre 2 e 100 anos, para Gumbel

\begin{tabular}{|l|c|c|c|c|c|}
\hline B & 20,33 & 20,33 & 20,33 & 20,33 & 20,33 \\
\hline$\alpha$ & 57,39 & 57,39 & 57,39 & 57,39 & 57,39 \\
\hline Período de retorno (Tr) & 2 & 5 & 10 & 20 & 100 \\
\hline F (1dia; T) & 0,5 & 0,8 & 0,9 & 0,95 & 0,88 \\
\hline Q (1dia; T) m³ & 64,8 & 87,9 & 103,2 & 117,8 & 150,9 \\
\hline
\end{tabular}

Na tabela 7 é possível verificar os valores das estimativas para as vazões máximas, as quais foram de 64,8; 87,$9 ; 103,2 ; 117,8$ e $150,9 \mathrm{~m}^{3} . \mathrm{s}^{-1}$ para os tempos de retorno de 2, 5, 10, 20 e 100 anos, respectivamente. Tal qual fora observado nos resultados obtidos pelo método de Foster, os valores obtidos a partir de Gumbel apresentaram um comportamento similar, para o qual as vazões máximas estimadas aumentando de acordo com o aumento do tempo de retorno. 
Tabela 8:Comparação entre os métodos de estimativa de vazões máximas ( $Q$ máx) para diferentes Tempos de Retorno (Tr)

\begin{tabular}{|c|c|c|c|c|c|c|}
\hline \multirow{2}{*}{ Métodos } & \multicolumn{1}{c}{ Estimativa de } \\
& Vazão $\left(\mathrm{m}^{3} \cdot \mathrm{s}^{-1}\right)$ & 2 & 5 & 10 & 20 & 100 \\
\hline Foster & Q máx & 66,8 & 90 & 103,8 & 115,8 & 141,3 \\
\hline Gumbel & Q máx & 64,8 & 87,9 & 103,2 & 117,8 & 150,9 \\
\hline
\end{tabular}

Analisando a Tabela 7, observa-se que os valores de estimativa de vazão para os diferentes períodos de retorno em estudo $\left(2,5,10,20\right.$ e 100) variaram entre 66,8 a $141,3 \mathrm{~m}^{3} \cdot \mathrm{s}^{-1}$ para Foster e de 64,8 a $150,9 \mathrm{~m}^{3} \cdot \mathrm{s}^{-1}$ para a distribuição de Gumbel. Assim, pode-se perceber a pequena diferença entre os valores. A ligeira alteração nos resultados pode ser explicada devido aos distintos algoritmos de cálculo requeridos entre os diferentes métodos.

Deve-se considerar, neste estudo, a série histórica sem falhas de 10 (dez) anos somente. Ressalta-se a opção pelo não preenchimento das falhas. A incorporação dos valores faltantes tornaria maior a série temporal de dados na análise hidrológica de eventos de vazões máximas. Uma série de dados de tal magnitude (10 anos) aumenta a incerteza da estimativa. Em todo o caso, optou-se por preservar a maior série disponível e sem falhas.

As séries foram analisadas em busca de picos atípicos. Deve-se considerar que o nosso país ainda é carente de pontos de medição e cômputo das variáveis hidrológicas, o que limita sobremaneira a aplicação dos métodos probabilísticos.

Vale salientar, que a eficácia dos resultados é influenciada diretamente pela estabilidade das características principais do regime do curso d'água, sendo assim o rio não pode ter sofrido qualquer modificação hidrológica, tais como: desvios, construção de barragens e urbanização das margens. A falta de medição sistemática de fluxo na região também é um problema, pois limita a utilização dos métodos. No caso do rio Itapetininga, devido a sua extensão, é muito difícil determinar categoricamente que não houve nenhuma intervenção ao longo dos limites do rio, assim os resultados podem ter sido influenciados por esse motivo.

Os valores de vazões estimados pelas distribuições probabilísticas tiveram um comportamento esperado, aumentando proporcionalmente com o aumento do tempo de retorno. Considerando as estimativas realizadas, os métodos probabilísticos apresentaram valores de vazões muito próximos entre si, demonstrando pouca oscilação entre os mesmos. conforme pode ser mais claramente observado na Figura 04 , a seguir.

Figura 3: Comparação dos valores de vazões máximas, em função do Tempo de Retorno, entre os Métodos de Foster e Gumbel.

Eixo $\mathrm{x}$ : $\operatorname{Tr}\left(\right.$ anos); Eixo y: $\mathrm{Q}$ máx $\left(\mathrm{m}^{3} \cdot \mathrm{s}^{-1}\right)$

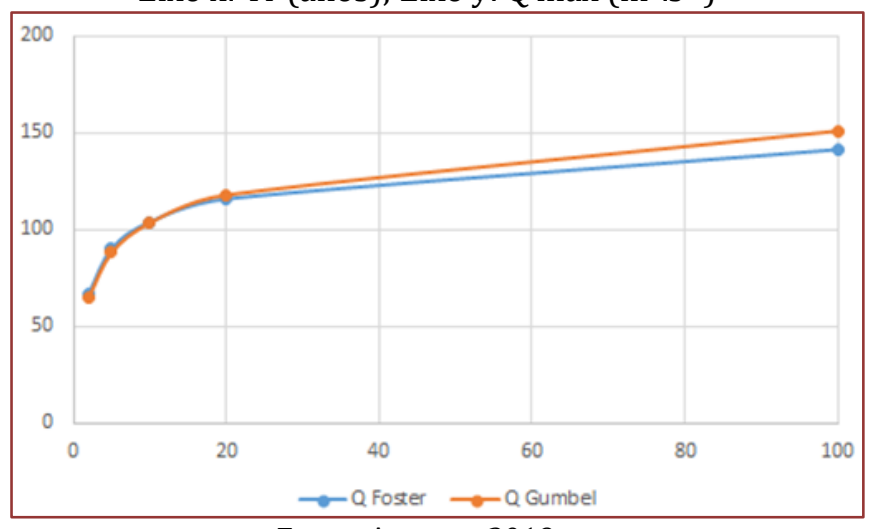

Fonte: Autores, 2019.

Comparando os valores apresentados na Figura 03, percebe-se que são muito próximos os valores de $Q$ máx, sendo que para o período de retorno de 100 anos é onde observa-se uma maior diferença, segundo o qual o método de Gumbel deteve uma vazão de $150,9 \mathrm{~m}^{3} \cdot \mathrm{s}^{-1}$ e por Foster $141,3 \mathrm{~m}^{3} \cdot \mathrm{s}^{-1}$. Gumbel tende a ser 
o mais comumente utilizado, devido à facilidade de sua aplicação, no entanto Foster também é muito viável, a despeito de seu algoritmo de cálculo ser um pouco mais trabalhoso.

Por este motivo, destaca-se a importância dessas informações para o manejo de bacias hidrográficas. Entretanto, ainda há pouca informação disponível para a maioria das bacias hidrográficas do Brasil. Isto demonstra a necessidade de se realizar estudos sobre vazão máxima local nas bacias hidrográficas.

\section{CONCLUSÃO}

Os fenômenos naturais são aleatórios, sendo assim apenas é possível estimar sua ocorrência através de modelos matemáticos. As enchentes podem ocasionar em inúmeros problemas desde a perda de bens materiais até mesmo a morte, por isso a importância de se prever as vazões máximas em diferentes tempos de retorno.

Portanto, através dos métodos de Gumbel, modificado por Riguetto, e o de Foster, baseado na distribuição Pearson III, foi possível prever as vazões máximas para o rio Itapetininga. Além disso, apesar do método de Gumbel ser mais sofisticado, e o método de Foster ser o mais utilizado no Brasil e de mais fácil aplicação, os resultados convergem.

Deve-se considerar que o nosso país ainda é carente de pontos de medição e cômputo das variáveis hidrológicas, o que limita sobremaneira a aplicação dos métodos probabilísticos. Para a uma maior eficácia dos métodos probabilísticos, bem como sua maior difusão, necessita-se que o sistema de informações hidrológicas seja constantemente aprimorado. Segundo Sueiro (2015), enchentes são recorrentes na região, portanto, com o aumento das vazões, inundações cada vez maiores estão sujeitas a ocorrer.

Figura 4: Enchente do ano de 2016 no bairro Porto Velho em Itapetininga.

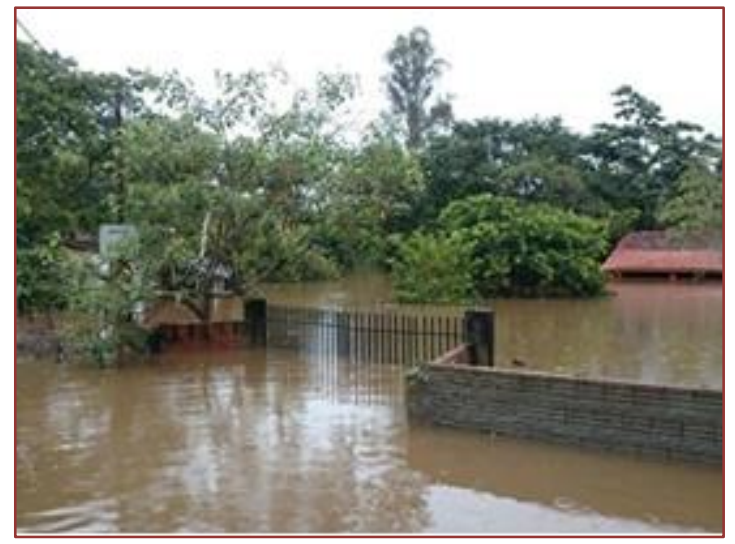

Fonte: G1 Itapetininga e região, 2016.

\section{AGRADECIMENTOS}

Nossos agradecimentos a Universidade Federal de São Carlos Campus Lagoa do Sino pelo ensino de qualidade proporcionado. Aos professores de excelência que mostraram maestria na disseminação do conhecimento, em especial Professor Jorge Luis Rodrigues Pantoja Filho. A Deus por nos dar força para enfrentarmos os desafios do final do semestre.

\section{REFERÊNCIAS}

[1] Cavalcanti, Daysy Lira Oliveira. Estudo comparativo de métodos de estimação de vazões máximas de projeto para grandes bacias hidrográficas. 2014. 226 f. Dissertação (Mestrado) - Curso de Engenharia Hidráulica e Saneamento, Departamento de Hidráulica e Saneamento, Universidade de São Paulo, São Carlos, 2014. Disponível em: <www.teses.usp.br/teses/disponiveis/18/18138/tde- 02102014.../DaysyLOCavalcanti.pdf>.Acesso em: 09 jul. 2019.

[2] Ferreira, Matheus Magnago; Reis, José Antônio Tosta dos; Mandonça, Antônio Sérgio Ferreira. Estimativas de vazões máximas para cursos d'água da bacia hidrográfica do rio itapemirim. Ciatec, Vitória, v. 7, n. 1, p.67-78, nov. 2015. Disponível em: <file:///C:/Users/playzone/Downloads/4217-Texto\%20do\%20artigo-17312-1- 1020150804.pdf>. Acesso em: 09 jul. 2019. 
[3] Martins, Camila Aparecida da Silva; Uliana, Eduardo Morgan; Reis, Edvaldo Fialho dos. Estimativa da Vazão e da Precipitação Máxima Utilizando Modelos Probabilísticos na Bacia Hidrográfica do Rio Benevente. Enciclopédia Biosfera, Goiânia, v. 1, n. 1, p.1-13, nov. 2011. Disponível em: <http://www.conhecer.org.br/enciclop/2011b/ciencias\%20ambientais/estimativ a.pdf>.Acesso em: 09 jul. 2019.

[4] Paz, Adriano Rolim da Paz Adriano Rolim da. Hidrologia Aplicada. Caxias do Sul: Moderna, 2004. Disponível em: <Http://Www.Ct.Ufpb.Br/ Adrianorpaz/Artigos/Apostila_Hidrologia_Aplicada_UERG.pdf>. Acesso em: 09 jul. 2019.

[5] Righetto, A. M.Hidrologia e Recursos Hídricos. São Carlos, EDUSP, 1998. 840 p

[6] Salles, A. J. Risco de enchente deixa moradores de bairros próximos aos córregos em estado de alerta. Itapetininga - Sp, 05 jan. 2019. Disponível em: <http://g1.globo.com/sao-paulo/itapetininga-regiao/tem-noticias1edicao/videos/t/edicoes/v/risco-de-enchente-deixa-moradores-de-bairros-proximos-aos-corregos-em-estado-dealerta/7278540/>. Acesso em: 09 jul. 2019.

[7] Santana, Michele Silva. Processos Hidrológicos Inundações, enchentes, enxurradas e alagamentos na geração de áreas de risco. In: Santana, Michele Silva. Prevenção e Gerenciamento de Riscos de Desastres Naturais. Belo Horizonte: Cprm, 2017. p. 1-49. Disponível em:

<https://defesacivil.es.gov.br/Media/defesacivil/Capacitacao/Material\%20Did\%C3\%A1tico/CBPRG\%20\%202017/Processos\%20Hidrol\%C3\%B3gicos\%20\%20\%20Inunda\%C3\%A7\%C3\%B5es,\%20Enchentes,\%20Enxurra das\%20e\%20Alagamentos\%20na\%20Gera\%C3\%A7\%C3\%A3o\%20de\%20\%C3\%81reas\%20de\%20Risco.pdf>. Acesso em: 09 jul. 2019.

[8] Studart, T. Apostila da Disciplina de Hidrologia Aplicada, Universidade Federal do Ceará. Disponível em:<http://www.deha.ufc.br/ticiana/Arquivos/Graduacao/Apostila_Hidrologia_grad>/Cap_9_Previsao_de_Enchentes .pdf>. Acesso em: 09 jul. 2019. Villela, S., 1975. Hidrologia Aplicada. Ed. McGraw-Hill, São Paulo.

[9] Sueiro, Isair Laurentina de Paula. Os efeitos da urbanização sobre o meio ambiente nos municípios de Itapetininga e Piracicaba - São Paulo. 2015. 98 f. Monografia (Especialização) - Curso de Geografia, Departamento de Geografia, Universidade de Brasília, Itapetininga, 2015. 


\section{Capítulo 2}

Aplicação de métodos probabilísticos na previsão de enchentes na Bacia Hidrográfica do Rio Piracicaba, no Município de Piracicaba-SP

\section{Júlia Rinaldi de Macedo Cortez}

Thiago de Oliveira Calsolari

Jorge Luis Rodrigues Pantoja Filho

Resumo: As inundações são um dos principais e mais devastadores fenômenos naturais, caracterizadas pela elevação do nível d'água normal a tal magnitude que as águas não se limitam à calha principal do rio, extravasando para áreas marginais, habitualmente não ocupadas pelas águas, em decorrência de uma precipitação intensa, por exemplo, causando diversos problemas de cunho ambiental, social e econômico. O Parque da Rua do Porto, localizado no município de Piracicaba, objeto do estudo, sofre com inundações frequentes e o número de trabalhos que visem estimar as vazões máximas por meio de métodos probabilísticos, os mais apropriados dentre os métodos existentes, uma vez que são baseados em registros de vazões anteriores ainda é escasso. Sendo assim, o trabalho teve como objetivo principal analisar o comportamento de vazões máximas para um curso de água localizado na bacia hidrográfica do rio Piracicaba, visando também fornecer subsídios para formulação de políticas públicas para prevenção e resposta às inundações. Para tanto, através de dados de séries históricas disponibilizados em domínio público, foram empregados os métodos probabilísticos de Foster e Gumbel conforme Righetto, os quais são baseados das funções densidade de probabilidade (FDP) de Pearson III e Gumbel, respectivamente. Através dos métodos utilizados, foram encontrados para tempo de retorno de 5 anos os valores de 833,25 e $828,47 \mathrm{~m}^{3} / \mathrm{s}$, e para o tempo de retorno de 100 anos os valores de 1398,18 e 1395,09 $\mathrm{m}^{3} / \mathrm{s}$ para os métodos de Foster e Gumbel conforme Righetto, respectivamente. Os resultados obtidos por ambos os métodos convergiram significativamente indicando a eficácia dos mesmos.

Palavras chave: vazões-máximas; modelos hidrológicos; previsão de inundações 


\section{INTRODUÇÃO}

As inundações são um dos principais e mais destrutivos fenômenos naturais, caracterizadas pela elevação acentuada do nível dos rios, alagando seus leitos e planícies adjacentes, o qual se acentua pelas atividades antrópicas (RECKZIEGEL, 2007).

Segundo Novaes e Perusi (2016), há reincidentes episódios de inundações entorno do Rio Piracicaba e a beira das vias públicas do Parque da Rua do Porto, no município de Piracicaba - SP que acometem danos ambientais e prejuízos na qualidade de vida populacional, que afere zelo e compromisso dos intendentes públicos ao direito qualitativo humano.

A consolidação da previsão de enchentes e o seu regime de vazões máximas nos cursos d'água são de extrema importância para supervisão de comportamento e condução aos possíveis métodos estruturais ou não estruturais no controle de inundações urbanas, e assim elaborar possíveis sistemas que atendem ao meio público a partir de metodologias apresentadas por Tucci (1993), que retrata as previsões por vazões máximas como dimensões em períodos curtos ou a longo prazo. As categorias de curto prazo demandam variáveis hidrológicas com projeções contínuas por um sistema de captação, transmissão ou reconhecimento de dados. As projeções de longo prazo são de usufruto às metodologias probabilísticas, distribuídas de acordo com as vazões máximas anuais a partir das séries históricas adotadas.

O método empírico ou método racional aborda de forma mais sucinta as resoluções de cálculo da vazão máxima, com coeficientes e segmentos envolvidos apenas em áreas com extensão relativamente pequenas (não adotando $>2,5 \mathrm{~km}^{2}$ ) e de diminutos valores para resolução dos dados. $\mathrm{O}$ hidrograma unitário ou HU se propõe em amostras de vazões elevadas a partir de chuvas intensas que remetem em função dependente da estrutura analisada, neste caso, as precipitações com fundamento hidrometereológico ou de base probabilística. A partir de sua durabilidade e intensidade de precipitação em uma determinada bacia hidrográfica, pode-se constituir como uma característica presente analiticamente ao meio.

Gumbel (1941) também explana seus fundamentos para avaliação de eventos ou vazões máximas, a partir da extrapolação de séries históricas desenvolvidas e também como aplicação na probabilidade. Scuisiato (2013) desenvolve o método de Foster, caracterizado pela semelhante abordagem dos demais propulsores, além de envolver a aplicação da distribuição Pearson III para a descrição do comportamento das vazões máximas anuais.

Ambos os métodos supracitados foram introduzidos com o objetivo de identificar os valores máximos de enchente em um rio, a máxima precipitação, o máximo vento, ou seja, ela busca individualizar os eventos de alta magnitude que promovem histereses nos sistemas naturais e sociais.

Como base histórica e de constantes acontecimentos de enchentes causadas por problemas estruturais e de planejamento diretor do município de Piracicaba próximo ao Parque da Rua do Porto, adota-se como objetivo deste trabalho a comparação dos métodos probabilísticos de Gumbel e Foster para previsão de enchentes com série histórica de 74 anos (1944 - 2017) da estação fluviométrica no bairro Ártemis, localizado no município de Piracicaba - SP.

\section{2.ÁREA DE ESTUDO}

0 rio Piracicaba é o principal corpo hídrico em sua bacia hidrográfica, reconhecido como um dos maiores afluentes que desaguam na bacia do rio Tietê. Sua formação se inicia na região do município de Americana - SP devido aos seus precursores: o rio Atibaia e o rio Jaguari.

Pertencente a região oeste paulista e reconhecido pela sua extensão de aproximadamente $115 \mathrm{~km}$ com ocupação territorial de $12.400 \mathrm{~km}^{2}$, sendo $11.020 \mathrm{~km}^{2}$ presentes no estado de São Paulo e o restante na região sudoeste do estado de Minas Gerais. Sua importância é atraída devido ao seu abastecimento regional e de suporte ao Sistema Cantareira na grande metrópole de São Paulo, construído na década de 60.

A bacia ainda faz parte como unidade das 21 bacias pertencentes ao Comitê de Gerenciamento dos Recursos Hídricos - UGRHIs, a qual é identificada UGRHI 5 envolvendo as bacias do rio Capivari e a bacia do rio Jundiaí. Atrelado as descrições remanescentes da Companhia Ambiental do Estado de São Paulo (CETESB), as correntes expansões e ocupação populacional gradativa ao processo de urbanização do meio rural na região, contribuíram para maiores reconhecimentos possíveis de impactos ambientais existentes em conjunto do planejamento autoritário das vigentes companhias e instituições responsáveis pelos relatórios e demandas de reconstrução dos equívocos e problemáticas antrópicas para com a bacia 
hidrográfica do Rio Piracicaba em todo seu percurso, que atende além do próprio município de Piracicaba, os demais distritos e municípios como Águas de São Pedro, Americana, Campinas, Charqueada, Hortolândia, Iracemápolis, Limeira, Monte Mor, Nova Odessa, Paulínia, Rio das Pedras, Saltinho, Santa Bárbara d'Oeste, Santa Maria da Serra, São Pedro e Sumaré.

\section{METODOLOGIA}

\subsection{DELINEAMENTO EXPERIMENTAL}

Para desdobramentos da didática deste trabalho atribuem-se análises a partir de conceitos e metodologias teóricas literárias associadas aos dispositivos e ferramentas de utilidade pública. Foram utilizados dados obtidos pela Agência Nacional de Águas (ANA) juntamente com o auxílio do Sistema de Informações Hidrológicas (Hidroweb) e planilhas para manipulação das séries históricas de vazões. Foi escolhida uma estação fluviométrica e suas informações estão apresentadas na tabela abaixo:

Tabela 1: Estação fluviométrica em operação em cursos de água do Rio Piracicaba.

\begin{tabular}{|l|c|}
\multicolumn{1}{|c|}{ Estação } & Ártemis \\
\hline \multicolumn{1}{|c|}{ Município } & Piracicaba - SP \\
\hline \multicolumn{1}{|c|}{ Curso d'água } & Rio Piracicaba \\
\hline Altitude & 445,0 (m) \\
\hline Latitude & S 22ㅇ 40' 45,12" \\
\hline Longitude & W 47ㅇ 46' 31,08" \\
\hline
\end{tabular}

\subsection{DELINEAMENTO MATEMÁTICO}

Na presente seção apresentamos o tratamento estatístico realizado no trabalho, para tanto, foram escolhidas duas técnicas de probabilidade e estatística com o objetivo de determinar a ocorrência de um evento hidrológico de uma determinada magnitude no futuro, com base em séries históricas.

\section{DISTRIBUIÇÃO LOG PEARSON TIPO III}

Segundo esta distribuição, calcula-se a média, o desvio padrão e um terceiro parâmetro estimado a partir dos dados, que é chamado coeficiente de assimetria como segue:

$$
\begin{aligned}
& f(x)=\frac{\lambda^{\beta}(x-\varepsilon)^{\beta-1} e^{-\lambda(x-\epsilon)}}{\Gamma(\beta)} \\
& \quad \text { Para } \lambda=\frac{s}{\sqrt{\beta}}, \beta=\left(\frac{2}{g}\right)^{2}, \varepsilon=\bar{x}-s \sqrt{\beta} .
\end{aligned}
$$

Sabendo que: $\Gamma=$ função gama e que pode-se usar a seguinte aproximação para $\beta$ não inteiro:

$$
\Gamma(\beta+1)=\sqrt{2 \pi \beta} \beta^{\beta} e^{-\beta}\left(1+\frac{1}{12 \beta}+\frac{1}{288 \beta^{2}}-\frac{139}{51840 \beta^{3}}\right)(2)
$$

A partir das considerações acima se pode estimar um determinado parâmetro em relação a um tempo de retorno: $x_{T}=\bar{x}+S . K_{T}(3)$ 
Figura 1: Exemplo das atribuições em gráfico da Distribuição de Log Pearson III.

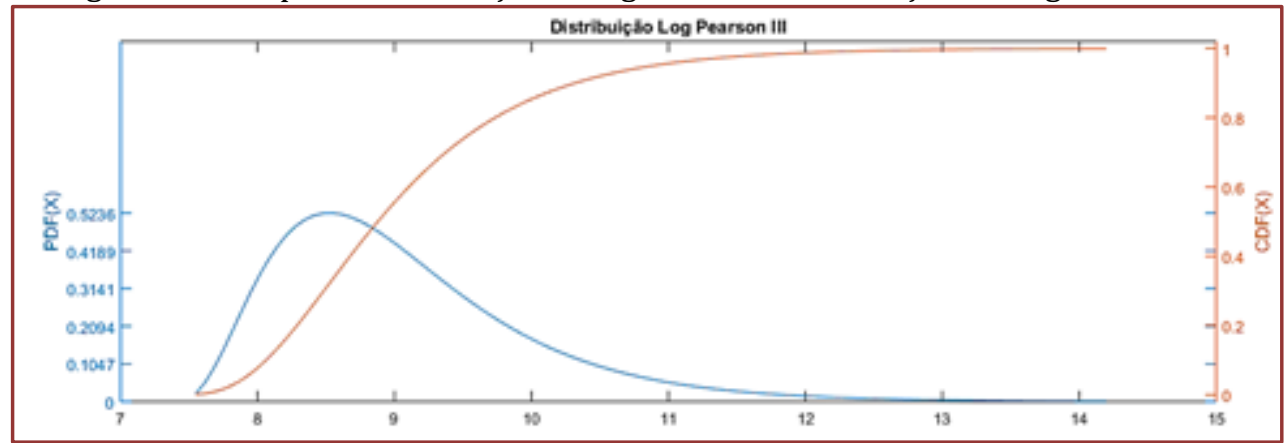

\section{MÉTODO DE FOSTER}

Este método emprega a aplicação da distribuição de Pearson III para a descrição de como se comporta o fenômeno deflúvio. Para trabalhar com este método é necessário a determinação de certas variáveis da seguinte forma:

$$
\bar{Q}=\frac{Q_{i}}{n}
$$

onde em (4) obtém-se a média;

$$
\sigma=\sqrt{\frac{\left(Q_{i}-\bar{Q}\right)^{2}}{(n-1)}}
$$

onde em (5) calcula-se o desvio padrão;

$$
C_{0}=\frac{\sum\left(Q_{i}-\bar{Q}\right)^{3}}{2 \sigma \sum\left(Q_{i}-\bar{Q}\right)^{2}}
$$

onde em (6) encontra-se o coeficiente de obliquidade de Pearson. $Q_{i}=$ vazões que compõem a série histórica anual e $\mathrm{n}=$ número de anos de observações.

Para a implementação deste método foi utilizado o seguinte algoritmo:

1. Utilizando a série histórica de vazões, foi determinado a média, o desvio padrão e o coeficiente de obliquidade de Pearson, de acordo com as expressões (4), (5) e (6).

2. Depois de determinado os resultados das expressões acima, foi ajustado o coeficiente de obliquidade de acordo com a correção proposta por Hazen:

3.

$$
C_{o}^{\prime}=\left(1+\frac{8.5}{n}\right) C_{0}
$$

4. Foi determinado a probabilidade associada ao período de retorno da seguinte maneira, onde $\mathrm{T}_{\mathrm{r}}$ é o tempo de retorno e $\mathrm{P}$ a probabilidade:

$$
P=\frac{1}{T_{r}}
$$


Tabela 2: Curva de frequência assimétrica - tipo III de Pearson.

\begin{tabular}{|c|c|c|c|c|c|c|c|}
\hline $\begin{array}{c}\text { Valores } \\
\text { de A (\%) }\end{array}$ & 0,0 & 0,1 & 0,2 & 0,3 & 0,4 & 0,5 & 0,6 \\
\hline 0,01 & $-3,73$ & $-3,32$ & $-2,92$ & $-2,53$ & $-2,18$ & $-1,88$ & $-1,63$ \\
\hline 0,1 & $-3,09$ & $-2,81$ & $-2,54$ & $-2,28$ & $-2,03$ & $-1,80$ & $-1,59$ \\
\hline 1,0 & $-2,33$ & $-2,18$ & $-2,03$ & $-1,88$ & $-1,74$ & $-1,59$ & $-1,45$ \\
\hline 5,0 & $-1,65$ & $-1,58$ & $-1,51$ & $-1,45$ & $-1,38$ & $-1,31$ & $-1,25$ \\
\hline 10,0 & $-1,28$ & $-1,25$ & $-1,22$ & $-1,19$ & $-1,16$ & $-1,12$ & $-1,08$ \\
\hline 20,0 & $-0,84$ & $-0,85$ & $-0,85$ & $-0,86$ & $-0,86$ & $-0,86$ & $-0,85$ \\
\hline 50,0 & 0,00 & $-0,03$ & $-0,06$ & $-0,09$ & $-0,13$ & $-0,16$ & $-0,19$ \\
\hline 80,0 & 0,84 & 0,83 & 0,82 & 0,80 & 0,78 & 0,76 & 0,74 \\
\hline 90,0 & 1,28 & 1,30 & 1,32 & 1,33 & 1,34 & 1,34 & 1,35 \\
\hline 95,0 & 1,65 & 1,69 & 1,74 & 1,79 & 1,83 & 1,87 & 1,90 \\
\hline 99,0 & 2,33 & 2,48 & 2,62 & 2,77 & 2,90 & 3,03 & 3,15 \\
\hline 99,9 & 3,09 & 3,38 & 3,67 & 3,96 & 4,25 & 4,54 & 4,82 \\
\hline 99,99 & 3,73 & 4,16 & 4,60 & 5,04 & 5,48 & 5,92 & 6,37 \\
\hline 99,999 & 4,27 & 4,84 & 5,42 & 6,01 & 6,61 & 7,22 & 2,85 \\
\hline 99,9999 & 4,76 & 5,48 & 6,24 & 7,02 & 7,82 & 8,63 & 9,45 \\
\hline
\end{tabular}

De posse dos dados da tabela (2) é possível encontrar o valor de x de acordo com as seguintes expressões:

$$
A=1-P
$$

$$
Q\left(T_{r}\right)=x+\bar{Q}
$$

onde $\mathrm{x}$ está relacionado a um fator de frequência da distribuição Pearson III e $\mathrm{T}_{\mathrm{r}}$ ao tempo de retorno (ou período de retorno), ou seja, o tempo médio em anos que um evento é igualado ou superado pelo menos uma vez.

\section{DISTRIBUIÇÃO DE GUMBEL}

Segundo Gumbel (1941), em princípio, se data a função densidade de probabilidade e demais propriedades de modelagem da seguinte forma:

$$
\begin{gathered}
F(x)=e^{-e^{\left(-\frac{x-u}{\alpha}\right)}} \Rightarrow y=\frac{x-u}{\alpha} \Rightarrow F(x)=e^{-e^{(-y)}} \\
\ln F(x)=\ln \left(e^{-e^{(-y)}}\right) \Rightarrow\left\{\ln (x)=-\ln \left(\frac{1}{x}\right)\right\} \Rightarrow \ln \left[\ln \frac{1}{F(x)}\right] \\
=\ln \left(e^{-y}\right) \Rightarrow y=-\ln \left[\ln \frac{1}{F(x)}\right] \\
\text { Portanto: } y_{T}=-\ln \left[\ln \left(\frac{T}{T-1}\right)\right]
\end{gathered}
$$


Figura 2: Distribuição de Gumbel.

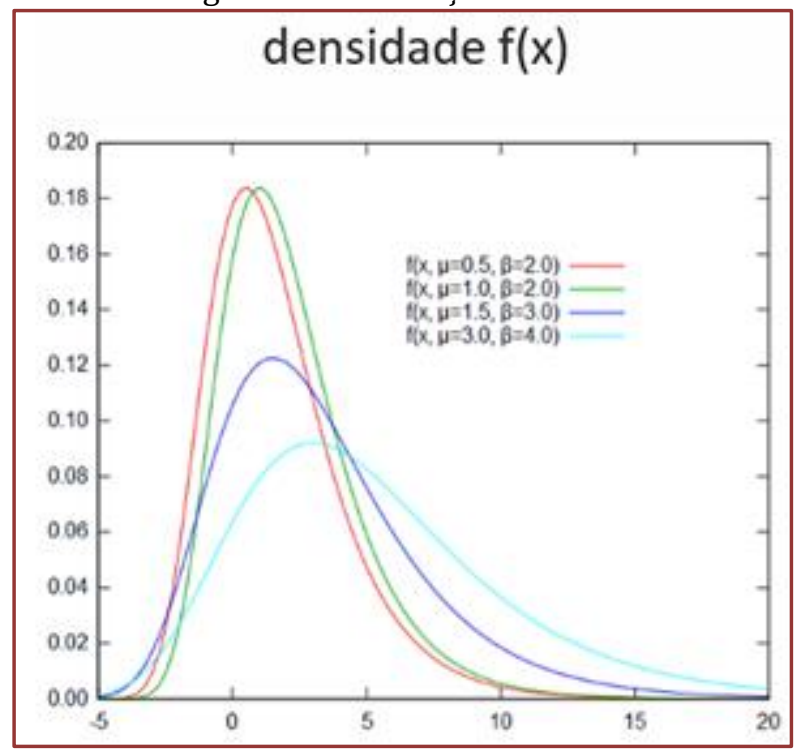

\section{MÉTODO DE GUMBEL, CONFORME RIGHETTO}

A distribuição de Gumbel tem como objetivo a avaliação de eventos extremos, ou seja, a máxima vazão de um rio, sua máxima precipitação, o máximo vento, etc. Esse método é o mais utilizado no Brasil e possui fácil aplicação.

De posse de vários dados das séries históricas, encontram-se os valores de desvio padrão (5) e de média (4), os quais permitem calcular os parâmetros das seguintes expressões:

$$
\begin{gathered}
\beta=6^{0.5} * \frac{\sigma}{\pi} \\
\alpha=(\bar{Q}-0.577 * \beta) \\
\frac{Q\left(\text { ano; } T_{r}\right)-\alpha}{\beta}=-\ln \left(\ln \left(\frac{1}{F\left(Q\left(\text { ano; } T_{r}\right)\right)}\right)\right)
\end{gathered}
$$

Sabendo-se que, $F\left(Q\left(\right.\right.$ ano $\left.\left.; T_{r}\right)\right)=1-\left(\frac{1}{T}\right)$, onde $\mathrm{T}_{\mathrm{r}}$ é o período de retorno e $\ln$ o logaritmo neperiano.

De posse dos dados do Tempo de Retorno $\left(\mathrm{T}_{\mathrm{r}}\right)$ de interesse, dos parâmetros $\alpha$ e $\beta$, e de frequência $(F)$, podemos aplicar o modelo matemático da distribuição de Gumbel conforme Righetto (1998) para estimarmos os valores de vazão (ou qualquer outro evento).

\section{DISCUSSÃO E RESULTADOS}

Os dados obtidos da série histórica da estação de Ártemis para os valores máximos de vazões anuais estão reunidos conforme a tabela abaixo: 
Tabela 3: Série histórica de vazões para a estação Ártemis.

\begin{tabular}{|c|c|}
\hline Ano & Vazão Máxima Anual $\left(\mathrm{m}^{3} / \mathrm{s}\right)$ \\
\hline 2011 & 1418,6 \\
\hline 1999 & 1226,0 \\
\hline 2016 & 1157,8 \\
\hline 1970 & 1157,0 \\
\hline 1983 & 1141,0 \\
\hline 2010 & 1028,9 \\
\hline 1960 & 981,0 \\
\hline 1995 & 968,0 \\
\hline 1991 & 947,0 \\
\hline 1958 & 929,0 \\
\hline 2009 & 928,7 \\
\hline 2002 & 897,0 \\
\hline 1965 & 886,0 \\
\hline 1947 & 832,0 \\
\hline 1957 & 812,0 \\
\hline 2017 & 807,6 \\
\hline 2005 & 801,0 \\
\hline 2007 & 781,0 \\
\hline 1950 & 780,0 \\
\hline 1976 & 759,0 \\
\hline 2012 & 746,1 \\
\hline 1963 & 742,0 \\
\hline 1966 & 742,0 \\
\hline 1951 & 728,0 \\
\hline 1975 & 727,0 \\
\hline 1962 & 722,0 \\
\hline 1974 & 721,0 \\
\hline 1967 & 715,0 \\
\hline 1990 & 691,0 \\
\hline 1997 & 673,0 \\
\hline 1988 & 669,0 \\
\hline 1989 & 669,0 \\
\hline 1981 & 668,0 \\
\hline 1982 & 653,0 \\
\hline 2003 & 647,0 \\
\hline 2015 & 645,8 \\
\hline 2004 & 641,2 \\
\hline 1972 & 641,0 \\
\hline 1977 & 625,0 \\
\hline 1964 & 618,0 \\
\hline 2000 & 617,0 \\
\hline 1996 & 614,0 \\
\hline 1961 & 602,0 \\
\hline 1948 & 589,0 \\
\hline 2006 & 580,0 \\
\hline 1987 & 571,0 \\
\hline 1968 & 553,0 \\
\hline 2014 & 550,8 \\
\hline 1998 & 550,0 \\
\hline 2013 & 540,4 \\
\hline 1952 & 540,0 \\
\hline 1994 & 540,0 \\
\hline 1946 & 537,0 \\
\hline
\end{tabular}


(Continuação)

Tabela 3: Série histórica de vazões para a estação Ártemis.

\begin{tabular}{|c|c|}
\hline \multicolumn{1}{|c|}{ Ano } & Vazão Máxima Anual $\left(\mathrm{m}^{3} / \mathrm{s}\right)$ \\
\hline 1973 & 534,0 \\
\hline 1959 & 528,0 \\
\hline 1954 & 502,0 \\
\hline 2001 & 499,0 \\
\hline 1984 & 475,0 \\
\hline 1993 & 473,0 \\
\hline 2008 & 456,2 \\
\hline 1985 & 405,0 \\
\hline 1992 & 405,0 \\
\hline 1945 & 400,0 \\
\hline 1949 & 394,0 \\
\hline 1980 & 381,0 \\
\hline 1986 & 381,0 \\
\hline 1944 & 377,0 \\
\hline 1969 & 376,0 \\
\hline 1955 & 368,0 \\
\hline 1978 & 364,0 \\
\hline 1971 & 344,0 \\
\hline 1979 & 312,0 \\
\hline 1956 & 291,0 \\
\hline 1953 & 252,0 \\
\hline & \\
\hline
\end{tabular}

A partir dos dados da Tabela (3) foram calculadas as variáveis das expressões (4), (5), (6) e (7), de acordo com a tabela seguinte:

Tabela 4: Variáveis calculadas para os dados de vazão máxima.

\begin{tabular}{|c|c|}
\hline Grandezas & Valores \\
\hline Média & $659,8\left(\mathrm{~m}^{3} / \mathrm{s}\right)$ \\
\hline Desvio padrão & 234,5 \\
\hline Coeficiente de Obliquidade de Pearson & 0,394 \\
\hline $\begin{array}{l}\text { Coeficiente de Obliquidade de Pearson } \\
\text { proposto por Hazen }\end{array}$ & 0,554 \\
\hline
\end{tabular}

Para o tempo de retorno foram considerados 5, 10, 20 e 100 anos e calculados as variáveis das expressões (8) e (9):

Tabela 5: Tempo de Retorno, Probabilidade e valores para A.

\begin{tabular}{|c|c|c|c|}
\hline $\mathrm{T}_{\mathrm{r}}$ (anos) & $\mathrm{P}\left(\mathrm{T}_{\mathrm{r}}\right)$ & \multicolumn{1}{c|}{$\mathrm{A}$} & $\mathrm{A}(\%)$ \\
\hline 5 & 0,2 & 0,8 & 80 \\
\hline 10 & 0,1 & 0,9 & 90 \\
\hline 20 & 0,05 & 0,95 & 95 \\
\hline 100 & 0,01 & 0,99 & 99 \\
\hline
\end{tabular}

Por fim, foram encontrados os valores para X com o auxílio da Tabela 2, do desvio padrão, da média e da equação (10). Ao passo que foram calculados também as variáveis $\beta$ e $\alpha$ através das equações (4), (15), (16). De posse de todos esses dados encontram-se as vazões máximas previstas segundo os métodos de Foster (MF) e Método de Gumbel conforme Righetto (MR), mostrados na tabela abaixo: 
Tabela 6: Dados para a Vazão de Projeto pelos métodos de Foster e Gumbel conforme Righetto.

\begin{tabular}{|c|c|c|}
\hline $\begin{array}{c}\text { Períodos de Retorno } \\
\text { (anos) }\end{array}$ & $\begin{array}{c}\text { MF-Vazões } \\
\text { máximas }\left(\mathrm{m}^{3} / \mathrm{s}\right)\end{array}$ & $\begin{array}{c}\text { MR-Vazões máximas } \\
\left(\mathrm{m}^{3} / \mathrm{s}\right)\end{array}$ \\
\hline 5 & 833,25 & 828,5 \\
\hline 10 & 976,24 & 965,6 \\
\hline 20 & 1105,17 & 1097,2 \\
\hline 100 & 1398,18 & 1395,1 \\
\hline
\end{tabular}

Através dos métodos explicitados e valores obtidos anteriormente, se submete as resoluções de comparação das vazões máximas de Foster (MF) e Método de Gumbel conforme Righetto (MR) de acordo com o tempo de retorno, por meio do gráfico abaixo:

Figura 1: Vazão de Projeto x Tempo (anos) da Bacia Hidrográfica do Rio Piracicaba, estação fluviométrica Ártemis.

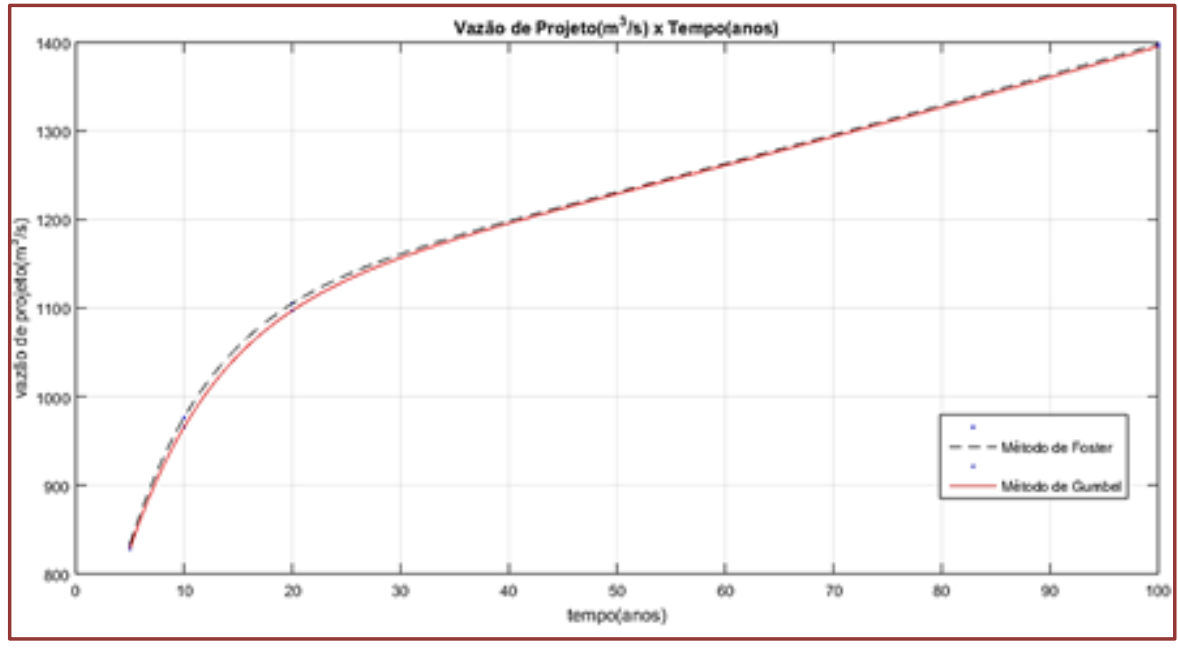

Avista-se que o Método de Foster estabeleceu os dados de maiores vazões máximas e em contrapartida, o Método de Gumbel (Righetto) introduziu menores vazões máximas para o curso d'água a partir da série histórica admitida, sendo o último mais simples nos cálculos de estimativas às vazões máximas.

Apesar do Método de Foster assumir maiores valores máximos ao projeto, o Método de Gumbel conforme Righetto não se distancia, pois atingiu resultados relativamente próximos, o que salienta a importância dos fundamentos literários neste trabalho, pois calculou-se através de abordagens com expressivos valores coerentes e significativos com relevância de ambos se apoiarem um no outro.

Em suma, se admite a partir das relações de vazão de projeto $\left(\mathrm{m}^{3} / \mathrm{s}\right) \mathrm{x}$ tempo de retorno (anos) que o Método de Foster e de Gumbel (Righetto) convergiram significativamente.

\section{CONSIDERAÇÕES FINAIS}

Salienta-se, de forma sucinta, a essencial necessidade de realocar as assertivas situações que se relacionam a coexistência do ser humano com a natureza, sendo, portanto, enaltecer os setores do direito ambiental, como parâmetro auxiliar na busca por uma qualidade de vida garantida, assegurando suas atividades de convivência e bem estar em ambientes rurais ou urbanos.

No artigo 225, "caput" da Constituição Federal de 1988, se conduz aos pretéritos de que poluir um curso d'água ou omitir-se na sua despoluição, seja em área urbana ou rural, é condenar a espécie humana à morte. Canalizar um córrego d'água (que não possui a ordem de classe adequada para ser um condutor de esgotos) poluído é fugir da obrigação legal de tratar os resíduos nele despejados e de reflorestar, de proteger, de preservar e de conservar suas áreas ciliares; é tentar esconder a própria incompetência e os próprios erros, é enterrar o valor ambiental (histórico, paisagístico, turístico, cultural, educacional, etc.) 
dos corpos hídricos urbanos ou rurais, negando-os à presente e futuras gerações; é alterar e desvalorizar a cultura, a educação e o comportamento de uma sociedade; é aniquilar a esperança de um futuro melhor para jovens e velhos, enfim, é exterminar o direito da presente e futura geração ao meio ambiente sadio, essencial à boa qualidade de vida a qual o direito ambiental defende em suas ações de ética in situ.

Portanto, as consolidações constitucionais e o direito ambiental em âmbito dos fenômenos naturais, são devidamente preocupantes, pois se condiz a qualidade de vida do ser humano em risco, admitindo resquícios e ausência de compromisso material e ético para com a população diante de tais eventualidades. Sampaio (2017), ressalta a diligência dos compromissos do Ministério Público e o poder judiciário para com a vida e exercício integral a cidadania:

"A idealização do termo "sustentabilidade" se abraça a tutela com o ambiente e os direitos individuais e sociais, a qual se baseia qualitativamente em uma existência humana digna, postergando o ecossistema que reside como mero ambiente qualquer".

Ademais, embasa seus conceitos retratando que o direito ambiental, em suma importância vem como auxiliador na busca por uma qualidade de vida garantida para seres vivos racionais, neste caso, ao homem, assegurando suas atividades de convivência e de bem estar em ambientes rurais ou urbanos, os quais não se devem surpreender perante as evidencias naturais que devem coexistir de maneira recíproca as interações, nomeadamente, aos recursos hídricos.

Por conseguinte, se traz em compensatória sob os expressivos métodos estatísticos abordados que o Método de Foster apresentou os dados de maiores vazões máximas para a estação fluviométrica que se opera na bacia hidrográfica do rio Piracicaba e o método de Gumbel conforme Righetto as menores vazões máximas para o curso d'água com 74 anos de série histórica analisada no conjunto deste trabalho e que a metodologia se conduz como satisfatória para possíveis projetos de engenharia hidráulica em planos diretores municipais com ausência quaisquer de alternativas sob fenômenos naturais tal como as inundações.

\section{REFERÊNCIAS}

[1] Bobee, B., "The log-Pearson Type III Distribution and Its Application in Hy-drology," Water Resource Research, Vol. 11, No. 5, 1975, pp. 681-689.

[2] Foster, H. A. Theoretical Frequency Curves and Their Application to Engineering Problem. Transactions of the American Society of Civil Engineers, 1924, Vol. LXXXVIII, Issue 1, Pg. 142-173.

[3] Gumbel, E. J. The Return Period of Flood Flows. The Annals of Mathematical Statistics, v. 12, n.2, p. 163-190, 1941.

[4] Novaes, C. P.; Perusi, M. C. Revista Formação (ONLINE) Vol. 3; n.23, Mai - Ago/2016. p. 143-162. ISSN: 21787298. ISSN-L: 1517-543X.

[5] Reckziegel, B.W. Levantamento dos desastres desencadeados por eventos naturais adversos no estado do Rio Grande do Sul no período de 1980 a 2005. 2017, 261 p. Dissertação de Mestrado em Geografia. Universidade Federal de Santa Maria, Santa Maria, 2007.

[6] Sampaio, Rômulo. DIREITO AMBIENTAL. Direito. Fundação Getúlio Vargas. Rio de Janeiro. FGV Direito Rio. 2017. Disponível em: <https://direitorio.fgv.br/sites/direitorio.fgv.br/files/u1882/direito_ambiental_2017-2_0.pdf>. Acesso em 04 Jul 2019.

[7] Scuissiato, C; Comparação dos métodos de séries de duração parcial e séries de máximos anuais na estimativa de cheias de projeto. Dissertação(Mestrado). Universidade Federal do Paraná, Curitiba, 2013.

[8] Tucci, C.E.M. (Organizador). Hidrologia. Ciência e Aplicação. Porto Alegre: ABRH, 1993. 


\section{Capítulo 3}

Avaliação da eficiência de tratamento piloto de filtro ascendente e bloco cerâmico para a água do Rio Paraopeba pós -rompimento da Barragem B1 da Vale, em Brumadinho- $M G$

Tiago Lucas Ferreira

Jessica Cristina de Souza Caetano

Hygor Aristides Victor Rossoni

Resumo: Observou-se as propriedades da água do rio Paraopeba, após o rompimento da barragem da Mina do Feijão em Brumadinho-MG, diante do laudo apresentado pelo Instituto Mineiro de Gestão das Águas, percebeu-se a importância de propor um tratamento da água utilizando materiais alternativos, encontrados com facilidade no setor de construção civil. Foram realizados ensaios físicos e químicos, com amostra bruta, coletada no Rio Paraopeba próximo ao ponto de captação água para o abastecimento do município de Pará de Minas. Para a realização do tratamento alternativo, foi utilizado um sistema piloto composto por filtração direta com fluxo ascendente utilizando brita e área. Elaborado pelos alunos do Mestrado Profissional em Sustentabilidade e Tecnologia Ambiental do IFMG em Bambuí. Constatou-se através das analise da água que houve uma redução na tubidez, sólidos em suspensão totais e metais como ferro, alumínio, arsênio,chumbo, cromo e manganês.

Palavras-chave: Tratamento de água; Rio Paraopeba; argila; barragem; mineração 


\section{INTRODUÇÃO}

A qualidade da água é determinada por suas propriedades físicas, químicas e biológicas, que estão diretamente ligadas aos processos naturais (cobertura vegetal, intemperismo, intensidade das precipitações) e à ação antrópica.

Diante da ruptura da Barragem 1 da empresa Vale em Brumadinho, Minas Gerais, no dia 25 de janeiro de 2019, o rejeito acumulado na barragem atingiu diretamente as comunidades ao redor da Mina do Feijão, afetando aproximadamente 290 hectares, $420 \mathrm{~km}$ pelo rio Paraopeba, levando os sedimentos ate a represa de Três Marias. (Semad, 2019)

Desde o dia 29 de janeiro de 2019, instituições estaduais e federais estabeleceram uma rede com 16 pontos para monitoramento diário (de água e sedimentos) ao longo do curso do rio Paraopeba. Em consequêencia dos materiais encontrados na água, a secretaria de meio ambiente assumiu como medida preventiva a suspensão do uso da água bruta do rio para consumo humano, animal e atividades agrícolas (Semad, 2019).

Os relatórios de monitoramento de qualidade da água do rio Paraopeba, publicados a partir do rompimento da barragem, demonstraram elevação na concentração dos metais pesados em relação aos níveis esperados. Os metais pesados são considerados contaminantes não biodegradáveis e biocumulativos (Silva, 2015).

Com base nesse contexto, a proposta do presente trabalho é verificar a eficiência do tratamento da água por meio da filtragem direta com fluxo ascendente para a remoção de turbidez, e avaliar a eficiência de argilas (presentes como constituintes em materiais de construção civil) como adsorventes.

\section{METODOLOGIA}

Como levantamento bibliográfico foram consultados os informativos dos parâmetros de qualidade das águas, após o rompimento da barragem B1, disponibilizados no site da Semad (2019).

Realizou-se a coleta de amostras de água no rio Paraopeba, utilizando a metodologia proposta no Guia Nacional de Coleta e Preservação de Amostras (Brandão, 2011), a fim de se caracterizar mesma. Os valores para cada parâmetro foram confrontados com os limites estabelecidos para Classe 2 de acordo com a Classe 2 de acordo com a DN COPAM/CERH 01/08 (Minas Gerais, 2008).

A amostragem foi realizada no rio Paraopeba, Município de São José da Varginha, no ponto de captação para o abastecimento da cidade de Pará de Minas referenciado pelas coordenadas 1942'40,73"S e

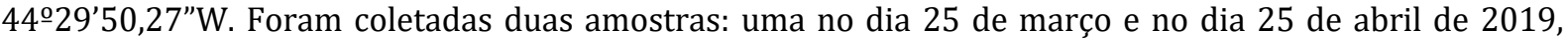
contados a partir do rompimento da Barragem 1. Estas duas amostras deram origem a uma amostra composta, submetida a análises prévias e posteriores ao tratamento piloto.

Caracterizou-se a amostra composta quanto aos parâmetros de turbidez, condutividade elétrica, sólidos totais, $\mathrm{pH}$ da água e metais (antes e depois do tratamento proposto).

Com o propósito de tratar a água do manancial, foi construído um projeto piloto de estação de tratamento de água, constituído por quatro bombonas em plástico de 50 litros, ligadas em série. A primeira bombona foi utilizada como reservatório de água bruta, na segunda foi construída um filtro composto por brita

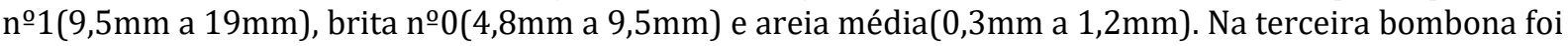
colocado um bloco cerâmico de construção triturado (argila caulinita) para atuar como meio adsorvente, e finalmente o quarto o tanque foi admitido como reservatório de água tratada.

Para a estabilização do sistema, foi admitido o período de 7 dias em que a água do rio Paraopeba ficou em circulação sem interferência externa.No sétimo dia, coletou-se água no tanque 4 que foi destinada para análises para verificar a eficiência do tratamento e se houve o atendimento dos padrões Classe 2 da DN COPAM/CERH 01/08. 


\section{RESULTADOS E DISCUSSÃO}

Os ensaios de turbidez, $\mathrm{pH}$, sólidos em suspensão totais, condutividade, apresentaram os resultados expostos na Tabela 1.

Tabela 1: Parâmetros das análises de água do Rio Paraopeba com 60 e 90 dias após o rompimento da barragem B1 do Córrego do Feijão e após o tratamento do projeto piloto.

\begin{tabular}{|c|c|c|c|c|c|c|c|c|}
\hline & \multicolumn{4}{|c}{ Amostra de 60 dias } & \multicolumn{2}{c|}{ Amostra de 90 dias } & \multicolumn{2}{c|}{ Amostra tratada } \\
\hline & Valor & Unid. & Valor & Unid. & Valor & Unid. & Valor & Unid. \\
\hline Turbidez & 103,25 & $\mathrm{NTU}$ & 36,25 & $\mathrm{NTU}$ & 0,09 & $\mathrm{NTU}$ & 100 & $\mathrm{NTU}$ \\
\hline $\mathrm{pH}$ & 7 & $\mathrm{pH}$ & 7 & $\mathrm{pH}$ & 7 & $\mathrm{pH}$ & $6 \mathrm{e} 9$ & $\mathrm{pH}$ \\
\hline $\begin{array}{c}\text { Condutividade } \\
\text { elétrica }\end{array}$ & 98 & $\mathrm{Ms}$ & 128 & $\mathrm{Ms}$ & 348 & $\mu \mathrm{s}$ & \multicolumn{2}{c|}{ Não previsto } \\
\hline $\begin{array}{c}\text { Sólidos em } \\
\text { suspensão } \\
\text { totais }\end{array}$ & 5400 & $\mathrm{mg} / \mathrm{L}$ & 1333 & $\mathrm{mg} / \mathrm{L}$ & 0,0 & $\mathrm{mg} / \mathrm{L}$ & 100 & $\mathrm{mg} / \mathrm{L}$ \\
\hline
\end{tabular}

Em um contexto os resultados apresentados na Tabela 1, constata-se a diminuição na turbidez: de $103 \mathrm{NTU}$ para 0,09NTU (após o tratamento a água tornou-se translúcida). $0 \mathrm{pH}$ manteve-se 7 , dentro do limite para classe 2 da DN COPAM/CERH 01/08: para a vida aquática, o pH deve ficar na faixa de 6 a 9 . Para os sólidos em suspensão totais houve redução de $5400 \mathrm{mg} / \mathrm{L}$ para $0,00 \mathrm{mg} / \mathrm{L}$, obtendo eficiência de remoção de $100 \%$, na filtragem da água.

Para o parâmetro condutividade elétrica (Tabela 1), a água com sólidos em suspensão (antes da filtragem), apresentou valores $98 \mu \mathrm{S}$ com 60 dias pós-rompimento da barragem e $128 \mu \mathrm{S}$ com 90 dias após rompimento. Entretanto, após a filtragem da água, observou-se um aumento no valor de condutividade de aproximadamente três vezes o valor inicial, cerca de $348 \mu \mathrm{S}$.

Diante dados supracitados, observado, uma vez que houve remoção dos sólidos suspensos inicialmente presentes na água, os metais dissolvidos ficaram 'aparentes', aumentando a condutividade elétrica da água. Na Tabela 2, são apresentados os resultados para análise dos metais presentes realizado pelo laboratório de química da UFLA, (antes e após o tratamento proposto):

Tabela2: Análise de metais na amostra composta pré-tratamento e pós tratamento.

\begin{tabular}{|c|c|c|c|c|} 
Metais e não metais & $\begin{array}{c}\text { Amostra composta } \\
\text { pré-tratamento } \\
(\mathrm{mg} / \mathrm{L})\end{array}$ & $\begin{array}{c}\text { Amostra após } \\
\text { tratamento } \\
(\mathrm{mg} / \mathrm{L})\end{array}$ & $\begin{array}{c}\text { Limites de classe 2 } \\
(\mathrm{mg} / \mathrm{L})\end{array}$ & $\begin{array}{c}\text { Eficiência de } \\
\text { redução (\%) }\end{array}$ \\
\hline Ferro (Fe) & 15 & $<0,025$ & - & 78,0 \\
\hline Alumínio (Al) & 2,4 & $<0,005$ & 0,01 & 98,9 \\
\hline Chumbo (Pb) & 0,007 & $<0,005$ & 0,05 & - \\
\hline Cromo (Cr) & $<0,005$ & 0,272 & 0,1 & 93,0 \\
\hline Manganês (Mn) & 3,9 & 0,00128 & 0,01 & 32,6 \\
\hline Arsênio (As) & 0,0019 & & & \\
\hline
\end{tabular}

Como pode ser observado na Tabela 2, as etapas de filtragem e adsorção demonstraram resultados positivos na remoção de metais pesados, visto apenas um valor acima dos limites da classe 2 da DN COPAM/CERH 01/08 apenas o manganês, que por sua vez, teve uma eficiência de 93\%.

\section{CONCLUSÕES OU CONSIDERAÇÕES FINAIS}

Com base nos dados apresentados, foi possível observar que na amostras coletadas do rio Paraopeba, estavam acima dos limites da classe 2 da DN COPAM/CERH 01/08, na turbidez e sólidos em suspensões totais.

Com o projeto piloto de tratamento de água utilizado materiais alternativos, composto por filtração direta com fluxo ascendente, teve um resultado satisfatório, reduzindo mais de $99 \%$ na turbidez, sólidos em suspensão e os metais. A condutividade elétrica apresentou aumento em seu valor, podendo ser troca dos íons dos materiais do filtro e da cerâmica. 


\section{REFERÊNCIAS}

[1] Brandão, C. J. Guia nacional de coleta e preservação de amostras: água, sedimentos, comunidades aquaticas e efluentes liquidos. São Paulo: Companhia Ambiental do Estado de São Paulo, 2011.

[2] Pinto, C. C. Informativo dos parâmentros de qualidade das águas do Rio Paraopeba, após o desastre na barragem B1 no municipio de Brumadinho / MG. Belo Horizonte. 2019.

[3] HTTP://WWW.IGAM.MG.GOV.BR/COMPONENT/CONTENT/ARTICLE/2053-SUSPENSAO-DO-USO-DE-AGUABRUTA-E-AMPLIADA-NO-RIO-PARAOPEBA 


\section{Capítulo 4}

\section{Avaliação do uso de coagulantes naturais no tratamento de águas residuárias do processo de fabricação de fogos de artifício}

\section{Sueli Maria dos Santos}

\section{Hygor Aristides Victor Rossini}

Resumo: Neste trabalho avaliou-se a eficiência de diferentes agentes coagulantes naturais no processo de tratamentos de águas residuárias industriais de uma empresa de fogos de artifícios. Os agentes coagulantes avaliados foram semente de Moringa oleífera, Helianthus annuus e Cucurbita. Para tanto, foram avaliados os parâmetros referentes aos sólidos sedimentáveis, sólidos suspensos e turbidez. Ensaios foram realizados a partir de cada amostra de $1000 \mathrm{ml}$ de águas residuárias industriais com uma adição de $20 \mathrm{~g}$ de semente de coagulantes, cada ensaio foi conduzido por meio de agitações manuais, em um tempo de 15 minutos, sendo destinadas as avaliações dos parâmetros em três diferentes tempos de sedimentação, sendo esses de 30 minutos, 4 horas e 8 horas. 0 agente coagulante Moringa oleífera apresentou a maior eficiência no tratamento, no qual foram obtidos os melhores resultados de eficiências de redução de 93,3\% de sólidos sedimentáveis, de 84,8\% de sólidos suspensos e de 78,1\% de Turbidez, no tempo de sedimentação de 8 horas. Para os demais agentes coagulantes aconselha-se a realização de novos ensaios. Observou-se que utilizando o coagulante de Moringa oleífera para tratamento das águas residuárias, é possível o seu reuso no processo de limpeza das oficinas e equipamentos durante a confecção dos fogos de artifícios.

Palavras chaves: Coagulantes naturais, águas residuárias industrias, reuso. 


\section{INTRODUÇÃO}

Cada vez mais o meio ambiente está sendo afetado com a poluição química de natureza orgânica ou inorgânica, decorrentes de resíduos industriais. Dessa forma as indústrias de fogos de artifícios contribuem indiretamente com essa poluição, proporcionando impactos ao meio ambiente por meio desses resíduos líquidos e sólidos contaminados com metais pesados tais como: (alumínio, níquel, cobre, estrôncio, bário) e sais antimônio, litopônio e potássio (MAZZER e CAVALCANTI 2004).

Segundo Deliberação Normativa do COPAM/DN-MG no217 (Minas Gerais, 2017) todos empreendimentos com o potencial poluidor, classe médio, devem serem licenciados cumprindo-se as obrigações legais.

No que refere qualidade de descarte das águas residuárias industriais, a empresa contribuinte no estudo localizada no município de Santo Antônio do Monte, no centro Oeste de Minas Gerais, gera águas residuárias proveniente a limpeza das oficinas e equipamentos durante a produção de fabricação dos fogos de artifícios. 0 tratamento dessa é realizado de forma convencional utilizando sulfato de alumínio, o que proporciona águas residuárias tratadas com alta toxidade (BRATBY, 2006).

Com base nesse contexto, o objetivo desse trabalho é propor a substituição do tratamento físico-químico, com o sulfato de alumínio, por coagulantes naturais, proporcionando o reuso das águas residuárias, como por exemplo em processo de limpeza das oficinas e equipamento. Dessa forma, diminui-se o impacto ambiental além de menor custo financeiro com o tratamento convencional das águas residuárias.

\section{METODOLOGIA}

Neste presente trabalho, foram utilizados coagulantes naturais, tais como, sementes de Acácia-branca (Moringa oleifera), Girassol (Helianthus annuus), Abóbora (Cucurbita) trituradas, como alternativa para tratamento das águas residuárias industriais provinda de uma empresa de fogos de artifícios, localizada em Santo Antônio do Monte-MG. A empresa em questão é de porte e de potencial poluidor classificado como médio, avaliada conforme a Deliberação Normativa do COPAM/DN-MG no217 (MINAS GERAIS, 2008). Essas águas residuárias são oriundas da limpeza das oficinas e equipamentos, utilizados durante a fabricação dos fogos de artifícios, são destinadas para um único tanque de tratamento. As amostras para os ensaios foram coletadas desse tanque.

Foram utilizados para análises das eficiências dos tratamentos com os coagulantes naturais os parâmetros referentes aos sólidos sedimentáveis (SSed), sólidos suspensos (SS), turbidez (NTU) e pH, em cada amostra conforme Deliberação Normativa Conjunta do COPAM/CERH-MG n0ㅜㄹ, (MINAS GERAIS, 2008).

As análises foram realizadas no laboratório do Serviço de Autônomo de Águas e Esgotos (SAAE) localizado em Lagoa da Prata-MG.

As amostras de águas residuárias industriais foram coletadas em três béqueres de $1000 \mathrm{~mL}$, para assim, analisar, o pH inicial, a qual foi encontrado o valor de 6,0. Logo em seguida realizou a precipitação com adição de solução $5 \mathrm{~g}$ de $\mathrm{Ca}(\mathrm{OH})_{2}$ e ajustado o pH para 7,0. Esse ensaio teve finalidade identificar o pH inicial para precipitação dos compostos da água residuárias (VAZ, et. at. 2010). Para os tratamentos de coagulação natural foram utilizadas sementes de Moringa oleífera, Helianthus annuus e Cucurbita. Essas sementes foram trituradas e colocadas em béqueres de $250 \mathrm{~g}$, separadamente. A partir disso, foram separadas três amostras de água residuárias industriais de fogos de artifícios, cada uma contendo um volume de $1000 \mathrm{~mL}$. Logo em seguida, foi adicionada uma proporção de $20 \mathrm{~g}$ das sementes trituradas em cada amostra de água de $1000 \mathrm{~mL}$.

Para a realização dos ensaios com os coagulantes naturais procedeu-se a mistura manual, por meio de agitação, em um tempo de 15 minutos a cada ensaio. Foi observado um tempo de sedimentação de 30 minutos, logo em seguida foi realizada uma coleta de amostra para a análise da eficiência do tratamento; depois de 4 horas, outra análise; e por fim após 8 horas foi realizada a última análise. Após cada um dos três tempos de sedimentação colocou-se as amostras de água residuárias tratadas, no Cone de Inhoff de $1000 \mathrm{~mL}$ sendo retiradas alíquatas do sobrenadante para a realização das análises dos parâmetros: pH, turbidez, sólidos suspensos totais e sólidos sedimentáveis. 


\section{RESULTADOS E DISCUSSÃO}

Na Tabela 1 são apresentadas as características das águas residuárias industriais de limpeza das oficinas e equipamentos oriundos da confecção de fogos de artifícios, segundo da Deliberação Normativa Conjunta COPAM/CERH-MG no01 (Minas Gerais, 2008) são obrigadas a submeter-se ao tratamento antes do seu descarte ou reuso.

Tabela 1 - Característica das amostras das águas residuárias provindas da lavagem das oficinas de fogos de artifícios.

\begin{tabular}{|c|c|c|c|c|c|}
\hline \multirow{3}{*}{$\begin{array}{c}\text { Águas } \\
\text { Residuárias } \\
\text { Industrial } \\
\text { Bruto }\end{array}$} & \multicolumn{5}{|c|}{ Parâmetros } \\
\hline & $\begin{array}{c}\text { L.Q. }(2,26 \text { - } \\
14,00)\end{array}$ & & L.Q. $\leq 500$ & L.Q. $\leq 500$ & L.Q. $\leq 100$ \\
\hline & 6.0 & $23^{\circ} \mathrm{C}$ & $295,67 \mathrm{mg} / \mathrm{L}$ & $1,5 \mathrm{mg} / \mathrm{L}$ & $134,0 \mathrm{NTU}$ \\
\hline
\end{tabular}

Fonte: Próprios autores, 2019.

Os ensaios de coagulantes naturais no tratamento das águas residuárias obtiveram os resultados demonstrados na Tabela 2. Assim, foram avaliadas as eficiências de remoção ao analisar os parâmetros de turbidez, sólidos suspensos e sólidos sedimentáveis de cada amostra de água residuárias tratada.

Tabela 2 - Resultados analíticos em cada amostra com Coagulantes Naturais

\begin{tabular}{|c|c|c|c|c|c|c|c|c|c|}
\hline \multirow{3}{*}{ 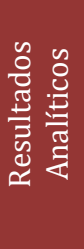 } & \multicolumn{6}{|c|}{ Parâmetros } & \multicolumn{3}{|c|}{ Eficiência (\%) } \\
\hline & \multirow[b]{2}{*}{ TS } & \multirow{2}{*}{$\begin{array}{c}\mathrm{pH} \\
(2,26 \\
- \\
14,00 \\
)\end{array}$} & \multirow[b]{2}{*}{$\begin{array}{c}\mathrm{TA}^{\mathrm{o}} \\
\mathrm{C}\end{array}$} & SS & SSed & Turbidez & SS & SSed & Turbidez \\
\hline & & & & L.Q. $\leq 500$ & L.Q. $\leq 500$ & L.Q. $\leq 100$ & $\begin{array}{l}\text { TS } \\
30 \mathrm{~min}\end{array}$ & TS $4 \mathrm{~h}$ & TS $8 \mathrm{~h}$ \\
\hline \multirow{3}{*}{ 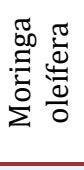 } & $30 \mathrm{~min}$ & 7,0 & 21 & $178,0 \mathrm{mg} / \mathrm{L}$ & $0,2 \mathrm{mg} / \mathrm{L}$ & $149,0 \mathrm{NTU}$ & $39,80 \%$ & $86,7 \%$ & $-11,2 \%$ \\
\hline & $4 \mathrm{~h}$ & 7,0 & 21 & $172,0 \mathrm{mg} / \mathrm{L}$ & $0,1 \mathrm{mg} / \mathrm{L}$ & $101,0 \mathrm{NTU}$ & $41,8 \%$ & $93,3 \%$ & $24,6 \%$ \\
\hline & $8 \mathrm{~h}$ & 7,0 & 21 & $45,0 \mathrm{mg} / \mathrm{L}$ & $0,1 \mathrm{mg} / \mathrm{L}$ & $29,4 \mathrm{NTU}$ & $84,8 \%$ & $93,3 \%$ & $78,1 \%$ \\
\hline \multirow{3}{*}{ 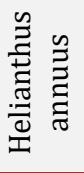 } & $30 \mathrm{~min}$ & 7,0 & 21 & $385,0 \mathrm{mg} / \mathrm{L}$ & $0,1 \mathrm{mg} / \mathrm{L}$ & $457,0 \mathrm{NTU}$ & $-30,2 \%$ & $80,0 \%$ & $-241,0 \%$ \\
\hline & $4 \mathrm{~h}$ & 7,0 & 21 & $362,0 \mathrm{mg} / \mathrm{L}$ & $0,2 \mathrm{mg} / \mathrm{L}$ & $244,0 \mathrm{NTU}$ & $-22,4 \%$ & $86,7 \%$ & $-82,1 \%$ \\
\hline & $8 \mathrm{~h}$ & 7,0 & 21 & $443,3 \mathrm{mg} / \mathrm{L}$ & $0,2 \mathrm{mg} / \mathrm{L}$ & $354,0 \mathrm{NTU}$ & $-49,9 \%$ & $86,7 \%$ & $-164,2 \%$ \\
\hline \multirow{3}{*}{ 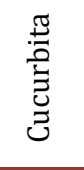 } & $30 \mathrm{~min}$ & 7,0 & 21 & $395,0 \mathrm{mg} / \mathrm{L}$ & $0,5 \mathrm{mg} / \mathrm{L}$ & 702,0NTU & $-33,6 \%$ & $66,7 \%$ & $-423,9 \%$ \\
\hline & $4 \mathrm{~h}$ & 7,0 & 21 & $374,0 \mathrm{mg} / \mathrm{L}$ & $0,6 \mathrm{mg} / \mathrm{L}$ & 294,0NTU & $-26,5 \%$ & $73,3 \%$ & $-119,4 \%$ \\
\hline & $8 \mathrm{~h}$ & 7,0 & 21 & $456,7 \mathrm{mg} / \mathrm{L}$ & $0,3 \mathrm{mg} / \mathrm{L}$ & $215,0 \mathrm{NTU}$ & $-94,5 \%$ & $80,0 \%$ & $-60,4 \%$ \\
\hline
\end{tabular}

CN - Coagulantes Naturais; TS - Tempo de Sedimentação; pH - potencial Hidrogeniônico; TA - Temperatura da Amostra; SS - Sólidos Suspensos; SSed - Sólidos Sedimentáveis; T - Turbidez; min - minutos; h - hora.

Fonte: Próprios autores, 2019.

De acordo Vaz et. at. (2010) dentre os coagulantes naturais analisados, é perceptível verificar que o tratamento utilizando as sementes de Moringa oleífera obteve os melhores resultados de eficiência de remoção dos parâmetros analisados, como pode-se observar na Tabela 2, possibilitando assim, a reutilização das águas residuárias tratadas no processo de limpeza das oficinas e equipamentos.

0 agente coagulante Moringa oleífera apresentou a maior eficiência no tratamento, no qual foram obtidos os melhores resultados de eficiências de redução de 93,3\% de sólidos sedimentáveis, de 84,8\% de sólidos suspensos e de 78,1\% de turbidez, no tempo de sedimentação de 8 horas. 


\section{CONCLUSÕES}

Os coagulantes naturais testados mostraram-se maior eficiência na remoção dos sólidos sedimentáveis, sólidos suspensos e turbidez, no tempo de sedimentação de 8 horas, das águas residuárias industriais oriundas da limpeza das oficinas e equipamentos do processo de fabricação de fogos de artifícios. Dessa forma, pode-se constatar que o melhor resultado para a utilização das sementes de Moringa oleífera. Nesse contexto, certifica-se possibilidade da reutilização dessas águas residuárias tratadas no processo de limpeza das oficinas e equipamentos de fogo de artifícios. Para os demais coagulantes testados não foram obtidas eficiências satisfatórias na remoção dos parâmetros analisados, porém devem ser conduzidos outros estudos visando a otimização desses tratamentos.

\section{AGRADECIMENTOS}

Os autores agradecem com uma imensa gratidão ao laboratório do Serviço Autônomo de Águas e Esgoto (SAAE) de Lagoa da Prata pela a disponibilidade na condução das análises laboratoriais dos parâmetros avaliados no presente estudo. Além disso, agradecemos a empresa Artesanato de Fogos Vitoria Ltda., por ter disponibilizando as amostras de água residuárias industriais.

\section{REFERÊNCIAS}

[1] Bratby, Jonh. Coagulation and flocculation in water and wastewater treatment. 2 th ed. London, UK: IWA Publishing, 2006.

[2] Brasil, Ministério do Meio Ambiente Conselho Nacional do Meio Ambiente Resolução Conama nㅜㅜㄱㅜ de 29 de agosto de 2006. Define critérios e procedimentos, para o uso agrícola de lodos de esgoto gerados em estações de tratamento de esgoto sanitário e seus produtos derivados, e dá outras providências. Brasília, DF, ago 2006.

[3] Mazzer, Cassiana e Cavalcanti, Osvaldo Albuquerque. Introdução à Gestão Ambiental de Resíduos. Distrito de Floriano, Maringá, PR, 2004.

[4] Minas Gerais, Deliberação Normativa COPAM/DN-MG no 217, de 06 de dezembro de 2017. Estabelece critérios para classificação, segundo o porte e potencial poluidor, bem como os critérios locacionais a serem utilizados para definição das modalidades de licenciamento ambiental de empreendimentos e atividades utilizadores de recursos ambientais no Estado de Minas Gerais e dá outras providências. Diário de Executivo, Belo Horizonte, MG, 08 de dez 2017.

[5] Minas Gerais, Deliberação Normativa Conjunta COPAM/CERH-MG no01, de 05 de maio de 2008. Dispõe sobre a classificação dos corpos de águas e diretrizes ambientais para o seu enquadramento, bem como estabelece as condições e padrões de lançamento de efluentes, e dá outras providências. Publicação - Diário do Executivo - "Minas Gerais”. Belo Horizonte, MG, 13 Ago 2008

[6] Vaz, Luiz Gustavo de Lima; Klen, Márcia Regina Fagundes, Veit, Márcia Teresinha; Silva, Edson Antônio da; Barbiero. Avaliação da Eficiência de Diferentes Agentes Coagulantes na Remoção de Cor e Turbidez em Efluente de Galvanoplastia. Universidade Estadual de Maringá (UEM) - Departamento de Engenharia Química - Maringá - PR. Eclética Química, Volume 35, número4 Artigo, 2010. 


\section{Capítulo 5}

\section{Avaliação da eficiência das sementes de Moringa Oleifera Lam. para remoção de turbidez em afluentes}

\section{Filipe de Souza Pinto \\ Ana Claudia Pimentel de Oliveira}

Resumo: Os usos múltiplos dos corpos hídricos favorecem uma perda da qualidade da água geralmente decorrente do lançamento de esgotos nos afluentes sem tratamento, ou tratado de forma inadequada, devido aos altos custos operacionais. Sendo assim, o presente trabalho tem como objetivo avaliar a eficiência das sementes de Moringa oleifera Lam. para clarificação da água de dois afluentes receptores de esgotos domésticos sem tratamento. As concentrações de sementes testadas foram $100 \mathrm{mg}, 200$ $\mathrm{mg}, 300 \mathrm{mg}$ e $400 \mathrm{mg}$ a cada $500 \mathrm{~mL}$ de água. Em ambos os rios, as maiores concentrações de sementes utilizadas ( $400 \mathrm{mg}$ ) favoreceram a clarificação das amostras em cerca de 50\%. Logo, as sementes de M. oleífera Lam. se mostraram como um ótimo tratamento alternativo para remoção de turbidez de afluentes.

Palavras-Chave: Moringa oleifera; Clarificação; Tratamento. 


\section{INTRODUÇÃO}

Devido ao crescimento exponencial da população e os gastos dos recursos naturais, atualmente fala-se muito sobre a gestão e preservação do meio ambiente. A água por ser uma substância fundamental para todos os seres vivos tem seu destaque dentro deste assunto, principalmente por ser um recurso finito e estar ameaçado por ações antrópicas como a poluição, urbanização e industrialização (VOROSMARTY, 2010).

A crise hídrica é um assunto global, uma vez que cerca de $70 \%$ da superfície terrestre é formada por água, porém apenas $3 \%$ é doce e/ou potável (SAVEH, 2016). Sua escassez atinge nosso planeta em diversas esferas, tanto econômicas quanto sociais, como exemplo, temos a China, com mais de 300 milhões de pessoas sem acesso à água própria para o consumo (CARLÃO, 2018).

Apesar de $12 \%$ da água doce do planeta estar em nosso país, o Brasil também passa por esta dificuldade. Desde a seca no Nordeste até os vazamentos das tubulações nos municípios, já é notável a falta deste recurso, até porque, segundo dados do Sistema Nacional de Informação sobre Recursos Hídricos (SNIRH), o menor uso da água doce é para o consumo, já que a maior parte desta é utilizada para irrigação, uso industrial e agricultural, além da contaminação que também é um dos mais preocupantes fatores de impotabilidade da água.

Em 2017, o Sistema Nacional de Informações sobre Saneamento (SNIS) e o IBGE divulgaram dados de que mais de $16 \%$ da população brasileira não tem acesso à água, mais de $47 \%$ não possui esgoto tratado e cerca de $14 \%$ não recebe água com regularidade adequada. Ou seja, uma grande parcela dos brasileiros não tem acesso à água própria para o consumo e seu esgoto é lançado sem qualquer, ou quase nenhum, tipo de tratamento nos corpos hídricos.

Desta maneira, há uma perda da qualidade hídrica, e, muitas vezes, este mesmo esgoto é lançado diretamente nos afluentes por todo o Brasil. Esse despejo gera um crescimento de matéria orgânica, colônias de microrganismos, eutrofização e, pode-se destacar também, o aumento da turbidez (LAMPARELLI, 2004).

Lopes e Duarte (2017), em seu estudo, apontaram que utilizar métodos alternativos vem demonstrando um ótimo resultado no tratamento e absorção de contaminantes com o intuito de retirar o agente químico e substituí-lo por um agente natural. Um destes métodos é a utilização de sementes de Moringa oleifera Lam., na qual já apresentou resultados surpreendentes e positivos para remoção, floculação e adsorção de diferentes materiais como metais e corantes (ARAUJO et al., 2010; CAMACHO et al., 2015; JAMARIM et al., 2018; COSTA et al., 2016). Além disso, o uso da Moringa não altera o pH da água e, por apresentar uma proteína específica, promove uma boa remoção de cor e turbidez (CAMACHO et al., 2015; BERGAMASCO et al., 2018).

Sendo assim, objetiva-se com este estudo analisar a eficiência das sementes de Moringa oleifera Lam. para clarificação da água de dois afluentes receptores de esgotos domésticos sem tratamento.

\section{METODOLOGIA}

\section{$\checkmark \quad$ Preparo das Sementes}

As sementes de Moringa oleífera Lam. foram trazidas de Mato Grosso do Sul para o Núcleo de Meio Ambiente (NMA) da Universidade Castelo Branco (Campus Realengo/RJ) e acondicionadas à câmara fria em embalagem plástica durante todo o estudo (5 meses) à $-360^{\circ} \mathrm{C}$ para não perder sua viabilidade (BEZERRA, 2004).

As sementes foram descascadas, maceradas até virar um pó e peneiradas a fim de padronizar o diâmetro médio de partículas. Estas foram pesadas através de balança de precisão (SCHIMADZU - AUY220) e separadas em quatro concentrações (100mg, $200 \mathrm{mg}$, 300mg e $400 \mathrm{mg}$ ).

\section{$\checkmark \quad$ Afluentes}

Foram coletadas três amostras de água do Rio Catarino, próximo a Av. de Santa Cruz, 1631 (Fig. 1), e Rio Piraquara, próximo a Av. Marechal Fontenele, 5721 (Fig. 2), ambos localizados no bairro de Realengo, Zona Oeste do Rio de Janeiro/RJ. 
Figura 1: Rio Catarino - Ponto de Coleta.

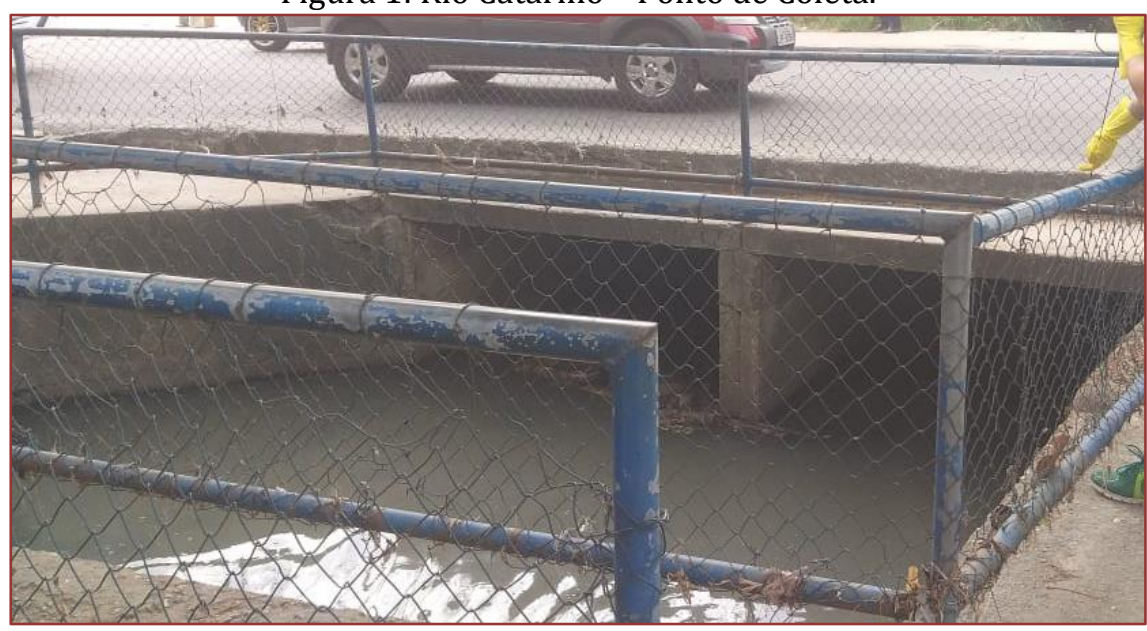

Fonte: Acervo Pessoal.

Figura 2: Rio Piraquara - Ponto de Coleta.

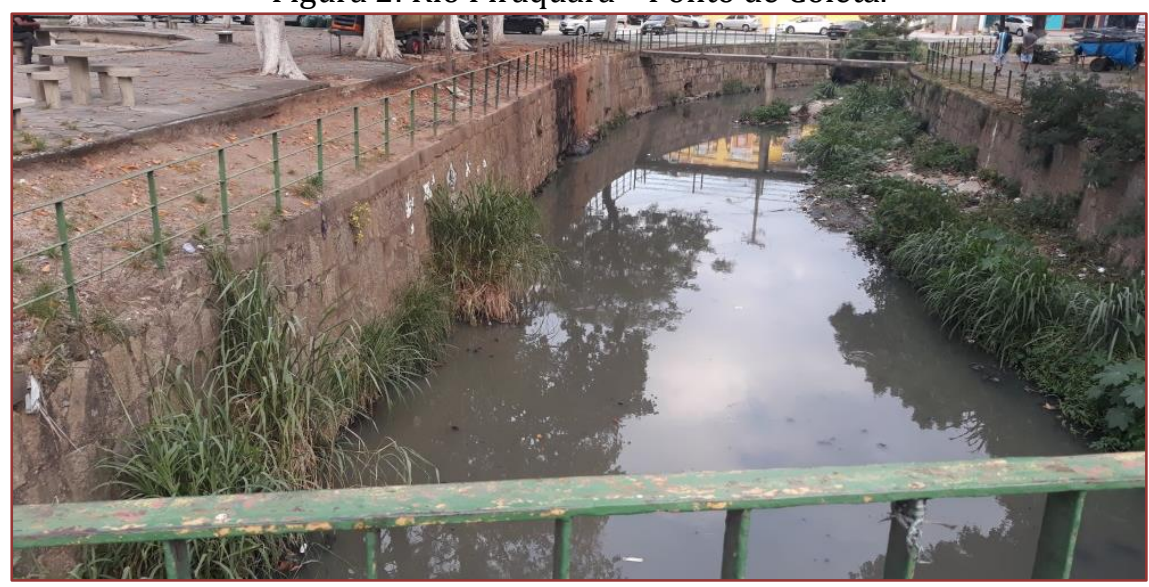

Fonte: Acervo Pessoal.

As coletas foram realizadas em dias distintos (Fig. 3) de acordo com o clima, uma vez que a turbidez do corpo hídrico está diretamente relacionada à escassez de chuva (JARDIM et al., 2014).

Figura 3: Datas das coletas de cada amostra.

\begin{tabular}{|c|c|}
\hline \multicolumn{1}{|c|}{ Rio Catarino } & Rio Piraquara \\
\hline CAT. A - 24/04/2019 & PIR. A - 29/04/2019 \\
\hline CAT. B - 28/05/2019 & PIR. B - 27/05/2019 \\
\hline CAT. C - 18/06/2019 & PIR. C - 18/06/2019 \\
\hline \multicolumn{2}{|c}{ Fonte: Presente Estudo. }
\end{tabular}

\section{$\checkmark \quad$ Preparos das Amostras}

Durante todo o ensaio foram utilizadas amostras com $500 \mathrm{~mL}$ de água coletada do corpo hídrico, aferida através de uma proveta, e separada em quatro amostras iguais mais um controle, depositadas em garrafas pet cortadas em $11 \mathrm{~cm}$ de altura e 10 de diâmetro.

As diferentes concentrações de pó de semente de M. Oleifera foram adicionadas às diferentes amostras de água e misturadas com Agitador Magnético (Fisatom - 762 à ) 7 RPM por 2 minutos para maior homogenia. 


\section{$\checkmark \quad$ Acondicionamento}

Estas amostras foram lacradas e acondicionadas em temperatura ambiente em um local arejado e fresco durante o prazo total de $48 \mathrm{~h}$.

\section{$\checkmark \quad$ Medição da Turbidez}

A eficiência do tratamento foi avaliada pela medida de turbidez em dois tempos amostrais: T1 (24h) e T2 (48h), na escala JTU (Unidade de Turvação de Jackson), através do método do Tubo de Turbidez (FACALDE, MANNICH e COLOMBO, 2017) que no qual é baseado no Índice de Qualidade da Água (IQA baseado na Resolução CONAMA № 357/2005).

Foram retirados $25 \mathrm{~mL}$ de cada amostra, inclusive o controle, e adicionada em uma cubeta de turbidez e colocada acima da área central marcada na escala de teste (Fig. 4). Através dos discos de Secchi, comparase visualmente o disco central com os outros discos presentes na escala.

Figura 4: Método do Turbo de Turbidez.

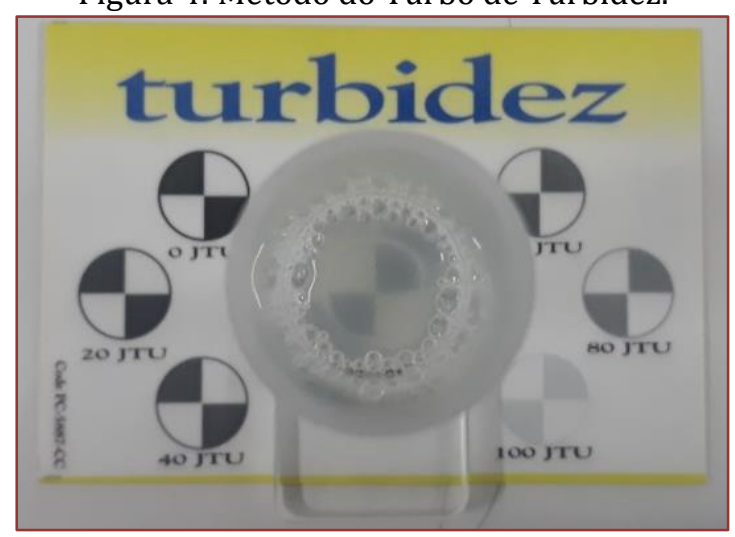

Fonte: Presente Estudo.

\section{RESULTADOS E DISCUSSÃO}

As sementes de M. oleifera Lam. apresentaram resultados satisfatórios para a redução de valores da turbidez nos dois corpos hídricos, no tempo amostral de 24h, nas três coletas realizadas (Fig. 5 e 6).

Figura 5: Tabela apontando a diferença de turbidez apresentada nas amostras após $24 \mathrm{~h}$ da ação das sementes no Rio Catarino.

\begin{tabular}{|cccc|}
\hline $\begin{array}{c}\text { Concentração } \\
\text { de Moringa }\end{array}$ & CAT. A & CAT. B & CAT. C \\
\hline Controle & 40 JTU & 70 JTU & 70 JTU \\
\hline $\mathbf{1 0 0} \mathbf{m g}$ & 40 JTU & 70 JTU & 70 JTU \\
$\mathbf{2 0 0} \mathbf{m g}$ & $30 \mathrm{JTU}$ & $60 \mathrm{JTU}$ & $65 \mathrm{JTU}$ \\
$\mathbf{3 0 0} \mathbf{m g}$ & $25 \mathrm{JTU}$ & $40 \mathrm{JTU}$ & $55 \mathrm{JTU}$ \\
$\mathbf{4 0 0 \mathbf { m g }}$ & $20 \mathrm{JTU}$ & $40 \mathrm{JTU}$ & $40 \mathrm{JTU}$ \\
\hline
\end{tabular}

Fonte: Presente Estudo. 
Figura 6: Tabela apontando a diferença de turbidez apresentada nas amostras após 24h da ação das sementes no Rio Piraquara.

\begin{tabular}{|cccc|}
\hline $\begin{array}{c}\text { Concentração } \\
\text { de Moringa }\end{array}$ & PIR. A & PIR. B & PIR. C \\
\hline Controle & $100 \mathrm{JTU}$ & $80 \mathrm{JTU}$ & $60 \mathrm{JTU}$ \\
\hline $\mathbf{1 0 0} \mathbf{~ m g}$ & $90 \mathrm{JTU}$ & $80 \mathrm{JTU}$ & $60 \mathrm{JTU}$ \\
$\mathbf{2 0 0} \mathbf{~ m g}$ & $\mathbf{7 0 ~ J T U}$ & $60 \mathrm{JTU}$ & $40 \mathrm{JTU}$ \\
$\mathbf{3 0 0} \mathbf{~ m g}$ & $\mathbf{7 0 ~ J T U}$ & $60 \mathrm{JTU}$ & $40 \mathrm{JTU}$ \\
$\mathbf{4 0 0} \mathbf{~ m g}$ & $60 \mathrm{JTU}$ & $40 \mathrm{JTU}$ & $10 \mathrm{JTU}$ \\
\hline
\end{tabular}

Fonte: Presente Estudo.

Em ambos os rios, as maiores concentrações de sementes utilizadas (400 mg) favoreceram a clarificação da água com remoção de cerca de $50 \%$ de turbidez. Sendo assim, cabe ressaltar que as sementes de moringa é um ótimo tratamento alternativo, como destaca Bergamasco et al. (2018) que observou esta eficiência na qualidade de água tratada.

Em contra partida, durante T2, a eficiência para clarificação se mostrou insatisfatória, uma vez que após 48h, a turbidez teve um acréscimo acima de 50\% do controle em T0 e T1. Este resultado corrobora com os estudos passados, uma vez que a Moringa perde sua capacidade de coagulação com o decorrer do tempo (NDABIGENGESERE et al., 1995; OKUDA et al., 1999; KATAYON et al., 2006; MADRONA, 2010).

Destaca-se que nesse estudo foi verificado apenas a capacidade de coagulação da semente para turbidez, o que não caracteriza utilizar este fitorremediador como filtrador para potabilidade da água, porém já foi confirmado também uso do coagulante natural moringa associado ao sistema de filtração em múltiplas etapas (FIME) (FRANCO, 2010).

É discutível, no entanto, a forma como estas sementes poderão ser retiradas das amostras, até mesmo para utilização futura desta água. Arantes et al (2010), retrata a utilização de diferentes materiais para conter o pó dessas sementes e informa que não houve implicação na diminuição da eficiência. Desta maneira, salienta-se que a utilização destes materiais poderá trazer um benefício, até mesmo para um reaproveitamento deste afluente, porém este deverá ser estudado futuramente.

\section{CONCLUSÃO}

Destaca-se a capacidade de coagulação da semente para a remoção de turbidez, o que não caracteriza o sistema para a potabilidade da água. Assim, ressalta-se que as sementes de M. oleifera Lam. apresentaram resultados idôneos para a clarificação.

Propõe-se aprimorar esta pesquisa com técnicas e resultados de outros diferentes afluentes com o intuito de levar à população, futuramente, a possibilidade do uso dessas sementes, uma vez que, a falta de tratamento de água ainda é um fator pertinente.

\section{REFERÊNCIAS}

[1] Albertto, A.; Filho, B. G. R. Influência do despejo de esgoto doméstico nas características limnológicas do rio Camandocaia, bacia hidrográfica do rio Piracicaba, Estado de São Paulo. Acta Scientiarum. Biological Sciences, v. 34, n. 2, p. 173-179. Maringa, Abr/Jun, 2012.

[2] Arantes, C.C.; Silva. G.K.; Paterniani, J.E.S. Desenvolvimento de Sache para Aplicação de Coagulante à Base de Sementes de Moringa oleífera no Tratamento de Água. In: Encontro Nacional de Moringa. Aracaju: UFS, 2010.

[3] Bergamasco, R.; et al. Aplicação da Moringa no Tratamento de Águas de Abastecimento e Residuárias. In: Silva, G. F.; et al. Potencialidade da Moringa oleifera Lam. UFS, c. 5. p. 93-144. São Cristóvão, 2018.

[4] Bezerra, A. M. E; Filho, S. M; Freitas, J. B. S; Teófilo, E.M. Avaliação da qualidade das sementes de Moringa oleifera lam. durante o armazenamento. Ciênc. Agrotec., v. 28, n. 6, p. 1240-1246. Lavras, Nov/Dez, 2004.

[5] Camacho, F. P.; Silva, M. O.; Moreti, L. O. R.; et al. uso do Coagulante Natural Moringa Oleifera Lam no Tratamento de Água Com Florações de Cianobactérias. Revista Tecnológica - Edição Especial 2014. p. 305-313. 
Maringá, 2015.

[6] Carlão, L. F. B. A Escassez de Água no Mundo Não é mais Uma Hipótese ou Teoria: é o Alerta para a Mudança do Modelo DE Desenvolvimento Humano. Leopoldianum - Revista de Estudos e Comunicações da Universidade Católica de Santos, V. 44, N. 123, p. 11-16, 2018.

[7] Coagulation Of Turbid Waters Using Moringa oleifera. Waterresearch 29 (2) 703-612., 1995.

[8] Costa, G. H.G.; Freita, C. M.; Mendes, F. Q.; Mutton, M. J. R. Extrato de Sementes de Moringa como Floculante de Caldo de Cana-de-Açúcar. Pesq. agropec. bras. v.51, n.10, p.1794-1798. Brasília, Out/2016.

[9] Falcade, D. R; Mannich, M; Colombo, G. T. Tubo de turbidez para determinação de baixo custo da turbidez em corpos d'água superficiais. Rega, v. 14, ed. 5. Porto Alegre, 2017.

[10] Franco, M. Uso de coagulante extraído de sementes de Moringa oleífera como auxiliar no tratamento de água por filtração em múltiplas etapas. Dissertação de Mestrado, Faculdade de Engenharia Agrícola, Unicamp, Campinas, SP. 2010 .

[11] Jamarim, V. M.; Kopko, L. B.; Bergamasco, R.; Vieira, M. F. Remoção do Corante Azul de Metileno Utilizando A Casca da Semente DA Moringa oleífera Lam Como Adsorvente. 12ํㅡㄹ Encontro Brasileiro sobre Adsorção. Gramado, 2018.

[12] Jardim, F. A; Sperling, E. V; Jardim, B. F. M; Almeida, K. C. B. Fatores Determinantes das florações de cianobactérias na água do Rio Doce, Minas Gerais, Brasil. Eng Saint Ambient, V.19, n. 3, p. 207-218. Jul/Set, 2014.

[13] Katayon, S.; Noor, M.J.M.M.; Asma, M.; Ghani, L.A.A.; Thamer, A.M.; Azni, I.; Ahmad, J.; Khor, B.C.; Suleyman, A.M. Effects of storage conditions of Moringa oleifera seeds on its performance in coagulation. Bioresource Technology, v. 97, n. 13, p. 1455-1460, 2006.

[14] Lamparelli, M. C. Grau de trofia em corpos d'água do Estado de São Paulo: avaliação dos métodos de monitoramento. Tese (Doutorado em Ciências), Universidade de São Paulo, São Paulo, 2004.

[15] Lopes, A. E; Duarte, N. F. R. O Tratamento de Efluentes Líquidos Através de Sistemas Utilizando Agentes de Fitorremediação: Uma Revisão Sistemática. Gest. Sust. Ambient, v. 6, n. 1, p. 432 - 441. Florianópolis, Abr/Set, 2017.

[16] Madrona, G.S. Extração/purificação do composto ativo da semente da Moringa oleifera Lam e sua utilização no tratamento de água para consumo humano. Tese de Doutorado em Engenharia Química, Universidade Estadual de Maringá. Maringá, 2010

[17] Ndabigengesere A., K. S. Narasiah, B. G. Talbot, Active Agents And Mechanism Of

[18] Okuda, T.; Baes, A.U.; Nishijima, W.; Okada, M. Improvement of extraction method of coagulation active components from Moringa oleiferaseed. Water Research, v.33, n.15, p.3373-3378, 1999.

[19] Saveh. A Disponibilidade de Água no Mundo e no Brasil.2016. Disponível em: https://saveh.com.br/artigos/a-disponibilidade-de-agua-no-mundo-e-no-brasil/. Acesso em: 16 maio 2019.

[20] Silva, G. F. et al. Potencialidade da Moringa oleifera Lam: 1 ed. São Cristóvão: Editora Ufs, 2018.

[21] Snirh (Sistema Nacional de Informações sobre Recursos Hídricos). Usos da Água. 2019. Disponível em: http://www.snirh.gov.br/snirh/snirh-1/acesso-tematico/usos-da-agua. Acesso em: 16/05/2019.

[22] Snis (Sistema Nacional de Informações sobre Saneamento). Diagnóstico dos Serviços de Água e Esgotos 2017. Disponível em: http://www.snis.gov.br/diagnostico-agua-e-esgotos/diagnostico-ae-2017. Acesso em: 16/05/2019.

[23] Vorosmarty, C. J; Et al. Global Threats to Human Water Security and river biodiversity. Nature, vol. 467, n. 7315, pg. 555-561, 2010. 


\section{Capítulo 6}

\section{Estudo da capacidade de adsorção de íons $\mathrm{Mn}^{2+}$ em cabelo}

\section{Tania Regina Giraldi \\ Breno Cantadori \\ Juan Douglas Carvalho Guidio \\ Luis Henrique Nery}

Resumo: 0 manganês, metal de transição muito presente na indústria metalúrgica, comumente aparece em efluentes, fazendo-se então necessária a investigação de métodos para a descontaminação desses efluentes. A adsorção é um método por vezes eficiente e estabelecido quando se trata de purificação de efluentes e águas. Logo, buscase variações nesse processo de forma a otimizar seu custo e eficiência. Neste trabalho, estudou-se o uso do cabelo como adsorvente de Mn2+, por se tratar de um sólido poroso ainda pouco explorado e alternativo aos adsorventes já estabelecidos. Através de diversos ensaios de adsorção foram determinados parâmetros que otimizaram a adsorção de íons de manganês na superfície do cabelo, sendo esses pH e tempo de contato. Por meio de análises de absorção atômica verificou-se a concentração de Mn2+ adsorvida, podendo-se assim, avaliar a eficiência do cabelo em condições ideais levantadas. 0 estudo completo foi realizado em pH 6,5, tempo de 30 minutos e 0,4 mg de cabelo em $30 \mathrm{~mL}$ da mistura. A maior porcentagem de adsorção de Mn2+ foi de 80\%. No estudo da isoterma de adsorção, concluiu-se que o modelo de Langmuir para adsorção adequou de forma satisfatória ao conjunto de dados obtido, indicando assim um processo de adsorção que ocorre em monocamadas. 


\section{INTRODUÇÃO}

No âmbito das mudanças na vida contemporânea a mineração e o beneficiamento se tornam cada vez mais frequentes. Muitas vezes, essas operações, produzem efluentes com altas concentrações do íon $\mathrm{Mn}^{2+}$, que se ingerido em altas concentrações pode ter efeitos adversos à saúde (ATSDR, 2012). Dessa forma, é importante que se investigue métodos capazes de retirar de fontes de água e efluentes o $\mathrm{Mn}^{2+}$ de forma satisfatória e sustentável.

Nesse sentido, este trabalho investiga o uso de cabelo humano como adsorvente do íon $\mathrm{Mn}^{2+}$ em escalas laboratoriais. 0 interesse pelo cabelo surge de sua porosidade, resultante da estrutura escamada e da ausência de estudos utilizando cabelo, um rejeito não explorado, como adsorvente.

Logo, buscou-se avaliar a capacidade adsortiva do cabelo e otimizar as condições operacionais do processo, como pH, tempo de contato e concentração de adsorvato.

\section{METODOLOGIA}

Os cabelos utilizados como adsorventes foram do tipo ocidental, e coletados em salões de Poços de CaldasMG. Para os experimentos, foram lavados e cortados, afim de aumentar a superfície de contato.

Para os estudos, utilizou-se solução de $\mathrm{Mn}^{2+} 10$ ppm, preparada a partir do acetato de manganês II P.A. tetrahidratado (Vetec). Os ensaios de adsorção foram conduzidos na sequência: variação de $\mathrm{pH}$, variação do tempo e variação da concentração de $\mathrm{Mn}^{2+}$.

No estudo de pH, utilizou-se $30 \mathrm{~mL}$ de solução de $\mathrm{Mn}^{2+}, 0,04 \mathrm{~g}$ de cabelo e tempo de agitação de 30 minutos. A agitação foi realizada em placa de agitação, sendo a mistura mantida em béquer de $100 \mathrm{~mL}$.Variou-se $o$ $\mathrm{pH}$ em 3, 4, 5, 6 e 7, o qual foi ajustado com soluções de $\mathrm{HCl}$ e $\mathrm{NaOH}$.

Com o pH que proporcionou melhor adsorção, foi feito o estudo de tempo de contato. Os tempos estudados foram: 1, 2, 5, 10, 20 e 30 minutos. As demais condições experimentais foram mantidas. Por fim, com as melhores condições selecionadas a partir dos experimentos realizados, foi feito o estudo da isoterma de adsorção. Para este estudo, variou-se concentração da solução de $\mathrm{Mn}^{2+}$ com os valores: 2, 5, 10, 20, 30 e 50 ppm.

A porcentagem de adsorção foi determinada por análise de absorção atômica conduzida nas instalações da LAPOC/CNEN em Poços de Caldas utilizando equipamento ICP-OES Varian Liberty RL e os dados tratados em softwares como Excel e Origin.

\section{RESULTADOS E DISCUSSÃO}

Dos resultados encontrados destacam-se os estudos do comportamento em diferentes pHs, do efeito do tempo de contato e do comportamento da isoterma de adsorção.

\subsection{COMPORTAMENTO PH}

No estudo da variação de adsorção em função do pH os resultados obtidos podem ser observados na Figura 1.

Figura 1 - Resultados de ensaio para diferentes pHs. Fonte: Autoria própria.

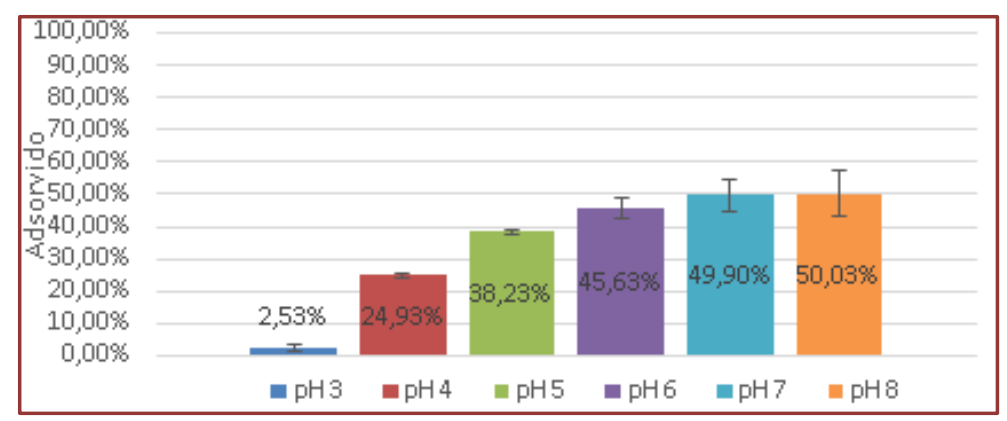


Observa-se um aumento da eficiência diretamente proporcional ao aumento do pH. A primeira hipótese é de que o pH mais ácido fecha as cutículas do cabelo e diminui a superfície de contato, abaixando a eficiência (VELASCO et al., 2009).

A segunda hipótese é de que elevados valores de $\mathrm{pH}$ tornam a superfície do cabelo carregada negativamente, atraindo o íon $\mathrm{Mn}^{2+}$ e favorecendo a adsorção.

No presente estudo, apesar do pH 8 ter promovido maior porcentagem de adsorção, optou-se em utilizar nos próximos ensaios o pH entre 6,5 e 8. Isto porque a eficiência de adsorção em pH 8 foi somente 4,4\% maior do que a eficiência de adsorção em pH 6 e por ser o pH inicial da solução.

\section{TEMPO DE CONTATO}

O ensaio para estabelecer relação entre o tempo de contato e a adsorção foi executado em 6 intervalos de tempo e os resultados são apresentados na Figura 2.

Figura 2 - Isoterma de adsorção de íons $\mathrm{Mn}^{2+}$. Fonte: Autoria Própria.

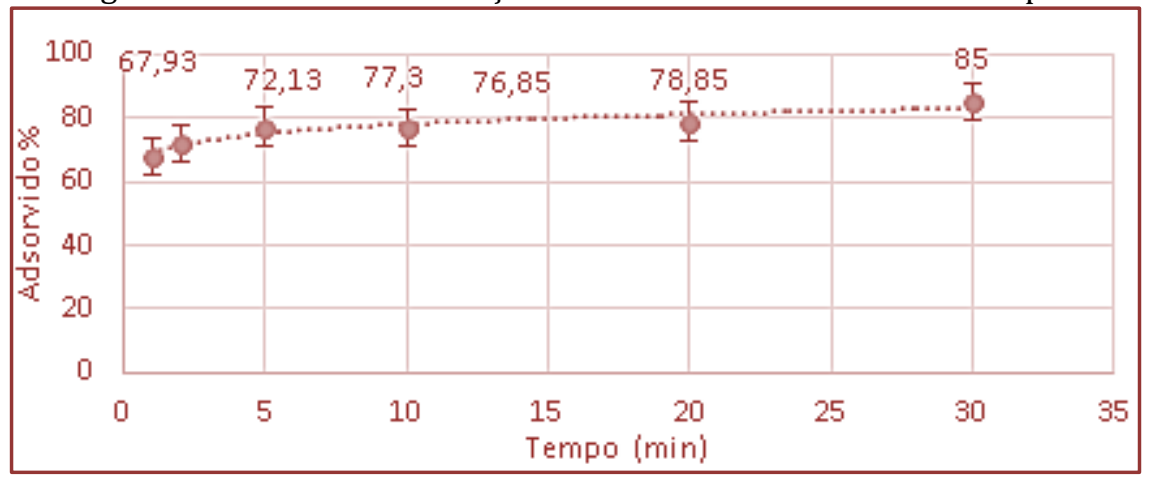

Para melhor entender a isoterma, linearizar-se-á a partir do modelo de Langmuir [REF]. Permitindo calcular constantes que regem o comportamento como a capacidade máxima de adsorção (Qmax) dado em $\mathrm{mg} / \mathrm{g}$, interação adsorvato/adsorvente $\left(\mathrm{K}_{\mathrm{L}}\right)$ em L/mg e o fator de separação $\left(\mathrm{R}_{\mathrm{L}}\right)$ que é adimensional.

Figura 3 - Linearização da isoterma de adsorção de íons $\mathrm{Mn}^{2+}$. Condições experimentais: 13,3 g/L de concentração de adsorvente, $30 \mathrm{~mL}$ de solução de $\mathrm{Mn}^{2+}$ de 10 ppm, 30 min de tempo

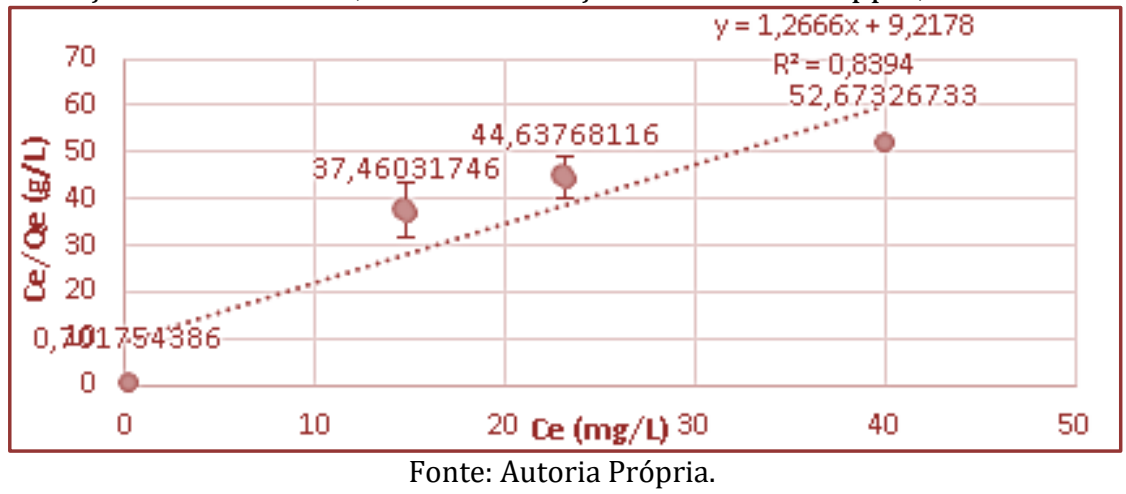

Tabela 1 - Constantes da isoterma da Figura 5 utilizando o modelo de Langmuir para adsorção do íon $\mathrm{Mn}^{2+}$.

\begin{tabular}{|c|c|c|c|}
\hline$K_{L}(L / m g)$ & $Q_{\max }(m g / g)$ & $R^{2}$ & $R_{L}$ \\
\hline 0,137 & 0,789 & 0,839 & 0,902 \\
\hline
\end{tabular}

Fonte: Autoria Própria. 
Na Tabela 1, a constante indica se a adsorção é favorável, desfavorável, linear ou irreversível. Como $\mathrm{R}_{\mathrm{L}}$ está entre 0 e 1, diz-se que o processo é favorável. Também é possível observar que $\mathrm{R}^{2}$ é um valor próximo de 1 , o que permite dizer que os dados experimentais se ajustaram ao modelo linear de Langmuir. Tem-se então um processo de adsorção química com a formação de uma monocamada.

\section{CONCLUSÕES OU CONSIDERAÇÕES FINAIS}

Com este estudo foi possível concluir que o cabelo apresenta eficácia na adsorção do íon $\mathrm{Mn}^{2+} \mathrm{em}$ condições ótimas de pH entre 6,5 e 8 e tempo de contato de 30 minutos.

Por fim, no ensaio da isoterma determinou-se a capacidade máxima de adsorção (Qmax) em mg/g, a interação adsorvato/adsorvente $\left(\mathrm{K}_{\mathrm{L}}\right)$ em $\mathrm{L} / \mathrm{mg}$ e o fator de separação $\left(\mathrm{R}_{\mathrm{L}}\right)$ que é adimensional. A capacidade máxima de adsorção foi de $0,789 \mathrm{mg}$ do íon $\mathrm{Mn}^{2+}$ por grama de cabelo, e o modelo de isoterma que se adequou aos resultados experimentais foi o modelo de Langmuir indicando então adsorção em monocamadas

\section{REFERÊNCIAS}

[1] ATSDR (Org.). Toxicological profile for manganese. [s. L.]: ATSDR, 2012.

[2] Departamento Nacional de Produção Mineral - DNPM. Anuário Mineral Brasileiro: Principais Substâncias Metálicas. Brasília: DNPM, 2018.

[3] Gonçalves, Patrícia. Síntese de materiais à base de $\mathrm{TiO}_{2}, \mathrm{ZnO}$ e $\mathrm{SiO}_{2}$ : tratamento de áreas degradadas e efluentes. 2017. 100 f. Dissertação (Mestrado) - Curso de Engenharia Química, Universidade Federal de Alfenas, Poços de Caldas, 2017.

[4] Velasco, Maria Valéria Robles et al. Hair fiber characteristics and methods to evaluate hair physical and mechanical properties. Revista Brasileira de Ciências Farmacêuticas, [s. L.], v. 45, n. 1, p.153-162, jan. 2009. 


\section{Capítulo 7}

Estudo da viabilidade de utilização de técnicas alternativas para a produção de peças porosas de ZnO para fotocatálise

\section{Paula Guimarães Neves}

Rodrigo Amorim Munhoz.

Sergio Andres Villalba Morales

Sylma Carvalho Maestrelli

Resumo: Corantes são substâncias muito utilizadas processos industriais e se configuram como uma classe de resíduos perigosos ao meio ambiente se descartados de maneira inadequada, sobretudo em recursos hídricos. Os Processos Oxidativos Avançados (POAs) baseiam-se na fotocatálise heterogênea, a qual consiste na ativação, pela radiação, de um semicondutor para que ocorram transições eletrônicas entre a banda de valência e condução, gerando sítios oxidantes e redutores capazes de desencadear reações de mineralização de compostos poluentes, como os corantes. Pesquisas utilizando peças sólidas para fins fotocatalíticos são ainda pouco encontradas, sendo importante que essa peça possua elevada porosidade, para que a luz nela penetre, promovendo a fotocatálise e que apresente resistência mecânica suficiente para ser utilizada sem ruptura prematura. Esta pesquisa envolveu a obtenção de cerâmicas porosas de $\mathrm{ZnO}$ com boa resistência mecânica através da técnica consolidação por conformação por amido, pouco estudada para tal fim. Foram investigadas formulações contendo $\mathrm{ZnO}$ com adições de 10, 20, 30, 40 e 50\% em massa de amido comercial, além de água. As amostras foram caracterizadas através de medidas de propriedades físicas (densidade a verde, massa específica e porosidade aparente) e fotocatalíticas. A viabilidade da técnica para a obtenção das peças porosas foi comprovada com os melhores resultados obtidos para adições de 30\% de amido, observando-se uma degradação de $73,8 \%$ do corante Rodamina B e porosidade maior que $52 \%$.

Palavras chave: ZnO; Fotocatálise; Consolidação por conformação por amido; Porosidade aparente. 


\section{INTRODUÇÃO}

Produtos gerados pelos processos de produção de bens e serviços contribuíram e ainda contribuem para a degradação do meio ambiente; exemplo disso é o caso das indústrias têxteis, que descartam cerca de vinte por cento de todo corante utilizado em tecidos (DEZOTTI, 2008; LOPES et al, 2013). Essas substâncias se configuram como uma classe de resíduos bastante nocivos ao meio ambiente se descartados inadequadamente, apresentando uma grande toxidade, mesmo encontrada a baixas concentrações (BRITES; MACHADO; SANTANA, 2011).

Os processos oxidativos avançados (POA's) são um dos mais estudados atualmente para o tratamento de corantes. Neste, destaca-se a fotocatálise heterogênea, a qual se baseia na oxidação química dos poluentes utilizando um semicondutor ativado por irradiação luminosa (AKPAN, HAMEED, 2009; MELO et al., 2014). A pesquisa acerca da utilização da fotocatálise heterogênea aplicada ao tratamento de efluentes têxteis, se mostra promissora, uma vez que esse método promove a destruição da molécula do corante eliminando-o do meio (RIBEIRO; TAVARES, 2018).

Os semicondutores baseados em pós nanométricos de óxido de zinco ( $\mathrm{ZnO}$ ) são empregados nos processos fotocatalíticos para ajudar na degradação de compostos orgânicos; porém, a utilização desses pós é de baixa praticidade e, se não fixados de maneira correta, podem ser arrastados durante o processo. Assim, a produção de peças porosas cerâmicas de $\mathrm{ZnO}$ vem sendo estudada com o intuito de se ter um semicondutor aplicável no cotidiano para a despoluição de águas (MARÇAL 2014).

Esta pesquisa objetivou investigar e otimizar as condições de produção de peças cerâmicas porosas baseadas em Óxido de Zinco, obtidas através das técnicas de colagem por amido, com subsequente avaliação de suas propriedades físicas e fotocatalíticas e do potencial de produção dessas peças em larga escala, para uso comercial.

\section{METODOLOGIA}

Peças porosas de ZnO (Synth, 99,5\% pureza), na forma de partículas micrométricas foram obtidas a partir da técnica de conformação por amido. Foram investigadas diferentes relações mássicas de ZnO e amido e água. Após homogeneização da mistura (amido, $\mathrm{ZnO}$ e defloculante) em água, a mesma foi levada lacrada à estufa até $75^{\circ} \mathrm{C}$ por 60 minutos. Após esse tempo deixou-se esfriar as amostras dentro da estufa até a temperatura ambiente e então retirou-se o lacre das amostras. Assim, foi realizado um novo aquecimento aumentando a mesma de $15^{\circ} \mathrm{C}$ em $15^{\circ} \mathrm{C}$ até atingida a temperatura final de $120^{\circ} \mathrm{C}$. Após os 60 minutos, a estufa foi desligada e as amostras foram resfriadas dentro dela. Por esse método foram produzidas 5 peças e suas proporções estão indicadas na tabela 1.

Tabela 1: Composições das peças fabricadas de $20 \mathrm{~mL}$.

\begin{tabular}{|c|cc|cc|rrl|}
\multirow{2}{*}{ Amostras } & \multicolumn{2}{c}{ Volume (ml) } & \multicolumn{2}{c|}{ Teor (\%) } & \multicolumn{3}{c|}{ Massa (g) } \\
& Sólido & Líquido & Amido & Zno & Amido & ZnO & Agua \\
\hline 1 & 6,0 & 14,0 & 10 & 50 & 0,914 & 30,294 & 14,0 \\
\hline 2 & 6,0 & 14,0 & 20 & 40 & 1,829 & 26,928 & 14,0 \\
\hline 3 & 6,0 & 14,0 & 30 & 30 & 2,743 & 23,562 & 14,0 \\
\hline 4 & 6,0 & 14,0 & 40 & 20 & 3,658 & 20,196 & 14,0 \\
\hline 5 & 6,0 & 14,0 & 50 & 10 & 4,572 & 16,830 & 14,0 \\
\hline \multicolumn{8}{c}{ Fonte: Próprio autor. }
\end{tabular}

A etapa seguinte consistiu na queima das peças, com uma taxa de aquecimento de $1^{\circ} \mathrm{C} / \mathrm{min}$; o patamar de queima de 120 minutos e a temperatura de queima a $800^{\circ} \mathrm{C}$.

Após a obtenção das peças sinterizadas, as mesmas foram caracterizadas através de medidas de propriedades físicas (massa específica e porosidade aparente, utilizando-se o princípio de Archimedes) e fotocatalíticas. Para as propriedades fotocatalíticas, foi aplicado método de absorção no UV-Vis. Espectro de absorção do corante no UV-A e visível foi realizado com base na solução aquosa do corante (Rodamina B) a $5 \mathrm{mg} . \mathrm{L}-1$ em água deionizada $(3 \mu \mathrm{S} . \mathrm{cm}-1)$. A varredura foi efetuada entre 400 e $800 \mathrm{~nm}$ a fim de se obter o comprimento de onda de máxima absorção. 
A análise foi executada no espectrofotômetro HACH DR3900, presente no Laboratório de Biotecnologia da Universidade Federal de Alfenas, campus Poços de Caldas/MG. Os béqueres foram colocados em um reator e expostos a radiação de luz UV para a análise de degradação no espectrofotômetro, analisando a absorbância de cada peça.

\section{RESULTADOS E DISCUSSÃO}

Após a conformação das peças a verde, foram tiradas suas medidas e aferidas suas massas para o cálculo da densidade a verde (tabela 2 ).

Tabela 2: Densidade a verde das amostras de $20 \mathrm{ml}$

\begin{tabular}{|ccc|}
\hline Amostras & \% amido & $\begin{array}{c}\text { Densidade a verde } \\
\left(\mathrm{g} / \mathrm{cm}^{-3}\right)\end{array}$ \\
\hline 1 & 10 & $4,424 \pm 1,3 \times 10^{-2}$ \\
2 & 20 & $3,652 \pm 8,7 \times 10^{-3}$ \\
3 & 30 & $3,109 \pm 6,3 \times 10^{-3}$ \\
4 & 40 & $2,707 \pm 4,8 \times 10^{-3}$ \\
\hline 5 & 50 & $2,397 \pm 3,7 \times 10^{-3}$ \\
\hline
\end{tabular}

Fonte: Próprio autor

Após a queima nas condições previamente especificadas, foram determinadas as massas específicas aparente (MEA) e porosidade aparente (PA) dessas peças, como indicados na figura 1.

Figura 1: (A) MEA para as peças queimadas. (B) Porosidade aparente das peças
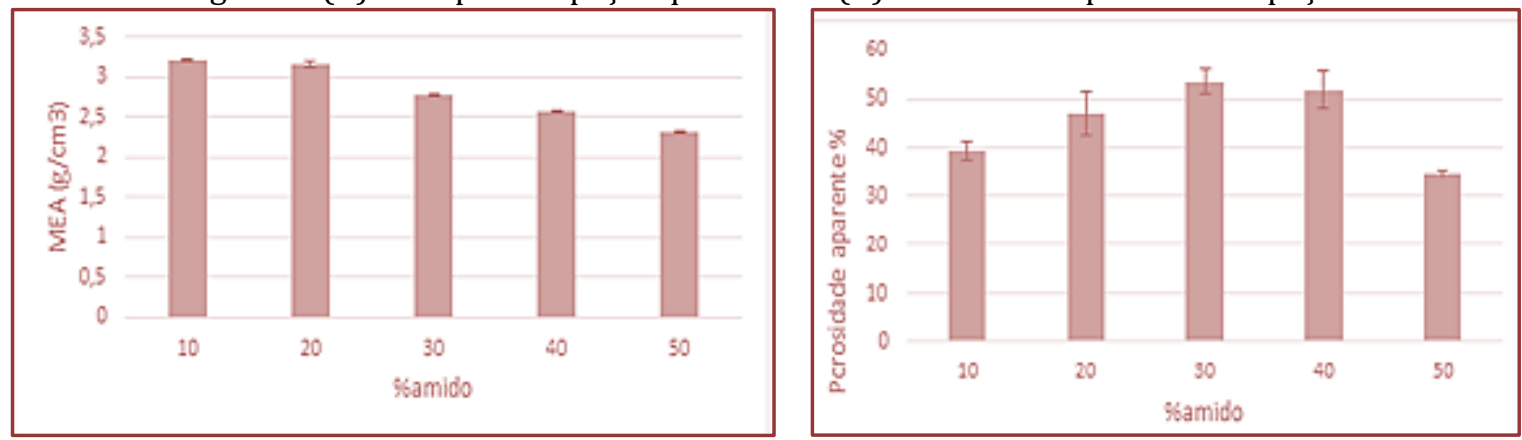

Fonte: Próprio autor.

Pela tabela 2, nota-se que os maiores valores de densidade se encontram em peças que apresentaram maiores teores de ZnO. Este apresenta maior relação de massa por volume em relação ao amido, visto que para realizar o cálculo da densidade a verde, a fórmula considera o teor presente de cada material na peça, além de sua densidade, em que do ZnO é maior que do amido. Assim, a amostra com $90 \%$ de $\mathrm{ZnO}$ apresentou maior densidade a verde que as demais e, de acordo com a figura 1, essa amostra apresentou maior massa específica aparente (MEA).

Teoricamente, era de se observar que quanto maior a quantidade de amido na amostra, maior formação de poros. Entretanto isso não ocorreu visto que as peças que contem 30\% de amido apresentaram maiores porosidades que as demais. Isso pode ser dado pelo tipo de poro que se forma nas amostras, ou seja, se esses poros são abertos ou fechados ou interconectados. Esses fatores contribuem para uma diminuição da porosidade. 
Ao analisar a absorção de água das peças,a partir da tabela 2, prova-se que as peças que contem 30\% de amido apresentaram ótimas condições de processamento. São peças que apresentam uma maior porosidade aparente e, consequentemente, ótima absorção de água. As peças que apresentaram menores resultados podem ter como justificativa a presença de poros que não se interconectam, e isso dificulta a entrada de água nessas peças.

Os resultados referentes à fotocatálise e degradação da Rodamina B para as diferentes amostras investigadas são indicados na figura 2. A amostra três apresentou uma maior degradação da Rodamina B em relação às outras composições (cerca de 74\% de degradação). Portanto, tem-se que a composição 3 apresentou a melhor relação encontrada entre porosidade e resistência mecânica trazendo os melhores resultados em termos de fotocatálise.

Figura 2: Ensaio Fotocatalítico em função da composição das amostras.

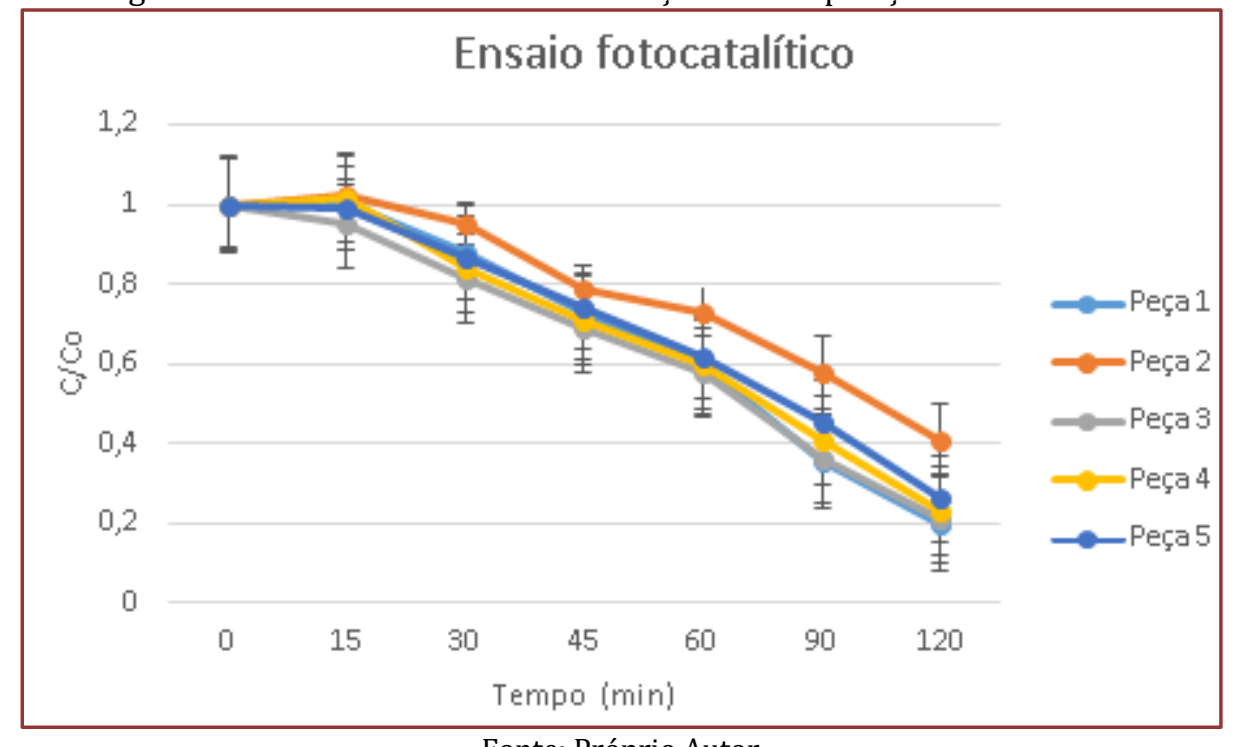

Fonte: Próprio Autor.

\section{CONCLUSÕES}

A técnica colagem por amido mostrou-se viável e possibilitou a obtenção de peças cerâmicas porosas de óxido de Zinco com boa relação entre as propriedades mecânicas e porosidade. Dentre as composições investigadas, a composição de partida contendo $70 \%$ de $\mathrm{ZnO}$ e $30 \%$ de amido obteve os melhores resultados fotocatalíticos, degradando $73,8 \%$ da Rodamina B, apresentando porosidade superior a $52 \%$.

\section{REFERÊNCIAS}

[1] Akpan, U. G.; Hameed, B. H. Parameters affecting the photocatalytic degradation of dyes using Ti02 - based photocatalysts: A review. Journal of Hazardous Materials, Nibong Tebal, Penang, Malaysia, p. 520-529, May 2009.

[2] Brites, F. F; Machado, N. R. C; Santana, V. S. Effect on the photocatalytic degradation of textile effluents using Nb205 and ZnO: Photocatalytic degradation of textile dyes. Brazil: Springer Science Business Media, n.544, p. 264-269, Jan. 2011.

[3] Dezotti, M. Processos e técnicas para o controle ambiental de efluentes líquidos. Rio de Janeiro-Brasil: ed. Epapers Serviços Editoriais Ltda, 2008.

[4] Lopes, O. F.; Mendonça, V. R.; Ribeiro, C.; Umar, A. Alto desempenho fotocatalítico do Sn(OH)6 na degradação da Rodamina B. In: VII Workshop de Tecnologia, 7, 2013, São Carlos-SP. Anais... São Carlos: Embrapa Instrumentação, 2013. p.389-391.

[5] Marçal, R. L. S. B. Combinação de "Freeze Casting" e colagem por barbotina para produção de alumina densa/porosa. Tese de Doutorado. Instituto Militar de Engenharia. Rio de Janeiro, 2014.

[6] Ribeiro, V. A. S.; Tavares, C; R; G. Analysis of reuse of jeans laundry effluent treated by heterogeneous photocatalysis. Brazilian Journal of Animal and Environmental Research, Curitiba, v. 1, n. 2, p. 395-404, out./dez. 2018. 


\section{Capítulo 8}

Estudo do teor de Enxofre presente na gasolina comercializada no Território Brasileiro

\section{Rosana Petinatti da Cruz \\ Isabella Oliveira da Silva \\ Tiago Nascimento da Silva Faria \\ Karine Resende Corrêa Florentino \\ Domenique Ramalho Corrêa}

Resumo: 0 presente trabalho foi realizado como projeto de conclusão do curso técnico de meio ambiente para o Colégio Técnico da UFRRJ. 0 estudo envolveu pesquisas sobre poluição atmosférica e consequências da emissão de dióxido de enxofre na atmosfera pela queima de combustíveis fósseis. Seu escopo foi definido pela realização da análise de resultados para teor de enxofre presente na gasolina automotiva comercializada no território brasileiro. Sendo estes resultados disponibilizados mensalmente por meio do Programa de Monitoramento da Qualidade de Combustíveis (PMQC) da ANP (Agência Nacional de Petróleo, Gás Natural e Biocombustíveis). Ao término da análise dos dados, concluiu-se que o cumprimento, pelos postos revendedores, da especificação estabelecida pela legislação vigente é regular tendo em vista que 99,5\% das amostras analisadas encontram-se dentro do limite especificado.

Palavras-chave: poluição atmosférica; gasolina; chuva ácida; dióxido de enxofre; PMQC. 


\section{INTRODUÇÃO}

A poluição atmosférica é um problema ambiental e social em diversos países, sejam eles desenvolvidos ou não, e é ditado pela distribuição das emissões industriais e veiculares (DRUMM et. al., 2014).

A gasolina é um combustível enquadrado na categoria dos fósseis. Estes tipos de combustíveis possuem, em geral, o petróleo como matéria prima em comum, ou seja, é uma classe de combustíveis não renováveis. A gasolina é formada por uma mistura complexa de hidrocarbonetos advinda do refino por processos como craqueamento, destilação e outros (CARVALHO; DANTAS FILHO, 2013).

Após a queima destes combustíveis, há não apenas a emissão de dióxido de carbono, como também são gerados óxidos de enxofre $\left(\mathrm{SO}_{\mathrm{x}}\right)$. 0 primeiro é conhecido como o principal gás estufa devido a suas altas taxas de emissão. Seu crescimento tem se tornado alarmante e é um dos principais tópicos de políticas e movimentos ambientais atualmente (MMA, 2007). Já o óxido de enxofre resulta da oxidação de compostos de enxofre presentes nos combustíveis fósseis (DRUMM et. al., 2014) e se combina facilmente a água presente na atmosfera gerando ácidos como o ácido sulfúrico, o qual exerce influência na acidificação da atmosfera. $0 \mathrm{pH}$ das chuvas é levemente baixo, em torno de 5,6, devido a interação das gotículas da atmosfera com gases ácidos normalmente presentes na atmosfera como o dióxido de carbono, neste caso forma-se o ácido carbônico $\left(\mathrm{H}_{2} \mathrm{CO}_{3}\right)$ (ABREU, 2005). A chuva ácida, além de causar corrosão de construções urbanas, é capaz de tornar estéril o ambiente exposto a ela. Áreas de cobertura vegetal apresentam-se inférteis devido a alteração de seu pH, ocasionando diminuição na absorção pelas plantas de seus nutrientes além da morte de alguns seres vivos pouco tolerantes a ambientes ácidos. E em ambientes aquáticos, há um desencadeamento da mortandade de seus seres vivos sensíveis a diminuição do pH (ABREU, 2005).

Levando em conta essa problemática, a Agência Nacional do Petróleo, Gás Natural e Biocombustíveis (ANP) impôs limites no parâmetro teor de enxofre presente em combustíveis movimentados no território brasileiro. Para a gasolina automotiva, por exemplo, existe atualmente o limite de $50 \mathrm{mg} / \mathrm{kg}$ para esta especificação. Dado este declarado pela Resolução da ANP de n 40/2013 que trata das especificações dos parâmetros da qualidade para a gasolina automotiva.

O Programa de Monitoramento da Qualidade de Combustíveis (PMQC) instituído pela ANP divulga mensalmente dados da qualidade obtidos de combustíveis coletados em diversos postos de revendedores, mais conhecidos como postos de gasolina (ANP,2016).

0 presente trabalho objetiva-se na realização da análise do monitoramento dos dados de teor de enxofre disponibilizados desde o ano de 2016 pelo PMQC como trabalho de conclusão para o curso técnico de meio ambiente do Colégio Técnico da UFRRJ.

\section{METODOLOGIA}

Inicialmente, foi realizada uma pesquisa bibliográfica pelos alunos sobre temas como poluição atmosférica, emissões de gases poluentes, consequências da chuva ácida, queima de combustíveis fósseis, entre outros. A definição da gasolina como combustível de foco foi estipulada em segundo lugar. E os processos de aquisição das planilhas através dos dados abertos da ANP puderam ser iniciados. Diversas ferramentas do excel foram utilizadas para que todos os resultados dos ensaios de teor de enxofre fossem reunidos em uma só planilha com a finalidade de os dados serem analisados pelos alunos do curso técnico.

\section{RESULTADOS E DISCUSSÃO}

Os dados obtidos foram de janeiro de 2016 a junho de 2019. A distribuição da quantidade de amostras analisadas em cada ano foi disposta em um gráfico de rosca. 0 ano de 2018 obteve, até o momento, o maior número de amostras analisadas, como pode ser observado abaixo. 


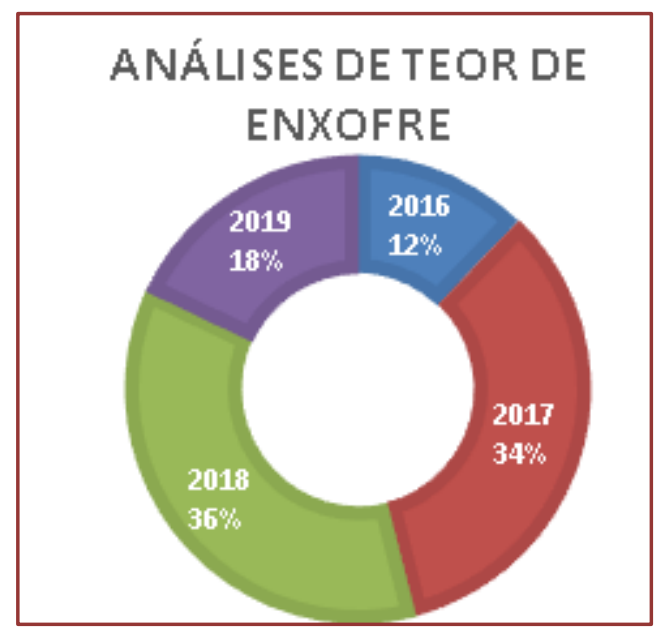

Em média, os resultados pertencem a uma faixa entre 30 e $35 \mathrm{mg} / \mathrm{kg}$ ao longo dos anos, de acordo com as barras azuis do gráfico de barras abaixo. Além disso, as barras de cor laranja demostram o desvio padrão de cada ano, sendo o ano de 2018 o menos homogêneo dentre os estudados.

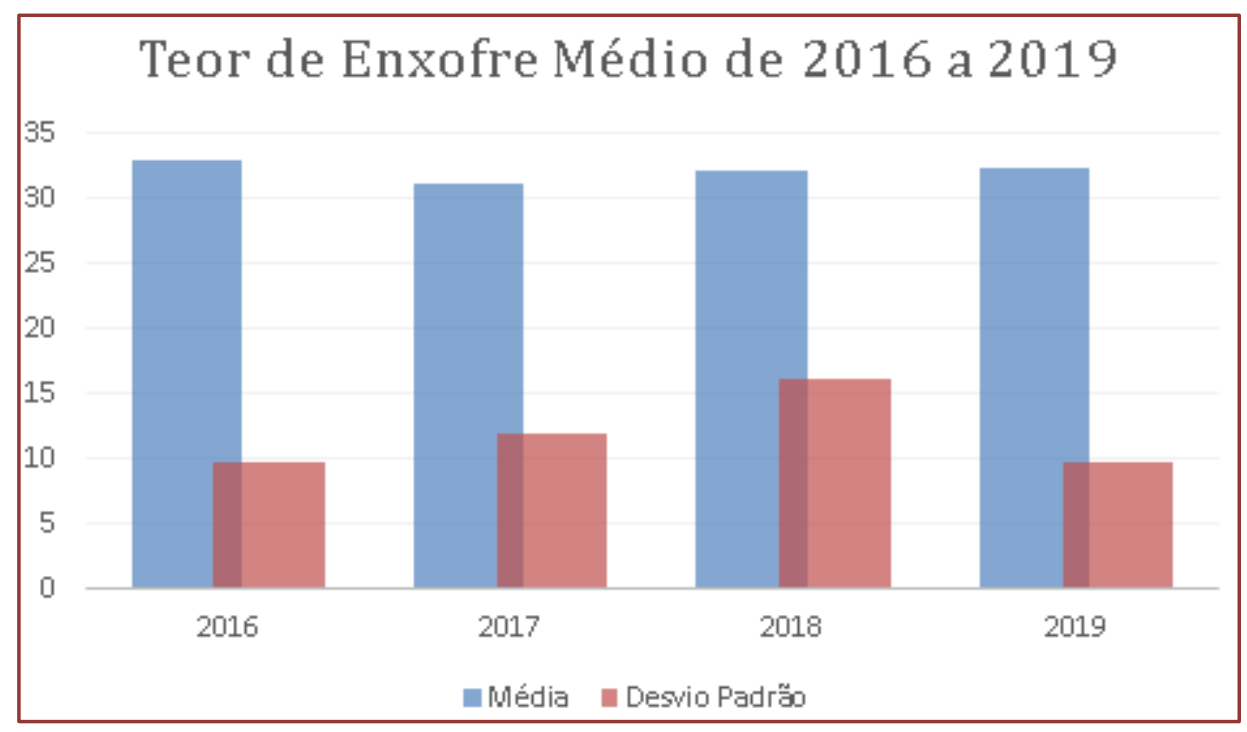

Por fim, foi identificado que o percentual de conformidade das amostras analisadas se encontra acima de $99,50 \%$, conforme gráfico apresentado abaixo. 


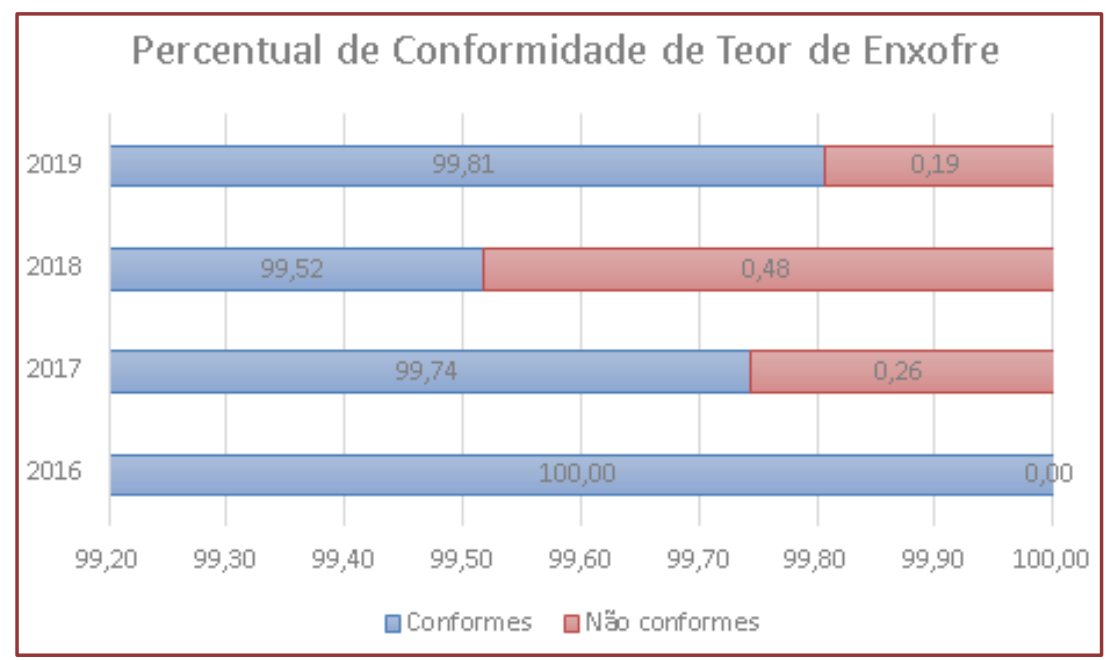

\section{CONCLUSÕES OUCONSIDERAÇÕES FINAIS}

Ao analisar os dados do teor de enxofre para a gasolina automotiva comercializada no Brasil, conclui-se que o cumprimento do nível da qualidade estabelecida pela ANP está bastante regular. Apesar disso, a problemática ambiental pela emissão dos compostos de enxofre continua alarmante e exige melhorias advindas do poder público. Uma alternativa que já vem sendo implementada é a adição de combustíveis renováveis em alguns combustíveis fósseis. Atualmente, Etanol Anidro é adicionado num percentual de $27 \%$ à gasolina automotiva. E o diesel deve conter $10 \%$ de biodiesel. Ainda existem estimativas para os próximos anos do aumento destes teores de biocombustíveis adicionados àqueles de origem fóssil.

\section{REFERÊNCIAS}

[1] Abreu, Mauricio Lobo. Ocorrência de Chuva Ácida Emunidades Deconservaçãoda Naturezaurbanas Estudode Casonoparque Estadual da Pedra Branca - Rio de Janeiro- RJ. 2005. 140 f. Dissertação (Mestrado) - Curso de Engenharia Ambiental, Centro de Tecnologia e Ciências, Universidade Estadual do Rio de Janeiro, Rio de Janeiro, 2005. Disponível em: <http://www.peamb.eng.uerj.br/trabalhosconclusao/2005/MauricioLoboAbreuPEAMB2005.pdf>. Acesso em: 19 ago. 2019.

[2] ANP. Programa de Monitoramento da Qualidade de Combustíveis. 30 set. 2016. Disponível em: < http://www.anp.gov.br/qualidade-produtos/158-programas-de-monitoramento/1864-pmqc >. Acesso em: 19 ago. 2019.

[3] Carvalho, Fábio Israel M.; Dantas Filho, Heronides A.. Estudo da qualidade da gasolina tipo A e sua composição química empregando análise de componentes principais. Química Nova: Redes Metalorgânicas e suas aplicaçãoes em catálise, Belém, v. 37, n. 1, p.33-38, nov. 2013. Disponível em: <http://quimicanova.sbq.org.br/imagebank/pdf/v37n1a07.pdf>. Acesso em: 19 ago. 2019.

[4] Drumm, Fernanda Caroline et al. Recebido em: 10.10.13 Aceito em:13.12.13 Poluição atmosférica proveniente da queima de combustíveis derivados do petróleo em veículos automotores. Revista Eletrônica em Gestão, Educação e Tecnologia Digital, Santa Maria, v. 18, n. 1, p.66-78, mar. 2014.

[5] MMA. Combustíveis fósseis são maiores responsáveis pelo efeito estufa. 2007. Disponível em: <https://www.mma.gov.br/informma/item/4125-combustiveis-fosseis-sao-maiores-responsaveis-pelo-efeitoestufa>. Acesso em: 19 ago. 2019. 


\section{Capítulo 9}

\section{Analise do desenvolvimento de biossensores com ênfase ambiental nas últimas décadas}

\section{Jocimara Camargo da Silva \\ Wyllerson Evaristo Gomes \\ Regina Marcia Longo \\ Renata Kelly Mendes}

Resumo: A busca desenfreada pela urbanização das cidades trouxe consigo consequências ao ambiente natural e, proporcionalmente, ao próprio ser humano, além de efeitos devastadores à fauna e flora. Sendo assim, é necessário o monitoramento constante de espécies poluentes no meio ambiente. Para este propósito, os biossensores se mostram uma alternativa viável devido a sua alta sensibilidade, baixo custo, alta seletividade e capacidade de miniaturização. Os biossensores são bastante versáteis e, por isso, estão presentes em diversas áreas de estudo. Neste trabalho, o objetivo foi realizar um levantamento bibliométrico na base de dados Web of Science sobre o desenvolvimento de biossensores para aplicações diversas e aqueles desenvolvidos especificamente para monitoramento ambiental, no período de 2008 a 2018. Para este levantamento, foram utilizados os seguintes termos: biosensor e environmental biossensor. Por meio dos trabalhos encontrados com os termos anteriormente descritos foram analisadas as áreas de aplicação, quantidade de trabalhos publicados e relação entre os artigos e ano de publicação. Para o termo biossensor foram encontrados 41.305 trabalhos e dentre esses, 34.429 artigos. Já para o termo environmental biossensor, foram encontrados 2.141 trabalhos e 1.638 artigos. Concluiu-se que o interesse pelo desenvolvimento de novos biossensores apresentou um crescente aumento nas últimas décadas e, sua aplicação na área ambiental apresenta tendência de crescimento.

Palavras-chave: Biossensores; Monitoramento Ambiental; Levantamento bibliométrico. 


\section{INTRODUÇÃO}

As consequências da falta da preocupação com a sustentabilidade associadas à falta de planejamento no crescimento de grandes centros urbanos, já podem ser observadas e sentidas pela humanidade por meio das, por exemplo, mudanças climáticas e enfermidades (BÔLLA et al., 2013). No entanto, essa urbanização ocasionou, adicionalmente, problemas relacionados ao meio ambiente, gerando poluição nas três categorias naturais principais: solo, ar e água (SILVA; MARTINS 2016). Neste contexto, o monitoramento dessas espécies contaminantes em matrizes ambientais é de suma importância. Dessa maneira, é essencial o desenvolvimento de metodologias para a determinação dos poluentes que sejam extremamente sensíveis e seletivas, de forma que os outros compostos presentes nessas matrizes complexas não interfiram, no sinal. Para isso, o desenvolvimento de dispositivos como biossensores se mostra viável e promissor que, além das vantagens descritas, ainda possibilitam monitoramento em tempo real, versatilidade com relação ao formato e tamanho, permitindo facilmente a aquisição de dados por meio de dispositivos miniaturizados (DERKUS, 2016; RIBOVSKI, 2015; SOUTO, 2016). Os biossensores podem ser definidos como uma subclasse dos sensores químicos, que apresentam como elemento de reconhecimento um composto biológico, tais como enzimas, anticorpos, DNA, RNA, células, que reconhece o analito de interesse gerando um sinal mensurável (BARROCAS et al., 2008).

Barrocas et al., 2008, para mostrar o aumento do uso dos biossensores em diversas áreas de estudo, realizaram um levantamento nas bases de dados PubMed e Web of Science utilizando o termo biossensor, como palavra-chave, obtendo resultados similares nas duas bases. Os autores constataram um aumento significativo no desenvolvimento destes dispositivos nas últimas décadas sendo que, entre 1997 a 2007, encontraram cerca de 12.000 artigos.

Sabendo-se que o monitoramento de espécies contaminantes em amostras ambientais é essencial, para garantir a qualidade dessas matrizes, e que os biossensores são capazes de serem aplicados nessas análises com baixo custo, o objetivo desse trabalho foi realizar um levantamento bibliométrico, sobre o desenvolvimento biossensores para aplicações em diversas áreas e biossensores desenvolvidos especificamente para monitoramento ambiental, na base de dados Web of Science, no período dos últimos dez anos, e realizar uma breve comparação com os resultados obtidos por Barrocas et al., 2008. Ressaltase que este trabalho foi apresentado no 16을 Encontro Nacional de Meio Ambiente, em setembro de 2019, em Poços de Caldas.

\section{METODOLOGIA}

Inicialmente, por meio do portal de periódicos CAPES/MEC, foi selecionada a base de dados Web of Science, utilizando como palavras-chave: biossensor ou environmental biossensor. Foi determinado o intervalo de anos entre 2008 e 2018. Ainda, dos trabalhos inicialmente exibidos, foi dado ênfase aos trabalhos classificados como artigos. 0 levantamento bibliométrico foi realizado no dia 13 de abril de 2019 e o tratamento de dados foi feito com o auxílio da própria base de dados.

\subsection{ESTUDO REALIZADO PARA O TERMO BIOSSENSOR}

Os resultados inicialmente encontrados foram classificados, pela própria base de dados, entre nove diferentes áreas e um tópico mais geral denominado de "outras áreas", com intenção de mostrar a diversidade do dispositivo qualitativamente. Em seguida, foram classificados os trabalhos do tipo artigo e relacionando com os anos de publicação. 0 resultado obtido, foi então comparado com os resultados obtidos por Barrocas et al., 2008, na década anterior.

\subsection{ESTUDO REALIZADO PARA O TERMO ENVIRONMENTAL BIOSSENSOR}

Os trabalhos inicialmente encontrados foram relacionados aos países de origem, junto à uma busca mais aprofundada sobre os trabalhos realizado no Brasil. Após, usando os resultados encontrados, foram determinados os artigos que foram relacionados com o ano de publicação. 


\section{RESULTADOS E DISCUSSÃO}

\subsection{ESTUDO REALIZADO PARA O TERMO BIOSSENSOR}

A busca inicial exibiu 41.305 trabalhos que, conforme já descritos, foram distribuídos entres nove áreas de estudos e um tópico denominado de "outras áreas". Entre as áreas em que foram distribuídos, a Química se encontrou com a maior quantidade, que pode ser atribuído ao princípio de funcionamento do biossensor. Ainda, ressalta-se a versatilidade dos dispositivos. Em seguida, 34.429 trabalhos foram classificados como artigos e então, relacionados com seus respectivos anos de publicação como apresenta a Figura 1.

Figura 1. Artigos publicados envolvendo o desenvolvimento de biossensores por ano no período de 2008 a 2018.

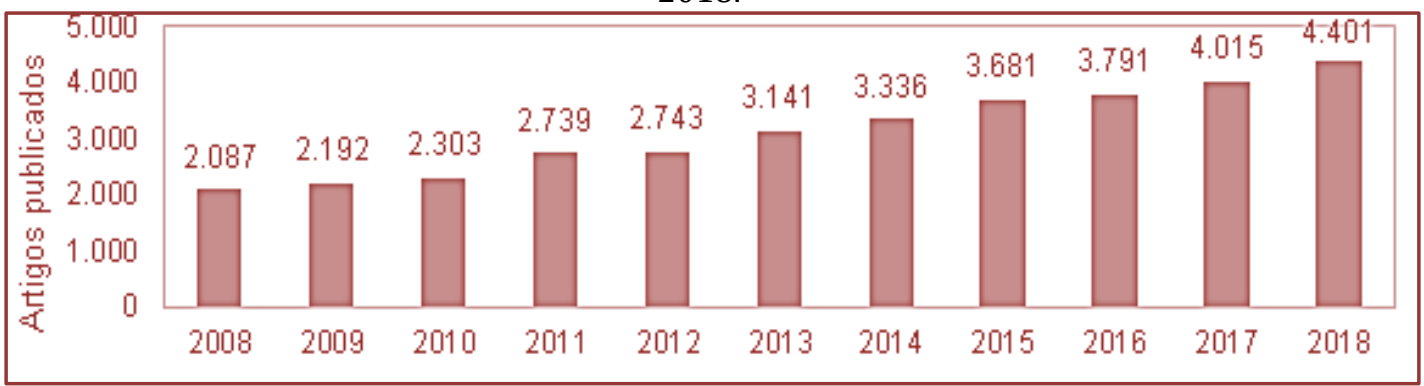

Observando a Figura 1, verifica-se um crescimento gradativo no desenvolvimento dos biossensores. Segundo Barrocas et al., 2008, na década anterior (1997 a 2007) foram publicados 12.000 artigos mostrando que, ocorreu um aumento significativo por pesquisas relacionadas a estes dispositivos.

\subsection{ESTUDO REALIZADO PARA O TERMO ENVIRONMENTAL BIOSSENSOR}

Foram obtidos 2.141 trabalhos relacionados ao termo mais especificamente relacionado à área ambiental, sendo que pesquisadores chineses foram os que publicaram a maior quantidade deles $(32,415 \%)$. 0 Brasil, nessa distribuição, apresentou apenas 2,149\% dos trabalhos encontrados, constatando-se um sutil aumento de trabalhos de 2008 a 2018. Da quantidade total, 1.638 trabalhos foram classificados como artigo e, então, relacionados com o ano de publicação. A relação é apresentada na Figura 2.

Figura 2. Artigos relacionados à biossensores aplicados à área ambiental publicados por anos no período de 2008 a 2018.

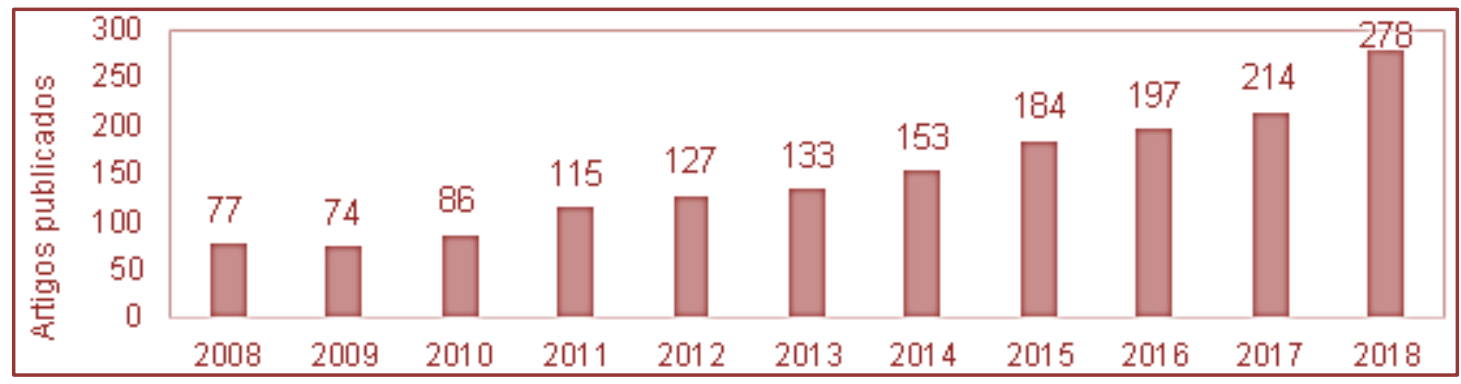

A Figura 2 mostra a tendência crescente no interesse de desenvolvimento de biossensores para aplicações ambientais, assim como nas outras áreas. 
Principalmente nesta área, de constante preocupação mundial, os dispositivos se mostram atrativos devido a possibilidade de poderem ser levados a campo e, desta forma, evita-se a etapa laboriosa de coleta de amostras e, na maioria das vezes, sem necessidade de pré-tratamento.

\section{CONCLUSÕES OU CONSIDERAÇÕES FINAIS}

O levantamento bibliométrico realizado sobre os biossensores, de modo geral, no período de dez anos (2008 a 2018), mostrou 34.429 artigos. Quando comparado com a quantidade de artigos encontrados por Barrocas et. al., 2008, na década anterior (1997 a 2007), foi observado que um crescente interesse, por parte da comunidade científica, no desenvolvimento destes dispositivos. Especificamente para biossensores aplicados no monitoramento ambiental, foi observado uma tendência no aumento na construção destes aparatos, mesmo a nível mundial. No Brasil, foram poucos os trabalhos encontrados relacionados à área ambiental.

\section{AGRADECIMENTOS}

O presente trabalho foi realizado com apoio da Coordenação de Aperfeiçoamento de Pessoal de Nível Superior - Brasil (CAPES) - Código de Financiamento 001 (J.C.Silva) e (W.E.Gomes).

\section{REFERÊNCIAS}

[1] Barrocas, P. R. G. et al. Cad. saúde colet. Rio de Janeiro, v. 16 n. 4, 677 - 700, 2008.

[2] Bôlla, K. D. S. et al. Interthesis. Florianópolis, v. 10, n. 2, p. 310-333, 2013.

[3] Derkus, B. Biosens. Bioelectron. v. 79, p. 901-913, 2016.

[4] Ribovski, L. Biossensores eletroquímicos para fins ambientais e medicinais. 2015. 110 p. Dissertação (Mestrando em programa de pós-graduação em física aplicada biomolecular) - Instituto de Física de São Carlos, Universidade de São Paulo, 2015.

[5] Silva, P.F.; Martins, D.R. Rebames v. 1, n.2, p. 56-62, 2016.

[6] Souto, L. A. S. Desenvolvimento de biossensores amperométricos á base de acetilcolinesterase para detecção de microcistinas. 2016. 76 f. Dissertação (Mestrando em programa de pós-graduação em Química) -Universidade Federal do Maranhão, São Luis, 2016. 


\section{Capítulo 10}

Ruídos: Identificação e análise da poluição sonora nas regiões centrais dos Municípios Mineiros de Florestal e Betim

Nicole Júnia Lemos Chaves

Hygor Aristides Victor Rossoni

Laura Bueno Silva

Resumo: A Política Nacional de Meio Ambiente (Lei no 6.938/81) define a poluição como a degradação da qualidade ambiental, portanto, a poluição sonora é uma forma de poluição que pode ser derivada do som puro ou da conjugação de sons. Nesse contexto, o som consiste em qualquer variação de pressão (no ar, na água e outros) que o ouvido humano possa captar, enquanto ruído é o som ou conjunto de sons indesejáveis, desagradáveis e perturbadores. De acordo com a NBR ABNT 10151/2000, os ruídos recomendados em período diurno e noturno respectivamente para áreas mistas, com vocação comercial e administrativa, é $60 \mathrm{~dB}(\mathrm{~A})$ e $55 \mathrm{~dB}(\mathrm{~A})$ enquanto em áreas mistas predominantemente residencial é $55 \mathrm{~dB}(\mathrm{~A})$ e $50 \mathrm{~dB}(\mathrm{~A})$. Níveis acima de $60 \mathrm{~dB}(\mathrm{~A})$ podem interferir diretamente na saúde dos seres humanos. Dessa forma, o presente trabalho objetivou promover um estudo dos níveis de ruídos nos centros urbanos dos municípios mineiros de Florestal e Betim e avaliar se estes encontram-se dentro dos parâmetros determinados nas legislações. Para tanto, para as medições dos níveis de ruídos, foi utilizado o decibelímetro, por meio do qual foram analisadas medições por meio da ponderação da frequência A e de tempo em fast. Os resultados obtidos permitiram inferir que a média dos níveis de ruídos no município de Florestal, foi equivalente a 68,27 dB(A). Em Betim, a média dos valores obtidos foi maior, equivalente a $82 \mathrm{~dB}(\mathrm{~A})$. Concluiu-se que os valores encontrados em ambos os municípios podem ser prejudiciais à saúde humana, considerando o valor máximo de ruído apontado pela NBR ABNT10151/2000 em períodos diurnos. Palavras-chave: Poluição sonora; Pressão sonora; Poluição ambiental; Legislação ambiental. 


\section{INTRODUÇÃO}

A Lei no 6.938/81, que institui a Política Nacional do Meio Ambiente, em seu art. 30\%, define a poluição como a degradação da qualidade ambiental resultante de atividades que direta ou indiretamente: prejudiquem a saúde; criem condições adversas às atividades sociais e econômicas; afetem desfavoravelmente a biota; afetem as condições estéticas ou sanitárias do meio ambiente; lancem matérias ou energia em desacordo com os padrões ambientais estabelecidos (BRASIL, 1981). Portanto, a poluição sonora é a degradação da qualidade ambiental fruto de som puro ou da conjugação de sons. As atividades sonoras serão consideradas poluidoras por presunção legal, na medida em que se situarem fora dos padrões admitidos em lei.

Sobre a poluição sonora, é preciso distinguir som de ruído, em que o som é qualquer variação de pressão que o ouvido humano possa captar, enquanto ruído é o som ou conjunto de sons indesejáveis, desagradáveis, perturbadores. 0 critério de distinção é o agente perturbador, que pode ser variável, envolvendo o fator psicológico de tolerância de cada indivíduo. (JUSBRASIL, 2004).

A Resolução 001/90 do CONAMA, no seu item I, dispõe: I - A emissão de ruídos, em decorrência de quaisquer atividades industriais, comerciais, sociais ou recreativas, inclusive as de propaganda política. Obedecerá, no interesse da saúde, do sossego público, aos padrões, critérios e diretrizes estabelecidos nesta Resolução (BRASIL, 1990).

De acordo com a NBR 10151/2000, os ruídos recomendados para área mista, com vocação comercial e administrativa, em período diurno é $60 \mathrm{~dB}$ e em período noturno é de $55 \mathrm{~dB}$, enquanto em áreas mistas predominantemente residencial é $55 \mathrm{~dB}(\mathrm{~A})$ e $50 \mathrm{~dB}(\mathrm{~A})$, níveis acima destes podem interferir diretamente na saúde dos seres humanos. Os níveis encontrados em atividades diárias entre 60 e 100 decibéis estão relacionados aos seguintes fatores: conversa normal ( $60 \mathrm{~dB})$, aspirador de pó (75 dB), tráfego pesado (85 $\mathrm{dB})$, liquidificador (85 dB), moto (95 dB), secador de cabelo (100 dB) e buzina (100 dB).

Os especialistas afirmam que ficar surdo é só uma das consequências que podem ser causadas devido a constante exposição a altos níveis de ruídos. Esses são responsáveis por inúmeros problemas como a redução da capacidade de comunicação e de memorização, perda ou diminuição da audição e do sono, envelhecimento prematuro, distúrbios neurológicos, cardíacos, circulatórios e gástricos. Muitas de suas consequências perniciosas são produzidas inclusive, de modo sorrateiro, sem que a própria vítima se dê conta (JUSBRASIL, 2017).

Por esses motivos, o presente trabalho objetivou promover um estudo dos níveis de ruídos nos centros urbanos dos municípios de Florestal e Betim e avaliar se estes encontram-se dentro dos parâmetros determinados nas legislações.

\section{METODOLOGIA}

Para realizar a medição de ruídos é necessário a utilização de decibelímetro digital, cujo o nível da intensidade sonora é passível de medição através da grandeza denominada decibel (dB). 0 decibelímetro digital possui um microfone capacitivo pré polarizado e filtros que permitem à medição do nível de pressão sonora em ambas as ponderações e frequências que podem ser usadas para modificar a maneira pela qual o instrumento mede o ruído, buscando assim, equalizar aos ouvidos humanos, variando entre as frequências A e C. A ponderação de frequência A é o filtro padrão das frequências audíveis destinados a reproduzir a resposta do ouvido humano ao ruído. Nas baixas e altas frequências a capacidade auditiva não é muito sensível, mas entre $500 \mathrm{~Hz}$ e $6 \mathrm{kHz}$ tem uma sensibilidade maior (MEDISOM, 2015). Além do aparelho registrar valores das diferentes ponderações de frequência, ainda é possível obter as ponderações de tempo em fast e slow. Em que o primeiro é a medição de ruídos de impacto e o segundo a medição de ruído contínuo. No presente trabalho foi utilizado um decibelímetro, modelo SKDEC-01 (Figura 1) e fita métrica de 2 metros para realizar o procedimento de medição (Figura 2).

0 procedimento foi realizado em diferentes pontos da praça Coronel Torquato de Almeida, localizada em frente à paróquia São Sebastião, latitude: $-19.888090,-44.433213$, na cidade de Florestal, município de pequeno porte com população de aproximadamente 6.600 habitantes (IBGE, 2010a) e ao redor da Praça Tiradentes, localizada na latitude: -19.966728 , longitude: -44.199559 da cidade de Betim, município de grande porte com população estimada de 378.089 pessoas (IBGE, 2010a). Além disso, foi utilizado como parâmetro para posicionamento do aparelho (figura 2), a altura média dos habitantes de Minas Gerais, aproximadamente $166 \mathrm{~cm}$ (IBGE, 2010b). 
Destaca-se que as medições foram realizadas às 12:00 horas, pelo horário de Brasília, dos dias 07 de agosto (quinta-feira) de 2019 em Florestal e 08 de agosto (sexta-feira) de 2019 em Betim, período e dias da semana de grande movimentação nas cidades em estudo, sendo essas medições realizadas utilizando a ponderação de frequência $\mathrm{A}$, de tempo fast e escala $60 \sim 110 \mathrm{~dB}$ por cerca de 3 minutos em cada ponto visando obter um valor mais frequente dado que há oscilação constante de sons no ambiente. Foram selecionados três pontos ao acaso. Para a cidade de Florestal (Figura 3), o ponto 1 (P1) é localizado na praça em frente a Farmácia Inova, o ponto 2 (P2) em frente ao Supermercado Damasco e o ponto 3 (P3) na escadaria da paróquia. Já no município de Betim (Figura 4), o ponto1 (T1) é em frente à Loja Ponto Frio, o ponto 2 (T2) em frente ao Banco Itaú e o ponto 3 (T3) no centro da praça. Nas tabelas 1 e 2 encontram-se apresentadas as coordenadas geográficas de cada ponto selecionado.

Figura 2: Decibelímetro modelo SKDEC-01

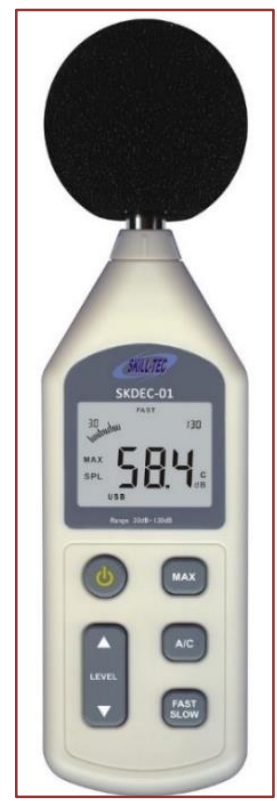

Fonte: Skill-Tec, 2019

Figura 3: Posicionamento do decibelímetro a $166 \mathrm{~cm}$ do solo

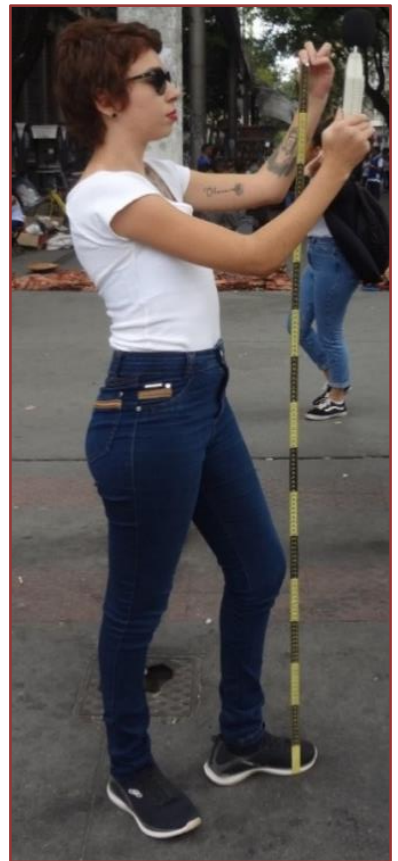

Fonte: Própria autora, 2019 
Figura 3: Praça Cel. Torquato de Almeida - Florestal

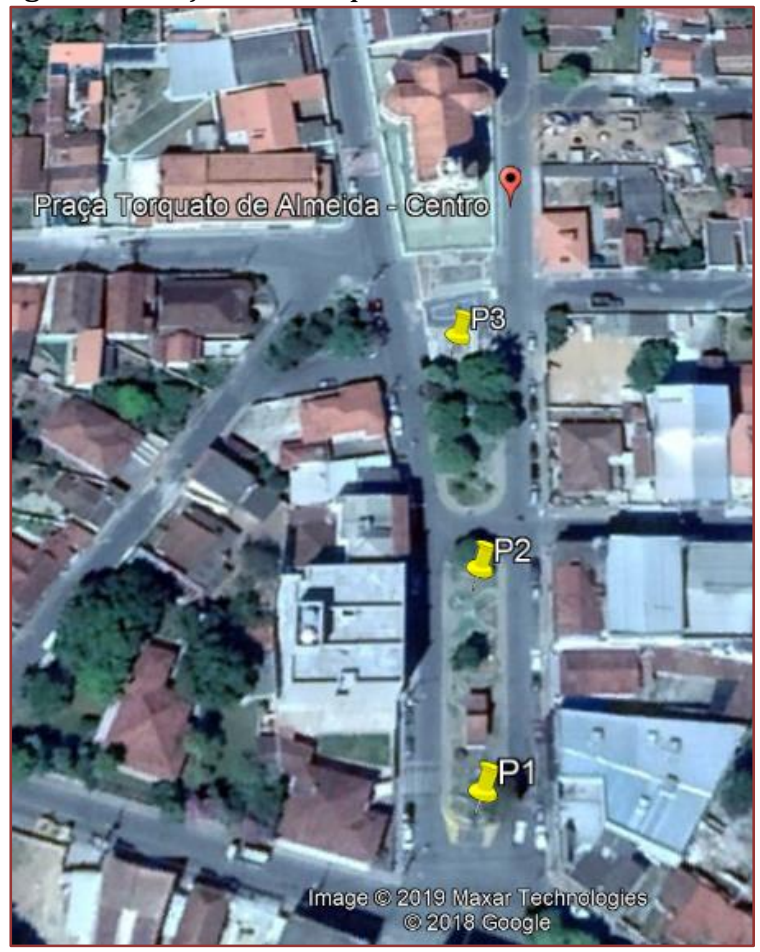

Fonte: Earth Google, 2019.

Figura 4: Praça Tiradentes - Betim

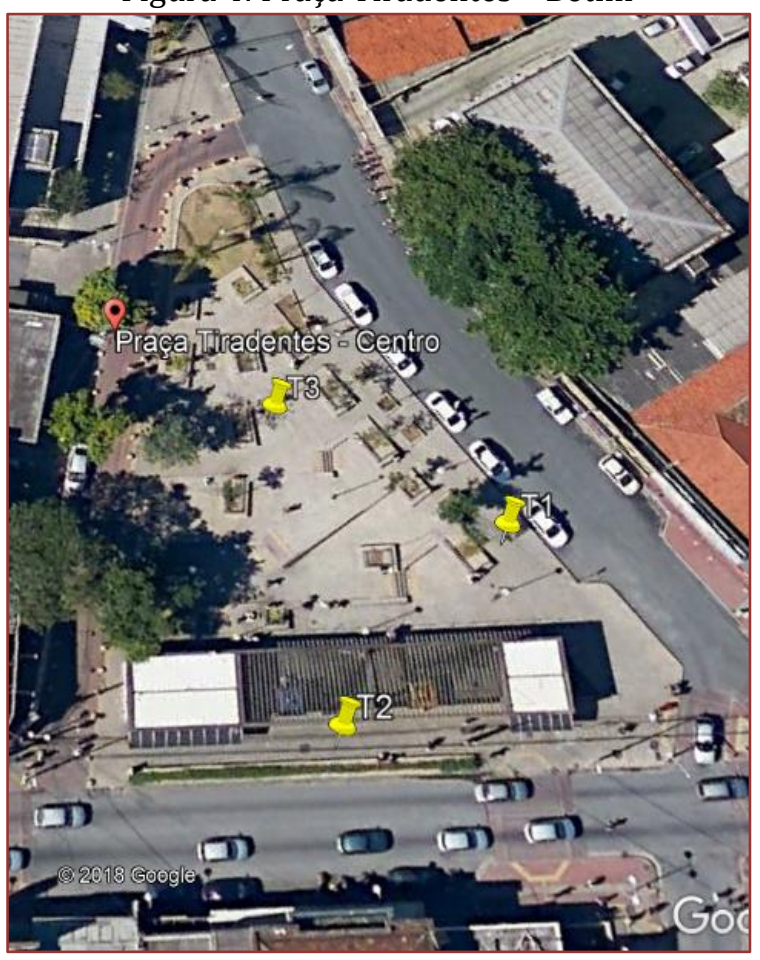

Fonte: Earth Google, 2019. 
Tabela 1: Coordenadas geográficas da praça Cel. Torquato de Almeida - Florestal

\begin{tabular}{|c|c|c|}
\hline Ponto & Latitude & Longitude \\
\hline P1 & 1953'15.94" S & 44은'59.55" W \\
\hline P2 & 19-53'17.38" S & 44은'59.53" W \\
\hline P3 & 19-53'1909" S & $44025 ' 59.57 " \mathrm{~W}$ \\
\hline
\end{tabular}

Fonte: Eart Google Pro - Maxter Tec, 2019.

Tabela 2: Coordenadas geograficas praça Tiradentes - Betim

\begin{tabular}{|c|c|c|}
\hline Ponto & Latitude & Longitude \\
\hline P1 & 1958'0.70" S & 44ำ11'58.23" W \\
\hline P2 & 19-57'59.96" S & $44^{\circ}-11^{\prime} 58.21^{\prime \prime} \mathrm{W}$ \\
\hline P3 & $19-58 ' 0.56^{\prime \prime} \mathrm{S}$ & $44^{\circ} 11^{\prime} 57.47^{\prime \prime} \mathrm{W}$ \\
\hline
\end{tabular}

Fonte: Eart Google Pro - Maxter Tec, 2019.

\section{RESULTADOS E DISCUSSÕES}

Os resultados médios no período analisado, obtidos da avaliação de ruídos no município de Florestal foram equivalentes a 73,8 $\mathrm{dB}(\mathrm{A})$ no $\mathrm{P} 1$, no $\mathrm{P} 2$ foi de 70,8 $\mathrm{dB}(\mathrm{A})$ e $60,2 \mathrm{~dB}(\mathrm{~A})$ no P3 (figura 4). Em Betim, T1 foi equivalente a 87,5 dB(A), T2 igual a 83,1 dB(A) e T3 75,4 dB(A) (figura 5). Comparando-se os valores das cidades de Florestal e Betim, pode-se concluir que a diferença média de aproximadamente $20 \mathrm{~dB}$ a mais na segunda, foi grande como o esperado, levando a questionar os reais impactos causados por esses níveis de ruídos.

Figura 4: Análise dos resultados obtidos na Praça Cel. Torquato de Almeida - Florestal

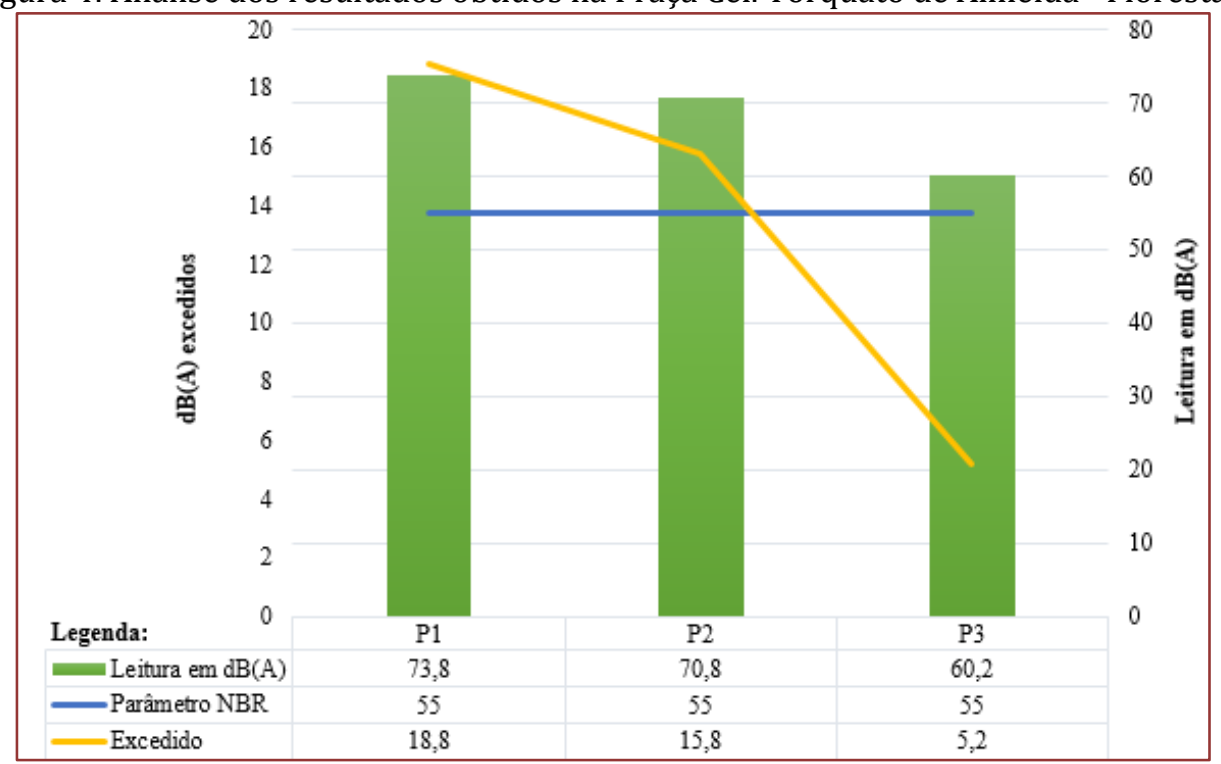

Fonte: própria autora, 2019. 
Figura 5: Análise dos resultados obtidos na Praça Tiradentes - Betim

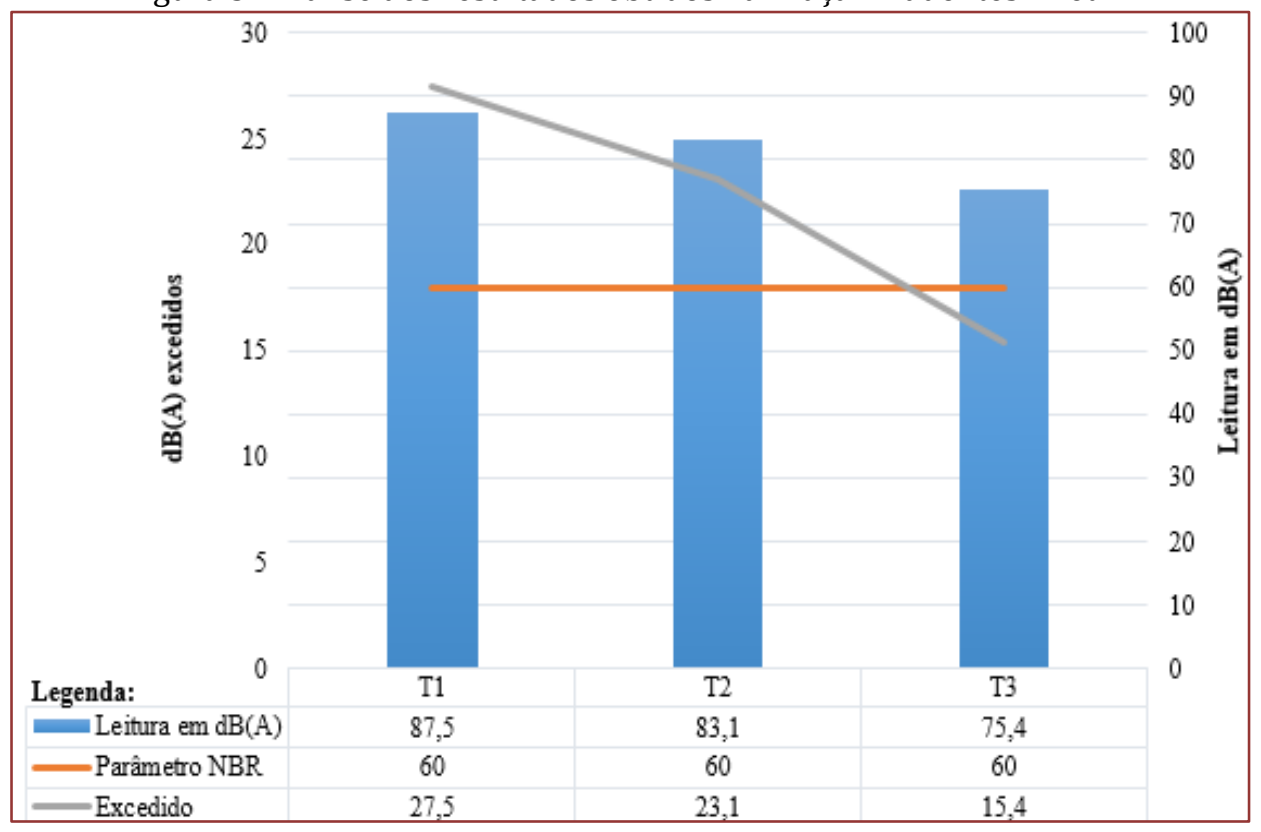

Fonte: própria autora, 2019.

Sabe-se que o ruído é recebido pelo organismo como alerta de perigo; a reação natural do corpo em autodefesa é liberar energia por meio do consumo das reservas de açúcar e gordura. Após esgotar essas reservas o corpo apresenta sinais de cansaço, irritabilidade (causando desentendimentos e episódios de violência), estresse, ansiedade, insônia, falha de memória, falta de concentração (que pode levar a acidentes no trânsito), gripe e até mesmo doenças cardíacas, respiratórias, digestivas e mentais. Com isso o excesso de ruído pode reduzir a expectativa de vida (OMS, 2018). Porém, não é possível afirmar, com a realização desse trabalho, quais os problemas de saúde ocasionados na população que está em contato direto com os níveis de ruídos avaliados, mas é evidente a possibilidade de serem desenvolvidas doenças por esse fator.

\section{CONCLUSÕES}

Concluiu-se que os valores encontrados em ambos os municípios podem ser prejudiciais à saúde humana, principalmente da população vizinha e os frequentadores dos locais, considerando o valor máximo (de 55 dB(A) para Florestal e de $60 \mathrm{~dB}(\mathrm{~A})$ para Betim) de ruído apontado pela NBR ABNT10151/2000 em períodos diurnos.

Sugere-se a realização de mapeamentos sonoros para a identificação dos locais de maior ou menor exposição da população auxiliando na tomada de decisão para a prevenção e controle dos ruídos, como por exemplo, a restrição do trafego urbano, bem como a promoção de inspeções veiculares periódicas e a conscientização dos comerciantes quanto ao uso adequado de equipamentos de som.

\section{AGRADECIMENTOS}

Agradeço ao meu professor e orientador Hygor Rossoni por me apoiar e incentivar na execução desse trabalho, à Universidade Federal de Viçosa, aos meus professores que me capacitaram e me transmitiram conhecimentos únicos nessa longa caminhada até aqui e aos que me deram apoio financeiro e emocional nos momentos difíceis. Agradeço também à minha família por me apoiar em todos os mementos e me dar conselhos engrandecedores, especialmente a minha irmã Kerollayne com seus conselhos acadêmico/científicos tão sábios. GRATIDÃO!! 


\section{REFERÊNCIAS}

[1] [Abnt] Associação Brasileira de Normas Técnicas. Brasil. Acústica - níveis de ruído para conforto acústico NBR 10.152:1987. Rio de Janeiro 1997.

[2] [Abnt] Associação Brasileira de Normas Técnicas. Brasil. Acústica - níveis de ruído em áreas habitadas, visando o conforto da comunidade - Procedimento, NBR 10.151:1999

[3] [Jusbrasil] 2017 texto de Machado, Anaxágora Alves. Poluição sonora como crime ambiental. Revista Jus Navigandi, ISSN 1518-4862, Teresina, ano 9, n. 327, 30 maio 2004. Disponível em: <https://jus.com.br/artigos/5261>. Acesso em: 24 jun. 2019.

[4] [Mma] Ministério do Meio Ambiente - Resolução [Conama] Conselho Nacional do Meio Ambiente 001/90

[5] [Mma] Ministério do Meio Ambiente - Resolução [Conama] Conselho Nacional do Meio Ambiente 002/90

[6] [Oms] Organização Mundial da Saúde -Westin, R. Silêncio! Jornal do Senado, Brasília, 29 maio 2018. anexo XIV. Disponível em

https://www2.senado.leg.br/bdsf/bitstream/handle/id/542358/Cidadania_636.pdf?sequence=1>.

[7] Medisom. Medisom- Tecnologia Em Monitoramento De Ruído., 2015. Disponivel Em: <Http://Medisom.Com.Br/Blog/Ponderacao-A-Ou-C>. Acesso Em: 28 Maio 2019.

[8] Westin, R. Silêncio! Jornal Do Senado, Brasília, 29 Maio 2018. Anexo Xiv. 


\section{Capítulo 11}

\section{Modelagem ambiental: Simulação de 30 anos do desmatamento no Município de Brasnorte - MT}

\section{Marcelo Alvares Tenenwurcel \\ Adriana Monteiro da Costa \\ Douglas Felipe Lucas \\ Lucas Antônio Brasil Gonçalves Lacerda}

Resumo: A Floresta Amazônica é um complexo ambiental de grande importancia, não apenas nacional, mas em escala global. Este bioma é responsavel por fornecer divesos serviços ecossitemicos, sendo fundamental preserva-lo. Neste contexto, o trabalho pretende analisar a dinamica do desmatamento no município de Brasnorte - MT, que é integrante da Amazônia brasileira. Para isso foi aplicado um modelo de mudança do uso e cobertura da terra, tendo como foco a evolução do desmatamento neste munícipio, indo de 2004 ate 2034 ( 30 anos). Conclui-se que o modelo possui um ajuste aceitável para modelar a evolução do desmatamento na área de estudo e as variáveis utilizadas explicam bem o processo de transição de florestas para pastos. Desta forma, percebe-se que o desmatamento tem maiores chances de ocorrer principalmente em áreas próximas a pastagens e a estradas e com distancia acima de 1,5 Km de áreas preservadas. 


\section{INTRODUÇÃO}

O crescimento acelerado das atividades antrópicas como urbanização, expansão agrícola e desmatamento modificou a superfície do planeta, principalmente nos dois últimos séculos. Observa-se um intenso processo de substituição de paisagens naturais por outros usos do solo e a conversão de áreas com cobertura florestal em fragmentos florestais, ocasionando a perda da biodiversidade e, muitas vezes, comprometendo a disponibilidade e qualidade de recursos naturais relevantes para a população (AGUIAR, 2003).

Uma das principais causas do desmatamento é a pecuária. A conversão de extensas áreas de vegetação natural para pastagens pode levar a degradação de ecossistemas terrestres e aquáticos e sua biodiversidade, podendo provocar a morte de indivíduos de várias espécies, redução de hábitat, intensificação dos processos erosivos, assoreamento, aumento da evapotranspiração potencial e emissão de gases do efeito estufa e comprometimento a qualidade da água (RIVERO et. al., 2011).

No Brasil, destaca-se a expansão da pecuária na Amazônia, bioma conhecido pela sua rica biodiversidade e serviços ecossistêmicos relevantes relacionados ao regime climático global. Em 2013 a pecuária brasileira ocupava aproximadamente 220 milhões de hectares, dos quais 70 milhões localizavam-se somente nos estados da Amazônia (BARBOSA et.al., 2015).

Esta ocupação ocorreu, sobretudo a partir dos anos 60, sendo caracterizada pelo ciclo desmatamento/extração de madeira/pecuária, no qual o desflorestamento é inicialmente realizado por posseiros, que abrem as florestas, estimulados por madeireiras, seguido pela sua expropriação por fazendeiros de gado ou empresas agropecuárias (AGUIAR, 2003).

O estudo das mudanças de uso e cobertura do solo (Land Use and Land Cover Change - LUCC) é responsável pela detecção de uma série de aspectos da mudança ambiental global e suas forças dirigentes e tem, por isso, recebido crescente atenção dos cientistas e tomadores de decisão. Nas últimas duas décadas, o foco da investigação tem se direcionado para a modelagem de sistemas, através da previsão de mudanças e da exploração de possíveis cenários futuros (MAS et.al., 2014).

A ampla disponibilização de dados de sensoriamento remoto e o desenvolvimento e popularização de plataformas de Geoprocessamento, em especial os Sistemas de Informação Geográfica (SIGs) impulsionou e facilitou esta tendência (LIMA et.al, 2013). A modelagem espacialmente explícita é uma importante técnica para projetar e explorar cenários alternativos futuros, para conduzir experimentações que auxiliam no entendimento e quantificação dos processos envolvidos na dinâmica da paisagem. Este enfoque exploratório e prospectivo permite que os modelos sejam usados como ferramentas de análise ambiental (OLIVEIRA, 2012).

Neste contexto o objetivo deste trabalho é analisar a dinâmica das mudanças de uso e cobertura do solo, especialmente expansão da pecuária e sua projeção futura ate o ano de 2034 , no município de Brasnorte/MT. Portanto, a análise das mudanças de uso e cobertura do solo do município, especialmente a conversão de áreas naturais em pastagens, contribuiria para elucidação dos processos indutores do desmatamento em áreas consolidadas da Amazônia.

\section{METODOLOGIA}

\subsection{CARACTERIZAÇÃO DA ÁREA DE ESTUDO}

O município de Brasnorte está localizado na região noroeste do Estado de Mato Grosso, na região da Amazônia Legal e tem como municípios limítrofes Castanheira, Juara, Nova Maringá, Campo Novo do Parecis, Sapezal e Juína. O município possui área territorial de aproximadamente $16.761 \mathrm{~km}^{2}$ e tem como principal via de acesso local, a rodovia estadual MT-170 que possui ligação com a MT-220. 
Figura 1 - Mapa de localização do Município de Brasnorte - MT

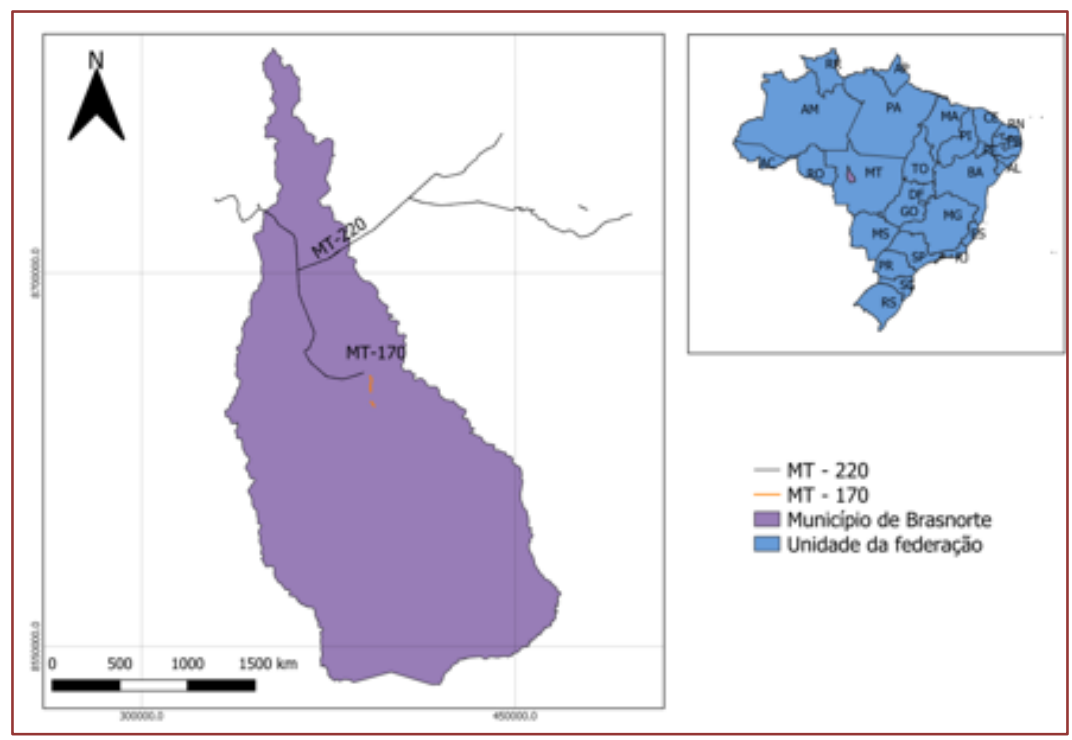

A população do município de Brasnorte, de acordo com dados do último censo demográfica realizado pelo IBGE (2010), era 15.537 habitantes havendo a predominância da população urbana, que representava $65 \%$ da população total.

A área de estudo esta inserida na Grande Bacia do Amazonas, que por sua vez abrange bacia hidrográfica do Rio Tapajós. Além disso, a área de estudo também recebe influencia da Bacia Hidrográfica do Rio Juruena, que é um dos principais afluentes do Rio Tapájos. Os principais rios tributários do Rio Juruena são os rios Sangue e Papagaio, presentes ao longo de toda a extensão territorial do município estudado.

Além disso, de acordo com a Fundação Nacional do Índio - FUNAI, (2011), percebe-se que há presença de duas terras indígenas que ocupam parte do município de Brasnorte, que são, as reservas indígenas Menku e Erikpatsá. A reserva Menku possui 146.398 Ha no total e a reserva Erikpatsá ocupa uma área de 79.934, 8010 Ha. Nestas reservas habitam aproximadamente 1.866 indígenas.

\section{a. Economia}

O município tem como principais atividades econômicas o cultivo agrícola e a pecuária. 0 crescimento de área plantada de lavouras no território de Brasnorte elevou- se a níveis superiores a 1.000\% (IBGE, 2019), considerando 1990, ano em que começaram a serem contabilizados os dados de produção agrícola municipal como tempo inicial e dados da última quantificação de áreas de lavouras, correponden ao ano de 2017. Neste último ano (2017), o município representou o município com a 20ª maior área plantada de todo o país.

Figura 2 - Área Plantada no município de Brasnorte.

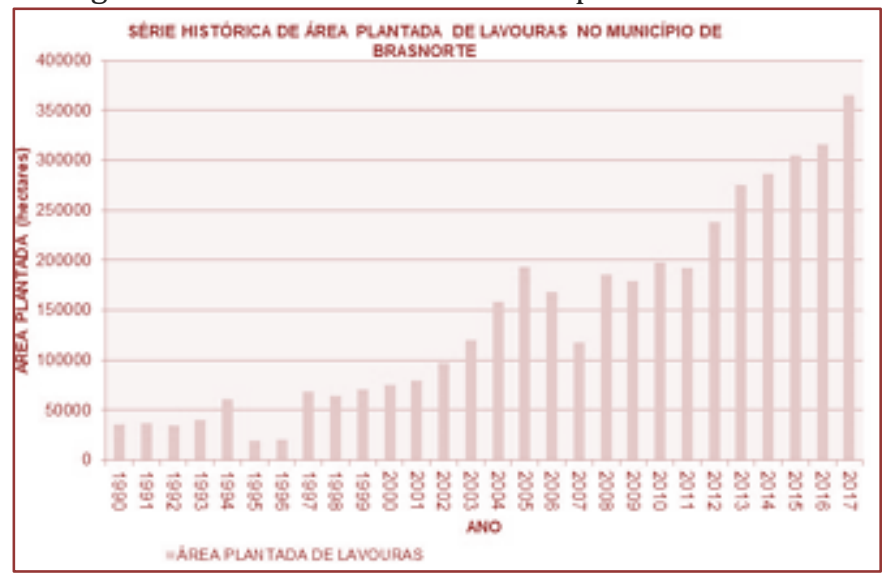

Fonte: Censo Demográfico 2010, IBGE. 
A importância das lavouras na dinâmica econômica de Brasnorte pode ser observada através de dados referentes ao produto interno bruto municipal, que considerando o valor adicionado bruto da agropecuária a preços corrente indica que Brasnorte possui no ano de 2017, o 88a maior PIB agropecuário do país, que consequentemente elevou o local a $30^{a}$ economia mais forte do estado naquele ano.

A representatividade de determinadas culturas como milho e principalmente a soja, na área total plantada de lavouras, evidenciam a grande potencialidade dessas duas variedades agrícolas como grandes bases do ciclo produtivo do setor no município de Brasnorte. Soja e Milho representaram em 2017, mais de 90\% da área plantada por cultivo temporário.

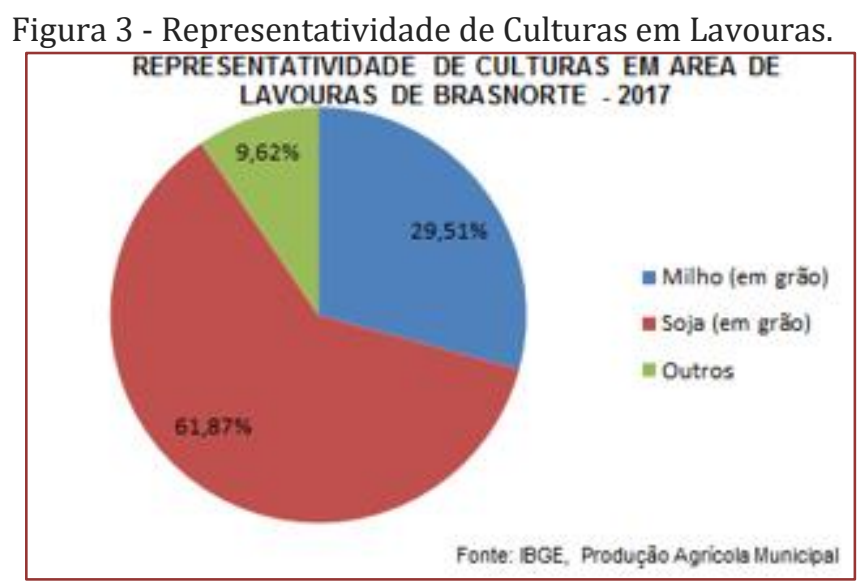

Fonte: IBGE, Produção Agrícola Municipal.

\subsection{MATERIAIS E MÉTODOS}

Os materiais utilizados neste estudo consistiram em:

a) Software QuantumGIS versão 3.0;

b) Software DINAMICA EGO versão 4.11;

c) Imagens de 2004, 2010 e 2014 do uso e cobertura da terra do banco de dados do Projeto TerraClass;

d) Mapa das áreas prioritárias para intensificação de rebanho bovino, mapa de frigoríficos do estado do Mato Grosso, Mapa de áreas protegidas do estado do Mato Grosso, Mapa das redes de drenagem do estado do Mato Grosso, Mapa de rodovias e estradas vicinais, Mapa de vegetação do estado do Mato Grosso e Mapa de áreas urbanas no banco de dados do Centro de Sensoriamento (CSR) da UFMG.

É válido elucidar que o DINAMICA EGO (Environment for Geoprocessing Objects) é uma plataforma de modelagem desenvolvida pelo Centro de Sensoriamento Remoto da Universidade Federal de Minas Gerais. Através vários operadores, chamados 'functores', que executam operações matemáticas, lógicas e de análise espacial, o usuário pode elaborar modelos espacialmente explícitos, além de utilizar algoritmos para calibração e validação das simulações (SOARES-FILHO et al., 2009).

O DINAMICA utiliza o método bayesiano de pesos de evidência para realizar o cálculo que gera os mapas de probabilidade de mudança ou mapa do potencial espacial de mudanças (BONHAM-CARTER, 1994). Este método utiliza probabilidades condicionais para estabelecer a relação entre presença/ausência de mudança, dada a presença/ausência de determinado fator. Os pesos de evidência trabalham as probabilidades de transição relacionadas a cada determinante espacial, apenas posteriormente unindo-as num mapa global de probabilidades (LIMA et al 2013).

O modelo de simulação de mudanças inicia-se com a definição dos elementos ou estados de uma paisagem e suas possíveis transições. Em geral, a análise espacial das mudanças é realizada através da comparação de mapas de uso e cobertura da terra, comumente oriundos da classificação de imagens obtidas por sensores remotos. Esta comparação permite estimar os tipos de transições e as quantidades de mudança, ou seja, a intensidade de mudança para um intervalo de tempo discreto. 
Desta forma, o software utiliza como dados de entrada principais ou input mapas de uso e cobertura da terra reclassificados em grupos por meio de técnicas de sensoriamento remoto. Ademais, o modelo emprega variáveis espaciais que procuram explicar o desmatamento para a transição observada na matriz de transição.

Como output ou dados de saída, o DINAMICA gera mapas de paisagem simulados (um para cada intervalo de tempo), os mapas de probabilidade de transição espacial, que representam a probabilidade de uma célula em uma posição $(\mathrm{x}, \mathrm{y})$ mudar de estado i para estado $\mathrm{j}$ (sendo i e j tipos de uso da terra e classe de cobertura da terra), e os mapas dinâmicos de variáveis espaciais (SOARES-FILHO, 2002).

Em relação às etapas metodológicas para aplicar o modelo de simulação de mudança do uso e cobertura da terra foram realizadas as seguintes atividades:

1. Seleção das imagens de uso e ocupação (TerraClass, 2014) dos anos de 2004, 2010 e 2014 para calibração e validação;

2. Separação em classes de uso e cobertura das imagens selecionadas;

3. Criação da matriz de transição entre 2004 e 2010;

4. Selecionar um conjunto de variáveis independentes para explicar o desmatamento, com foque na transição observada na multi matriz;

5. Calibração do modelo com as imagens de 2004 e 2010;

6. Cálculo dos pesos de evidencias para as variáveis e verificar a correlação entre as variáveis explicativas escolhidas;

7. Realização da simulação de evolução do desmatamento a partir de 2010 até 2014, com finalidade de testar o modelo;

8. Verificar a similaridade (validação) entre o mapa preditivo de 2014 e observado de 2014;

9. Simulação do desmatamento ate 2034;

10. Análise dos resultados

\section{RESULTADOS E DISCUSSÃO}

Para este trabalho foi realizado um levantamento bibliográfico que consistiu em leituras sobre os temas mapeamento do uso e cobertura da terra, sensoriamento remoto, modelagem preditiva, entre outros, para dar base às discussões metodológicas e análise dos resultados.

A primeira etapa para a construção do modelo foi criar uma matriz de transição que descreve a mudança no uso e cobertura à medida que ocorre incrementos de tempo discreto, nesse caso, indo de 2004 ate 2010, ou seja, 6 anos. A matriz de transição criada com múltiplos passos retornou o valor igual a 0,012 que significa dizer que a cada 1 incremento de tempo no modelo haverá um aumento de 0,012 de taxa de transição.

O functor utilizado para fazer o cálculo das taxas de transição foi o "Determine Transition Matrix". No caso do trabalho a transição observada foi a de florestas para áreas de pastagem.

Além desses mapas um conjunto de variáveis foi selecionado para tentar explicar o desmatamento na região estudada, foram elas: áreas de intensificação a pecuária, hidrografia, estradas vegetação, áreas protegidas, presença de frigoríficos e atração urbana. Outra variável, distância para áreas de pastagens também foi utilizada. Para todas as variáveis, exceto a vegetação, por ser uma variável categórica, foi realizado o cálculo de distancia em relação ao desmatamento, por meio do funtor "Calc distance map". Este functor calcula a distância das células mais próximas à classe do mapa de entrada escolhida pelo usuário, neste caso a classe escolhida foi as áreas de pasto, definida como 4 no mapa de uso e cobertura reclassificado.

A etapa de calibração do modelo consistiu em encontrar os melhores ranges, incrementos ou intervalos das variáveis selecionadas, de forma a alterar o menos possível a estrutura original dos dados, para o cálculo dos pesos de evidência. 0 functor utilizado para os cálculos dos incrementos é o "Determine Weights of evidence ranges". Depois de terem sido realizados vários testes foram encontrados os incrementos que apresentaram maior número de intervalos significantes. Os incrementos utilizados foram de 100 metros. Como a resolução adotada pelo trabalho foi também de $100 \mathrm{~m}$, deve-se perceber que o 
incremento adotado varia de um em um pixel. É válido frisar que as imagens de 2004 e 2010 foram utilizadas para calibrar o modelo.

Para gerar os coeficientes dos pesos de evidência utiliza-se o functor "Determine weights of evidence coefficients" que é responsável por determinar o peso para variáveis espaciais selecionadas. Os pesos de evidência aqui apresentados são estimados com base na independência dos eventos (Teorema de Bayes), com elucidado na metodologia. Para esse modelo foi solicitado criar pesos para uma transição de 3 para 4 , em que 3 são áreas florestadas e 4 áreas de pastagem.

Deve-se perceber que quanto mais negativo o peso menor a chance de o desmatamento ocorrer naquele pixel e quanto mais positivo, maior será a chance de desmatamento ocorrer.

Além disso, foi verificada a correlação entre as variáveis, através do funtor "Determine weights of evidence correlation", que devolve como resultado uma tabela de informações sobre os pares de variáveis correlacionadas. Os testes estatísticos analisado foram os testes de Cramer e Joint Uncertainty Information (BONHAM-CARTER, 1994). De acordo com estes métodos, as variáveis que apresentaram valores altos, geralmente acima de 0,6 ou $60 \%$, apresentariam uma correlação muito forte, podendo comprometer o resultado do modelo e desta forma estas variáveis devem ser excluídas. Para o presente trabalho as variáveis utilizadas não apresentaram alta correlação e por isso nenhuma precisou ser excluída.

Na figura 7 é possível analisar as curvas de distribuição dos pesos de evidência por intervalo para cada variável utilizada no modelo.

Figura 7 - Gráficos dos pesos de evidência das variáveis utilizadas no modelo.

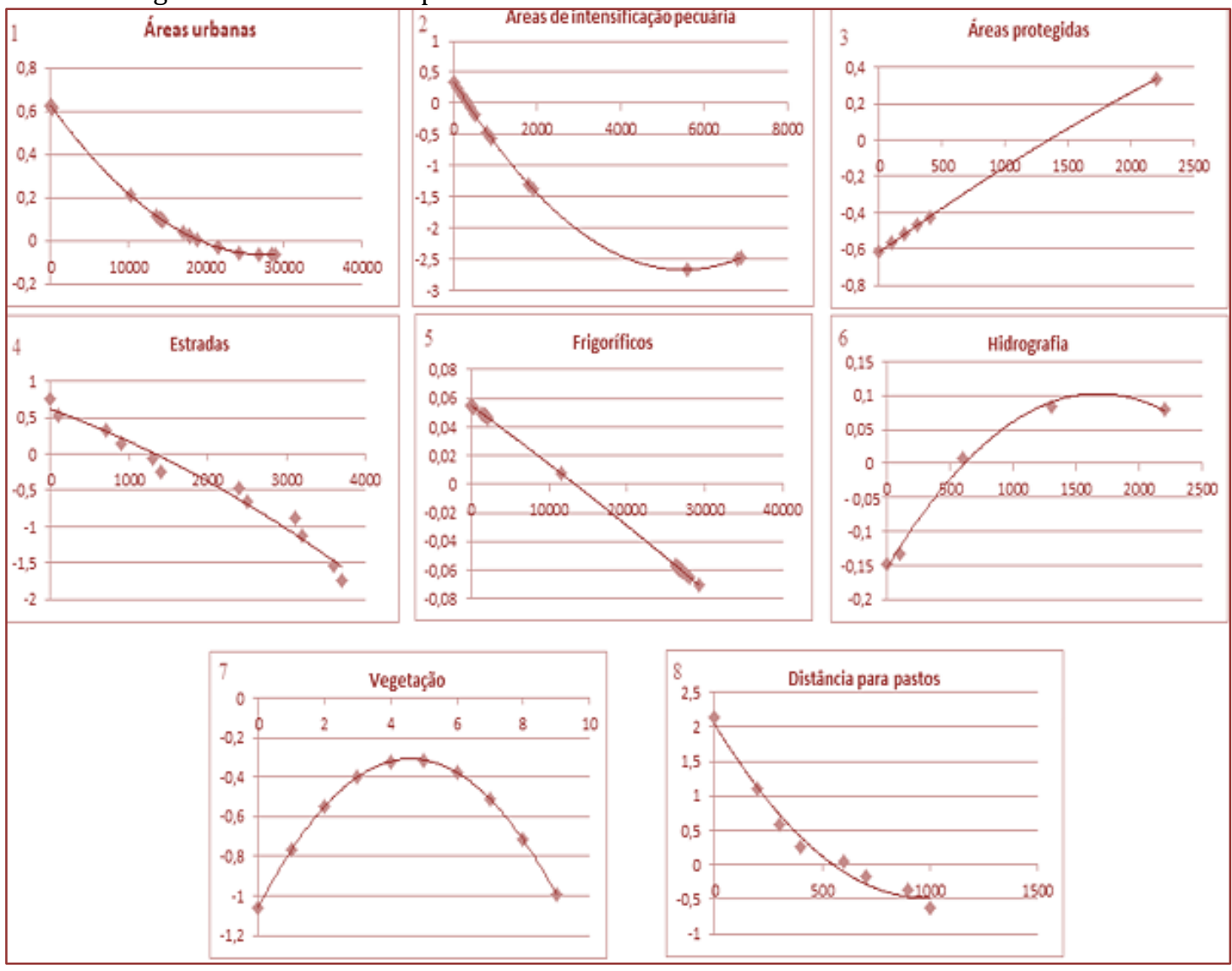

Para o gráfico 1 (distancia a áreas urbanas), deve-se perceber que a curva da função de regressão demonstra formato decrescente, além disso, à medida que a distancia dos centros urbanos aumenta os pesos demonstram uma tendência a diminuir. No entanto, com uma distancia aproximada de $20 \mathrm{~km}$ das áreas urbanas percebe-se a maior possibilidade de haver desmatamento e acima deste limiar os pesos são 
negativos, diminuído assim a chance de ocorrer desmatamento em áreas muito distantes dos centros urbanos.

Tal fato faz sentindo, pois a abertura de novas pastagens seria mais difícil em áreas isoladas, pois a distancia de grandes centros urbanos iria dificultar a comercialização e escoamento da madeira, gado, maquinário para abertura dos pastos, dentre outros produtos, como leite, carne e etc. Devido a isso, o desmatamento de áreas florestadas para pastos é mais improvável de ocorrer em áreas muito distantes de centros urbanos.

Em relação a distancia para áreas de intensificação a pecuária (gráfico 2), é necessário deixar claro que esta variável foi utilizada pelo trabalho, pois nas imagens coletadas para área de estudo no projeto TerraClass, havia a presença de uma vasta área que não foi categorizada de forma definitiva, não deixando claro qual tipo de uso e cobertura era empregado. Desta forma, dados sobre as áreas de intensificação a pecuária bovina foram utilizados para complementar a precisão do modelo e as informações sobre a distancia das áreas de pastos que foi prejudicada pela ausência de informações nas imagens coletadas.

Percebe-se que os pesos de evidencia das áreas de intensificação a pecuária são positivos até o intervalo de aproximadamente $1,5 \mathrm{Km}$, o que demonstra que o desmatamento possui maiores chances ocorrer em áreas bem próximas a pastagens previamente existentes. À medida que a distancia aumenta das áreas de pasto a probabilidade de ocorrer o desmatamento diminui, assim como os pesos de evidencia.

Isso pode ser explicado pelo fato de que a abertura de novas pastagens ocorre geralmente próxima a outras áreas de pastagem que existiam previamente. É mais provável e comum observar o desmatamento em uma área já desmatada e com presença de pastagens, onde a supressão vegetal ocorre para expandir os pastos. De forma contrária, é difícil observar a ocorrência de desmatamento em áreas isoladas, pois é mais custoso o trabalhoso de desmatar áreas intactas (RIVERO et al, 2011).

Os pesos de evidencia para as áreas protegidas (gráfico 3) demonstram ser positivos acima de aproximadamente $1,5 \mathrm{Km}$, o que indica que em áreas mais distantes de áreas protegidas existe uma probabilidade maior de ocorrer desmatamento. Ao observar este gráfico, podemos perceber que em áreas próximas a áreas protegidas os pesos de evidencia são negativos, o que demonstra que as áreas protegidas de fato exercem um papel fundamental para barrar ou diminuir a ocorrência de desmatamento, devido a maior fiscalização e leis que proíbem o desmatamento nestas áreas de conservação.

Ao analisar o gráfico dos pesos de evidencia para as estradas (gráfico 4), percebe-se que os eventos relacionados ao desmatamento possuem maior chance de ocorrer a ate aproximadamente 1,5 km, pois os pesos de evidencia são positivos ate este intervalo. Acima disso, percebe-se que os pesos demonstram valores negativos, o que diminui a chance de ocorrer desmatamento em áreas afastadas de estradas.

Esta análise corrobora o fato de que sem estradas próximas não haveria razão para realizar o desmatamento, pois o escoamento da madeira, do gado, dentre outros produtos seria um fator muito problemático, diminuindo a ocorrência desta atividade. Além disso, o deslocamento de maquinários seria muito prejudicado em áreas muito isoladas de estradas e rodovias, o que também diminuiria o desmatamento na região.

0 gráfico 5 ilustra que ate aproximadamente $11 \mathrm{Km}$ de distancia a frigoríficos percebe-se a ocorrência de desmatamento devido a proximidade com os estabelecimentos, o que facilita e incentiva a atividade da pecuária bovina. Desta forma, a proximidade com os frigoríficos pode aumentar o desmatamento, já que seriam abertas novas áreas de pastagem para criação de gado bovino em regiões próximas a frigoríficos. Além disso, a proximidade facilita o processo de escoamento da carne. Acima de $11 \mathrm{~km}$ os pesos de evidencia são negativos, demonstrando que a probabilidade de ocorrer desmatamento é menor.

Ao analisar o gráfico dos pesos de evidencia para distancia da hidrografia (gráfico 6) percebe-se que os pesos são negativos ate aproximadamente 500 metros, o que significa que a ocorrência do desmatamento seria menos provável nestas áreas. Acima deste limiar os pesos são positivos, o que indica que a probabilidade de ocorrer desmatamento é maior.

Este gráfico comprova a importância das Áreas de Preservação Permanentes (APP), pois a presença destas áreas de proteção em torno de rios e outros corpos hídricos, como por exemplo, nascentes, dificulta o avanço do desmatamento sobre estas áreas, devido à existência de leis e decretos que proíbe a supressão vegetal dentro das APPs.

Ao analisar o gráfico 7 percebe-se que a vegetação foi a variável que menos explicou a ocorrência de desmatamentos na área de estudo. Entre os intervalos de 10 e 12, que correspondem respectivamente a Floresta Ombrófila Densa Submontana com dossel emergente e Formação Pioneira com influência fluvial 
sem palmeiras são os dois tipos de vegetação que menos explicam a ocorrência de desmatamento, possuindo os menores pesos de evidencia.

Ao analisar o gráfico 8 (distancia para áreas de pastos), percebe-se que os pesos de evidencia são positivos ate a aproximadamente $600 \mathrm{~m}$ de áreas de pastagem, o que demonstra que em áreas próximas a pastos pré existentes é mais provável que ocorra o desmatamento, pois é mais fácil que uma área de pasto se expanda do que a abertura de novas áreas isoladas. Desta forma, nas áreas distantes os pesos de evidencia são negativos, o que corrobora este fato para o modelo, demonstrando que em áreas afastadas de pastos é menos provável que ocorra o desmatamento.

Pode-se concluir, a partir disso, que os intervalos de variáveis que mais contribuíram para ocorrência do desmatamento foram a distancia para áreas de pastos no intervalo de 0 a $200 \mathrm{~m}$, distancia para áreas de intensificação a pecuária no intervalo de 0 ate $1,5 \mathrm{Km}$ e distancia para áreas urbanas ate $5 \mathrm{Km}$. Os intervalos das variáveis que mais contribuíram para repelir o desmatamento foram a vegetação, a distancia para estradas acima de $3 \mathrm{Km}$, áreas protegidas no intervalo de 0 a $500 \mathrm{~m}$ e distância para áreas de intensificação a pecuária acima de aproximadamente $2 \mathrm{Km}$.

Para a simulação do modelo utilizou-se os dados de entrada (mapa reclassificado de 2010, o cubo de mapas que corresponde ao conjunto das variáveis utilizadas, os pesos ajustados e a matriz de transição) para configurar o modelo final (figura 17). Para esse modelo utilizou-se o funtor "Mux Categorical Map" que recebe o mapa inicial e armazena os mapas com as alterações de mudanças no uso de solo e probabilidade de mudança. Também foi usado o funtor "Calc Weights of Evidence Probability Map" que determina os mapas de probabilidade de mudança para cada intervalo de ano, indo de 2010 ate 2014.

Além disso, foi usado o "Allocate Transitions" que executa alocação de transições em um mapa de paisagem usando ao mesmo tempo os funtores "Expander" e "Patcher" de acordo com a matriz de transição, especificando as taxas líquidas, gerando um mapa de probabilidade e outro de paisagem com alterações na geometria das manchas das classes.

Figura 8 - Modelo para simulação da evolução do desmatamento na área de estudo.

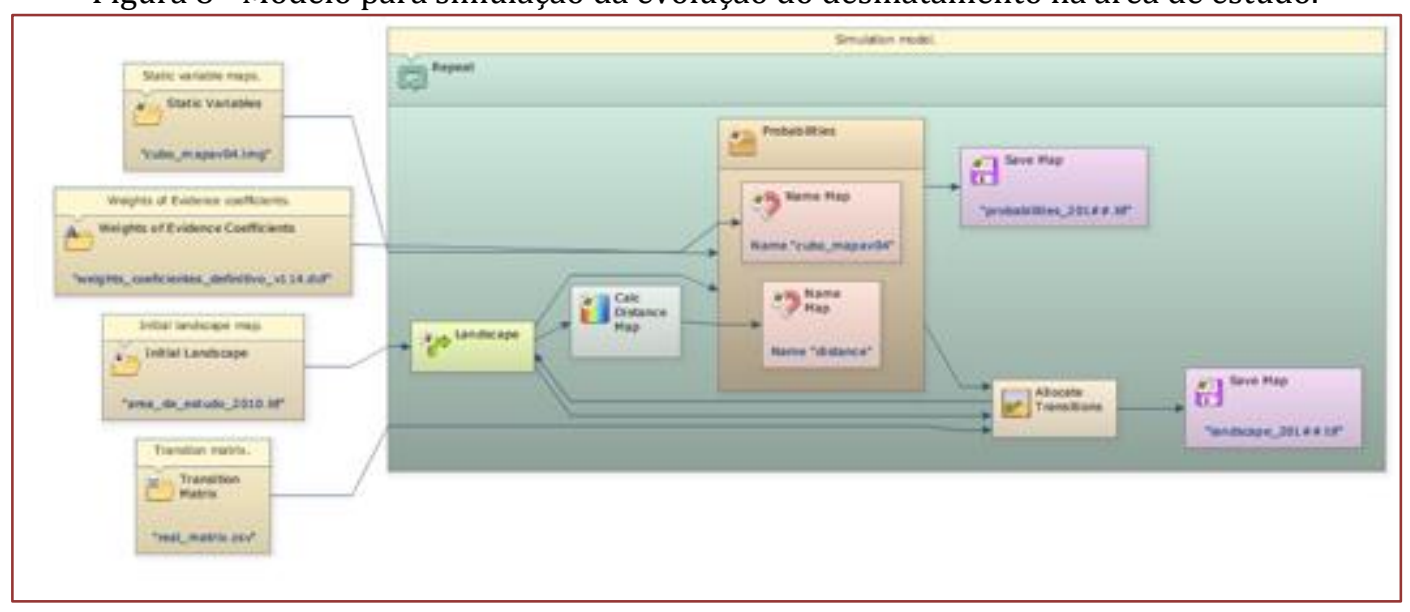

Para determinar os valores do tamanho médio da mancha de desmatamento, tamanho da variância da mancha e isometria da mancha, foi utilizado o functor "Calc Mean Patch Sizes And Standard Deviations". Este funtor analisa a diferença na estrutura da paisagem por meio das métricas das classes calculadas (métricas da paisagem) e, portanto retorna o valor médio do avanço da mancha de desmatamento em hectares e o desvio padrão do avanço da mancha. Para calcular a variância, o valor fornecido pelo funtor do desvio padrão foi elevado ao quadrado. 0 tamanho médio da mancha foi de 15,0488 ha, o tamanho da variância foi de 9.023 e a isometria utilizada foi de 1 .

Os mapas de probabilidade e paisagem para os anos de 2010 e 2014 demonstram que as áreas que possuem maior probabilidade de ocorrer desmatamento ou transição de floresta para pasto ocorrem nas bordas das áreas de pastagens como ilustrado pela figura 16, o que corrobora o fato de que o desmatamento para pastagens são mais prováveis de ocorrer em áreas já previamente ocupadas por outras pastagens. É mais provável observar um fenômeno de expansão das áreas de pasto do que ocorrer a abertura de novas fronteiras isoladas. 
Figura 9 - Mapas de probabilidade dos anos de 2010 e 2014

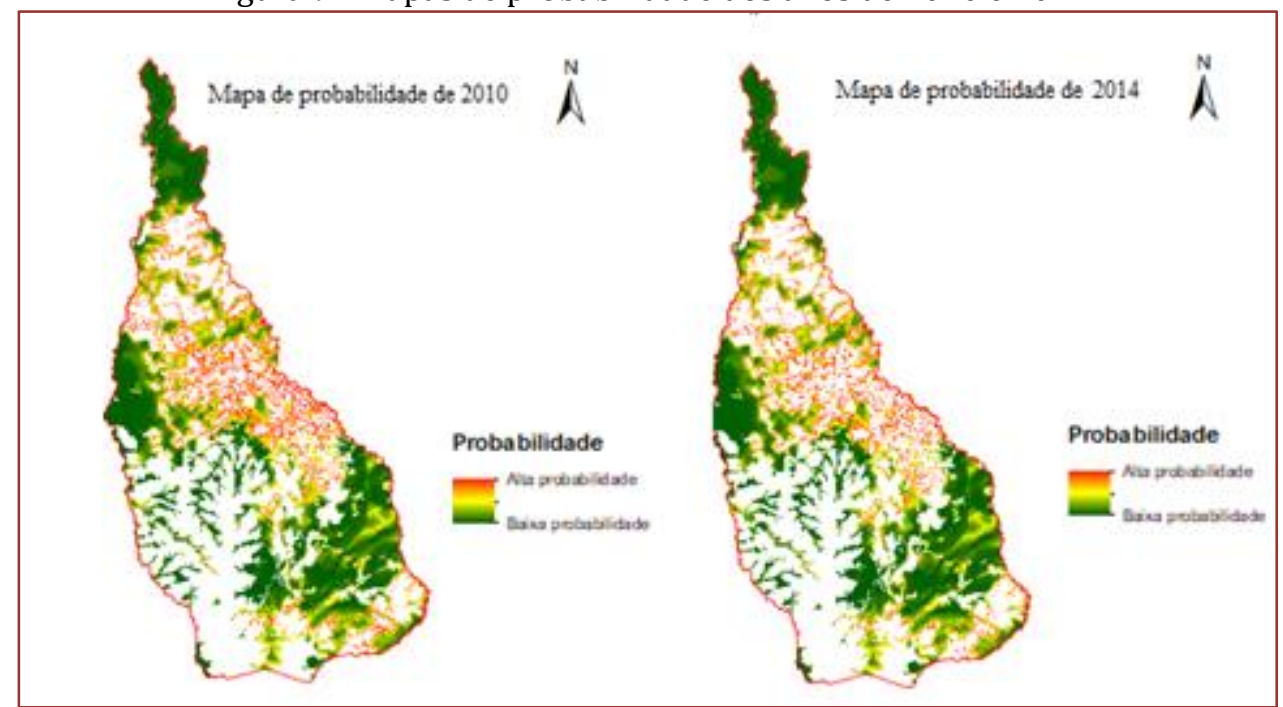

Figura 10 - Mapas de paisagem simulados dos anos 2010 e 2014

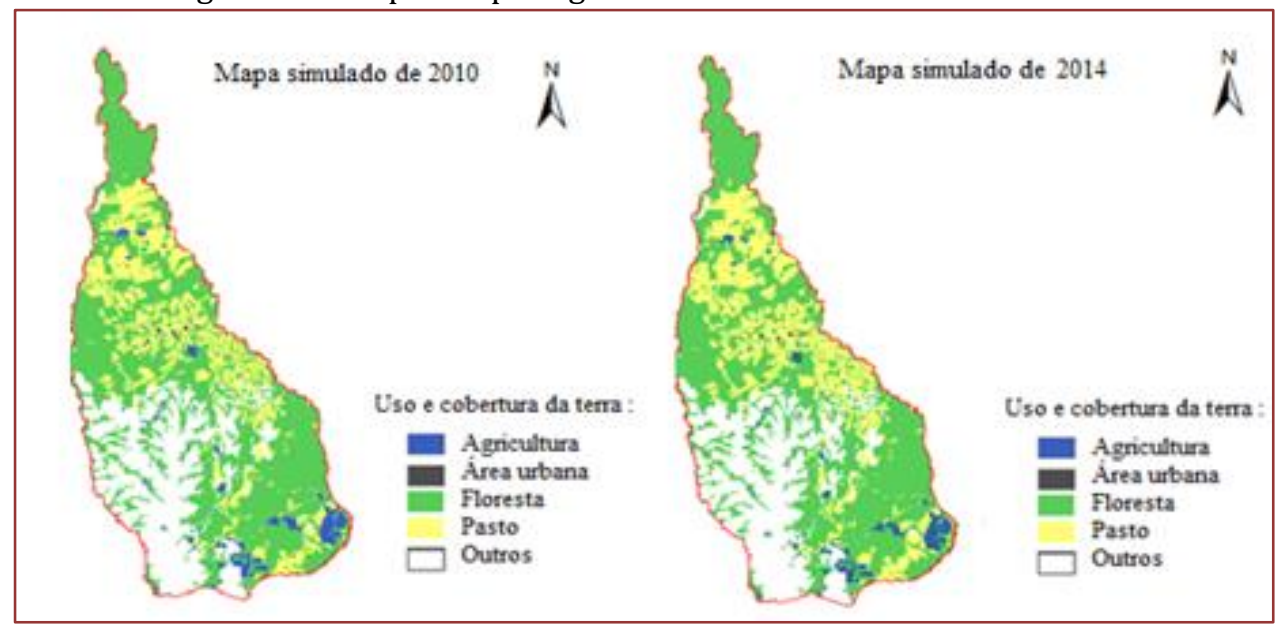

A validação do modelo foi feita a partir do funtor "Calc Mult Window Similarity Of Differences", que utiliza uma função de decaimento exponencial, que de acordo com Constanza (1989), realiza uma comparação entre mapas em tamanhos de janelas crescentes. Neste trabalho, a similaridade foi calculada utilizando como mapa inicial o mapa de uso e cobertura da terra de 2010 e foi realizada uma comparação entre o mapa simulado pelo modelo para ano de 2014 e a imagem de uso e cobertura da terra coletada do projeto TerraClass para o ano de 2014. Além disso, a similaridade foi verificada ate uma janela de $11 x 11$. É válido acrescentar que o trabalho considera como um bom resultado de validação por similaridade o valor utilizado por Delaneze (et al. 2014) igual ou acima de 0,5.

A Tabela 1 mostra que para janelas maiores os valores de máxima e mínima similaridade entre os mapas. Foi possível identificar que com uma janela de 11x11 a mínima similaridade de 0,14 e a máxima similaridade foi de 0,70 . Além disso, para verificar o quanto as variáveis utilizadas pelo modelo explicam a ocorrência de desmatamento de florestas para áreas de pastagem foi realizado um modelo nulo (sem as variáveis explicativas) utilizando os mesmos parâmetros de "patcher" e "expander" que o modelo anterior.

Para o modelo nulo foi dado a cada pixel o valor meio $(0,5)$ para assim criar um modelo aleatório, onde o desmatamento ocorre de forma aleatória. A validação por similaridade foi testada para o modelo nulo que retornou um valor de similaridade muito baixo, mesmo com uma janela de $11 \times 11$, como demonstrado pela tabela 2 . 
Tabela 1 - Similaridade, com múltiplas janelas, entre o mapa previsto e o mapa observado para 2014.

\begin{tabular}{|c|c|c|}
\multicolumn{3}{|c|}{ Similaridade do modelo com variáveis } \\
Janela & Similaridade Minima & Similaridade Máxima \\
\hline $1 \times 1$ & 0.069846 & 0.154924 \\
\hline $3 \times 3$ & 0.085606 & 0.308822 \\
\hline $5 \times 5$ & 0.100149 & 0.444180 \\
\hline $7 \times 7$ & 0.114282 & 0.551332 \\
\hline $9 \times 9$ & 0.127856 & 0.638967 \\
\hline $11 \times 11$ & 0.140436 & 0.708906 \\
\hline
\end{tabular}

Tabela 2 - Similaridade, com múltiplas janelas do modelo nulo.

\begin{tabular}{|c|c|c|}
\multicolumn{3}{|c|}{ Similaridade do modelo nulo } \\
Janela & Similaridade Minima & Similaridade Máxima \\
\hline $1 \times 1$ & 0.023808 & 0.052809 \\
\hline $3 \times 3$ & 0.035274 & 0.116135 \\
\hline $5 \times 5$ & 0.047110 & 0.182382 \\
\hline $7 \times 7$ & 0.060581 & 0.246201 \\
\hline $9 \times 9$ & 0.075375 & 0.305860 \\
\hline $11 \times 11$ & 0.090958 & 0.360327 \\
\hline
\end{tabular}

Através da análise das tabelas percebe-se que sem as variáveis o modelo perde grande parte de seu poder explicativo, pois enquanto a similaridade máxima do modelo com as variáveis foi de 0,70 , enquanto que a do modelo nulo foi de 0,36. Ao comparar os dois modelos (figura 18), observa-se, para uma janela de $11 \times 11$, que as variáveis utilizadas explicaram aproximadamente $34 \%$ da ocorrência de desmatamento na região estudada.

Figura 11 - Gráfico comparativo entre modelo com as variáveis e o modelo nulo

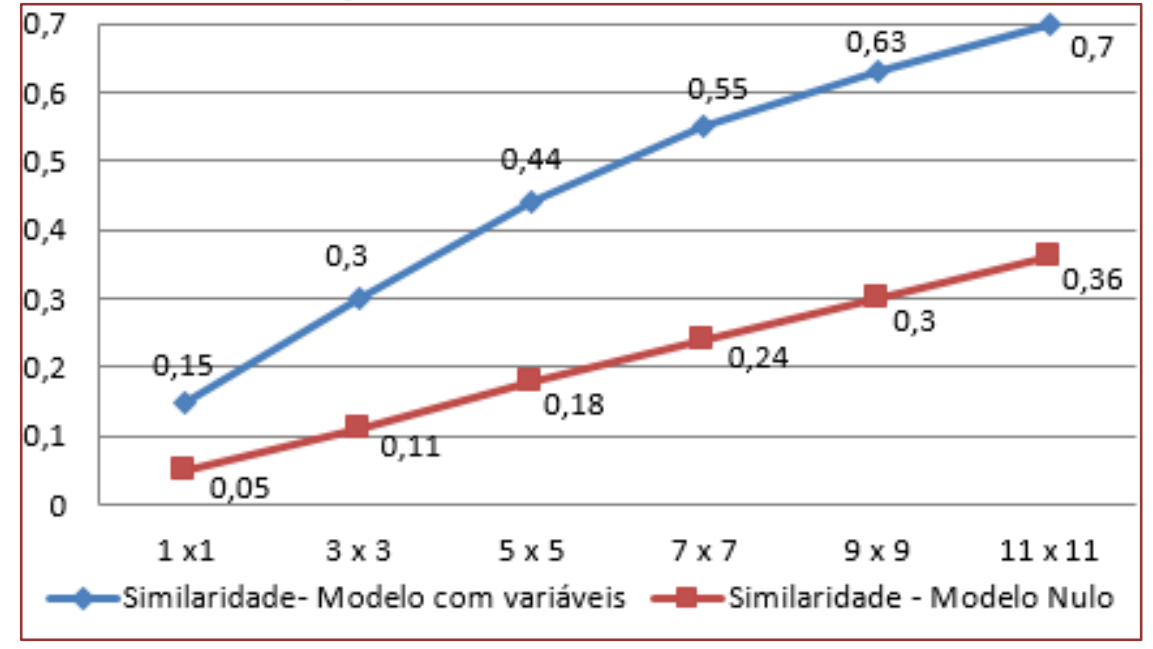

Depois de encontrar um resultado aceitável de validação o modelo foi utilizado para estimar a evolução do desmatamento para trinta anos. Os mesmos parâmetros foram aplicados a este modelo e por meio do funtor "For", repetimos o modelo 30 vezes, resultando em 30 mapas de 2004 a 2034. Na Figura 19 pode ser visto a evolução do desmatamento a cada 5 anos e a Tabela 3 apresenta a diminuição de floresta, de um total inicial de 873.976 hectares. 
Tabela 3 - Redução de florestas a cada 5 anos (Ha)

\begin{tabular}{|c|c|}
\hline Ano & Desmatamento (Ha) \\
\hline $2004-2009$ & 49.188 \\
\hline $2009-2014$ & 14.720 \\
\hline $2014-2020$ & 51.127 \\
\hline $2020-2025$ & 40.927 \\
\hline $2025-2030$ & 34.428 \\
\hline $2030-2034$ & 26.895 \\
\hline
\end{tabular}

Observando a Figura 19 verifica-se que a evolução do desmatamento na área de estudo ocorre próximo de áreas anteriormente ocupadas por pastagens, ou áreas previamente desmatadas.

Figura 12 - Avanço do desmatamento ao longo do tempo.

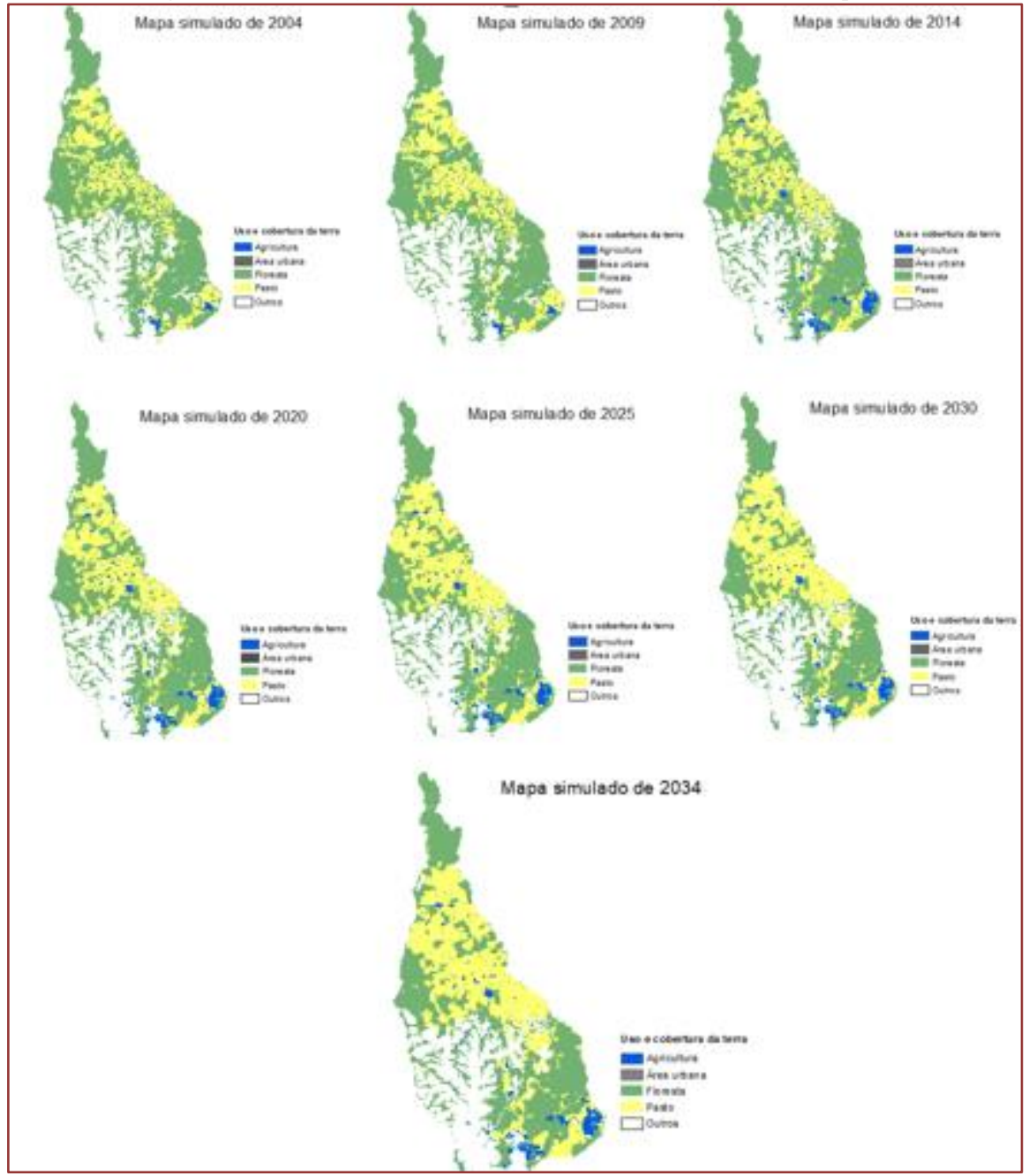

\section{CONCLUSÃO}

Conclui-se que o modelo possui um ajuste aceitável para modelar a evolução do desmatamento na área de estudo e as variáveis utilizadas explicam bem o processo de transição de florestas para pastos. Neste contexto, o desmatamento tem maiores chances de ocorrer principalmente em áreas próximas a pastagens e a estradas e com distancia acima de 1,5 Km de áreas preservadas. Com isso percebemos a influência dos pesos atribuídos as variáveis: distancia para áreas de pasto, distancia para áreas de intensificação pecuária, distancia para áreas preservadas e distancia para estradas. 
Verificou-se também que as áreas protegidas exercem papel fundamental para proteção e conservação das florestas, a biodiversidade e os serviços ecossistêmicos nelas existentes. A ocorrência de desmatamentos é muito menor em áreas próximas a unidades de conservação, já que o uso deste território é restrito, garantindo que as atividades antrópicas sejam limitadas nestas áreas.

\section{BIBLIOGRAFIA}

[1] Aguiar, A.P.D. Modelagem de mudanças de uso e cobertura do solo na Amazônia: Questões Gerais. In: Tutorial de Introdução à Modelagem Dinâmica Espacial. São José dos Campos: MCT/INPE. 2003.

[2] Atlas nacional do Brasil. Milton Santos/ IBGE, Diretoria de Geociências. Rio de Janeiro: IBGE, 2010.

[3] Barbosa et. al. Cenários para pecuária de corte amazônica. 1.ed. - Belo Horizonte : Ed: IGC/UFM, 2015. 146p.

[4] Bonham-Carter, G.F. Geographic Information Systems for Geoscientists: Modelling with GIS. New York, 1994 Pergamon/Elsevier, 398 p.

[5] Brasil. Ministério da Justiça. Fundação Nacional do Índio. Procedimentos para identificação de terras indígenas. Manual do Antropólogo-Coordenador, 1997. Disponível em: . Acesso em: 11 mar. 2011.

[6] Brasil. Ministério das Minas e Energia. Secretaria- Geral. Projeto Radambrasil. Folha SD.21 Cuiabá; geologia, geomorfologia, pedologia, vegetação e uso potencial da terra. Rio de Janeiro, 1982.

[7] Christofoletti, A. Modelagem de Sistemas Ambientais. São Paulo, Editora Edgard Blücher, 236p. 1999.

[8] Costanza, R., 1989. Model goodness of fit: a multiple resolution procedure. Ecol. Modelling, 47: 199--215.

[9] Delaneze, M. E.; Riedel, P. S.; Marques, M. L.; Ferreira, M. V.. Modelagem dinâmica espacial para o monitoramento do crescimento urbano no entorno do duto orbel. Revista Brasileira de Cartografia, Rio de Janeiro, N0 66/3, p. 473-484, Mai/Jun/2014.

[10] De Castro, César Nunes. A agropecuária na região Centro-Oeste: Limitações ao desenvolvimento e desafios futuros. Texto para Discussão, Instituto de Pesquisa Econômica Aplicada (IPEA), 2014.

[11] Cepea, Esalq. USP. Centro de Estudos em Economia Aplicada, 2018.

[12] Cidades, I.B.G.E. Disponível em: <

http://cidades.ibge.gov.br/xtras/perfil.php?lang=\&codmun=510792\&search=mato-grosso|Brasnorte> . Acesso em: Junho de 2019.

[13] Hagen, A. Fuzzy set approach to assessing similarity of categorical maps. International Journal of Geographical Information Science, 2003. Vol. 17, no 3 , 235-249, DOI: 10.1080/13658810210157822

[14] MAS,Jean-Francois; Kolb, Melanie, Paegelow, Martin,; Olmedo, Maria Teresa Camacho; Houet, Thomas. Inductive pattern-based land use/cover change models: A comparison of four software packages. Environmental Modelling and Software, Elsevier, 2014, pp.94-111. Disponível em <10.1016/j.envsoft.2013.09.010>. <hal-01187569>. Acesso em: 15 set. 2018.

[15] Lambin, Eric F.; GEIST, Helmut J. Land-use and land-cover change: local processes and global impacts. Springer Science \& Business Media, 2008.

[16] Lima et. al. Dinamica Ego e Land Change Modeler para simulação de desmatamento na Amazônia brasileira: análise comparativa. Anais XVI Simpósio Brasileiro de Sensoriamento Remoto - SBSR, Foz do Iguaçu, PR, Brasil, 13 a 18 de abril de 2013, INPE.

[17] Oliveira, Marianne Silva. Detecção de mudanças de uso e cobertura da terra no Sinclinal Moeda (MG) no período de 1991 a 2011 e previsões de mudanças futuras através de modelo espacial de simulação. Dissertação (Mestrado em Análise e Modelagem de Sistemas Ambientais) - Universidade Federal de Minas Gerais, Instituto de Geociências, 2012.

[18] Pnud - Programa das Nações Unidas Para o Desenvolvimento; Ipea -Instituto de Pesquisa Econômica e Aplicada; Fundação João Pinheiro. Atlas de desenvolvimento humano do Brasil de 2013. 2013. Disponível em:< http://atlasbrasil.org.br/2013/pt/perfil_m>. Acesso em: maio de 2019.

[19] Projeto MapBiomas - Coleção 3.1 da Série Anual de Mapas de Cobertura e Uso de Solo do Brasil, acessado em 15 jun. 19 através do link: http://mapbiomas.org

[20] Sawyer, Donald R. Ocupación y desocupación de la frontera agrícola en el Brasil: un ensayo de interpretación estructural y espacial. In: Expansión de la frontera agropecuaria y medio ambiente de América Latina. Centro Internacional de Formación en Ciencias Ambientales, CIFCA, 1983.

[21] Rivero, S.; Almeida, O.; Ávila, S.; Oliveira, W. Pecuária e desmatamento: uma análise das principais causas diretas do desmatamento na Amazônia. Nova Economia, v. 19, n. 1, 26 jan. 2011. 
[22] Soares-Filho, B. S., Rodrigues, H. O. , Costa, W.L. Modeling Environmental Dynamics with Dinamica Ego. 2 ed (2010). Belo Horizonte, 2009.120 p.

[23] Soares-Filho, B. S.; Cerqueira, G. C.; Pennachin, C. L. Dinamica - a stochastic cellular automata model designed to simulate the landscape dynamics in an Amazonian colonization frontier. Ecological Modelling, v. 154, p. 217-235. 2002.

[24] Soares-Filho, B. S.a; Garcia, R. A.; Rodrigues, H.; Moro, S.; Nepstad, D. Nexos entre as dimensões socioeconômicas e o desmatamento: A caminho de um modelo integrado. In: Batistella, Mateus; Alves, Diogenes; Moran, Emilio. (Org.). Amazônia. Natureza e Sociedade em Transformação. São Paulo, 2008, v. 1. Soares-Filho, B. S; Rodrigues, H; Follador, M. A hybrid analytical-heuristic method for calibrating land-use change models. Environmental Modelling \& Software. V. 43, May 2013, P. 80-87

[25] Soares-Filho, B.S.; Alencar, A.A.; Nepstad, D.C.; Cerqueira, G.C.; Diaz, M. Del C.V.; Rivero, S.; Solórzano, L.; Voll, E. Simulating the response of land-cover changes to road paving and governance along a major Amazon highway: The Santarém Cuiabá corridor. Global Change Biology 10(5): 745-764, 2004. 


\section{Capítulo 12}

\section{Adoção do selo verde em uma empresa do setor agrícola: Barreira ou oportunidade estratégica?}

\section{Thábata Fernandes Precrimo}

Márcia Thelma Rios Donato Marino

\section{Matheus Cordeiro Façanha}

Leonardo Holanda Lima

Suellen Galvão Moraes

Resumo: Este estudo realizou uma análise qualitativa das ações e medidas que a empresa Itaueira Agropecuária S/A adota em seus processos produtivos, destacando a obtenção de Certificações Ambientais e a utilização de Selos Verdes em seus rótulos. Para esta avaliação, a empresa foi escolhida por estar em uma área com limitações na obtenção dos recursos naturais. Atualmente, observa-se a crescente demanda de produtos ecologicamente corretos por parte da sociedade e dos governos e organizações não governamentais, o que melhora a qualidade ambiental à medida que os processos produtivos são acompanhados e passam por melhorias. Para a análise das boas práticas da empresa, foi realizada uma visita técnica, a fim de observar como o Sistema de Gestão Ambiental que a Empresa possui melhora as relações entre o homem e o meio ambiente. Foram analisados os aspectos sob o ponto de vista social, ambiental e econômico, e como preenchem critérios de gestão responsável, levando em consideração as atitudes sustentáveis aplicadas. Concluiu-se, assim, que a busca por Certificações Ambientais e Selos Verdes pela Itaueira, como forma de comprovação oficial de que as ações de sustentabilidade da mesma seguiram melhorando ano após ano, é fundamental para alavancar os resultados financeiros da empresa, e destacá-la em comparação a seus concorrentes no mercado de frutas. Isso traz benefícios não somente à região a qual está localizada, mas também aos trabalhadores e colaboradores e ao meio ambiente. É uma excelente oportunidade estratégica para garantir sua competitividade e sobrevivência.

Palavras-chave: Certificação ambiental, Selo verde, Setor agrícola, Sustentabilidade empresarial. 


\section{INTRODUÇÃO}

Sabe-se que, por muitas décadas, o meio ambiente foi visto e utilizado como fonte inesgotável de muitos recursos os quais necessitamos diariamente. Essa visão, ainda que equivocada, esteve presente no dia a dia da sociedade, retratando o consumo desenfreado de matérias primas, tanto por parte da população, como também da iniciativa pública e da iniciativa privada.

No período da revolução industrial, muitas mudanças em relação à qualidade do meio ambiente foram sendo percebidas, devido à produção em larga escala e ao incentivo do consumo. A partir dessa percepção, começaram a surgir movimentos em todo o mundo em prol da preservação ambiental. Essa demanda pela preservação do meio ambiente, atrelada à intrínseca relação da qualidade de vida da população, é fator alarmante e gera uma preocupação maior por parte das organizações públicas e privadas. Junto a isso, fezse necessária a padronização de algumas atividades empresariais para destacar as boas práticas na conservação dos recursos naturais.

A gestão ambiental nas empresas surgiu a partir da necessidade de uma postura correta em relação às práticas exercidas pelas mesmas, gerada graças à pressão por parte da sociedade, governo e organizações não governamentais, que, buscando o equilíbrio entre a produção e as ações antrópicas, exerceram no mercado o que chamamos de consciência verde. Assim, surgiram as Certificações Ambientais para estabelecer, em escala global, índices, padrões e conceitos ambientais aplicados aos processos de produção. Dentre as vantagens que as certificações trazem ao empreendimento, vale destacar a possibilidade da utilização de Selos Verdes, que atestam a qualidade ambiental do produto junto à população em geral.

Dentro da contextualização abordada, o estudo apresenta como objetivo geral analisar os impactos do Selo Verde em uma empresa brasileira do setor agrícola.

\section{METODOLOGIA}

Este estudo se trata de uma pesquisa do tipo qualitativa, de caráter interdisciplinar aplicado, pautada na abordagem descritiva e exploratória. A pesquisa foi desenvolvida a partir da análise de práticas caracterizadas por procedimentos de investigação da avaliação da qualidade dos parâmetros e relatórios da empresa investigada, de acordo com as diretrizes socioambientais adotadas para implantação do Selo Verde, tais como: produção sustentável, irrigação, manutenção, sistema de gestão ambiental, treinamento aos trabalhadores, controle ambiental e impactos socioeconômicos. Objetivando conhecer as medidas adotadas para a obtenção dos Selos Verdes e os impactos que estes trazem aos consumidores, trabalhadores, sociedade, meio ambiente e à economia empresarial, foi realizada uma visita técnica à sede da Empresa. Para a significativa análise qualitativa foram feitas comparações das atitudes da Empresa com outras empresas e estudos que abordam as práticas ambientais empresariais, mostrando a relação que há entre o meio ambiente, economia e sociedade, e a verificação se a adoção do Selo Verde na Empresa se apresenta como uma barreira ou oportunidade estratégica frente aos resultados esperados em uma região com limitações.

\section{RESULTADOS E DISCUSSÃO}

A Itaueira Agropecuária S/A foi fundada em 1983, com especialidade na produção de frutas frescas, como melão e melancia. Buscando avaliar os benefícios que esta Empresa traz, tanto no segmento alimentício, quanto social, ambiental e econômico, fez-se uma pesquisa com base nos Selos Verdes que os produtos e processos possuem. É imprescindível destacar que essa indústria alimentícia possui certificações que visam o bem-estar social, a preservação do meio ambiente, a qualidade dos seus produtos e processos. Mostrando a sua preocupação com a preservação do meio ambiente, com a saúde dos trabalhadores, com os consumidores e com a satisfação dos seus clientes, a Itaueira possui certificações que atendem aos padrões de sustentabilidade: Global G.A.P. (Figura 01); RainForest Alliance (Figura 02) e Garantia de Origem Carrefour (Figura 03). 
Figura 01 - Certificação Ambiental Global G.A.P.
Figura 02 - Selo Verde RainForest Alliance.

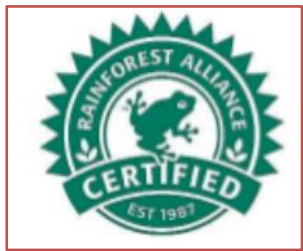

Figura 03 - Selo Verde Garantia de Origem Carrefour.

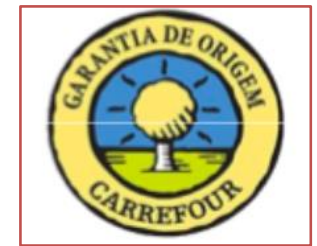

Fonte: Itaueira, 2016.

Possuir certificações ambientais, segundo Gianoni (2015), demonstra que a empresa se enquadra em ações de sustentabilidade e adquirem um diferencial competitivo para o produto, assim gerando benefícios econômicos para a organização.

No ano de 1997, foi lançado pelo Euro-Retailer Produce Working Group (EUREP), o referencial EurepG.A.P. (GAP - Good Agriculture Practices) que garante aos consumidores dessas redes de supermercado europeias, cada vez mais globalizadas, a qualidade e segurança dos produtos (Figura 01). Com isso, o desenvolvimento de uma certificação, além de interesse dos consumidores, mostra-se de grande interesse dos produtores, recebendo o produto uma aceitação mais generalizada. Assim, produtores de todo o mundo passaram a aderir ao conceito do EurepG.A.P., focando nas BPA - Boas Práticas Agrícolas (BORGER; SILVA, 2011).

Com a grande aceitação, ao final do ano de 2007, de acordo com Borger e Silva (2011), a marca Eurep G.A.P. foi alterada para Global G.A.P. e passou a ser uma solicitação não somente dos supermercadistas europeus, mas de vários outros países fora do continente. A organização privada reafirmava perante os consumidores que a produção agrícola daquelas fazendas certificadas era realizada com a minimização dos impactos negativos ao meio ambiente, com redução no uso de produtos químicos, estando diretamente relacionado à saúde, segurança e bem-estar dos trabalhadores e consumidores. É uma certificação que abrange a produção em sua totalidade, desde uso de água e fertilizantes, passando por todas as atividades agrícolas até a saída do produto embalado. Apesar de ser uma certificação voluntária, ela é obrigatória quando a empresa pretende exportar o produto para Europa, como exigência dos Governos, importadores e também da população, que exerce a consciência verde por meio do consumo de produtos que tem origem garantida e produção sustentável.

A certificação Global G. A. P. se baseia nas Boas Práticas Agrícolas (BPA) e nas Boas Práticas de Fabricação (BPF), sendo uma marca comercial baseada nos conceitos de segurança alimentar; proteção do ambiente; condições de saúde, higiene e segurança dos trabalhadores; e bem-estar animal (quando aplicável). De acordo com a empresa brasileira In Solo, os benefícios da Certificação Global G.A.P. abrangem, além de transparência da cadeia produtiva alimentar e benefícios ao meio ambiente, a redução nos custos e redução dos riscos de segurança alimentar.

RainForest Alliance foi criada em 1987, esta é uma certificação da Rede de Agricultura Sustentável (RAS) que apoia o produtor na melhoria contínua de gestão, aumento da eficiência, cumprimento da legislação ambiental e trabalhista vigente, elevação da produtividade, preservação dos recursos naturais e garantia dos direitos dos trabalhadores. Aplicada em fazendas de todos os tamanhos e locais do mundo, a RAS permite certificar todas as culturas agrícolas (Figura 02). Essa certificação concede aos produtores a utilização de um Selo Verde e possibilita ao produtor o acesso a um mercado diferente, tanto nacional como internacional. Definindo práticas agrícolas sustentáveis, a RainForest Alliance, visa a redução dos impactos ambientais causados por atividades antrópicas em seus empreendimentos, estabelecendo normas de gestão que beneficiam a sociedade, os trabalhadores, o meio ambiente e alavancam a economia da empresa (RAINFOREST ALLIANCE, 2016). No Brasil, a certificação chegou em 2003, e a primeira empresa nacional que exporta melão a aderir ao selo verde da RainForest Alliance foi a empresa Itaueira Agropecuária S/A, em 2016.

A Empresa visa, além das melhorias contínuas nos processos conservando o ambiente e a melhoria na saúde e das condições de vida dos trabalhadores, melhorar sua integração e convívio social com as comunidades locais e a alavancagem da sua situação econômico-financeira, e ganho de mercado, tanto interno quanto externo, principalmente na Alemanha e nos Estados Unidos da América. Esta certificação 
estimula os empresários a produzirem de maneira mais consciente, ambiental e socialmente, agregando valor ao produto com este Selo.

Em um estudo produzido por Marçal e Guimarães (2014), foram verificados os benefícios que a Certificação RainForest Alliance trouxe para alguns empreendimentos, citando principalmente a preservação e recuperação dos ecossistemas, treinamentos para os colaboradores, manejo de resíduos por meio da coleta seletiva e reciclagem, infraestrutura, destinação adequada de efluentes, entre outras medidas na área social, confirmados na seguinte citação: "Os resultados confirmam a importância da Certificação RAS para promover a conservação da biodiversidade e o desenvolvimento humano a curto e em longo prazo, atendendo as exigências dos consumidores que optam pelos produtos que possuem o selo Rainforest Alliance Certified". (MARÇAL; GUIMARÃES, 2014, p.19).

Criado em 1992, na França, de acordo com as informações registradas no sítio eletrônico Carrefour (2016), o programa de Garantia de Origem assegura uma produção ambientalmente correta e socialmente justa (Figura 03). Quando chegou ao Brasil, em 1999, conseguiu arregimentar muitos produtores que almejavam aumentar sua participação no mercado e garantir, ao consumidor, que o produto que chegaria à sua mesa teria um diferencial de qualidade. Os princípios dessa certificação vão além da qualidade do produto, sabor e preço justo, abrangem também a autenticidade, a segurança do alimento e o desenvolvimento sustentável. Concede ao produtor o direito de utilizar o Selo Verde GO em seu produto, garantindo que a produção obedeceu rigorosamente à todos os conceitos de qualidade, responsabilidade ambiental e social que a Certificação exige, tais como: o uso de produtos biológicos para controle de pragas e doenças; a rastreabilidade do processo de produção, desde a criação do produto até o consumo final; aumentar as oportunidade para os colaboradores e às comunidades; elevar o patamar para o de uma produção consciente (CARREFOUR, 2016).

Segundo Castro e Ferraz (2010), o Selo de Garantia de Origem Carrefour assegura que as empresas, para fornecer um produto de qualidade, devem preservar as matas e os rios, obedecer às legislações ambientais, valorizar a biodiversidade da região em que a empresa está localizada, dar tratamento adequado dos resíduos gerados, usar a água de forma racional e oferecer boas condições trabalhistas. A extensão do programa Garantia de Origem (GO) vai além das fronteiras brasileiras, de acordo com Zylbersztajn et al. (2008, p.5): "Realizar parcerias e distribuir produtos GO em um país com a extensão do Brasil é um grande desafio, tanto quanto informar o consumidor brasileiro e motivá-lo a valorizar atributos que já historicamente são valorizados e compreendidos em países desenvolvidos". As empresas que adquirem a Certificação da Garantia de Origem Carrefour têm a garantia ao acesso a novos nichos de mercado, diferenciando os seus produtos ao agregar valor a partir da Certificação.

\section{CONCLUSÃO}

O resultado do trabalho evidenciou que as medidas e ações de sustentabilidade na Empresa pesquisada trouxeram redução de custos, formalização de processos, um melhor controle e cuidado com o meio ambiente, destacando o equilíbrio que há entre o poder produtivo e a preocupação com as ações antrópicas. Conclui-se ainda que a busca da Empresa pelas Certificações Ambientais visava, inicialmente, garantir suas exportações para países da Europa, além dos Estados Unidos da América, Canadá, Argentina e Chile, mas hoje visa também oferecer um diferencial para suas vendas no mercado interno e a expansão de sua área de atuação no mercado externo, alavancando a economia da Empresa, da região e do país. Como consequência, a obtenção dos Selos Verdes, além de atestar o comprometimento da Empresa com o meio ambiente, proporciona também benefícios sociais para os trabalhadores, consumidores e sociedade como um todo.

Os resultados do estudo demonstram que com a implantação de um SGA e a obtenção das Certificações Ambientais e Selos Verdes, a Empresa consegue criar uma imagem ambiental forte, padronizando seus processos produtivos e realizando treinamentos constantes para a conscientização dos funcionários e população local. 0 investimento feito na gestão ambiental tem garantido ganhos em relação ao consumo de recursos, bem como a sua preservação, e conquista de mercados. Fica explícito que a utilização dos Selos Verdes contribui para o desenvolvimento sustentável. Em relação ao social, a Empresa possui projetos com resultados significativos, tanto em relação aos trabalhadores como à inclusão da sociedade no empreendimento. É indiscutível que os impactos que os Selos Verdes têm sobre os produtos e processos de produção são considerados como oportunidade estratégica para a Empresa em questão, melhorando seus resultados financeiros e de penetração no mercado, o grau de satisfação dos consumidores e trazendo benefícios em todos os âmbitos da sustentabilidade. 


\section{REFERÊNCIAS}

[1] BORGER, I.; SILVA, R. GlobalGAP: um sistema de certificação para a garantia das boas práticas agrícolas.

[2] Agrotec: Revista Técnico-Científica Agrícola, Portugal, n. 1, 2011.

[3] CARREFOUR. Certificações. Disponível em:

<https://www.carrefour.com.br/institucional/produtoscarrefour/garantia-de-origem>. Acesso em: 9 nov. 2016.

[4] CASTRO, M. C. D.; FERRAZ, F. T. Gestão integrada de modelos sustentáveis do agronegócio - 0 programa de garantia de origem. Niterói, 2010.

[5] GIANONI, M. A importância da certificação ambiental para seu negócio. Disponível em: <http://www.responsabilidadesocial.com/artigo/a-importancia-da-certificacao-ambiental-para-seu-negocio/>. Acesso em: 12 nov. 2016.

[6] ITAUEIRA. Certificações. Disponível em:

<http://www.itaueira.com.br/portugues/quemsomos?p=Certificacoes>. Acesso em: 31 out. 2016.

[7] MARÇAL S. M.; GUIMARÃES, A. R. Impactos socioambientais da certificação RainForest Alliance em fazendas produtoras de café no Triângulo Mineiro. Minas Gerais, 2014.

[8] RAINFOREST-ALLIANCE. Certifications. Disponível em: <http://www.rainforest-alliance.org/>. Acesso em: 9 nov. 2016.

[9] ZYLBERSZTAJN, D.; SPERS, E. E.; CUNHA, C. F. da. Expansão do conceito de sustentabilidade na cadeia de valor. Estudo de Caso Carrefour. Fundação Instituto de Administração. São Paulo: USP, 2008. 


\title{
Capítulo 13
}

Telhado verde: Uma proposta de utilização no Colégio Militar do Recife a partir da vivencia do Arco de Charles Maguerez

\author{
Brenda Silva dos Santos \\ Bruna Oliveira Bezerra \\ João Pedro Valuche de Andrade Pereira \\ José Henrique Nóbrega Albuquerque \\ Matheus Almeida de Sena \\ Pedro Soares de Lima Filho \\ Ana Paula Costa de Abreu e Melo
}

Resumo: Os processos de urbanização causam fortes impactos ambientais nas cidades por substituição da paisagem natural pelas edificações, redução da vegetação, impermeabilização do solo e poluição do ar. Esses fatores influenciam na elevação da temperatura ambiente e desconforto térmico dos habitantes, fenômeno denominado ilha de calor urbano. 0 objetivo deste estudo foi apresentar uma solução sustentável que combatesse o efeito do calor nas salas de aula do Colégio Militar do Recife-CMR e reduzisse as despesas com energia elétrica, por meio de implantação de telhados verdes. A proposta foi desenvolvida à luz da metodologia do Arco de Maguerez, que consiste na observação da realidade, permitindo a identificação de problemas e seus pontos chaves, seguida de teorização a fim de levantar hipóteses de solução para intervir na realidade. 0 telhado verde é a introdução de solo e vegetação sobre uma camada impermeabilizada das construções, neste caso, o telhado do Colégio. Além de embelezar áreas construídas ociosas, possuem características que melhoram a qualidade de vida das pessoas que frequentam o ambiente e reverbera também em seus arredores, reduzindo o calor e os alagamentos decorrentes das chuvas. A pesquisa incluiu um projeto para implantação do telhado verde no CMR. Este foi apresentado com maquete para visualização tridimensional; expositor de camadas do telhado e planilha de custo de implantação. Para viabilizar a implantação, o telhado verde terá uma horta, um novo espaço de convivência/ensino e áreas gramadas, que gerarão economia tanto no consumo de energia, quanto na compra de alimentos, trazendo conforto térmico e bemestar.

Palavras-chave: Sustentabilidade; Ilhas de calor; Paisagismo. 


\section{INTRODUÇÃO}

A humanidade vem diminuindo os recursos naturais com celeridade e a indústria da construção civil configura uma das maiores responsáveis por esta ação (Dilly, 2016). Os processos de urbanização causam fortes impactos ambientais, em decorrência da substituição da paisagem natural por numerosas edificações e superfícies pavimentadas, redução de áreas verdes, impermeabilização do solo e da poluição do ar, fatores que corroboram para a elevação da temperatura e desconforto térmico dos habitantes (Santos et al. 2013).

Nóbrega e Vidal (2010) ressaltam que o fenômeno da ilha de calor urbana (espaços com maiores concentrações de altas temperaturas), ocorre geralmente no centro das cidades, onde as construções formam um conjunto denso e compacto, denominados Cânions Urbanos. Essencialmente, as ilhas de calor são causadas pelos seguintes fatores: poluição do ar (quando algumas partículas em suspensão, como gases e aerossóis, modificam o balanço de energia, trazendo uma elevação do efeito estufa e o calor da região), fontes antrópicas de calor (à medida que o homem foi expandindo o meio urbano, ele também desenvolveu técnicas, como a combustão de combustíveis fósseis e utilização de equipamentos elétricos, que contribuem para mais gasto de energia e geram mais calor), tipo de cobertura da superfície (o modo, em que a superfície é utilizada, também, diz muito a respeito do aumento do calor, por exemplo, uma área asfaltada absorve mais quantidade de energia e reflete menos do que um local que possui cobertura vegetal) e distribuição da verticalização urbana (A estrutura dos edifícios que é vertical e irregular afeta nos fluxos de vento de ar, e também agem como labirinto para a radiação solar que acaba aprisionada, aumentando a temperatura).

A cidade de Recife possui em seus bairros centrais um pesado tráfego de veículos, grandes áreas de pavimentação do solo e de construções verticais, além pobre arborização, aspectos esses que apontam para a importância de estudos que gerem conhecimento sobre os processos de ilhas de calor que estão ocorrendo e suas consequências. A população crescente, hoje, também é um vilão da crise ambiental, pois quanto mais pessoas em uma cidade maiores os seus problemas em relação ao meio ambiente e consequentemente à saúde pública (Nóbrega e Vidal, 2010). Portanto, evidencia-se a necessidade de ampliar os estudos que busquem analisar o processo de formação de ilhas de calor, atrelado às políticas públicas e a produção dos espaços urbanos, pela importância de regular o desenvolvimento ambiental da cidade, e garantir a qualidade de vida e a saúde dos ambientes (Nobrega; Santos; Moreira, 2016).

Nóbrega, Santos e Moreira (2016), em um estudo sobre a morfologia urbana e ilhas de calor na cidade do Recife referem que a configuração urbana da cidade, uma Metrópole regional, tem uma expressiva contribuição na formação de ilhas de calor, principalmente pelo maior predomínio de construções verticais na faixa litorânea, fator que influencia diretamente na elevação da temperatura tanto no período diurno quanto no período noturno. Este estudo, com ênfase na interação entre as modificações exercidas no espaço e a atmosfera, analisou a distribuição espacial na cidade do Recife e a intensidade das ilhas de calor relacionando-as com as características da morfologia urbana. De forma comparativa foram utilizados dados de temperatura do ar, de áreas distintas da cidade, sendo possível identificar que áreas de baixa densidade urbana e com presença de vegetação podem promover na diminuição das ilhas de calor.

As práticas sustentáveis na construção civil têm como objetivo criar novas técnicas construtivas, visando a utilização de materiais alternativos, diminuindo, assim, os impactos ambientais adversos oriundos das técnicas construtivas tradicionais (Alberto et al., 2012).Essas práticas existem para direcionar e influenciar os projetos quanto a materiais, tecnologias e sistemas para que se sejam ecologicamente corretos, socialmente justos e economicamente viáveis. Neste cenário, o telhado verde aparece como um recurso de extrema expressão, ou até mesmo solução para os projetos com ênfase nos conceitos de desenvolvimento sustentável (Dilly, 2016).

O telhado verde pode ser configurado como um sistema sustentável, sobretudo em decorrência da sua vegetação, substrato e camada drenante. Essas características podem colaborar no gerenciamento absorção de parte das águas pluviais no próprio sistema, além de auxiliar na minimização dos efeitos de ilhas de calor, diminuindo as temperaturas em seu entorno e viabilizando a melhor circulação de ar nas cidades. 
No sistema de telhado verde, que também funciona como um excelente isolante térmico, a temperatura também pode ser mais facilmente controlada, não permitindo o calor adentrar na edificação no período de verão e mantendo o calor durante o inverno; e esta função reduz os gastos com energia. Alguns países, inclusive o Brasil, já consideram o uso do telhado verde de extrema relevância (Dilly, 2016). Entretanto, os incentivos para a implantação de telhado verde ainda seguem lentos em âmbito nacional, mas estão aumentando gradativamente e devem seguir com os estímulos, não apenas por ser um solucionador dos problemas urbanos, mas também como tecnologias que contribuem para sustentabilidade, assim compondo um mundo mais harmônico entre natureza e homem (Nascimento et al., 2018).

Em âmbito nacional, as políticas públicas com ênfase na implantação de telhados verdes ocorreram no final da primeira década do século XXI, conforme Tabela 01 (Setta, 2017).

Tabela 1: Políticas públicas de telhados verdes implantadas no Brasil.

\begin{tabular}{|c|c|}
\hline SANTA CATARINA & $\begin{array}{l}\text { A Lei Estadual no } 14.243 / 2007 \text { criou o Programa Estadual de Incentivo à Adoção de } \\
\text { Telhados Verdes em espaços urbanos densamente povoados, que definiu em seu art. } \\
2^{\circ} \text { que para fazer parte do programa, a implantação dos sistemas vegetados não } \\
\text { poderia ser inferior a } 40 \% \text { da área total do imóvel, responsabilizando o Poder } \\
\text { Executivo, no art. } 3 \% \text {, a criar parcerias, incentivos fiscais e financeiros aos municípios } \\
\text { partícipes do Programa. }\end{array}$ \\
\hline SÃO PAULO (SP) & $\begin{array}{l}\text { Aprovado o projeto lei } \mathrm{n}^{\circ} 115 / 09 \text {, extensivo a todos os prédios com mais de três } \\
\text { andares, porém, e até o presente momento, este não voltou a ser apreciado pelos } \\
\text { parlamentares. }\end{array}$ \\
\hline RIO DE JANEIRO & $\begin{array}{l}\text { A Lei Estadual no } 6.349 / 2012 \text { torna a obrigatoriedade de instalação de telhados verdes } \\
\text { nos prédios públicos, autarquias e fundações do Estado do Rio de Janeiro, para prédios } \\
\text { que fossem projetados a partir da promulgação da lei. }\end{array}$ \\
\hline NITEROI (RJ) & $\begin{array}{l}\text { Aprovado o projeto de Lei no } 090 / 2013 \text { que dispõe sobre a instalação de telhados } \\
\text { verdes em projetos de edificações residenciais ou não, que tiverem mais de três } \\
\text { andares agrupados verticalmente, e os respectivos incentivos fiscais e financeiros aos } \\
\text { que adotarem o telhado verde. }\end{array}$ \\
\hline RECIFE (PE) & $\begin{array}{l}\text { Foi aprovada a lei } n^{\circ} 18.112 / 15 \text {, que exige aos projetos de edificações habitacionais } \\
\text { multifamiliares com mais de quatro pavimentos e não habitacionais com mais de } \\
400 \mathrm{~m}^{2} \text { de área de coberta, a implantação de "Telhado Verde" para sua aprovação. }\end{array}$ \\
\hline PARAÍBA & $\begin{array}{l}\text { Lei Estadual, } \mathrm{n}^{\circ} 10.047 / 13 \text {, dispõe a obrigatoriedade aos projetos de condomínios } \\
\text { edificados, residenciais ou não, com mais de } 3 \text { (três) unidades agrupadas } \\
\text { verticalmente, a implantação de telhados verdes. }\end{array}$ \\
\hline
\end{tabular}

Fonte: SETTA, 2017.

Aderindo a esta ideia sustentável, a Cidade do Recife sancionou em 13 de Abril de 2015 a Lei Municipal $n^{\circ}$ 18.112/15, mais conhecida como Lei Telhado verde, que prevê o plantio de gramas, hortaliças, arbustos e árvores de pequeno porte em todas as coberturas pertencentes aos edifícios residenciais com mais de 04 pavimentos e coberta.

A Lei também se aplica às edificações não-habitacionais com mais de $400 \mathrm{~m}^{2}$ de área coberta, e vale apenas para as novas construções, porém a Prefeitura da Cidade do Recife prevê uma política motivacional para que instalações mais antigas possam se adequar à proposta.

Art. 1ำ Os projetos de edificações habitacionais multifamiliares com mais de quatro pavimentos e nãohabitacionais com mais de $400 \mathrm{~m}^{2}$ de área de coberta deverão prever a implantação de "Telhado Verde" para sua aprovação, da seguinte forma:

I - no pavimento descoberto destinado a estacionamento de veículo das edificações, cuja área não se contabilizará para efeito de área construída, desde que:

a) não sejam cobertas as áreas de solo permeável;

b) sejam respeitados os afastamentos legais previstos para os imóveis vizinhos;

c) seja respeitado um afastamento mínimo de $1 \mathrm{~m}$ (um metro) e máximo de $3 \mathrm{~m}$ (três metros) em relação à lâmina do pavimento tipo ou qualquer outro pavimento coberto; 
II - exclusivamente para os edifícios multifamiliares descritos no caput, nas áreas de lazer situadas em lajes de Piso, no percentual de 60\% (sessenta por cento), e nas áreas de lazer em pavimento de coberta, em pelo menos, 30\% (trinta por cento) de sua superfície descoberta.

§ 1ํ Para os fins desta Lei, "Telhado Verde" é uma camada de vegetação aplicada sobre a cobertura das edificações, como também sobre a cobertura da área de estacionamento, e piso de área de lazer, de modo a melhorar o aspecto paisagístico, diminuir a ilha de calor, absorver parte do escoamento superficial e melhorar o microclima local.

$\S 2$ o 0 "Telhado Verde" poderá ter vegetação extensiva ou intensiva, de preferência nativa para resistir ao clima tropical do município, com as suas variações de temperatura e umidade.

Art. 2o Com a finalidade de tornar públicos os modos de aplicação e os benefícios do "Telhado Verde", e de incentivar a sua aplicação nas edificações, podem ser elaborados:

I - estudos junto a organizações públicas ou privadas para a definição de padrões estruturais para implantação do "Telhado Verde" no Município;

II - cursos e palestras para a divulgação das técnicas imprescindíveis à implantação do "Telhado Verde, como na parte estrutural, tipos de vegetação e substrato(Recife, 2015).

De acordo com a referida Lei, o objetivo do "Telhado Verde" é diminuir os efeitos do calor, transformando dióxido de carbono ( $\mathrm{CO} 2$ ) em oxigênio (02), já que um prédio com telhado verde pode chegar a uma temperatura até seis graus mais baixa do que no seu entorno. Outro aspecto importante que a lei prevê, além da cobertura vegetal que visa melhorar o aspecto paisagístico da cidade, é que os projetos devem contemplar a construção de reservatórios de acúmulo e retardo das águas pluviais. Os reservatórios deverão cumprir a função de auxiliar na microdrenagem da cidade, podendo a água ser liberada gradativamente depois das chuvas ou sendo armazenada para reutilização em serviços como a limpeza de áreas comuns das edificações ou para regar, por exemplo.

O Colégio Militar do Recife (CMR), localizado no bairro do Engenho do Meio, possui em sua estrutura interna algumas árvores contrastando com as expressivas áreas construídas e asfaltadas nos seus arredores. A sensação térmica elevada no interior deste estabelecimento de ensino causa desconforto nos estudantes, responsáveis, educadores, militares e funcionários que também sofrem com os episódios de alagamento escoamento de água dentro e fora do colégio nos períodos de chuva. A instalação e manutenção de aparelhos ar condicionado nas salas de aula para minimização dos efeitos do calor dentro do CMR apontam para um consumo elevado de energia elétrica, onerando os gastos de orçamento mensal.

A construção do trabalho busca apresentar proposta de implantação do telhado verde na cobertura do Colégio Militar do Recife, visando o combate aos efeitos do calor, redução de gasto com energia elétrica, áreas de alagamento e problemas de infiltração de água em áreas cobertas. A proposta foi desenvolvida, à luz do Arco de Maguerez, para fazer parte da Feira de Ciências do Colégio Militar do Recife - CMR. 0 evento se pauta no tema "Bioeconomia: Diversidade e Riqueza para o Desenvolvimento Sustentável" da 16를 Semana Nacional de Ciência e Tecnologia (SNCT).

\subsection{BJETIVO}

Apresentar proposta de implantação do telhado verde no Colégio Militar do Recife, visando o combate aos efeitos do calor, redução de gasto com energia elétrica, áreas de alagamento e problemas de infiltração de água em áreas cobertas.

\section{PROCEDIMENTOS METODOLOGICOS}

A metodologia da Problematização é usada em ocasiões nas quais os temas estejam relacionados com a vivência em sociedade. Nessa perspectiva, o presente estudo ocorreu à luz do Método do Arco de Charles Maguerez (Figura 01), que consiste na observação da realidade permitindo a identificação de problemas e 
seus pontos chaves, seguida de teorização a fim de levantar hipóteses de solução para intervir na realidade (Prado, 2012).

Figura 01: Exemplificação do arco de Maguerez com suas etapas.

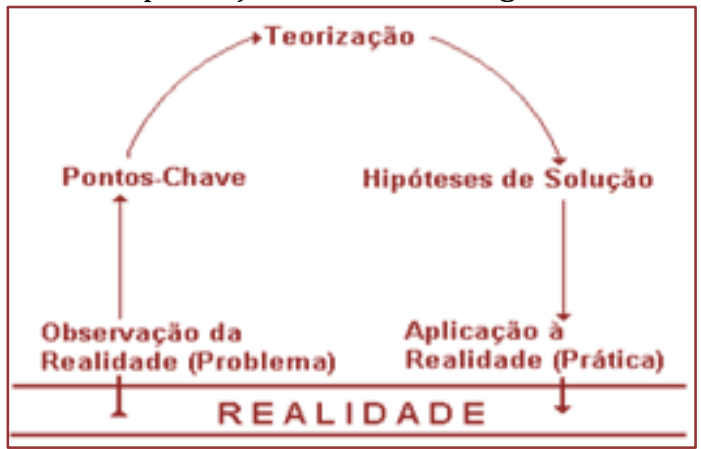

Fonte: Bordenave; Pereira, 1989

O grupo fez o percurso do Arco, conforme Figura 02, explorando a situação-problema eleita em cenário relacionado ao cotidiano dos alunos; tendo acesso aos seus conhecimentos prévios acerca do problema investigado; favorecendo a interdisciplinaridade do tema em discussão; trabalhando com vivências experimentais; privilegiando espaço de discussões em grupo, exposição, compartilhamento e confronto de ideias; exercitando a tomada de decisão e a interação direta com a comunidade que vivencia o problema identificado 'in loco' (Prado, 2012).

Com base, no Arco de Maguerez, o grupo realizou as etapas, descritas a seguir:

Figura 02: Etapas do Arco de Maguerez vivenciado pelo grupo.

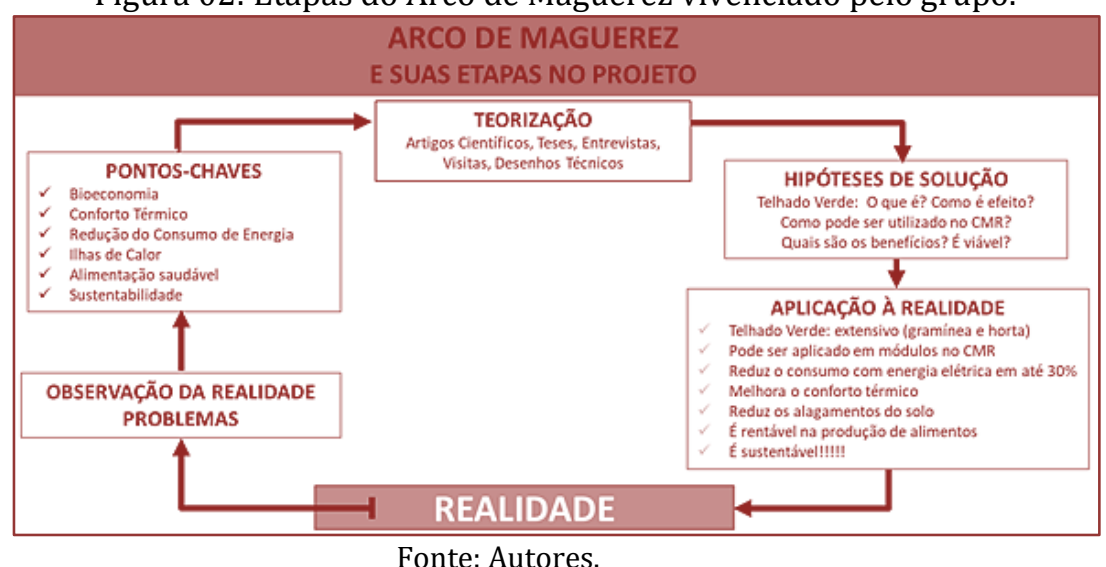

I. Observação da realidade e definição de um problema: Na etapa da observação da realidade, a primeira atividade elaborada foi a identificação do assunto a ser explorado no estudo. Reuniões entre os alunos e orientadora após a formação do grupo de trabalho buscaram articular os eixos temáticos da feira de ciências CMR 2019 (Contribuição da Bioeconomia para o Desenvolvimento da Sociedade e Inteligência Artificial) com as vivências e percepção dos alunos sobre essas temáticas no dia a dia.

O evento se pauta no tema "Bioeconomia: Diversidade e Riqueza para o Desenvolvimento Sustentável" da16 a Semana Nacional de Ciência e Tecnologia (SNCT), que acontecerá de 21 a 27 de outubro de 2019, e busca estimular o contato e a interação com a ciência e a tecnologia, através de tudo o que há de mais moderno e que está sendo feito pelas instituições brasileiras. A SNCT é promovida pelo Ministério da Ciência, Tecnologia, Inovações e Comunicações (MCTIC) e com a participação de instituições, parceiros e municípios.

Assim, nos primeiros encontros presenciais, foi possível tecer reflexões e articulações entre o problema dos impactos ambientais advindos do processo de urbanização e o meio real (desconforto térmico) em que o grupo está inserido, seguido de levantamento as características referentes à problemática no ambiente do CMR. Conclui-se que o colégio possui grande elevação de temperatura (ilhas de calor), áreas de alagamento (em períodos chuvosos), episódios de infiltração de águas pela cobertura e paredes, gasto excessivo com energia elétrica, essencialmente com a necessidade do uso intenso de aparelhos de ar- 
condicionado em suas dependências. Surge neste contexto a ideia de conhecer o telhado verde como possibilidade e alternativa sustentável para a problemática.

Para essa etapa de observação da realidade, é possível usar diversas estratégias como visitas técnicas, reportagens/notícias, discussão em grupo, entrevistas com população e especialistas, dentre outros recursos, que permitam aos alunos uma aproximação da realidade (Bordenave; Pereira, 2004).

Os estudantes neste momento utilizaram as estratégias de discussão em grupo, leitura de reportagens/noticias e entrevista com a professora/orientadora.

\section{Pontos-chave:}

Nesta etapa, os sujeitos elencam o que foi observado na realidade, destacando os elementos importantes, identificando os pontos-chave do problema ou assunto abordado, e as variáveis determinantes da situação, realizando uma síntese do que será estudado, os aspectos a serem conhecidos e melhor compreendidos de forma a buscar uma resposta ao caso (Prado et al., 2012). Esta fase foi contemplada de forma rápida, a partir do momento que foi possível identificar que esta é a fase de chuva de ideias, de inclusão de elementos que estão causando ou mesmo potencializando o problema.

Neste caso, os pontos chave do estudo eram: urbanização, Ilhas de calor, áreas de alagamento por chuvas, elevado custo com energia elétrica, infiltrações em áreas cobertas e telhado verde como alternativa sustentável. Compreende-se que esta etapa possibilitou ao grupo reflexões sobre a problemática. De acordo com Rocha (2008), é ótimo que os alunos percebam que os problemas de questão social são complicados e, em muitos casos, multideterminados.

0 estudo para a concepção da realidade deve ser crucial e reflexivo, tendo em vista que os estudantes procurem a busca da resolução para as dificuldades. A partir dessa análise, é elaborada uma síntese dos pontos principais que deverão ser estudados, objetivando compreender o problema de maneira densa e encontrando forma de inferir na realidade para solucioná-lo.

\section{Teorização}

A etapa de Teorização implica na construção de respostas mais elaboradas para o problema, proporcionando um aprofundamento e amadurecimento mental (Nunes, 2006). Uma teorização bem conduzida encaminha o sujeito a entender o problema e os princípios teóricos que os explicam, não apenas suas experiências empíricas. Nessa fase de teorização todos os envolvidos no processo devem estudar o assunto, pois é o período em que acontecem as operações mentais que proporcionam o crescimento intelectual dos alunos (Bordenave; Pereira, 2004).

A busca por estas informações deve ocorrer através das teorias já existentes, disponíveis em diversas fontes como livros, periódicos especializados, anais de congressos, palestras, artigos de jornais, dentre outras, e também na vivência das pessoas envolvidas com a temática em estudo por meio de questionários, roteiros de entrevistas, fichas de observação, assim como visitas a espaços que apresentem relação com o que é proposto na atividade, ou mesmo consultas a especialistas e usuários (Berbel, 1995).

0 grupo realizou entrevistas com os especialistas Paulo Jorge Pereira ${ }^{1}$ (Figura 03), Marcelo Kozmhinsky ${ }^{2}$ (Figura 04) e Bruno Luiz Oliveira ${ }^{3}$ (Figura 05), fez visita técnica ao Empresarial ITBC - Information Technology Business Center (Figura 06) e ao Núcleo SENAI de Sustentabilidade (Figura 07), ambas as edificações situadas na cidade do Recife, onde é possível vivenciar tecnologias sustentáveis aplicadas à construção civil, energia e meio ambiente.

0 grupo estabeleceu também que necessitava realizar estudos e pesquisas sobre: a urbanização e seus impactos ambientais, o fenômeno da ilha de calor urbana, ilhas de calor na cidade do Recife e telhado verde como um sistema sustentável. Entretanto elegeu a temática do sistema telhado verde para explorar na fundamentação teórica deste artigo.

\footnotetext{
1Paulo Jorge Pereira é Arquiteto e Urbanista, Doutorando da universidade de Lisboa e trabalha na Europa com Projetos de Prédios verdes, ecológicos e sustentáveis.

2Marcelo Kozmhinsky possui graduação em Agronomia pela Universidade Rural de Pernambuco - UFRPE, experiência na área de Paisagismo, Mestre em Engenharia Ambiental pela UFRPE.

${ }^{3}$ Bruno Luiz é Arquiteto e Urbanista do Núcleo SENAI de Sustentabilidade na cidade de Recife - PE.
} 
Figura 03 - Entrevista do arquiteto Paulo Jorge Pereira

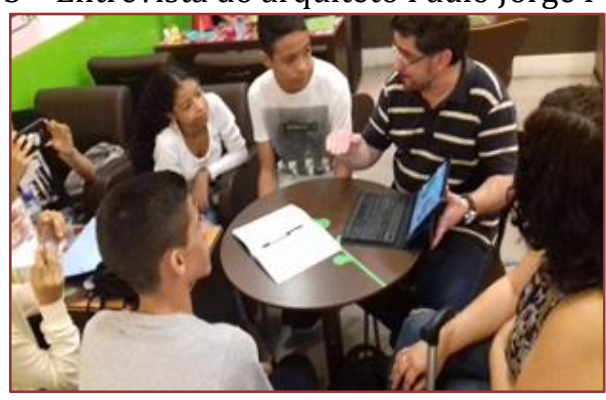

Fonte: Autores.

Figura 04 - Entrevista do paisagista Marcelo Kozmhinsky na visita ao ITBC- Softex, em Recife

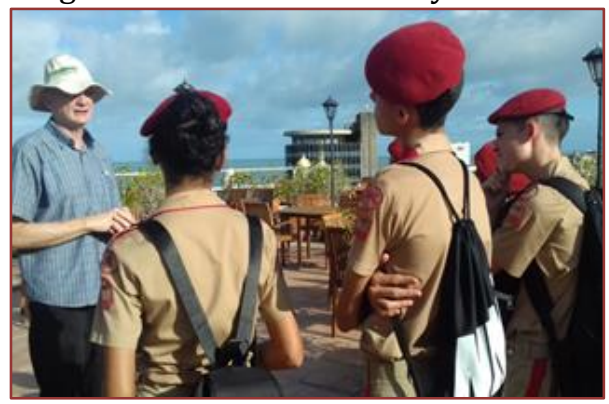

Fonte: Autores.

Figura 05 - Entrevista do arquiteto Bruno Luiz na visita ao SENAI Recife

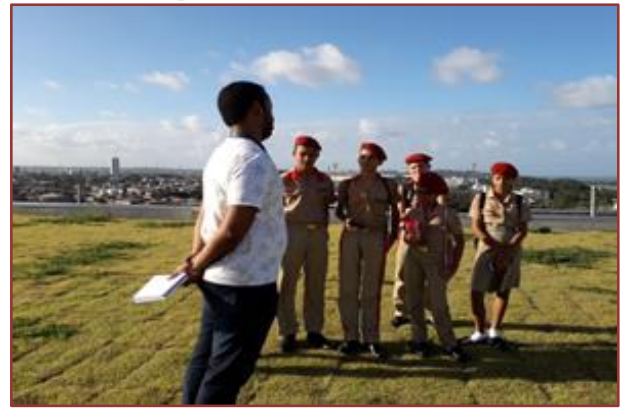

Fonte: Autores.

Figura 06 -Telhado Verde do Empresarial ITBC - Softex Information Technology Business Center.

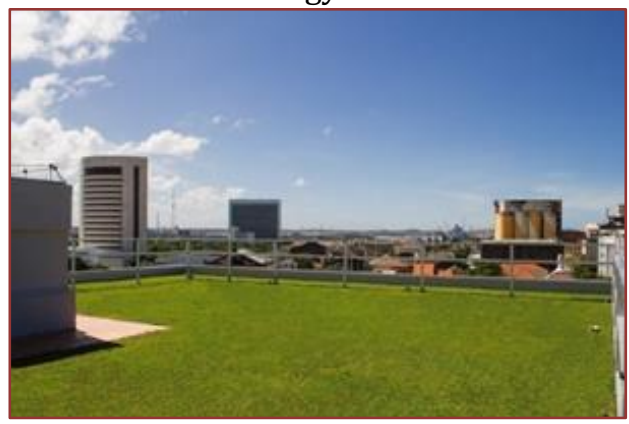

Fonte: Google imagens. 
Figura 07 - Telhado Verde do Núcleo SENAI de Sustentabilidade.

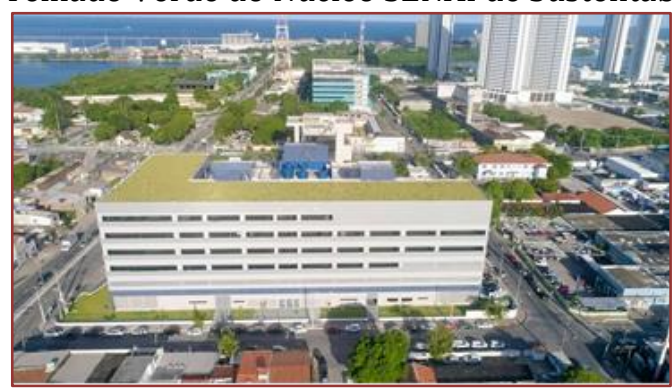

Fonte: Autores.Fonte: Autores.

0 estudo foi realizado de abril a julho de 2019, cuja etapa de seleção e pesquisa de artigos científicos se deu através da plataforma do Google Acadêmico, portal que aponta para artigos disponíveis em diversos periódicos online. Foram usadas as expressões: ilha de calor urbana, ilhas de calor na cidade do Recife, telhado verde. A seleção dos artigos utilizou os seguintes critérios: língua portuguesa e análise inicial dos seus títulos e resumos, havendo a exclusão dos artigos que não apresentaram a temática abordada no presente estudo.

A leitura exploratória dos artigos escolhidos subsidiou a etapa de Teorização e configura como referência para as etapas de Hipóteses de solução e Aplicação à realidade.

A construção da revisão bibliográfica teve seu corpo formado por textos selecionados, a priori, após leitura do resumo e do texto completo. A partir deles, foram realizadas outras pesquisas e leituras das obras citadas neles e assim progressivamente até a saturação de dados e a contemplação do objetivo do trabalho.

Estudos sobre soluções sustentáveis apontam que os telhados verdes agem como uma proposta interessante para diminuição do escoamento superficial e o gerenciamento das contribuições pluviais. 0 cultivo de plantas tropicais de espécies que apresentam melhores chances de adaptação, tendo em vista a construção de telhados verdes extensivos, ou seja, telhados cujas espécies de plantas que não sejam exigentes nas rotinas de manutenção periódicas e que têm custos de estrutura reduzidos em função de camadas mais estreitas e leves de camada geotêxtil, com impermeabilização e drenagem bem executados, é uma alternativa capaz de reduzir problemas ambientais relacionados a má gestão dos recursos hídricos, que fazem parte da rotina dos grandes centros urbanos, como enchentes e inundações (Koeller, 2000).

Os telhados verdes são divididos em dois tipos: o extensivo e o intensivo.

O sistema extensivo, modalidade melhor indicada para a utilização no CMR, geralmente são coberturas leves e de raízes rasas, criadas para comportar plantas que se acostumam a climas severos e situações climáticas extremas. Fisicamente, possui baixa profundidade (5 a $15 \mathrm{~cm}$ ), adicionando pouco peso à estrutura que o suporta. Apresenta comportamento satisfatório diante da diminuição de escoamento superficial de água, à contração dos efeitos das ilhas de calor e a elevação da umidade no ambiente (Pinto, 2007).

Já o método intensivo necessita de considerável profundidade $(15$ a $90 \mathrm{~cm})$, possibilitando o uso de vegetação de grande porte, como arbustos e até mesmo árvores. (Pessanha, 2017).

\section{TELHADO VERDE (ETAPAS DE EXECUÇÃO E TIPOS)}

Para a execução de um telhado verde, a laje deve ser preparada com impermeabilização e sistemas de drenagem para receber essa técnica. Em casos de edificações que já foram feitas sem o planejamento para receber o telhado, deverá ser feito uma análise para analisar a carga que pode ser colocada ou até mesmo fazer um reforço na estrutura. O cuidado com o crescimento das raízes também é um fator importantíssimo (Alberto et al., 2012).

Abaixo a demonstração de um telhado verde: 
Figura 08: Camadas de um telhado verde.

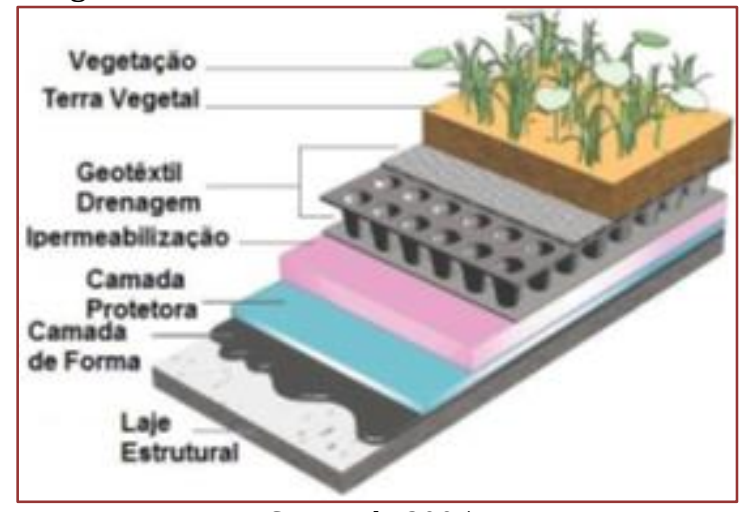

Fonte: PLEDGE, Earth, 2005.

As camadas da estrutura do telhado verde (Figura 08) têm diferentes funções para que o sistema consiga captar a quantidade exata de água para a vegetação e escoar a água, no entanto cada camada possui as seguintes atribuições:

I) Vegetação: a vegetação deve ser adequada ao substrato, de acordo com o clima da região e os tipos de plantas que não possuem raízes extensas e agressivas, para não danificar a estrutura abaixo;

II)Substrato: esta camada irá definir em qual tipo o telhado verde utilizado se encaixa e garante que a vegetação cresça com fluidez. Neste caso utiliza-se terra vegetal ou terra preta adubada;

III) Geotêxtil: esta camada funciona como uma espécie de filtro, permitindo que as águas pluviais escoem e que o substrato utilizado nas plantas escoe;

IV) Drenagem: é a camada de material granular de cerca de 7 a $10 \mathrm{~cm}$ e é responsável por dar vazão ao excesso de água do solo;

V) Impermeabilização: utiliza-se manta asfáltica, que são compostas por um filme de polietileno, por uma camada de asfalto alterado, um estruturante, outra camada de asfalto modificado e por fim um filme de polietileno ou alumínio;

VI) Camada protetora: é onde ocorre a retenção da umidade e nutrientes dentre a estrutura das camadas, protegendo a camada de impermeabilizante evitando o desenvolvimento das raízes da vegetação;

VII) Laje: esta etapa deve sustentar toda a carga do telhado verde. Para um funcionamento adequado a superfície da laje de cobertura deverá ter uma inclinação de 1,5\% que possibilite o escoamento de toda água drenada (Nascimento et al., 2018).

Nascimento (2018) analisou os custos iniciais da aplicação do telhado verde sem abordar os custos de longo prazo, como manutenção e redução de energia que irá exercer sobre o ambiente. Para fins de comprometimento com os resultados, foi considerado o parâmetro de $1 \mathrm{~m}^{2}$. No estudo, para o desenvolvimento da composição do custo do telhado verde (Tabela 2) foi analisado os valores fornecidos por empresas especializadas na execução deste tipo de cobertura.

TABELA 2: Composição dos custos total do $\mathrm{m}^{2}$ de telhado verde.

\begin{tabular}{|c|c|c|}
\hline \multicolumn{2}{|c|}{ COMPONENTES } & \multicolumn{2}{c|}{$\begin{array}{c}\text { UND. } \\
\text { Vegetação (grama esmeralda) }\end{array}$} & $\begin{array}{c}\mathrm{R} \$ \\
\mathrm{~m}^{2}\end{array}$ & $\mathrm{R} \$ 7,00$ \\
\hline Solo (substrato) & $\mathrm{m}^{2}$ & $\mathrm{R} \$ 7,00$ \\
\hline Manta filtrante (geotêxtil) & $\mathrm{m}^{2}$ & $\mathrm{R} \$ 53,00$ \\
\hline Drenagem (material granular) & $\mathrm{m}^{2}$ & $\mathrm{R} \$ 19,00$ \\
\hline Camada impermeabilizante & $\mathrm{m}^{2}$ & $\mathrm{R} \$ 9,00$ \\
\hline Camada protetora (proteção da raiz) & $\mathrm{m}^{2}$ & $\mathrm{R} \$ 12,00$ \\
\hline Manta limitadora de grama & $\mathrm{m}^{2}$ & $\mathrm{R} \$ 29,00$ \\
\hline Mão de obra & - & $\mathrm{R} \$ 114,00$ \\
\hline TOTAL (R\$) & - & $\mathrm{R} \$ 250,00$ \\
\hline
\end{tabular}


Dados de estudo recente sobre as principais características de implantação e execução do telhado verde, bem como as suas vantagens e as desvantagens, na perspectiva de vários autores, serão apresentados na Tabela 3.

TABELA 03: Vantagens e desvantagens do telhado verde.

\section{VANTAGENS DESVANTAGENS}

\begin{tabular}{|l|l|}
\hline \multicolumn{2}{|c|}{ VANTAGENS } \\
$\begin{array}{l}\text { O sistema retém uma parte de água da chuva, outra parte evapora, } \\
\text { diminuindo então o volume de enxurrada (Alberto et al., 2012). }\end{array}$ & $\begin{array}{l}\text { Investimento inicial alto (Alberto et al., } \\
\text { 2012). }\end{array}$ \\
\hline $\begin{array}{l}\text { Reduz gastos com energia elétrica, melhora no conforto térmico do } \\
\text { ambiente, reduzindo os gastos com ar-condicionado (Baltar, 2006). }\end{array}$ & $\begin{array}{l}\text { A mão de obra deverá ser especializada } \\
\text { (Rosseti et al., 2011). }\end{array}$ \\
\hline $\begin{array}{l}\text { Reduz a área de concreto das cidades, causadoras de grandes } \\
\text { elevações na temperatura (Alberto et al., 2012). }\end{array}$ & $\begin{array}{l}\text { Se o sistema não for aplicado de } \\
\text { maneira correta, pode gerar problemas } \\
\text { para edificação, como: infiltração e } \\
\text { umidade (Alberto et al., 2012). }\end{array}$ \\
\hline $\begin{array}{l}\text { O contato com área verde traz benefícios para a saúde humana } \\
\text { (Martins, 2010). }\end{array}$ & $\begin{array}{l}\text { Manutenção constante, principalmente } \\
\text { com a vegetação (Rangel et al., 2015). }\end{array}$ \\
\hline $\begin{array}{l}\text { Alguns tipos de substratos utilizados na aplicação do sistema, } \\
\text { regulariza o pH e filtra íons. (Santos et al., 2017). }\end{array}$ & \\
\hline $\begin{array}{l}\text { A vegetação absorve poluição deixando o ar mais limpo, saudável e } \\
\text { fresco (Martins, 2010). }\end{array}$ & \\
\hline $\begin{array}{l}\text { Áreas verdes são cada vez mais valorizados nas cidades, valorizando } \\
\text { o custo dos imóveis (Alberto et al., 2012). }\end{array}$ & \\
\hline $\begin{array}{l}\text { Proporcionam isolamento acústico, através da ação do substrato das } \\
\text { plantas, 12 centímetros de camada de substrato chegam a diminuir a } \\
\text { transmissão de 40db de ruídos (Oliveira, 2009). }\end{array}$ & \\
\hline $\begin{array}{l}\text { A durabilidade do telhado verde é calculada por volta de 30 anos, sem } \\
\text { necessidade de reparos, diferentemente das coberturas } \\
\text { convencionais (Lopes, 2007). }\end{array}$ & \\
\hline
\end{tabular}

Fonte: Nascimento, 2018.

A fase "teorização" foi essencial para definição dos conceitos de construção sustentável e busca de alternativas que minimizassem os custos de energia e desperdício de água potável.

Iv. Hipóteses de solução:

É na fase de hipótese de solução, e agora através dos estudos e conhecimentos aprimorados, que devem ser estruturadas, de maneira crítica e criativa, uma possibilidade para mudança na realidade do problema estabelecido no estudo (Rocha, 2008).

Deste modo, elaborou-se como hipótese de solução a implantação de Telhado verde na cobertura do Colégio Militar de Recife, por ser uma alternativa viável, tem a vantagem de ser executada em estrutura já existente, é um sistema que exige pouca manutenção e valoriza uma área que, normalmente, é subutilizada.

Foi produzida a maquete para a visualização tridimensional do projeto idealizado para o CMR (Figura 09), a partir do desenho elaborado no programa Autocad 2019 da Autodesk- versão estudante (Figura 10).

Figura 09 - Maquete do CMR com Telhado Verde.

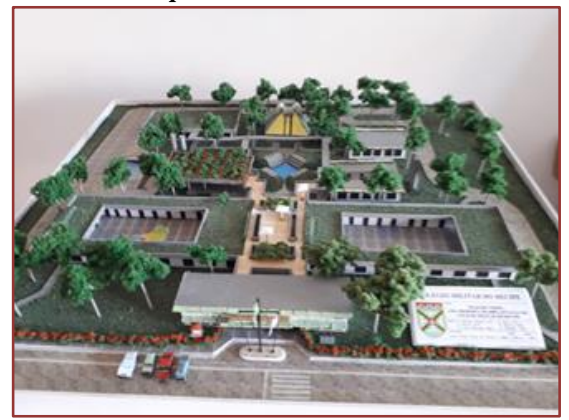

Fonte: Autores. 
Figura 10 - Projeto do telhado verde no CMR via Autocad 2019 da Autodesk.

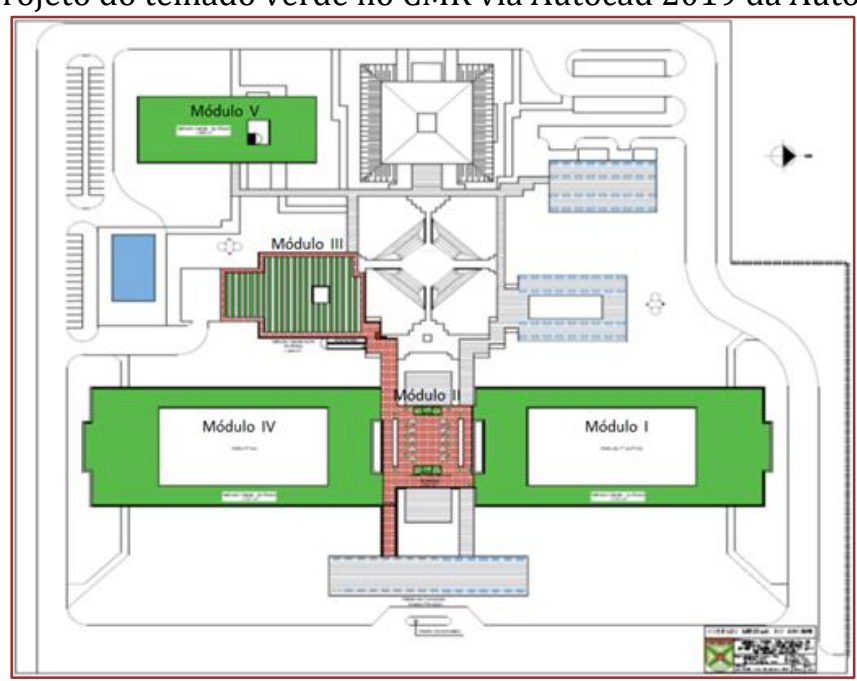

Fonte: Autores.

A equipe também montou um expositor numa caixa acrílica onde é possível observar as camadas existentes no telhado verde extensivo (Figura 11).

Figura 11 - Expositor com as camadas do Telhado Verde Extensivo.

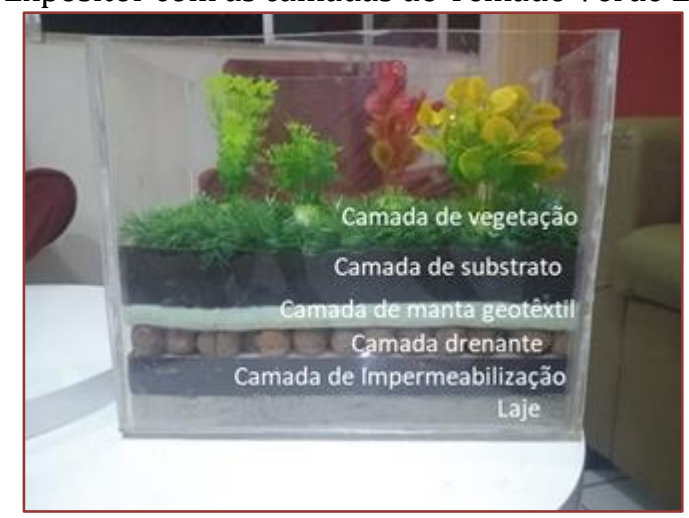

Fonte: Autores.

0 modelo idealizado para implementação do Telhado verde no CMR está dividido em 05 (cinco) módulos, que irão contemplar as coberturas das salas de aula da $1 \stackrel{a}{\underline{a}}, 2^{\underline{a}}$ e $3^{\underline{a}}$ companhias, sala de aula aberta, cantina e rancho e auditório, onde serão instalados gramíneas, construído um espaço de convivência e uma horta, conforme descrito na Tabela 04 a seguir:

TABELA 04 - Módulos de implantação do telhado verde no CMR.

\begin{tabular}{|c|l|l|}
\hline MÓDULO & COBERTURA UTILIZADA & \multicolumn{2}{|c|}{ TIPO } \\
\hline I & Salas da 1a e 2a Cia & Extensivo com gramíneas \\
\hline II & Corredor de acesso do CMR & $\begin{array}{l}\text { Jardim Sala de Aula - Área de convivência com 2 } \\
\text { grandes jardins suspensos com trepadeiras, vasos com } \\
\text { vegetação, tendas, mesas e cadeiras de jardim. }\end{array}$ \\
\hline III & Cantina, refeitórios e cozinha & Extensivo com horta \\
\hline IV & Salas da3a Cia & Extensivo com gramíneas \\
\hline V & Auditório & Extensivo com gramíneas \\
\hline
\end{tabular}


Nas coberturas onde serão instaladas gramíneas, Módulos I, II e V, evitará que o calor seja propagado para o interior das salas de aula, além de mais conforto, irá reduzir a necessidade do uso de ar condicionado.

Na cobertura onde será instalada a área de convivência, Módulo III, o objetivo é criar um agradável espaço para diversos tipos de usos, como ações educativas e promovendo o convívio com a natureza e melhorando a interação social.

No Módulo IV teremos uma horta para o cultivo de hortaliças e verduras. A ideia é utilizar os alimentos nas refeições fornecidas pelo Colégio, tendo a disposição produtos frescos e orgânicos, além de oferecer aos alunos um espaço onde eles irão colher seu próprio alimento.

A implantação do projeto através de etapas compreende-se como a forma que melhor se adapta para defender nossa hipótese e mitigar a problemática.

\section{Aplicação à realidade:}

O grupo nesta fase necessita executar as soluções mais viáveis encontradas e estar apto a utilizar os conteúdos aprendidos em outras situações (Mitre et al., 2008). Para a busca de resolução do problema, a equipe trabalhou na construção das representações ilustrativas do telhado verde no CMR defendendo sua multifuncionalidade.

Nesta compreensão, o arco se completa, visto que nessa metodologia pelo menos uma ação deve ser realizada dentro da aplicabilidade proposta, visando transformar a realidade existente (Berbel, 1995).

\section{RESULTADOS E DISCUSSÃO}

0 telhado verde consiste na implantação de solo e vegetação em uma camada impermeabilizada sobre as construções, como residências, escritórios e qualquer outro tipo de construção. Além de proporcionar beleza onde é instalado, a baixa inércia térmica da terra e a água resultante dos vegetais da cobertura configuram características que melhoram a qualidade de vida das pessoas que frequentam o ambiente beneficiado pelo telhado verde e reverbera também em seus arredores.

A cobertura verde pode ser usada em construções com estruturas de metal, de concreto e de madeira. De acordo com o uso e o formato do telhado verde, ele pode ser montado de diferentes maneiras. Para implantação do telhado verde no CMR é necessário:

- Verificar a carga de suporte da laje;

- Impermeabilizar a coberta;

- Implantar um sistema de drenagem com reservatório;

- Preparar o solo;

- Plantar a vegetação definida.

Os custos desta aplicação podem variar expressivamente de acordo com o sistema adotado e a mão de obra disponível, entretanto existem empresas especializadas que fabricam módulos que facilitam a implantação evitando problemas de vazamento e infiltrações, e tornam a proposta viável.

O Investimento financeiro inicial pode ser alto, entretanto a relação custo e benefício é bastante compensatória, visto que reduz o consumo de energia, e melhora a eficiência energética devido à redução da temperatura no ambiente interno, diminuindo a necessidade de refrigeração.

Como vantagem se evidencia também o ciclo de vida completo da estratégia, pois sua duração é em média o dobro tempo da opção convencional.

Embora a mão de obra para a manutenção do telhado verde ser maior que a dos outros sistemas (Nascimento, 2018), a escola conta com um efetivo de soldados, que poderiam ficar responsáveis pela função de manter a sua estrutura saudável e com boa aparência.

Outros benefícios a serem considerados com a implantação do Telhado Verde no CMR são:

I) Amenização da radiação solar que atinge as coberturas, refletindo em um ambiente interno com temperaturas mais leves e influenciando diretamente no conforto térmico da edificação (Nascimento, 2018), pois o telhado verde não propaga calor como os sistemas de coberturas mais comuns, como a laje 
ou telhas convencionais. A estratégia vai auxiliar também na diminuição das Ilhas de Calor, visto que e as plantas produzem oxigênio, melhorando a qualidade do ar das proximidades;

II) Regulação da umidade do ar nas áreas próximas à edificação;

III) Decréscimo no risco de áreas de alagamento, pois quando há períodos chuvosos o local alaga muito facilmente prejudicando, inclusive, na logística das aulas, tendo que interromper ou transferir a turma para outro lugar. 0 sistema Telhado verde vai ajudar na retenção da água da chuva evitando que esta não caia direto nas galerias urbanas, portanto, o processo de escoamento dos telhados verdes vai retardar o caminho da agua, aliviando possíveis enchentes na região;

IV) Implantação do espaço da Horta deve gerar o benefício de inserir uma alimentação mais saudável e consequente redução do gasto na compra de alimentos para o rancho;

V) Criação de um agradável terraço para diversos tipos de usos, como proposto neste estudo, um espaço de convivência privilegiado pela presença do verde e menor temperatura com potencial para ser utilizado para fins de ensino e pequenos eventos do Comando;

VI) 0 sistema também vai absorver e amortecer os ruídos do entorno, servindo de isolamento acústico;

VII) Diminuição do custo com energia elétrica, já que a implantação do telhado verde proporciona maior conforto térmico e praticamente extingue a necessidade do uso de ar condicionado, e o CMR tem em seu patrimônio um número considerável de aparelhos de ar condicionado que são ligados diariamente e por muitas horas;

VII) Promoção do reequilíbrio ambiental, principalmente se forem usadas plantas nativas e pode servir, ainda, de habitat para espécies de pássaros locais.

\section{CONSIDERAÇõES FINAIS}

A implantação de um telhado verde nas dependências do CMR trará uma horta e um novo espaço de convivência/ensino, gerando economia, não só na redução de consumo de energia, mas também na redução do gasto na compra de alimentos para o rancho. 0 retorno do que for investido será garantido, não esquecendo o mais importante: a sustentabilidade e o bem-estar dos alunos e professores (Figura 12).

Figura 12 - Benefícios do Telhado Verde com a implantação do projeto

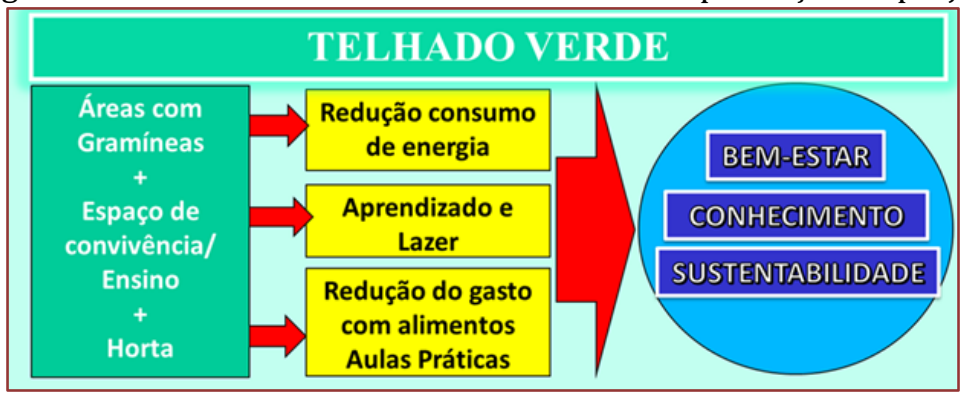

Fonte: Autores.

A culminância deste estudo, através da vivência das etapas do Arco de Maguerez, mostrou-se significativo, pois proporcionou um processo de aprendizagem crítico-reflexivo e experiências de transformação da realidade, além de contribuir para o resgate das necessidades da comunidade, valorizando seu contexto e especificidades. Evidencia-se ainda a importância do incentivo ao exercício das políticas públicas quanto à regulação do desenvolvimento ambiental da cidade, e garantia da qualidade de vida e a saúde dos ambientes. 


\section{REFERENCIAS}

[1] Alberto, E.Z. et al. Estudo do telhado verde nas construções sustentáveis. XII Safety, health and environment world congress.São Paulo, 2012.

[2] Baltar, M. G. Redução da Demanda de Energia Elétrica utilizando Parâmetros Construtivos visando ao Conforto Térmico. Dissertação (Mestre em Engenharia Elétrica). PUCRS. Agosto de 2006.

[3] Berbel, N. A. N.: (Org.): Metodologia da Problematização: uma alternativa metodológica apropriada para o ensino superior. SEMINA: Ci, Soc./Hum, Londrina, v. 16, n.2, Ed. Especial, p. 9-19, out. 1995.

[4] Bordenave, J. D., Pereira, A. M. P. Estratégias de ensino-aprendizagem. 25 a ed., Rio de Janeiro: Vozes, 2004.

[5] Diaz Bordenave, J.; Pereira, A. Martins.Estratégias de ensino-aprendizagem. 25a ed. Petrópolis, RJ: Vozes; 2004.

[6] Tratado sobre o sistema de telhado verde extensivo para coberturas planas em edificações de pequeno e médio porte

[7] Dilly, Diogo Pedro Appel Dissertação Mestrado Universidade do Vale do Rio dos sinos, São Leopoldo, RS, 2016

[8] Earth Pledge, 2005. Green Roofs: Ecological Design and Construction. A Shiffer Design Book, ShifferPublishingLtd.

[9] Ferreira, C. A; Moruzzi, R. B. Considerações sobre a aplicação de telhado verde para captação de água da chuva em sistema de aproveitamento para fins não potéveis. In: IV Encontro Nacional e II Encontro Latino-americano sobre edificações e comunidades sustentáveis. Campo Grande: UNESP, 2007.

[10] guedes, B. N.; Silva, M. I. T.; Silva, C. C. A metodologia da problematização na Escola de Posturas da UFPB: um processo emancipatório na prática da educação gerontológica. Revista Eletrônica de Enfermagem, Goiânia, v. 9, n. 2, p. 298-314, 2007.

[11] Koeller, M. Schmidt.Grenn Roofs in the temperate climates and in the hot humid tropics. 18th Int. Conference and Passive and Low Energy Arquiteture, Plea Proc. Florianopolis, Brasil, p. 493-499, 2000.

[12] Lopes, D. A. R. Avaliação do Comportamento Térmico de Coberturas Verdes Leves (Cvls) Aplicadas aos Climas Tropicais. Dissertação (Mestrado em Ciências da Engenharia Ambiental) - Universidade de São Carlos, São Carlos, 2007.

[13] Machado, M.; et al. Comportamiento térmico em modelos com cubiertas ecológicas. Tecnologia y Construccion, Caracas, v. 19, n.3, p. 49-58. 2003.

[14] Martins, F. D. P. Coberturas verdes - seu contributo para a eficiência energética e sustentabilidade. Dissertação (Mestre em Arquitetura). Universidade da Beira Interior. Covilhã, 2010.

[15] Nascimento, B. N.; Azevedo, J. C. A.; Raszi, S. M. A implantação de Telhados verdes como alternativas Sustentáveis.

[16] Nóbrega, Ranyére Silva; VITAL, Luis Augusto de Bakker. Influência da Urbanização sobre o Microclima de Recife e Formação de Ilha de Calor (InfluenceofUrbanizationontheClimateof Recife andDevelopmentofHeatIsland).Revista Brasileira de Geografia Física, [S.l.], v. 3, n. 3, p. 151-156, nov. 2010.

[17] Nobrega, R.S; Santos, P.F.C.; Moreira, E.B.M. morfologia urbana e ilhas de calor na cidade do Recife/PR: distribuição espacial e intensidade. Revista de Geografia (Recife) V. 33, No. 4, 2016.

[18] Oliveira, R.N. Certificação Ambiental na Construção Civil - Leed. 2009. 99p.. Monografia (Graduação em Engenharia Civil) - Universidade Anhembi Morumbi, São Paulo, 2009.

[19] Pessanha, L. B. Proposta de implantação de um sistema de telhado verde extensivo utilizando a técnica de wetland. Dissertação (Graduação em Engenharia Civil) - Escola Politécnica - UFRJ. Rio de Janeiro, 2017.

[20] Pinto, E. M. A. Gestão de Recursos Hídricos e as Interferências do Sistema Urbano: município de Queimados RJ. Revista Universidade Rural, Série Ciências Humanas e Sociais, Rio de Janeiro, v. 29, n. 1, p. 125-131. jan./jun. 2007.

[21] Prado, M., Velho, M., Espíndola, D., Sobrinho, S., \&Backes, V. (2012). Arco de Charles Maguerez: Refletindo estratégias de metodologia ativa na formação de profissionais de saúde. Escola Anna Nery - Revista de Enfermagem, 16(1), 172-177.

[22] Rangel, et al. Os telhados verdes nas políticas ambientais como medida indutora para a sustentabilidade. Programa de Pós-Graduação em Desenvolvimento e Meio Ambiente (Prodema), Universidade Federal da Paraíba (UFPB), João Pessoa/PB, 2015.

[23] Recife. Lei n. ${ }^{\circ}$ 18.112/2015. Dispõe sobre a melhoria da qualidade ambiental das edificações por meio da obrigatoriedade de instalação do "telhado verde", e construção de reservatórios de acúmulo ou de retardo do 
escoamento das águas pluviais para a rede de drenagem e dá outras providências. Disponível em: https://ecotelhado.com/wp-content/uploads/2015/03/Lei-telhado-verde-Recife-2015.pdf.

[24] Rocha, R. 0 método da problematização: Prevenção às drogas na escola e o combate a violência. (Programa de desenvolvimento educacional da Secretaria Estadual de Educação) - Universidade Estadual de Londrina. 2008.

[25] Rossetti; et al. Análise da interferência da cobertura verde na temperatura e umidade relativa do ar no entorno de uma edificação - estudo de caso em protótipo no município de Cuiabá/MT. Programa de pós graduação em Física Ambiental, Cuiabá-MT. Universidade Federal de Mato Grosso. 2011.

[26] Santos, Taciana 0. dos et al . Influence of urbanization on land surface temperature in Recife city. Eng. Agríc., Jaboticabal , v. 33, n. 6, p. 1234-1244, Dec. 2013.

[27] Santos; et. al. Telhado verde: uma proposta sustentável para a construção civil. Ciências exatas e tecnológicas | Alagoas | v. 4 | n. 2 | p. 195-206 | Novembro 2017.

[28] Setta, B. R. S. Telhados verdes como políticas públicas ambientais para o Município de Volta Redonda, RJ. Revista Labverde, São Paulo, v. 8, n. 1, p. 17 - 18, mar. 2017. 


\section{Capítulo 14}

"Aproveitamento alimentar sustentável": O uso da sustentabilidade alimentar como instrumento de fortalecimento do Programa Nacional de Alimentação Escolar (PNAE), nas Escolas Estaduais do Município de Barbacena $-M G$

\section{Luiza Gonçalves dos Santos}

\section{Flora Liz Doumith Oliveira Sobrinho}

Resumo: A redução do desperdício de alimentos nas escolas públicas ou privadas serve de instrumento para a aplicação de uma alimentação escolar sustentável e saudável. 0 Programa Nacional de Alimentação Escolar (PNAE), é uma política do governo que oferece alimentação escolar e propõe a utilização da EAN (Educação Alimentar e Nutricional), é destinado a estudantes em todas as etapas da educação básica, ensino médio, educação de jovens e adultos. Por intermédio de gestores e conselhos, regulamenta o repasse de recursos e benefícios às escolas de todo o país. Portanto, este projeto pretende intervir no fortalecimento das propostas do PNAE, empregando o aproveitamento integral das Partes Não Convencionais de Alimentos Convencionais, visando a redução do desperdício alimentar dentro das cozinhas e cantinas escolares, realizando a capacitação dos manipuladores de alimentos e a conscientização de um aproveitamento sustentável dos recursos financeiros direcionados a alimentação escolar. Utilizando a ferramenta da alimentação sustentável como ação transformadora na construção de uma sociedade consciente e valorizada.

Palavras-chave: Alimentação Escolar; Desperdício de ALIMENTOS; PNAE; Sustentabilidade Alimentar. 


\section{INTRODUÇÃO}

O Programa Nacional de Alimentação Escolar (PNAE) oferece alimentação escolar e ações de educação alimentar e nutricional a estudantes de todas as etapas da educação básica pública. A política remodelou a forma de fazer o tradicionalmente à merenda escolar e ofereceu uma maior segurança alimentar e nutricional aos alunos assistidos pelo programa.

As escolas acompanhadas pelo PNAE têm vários desafios, entre eles diminuir o desperdício no momento de preparar as devidas refeições e oferecer uma maior qualificação para as manipuladoras de alimentos. Mas essas qualificações estão diretamente ligadas ao valor repassado pela União a estados e municípios por dia letivo para cada aluno, definido de acordo com a etapa e modalidade de ensino.

Portanto, buscou-se reunir dados/informações com o propósito de solucionar ao seguinte problema de pesquisa: como reduzir o desperdício de alimentos em escola do Município de Barbacena-MG, por meio do aproveitamento integral e sustentável de Partes Não Convencionais de Alimentos Convencionais (PANC).

Para o desenvolvimento do presente trabalho foram utilizadas pesquisas bibliográficas e de campo, além de dados obtidos através do projeto de extensão. A pesquisa bibliográfica baseou-se em publicações científicas da área de nutrição.

\section{REFERENCIAL TÉORICO}

\subsection{PROGRAMA NACIONAL DE ALIMENTAÇÃO ESCOLAR (PNAE)}

A Lei no 11.947 de 26 julho de 2009, "prevê que a alimentação escolar é direito de todos os estudantes da educação básica pública e dever do Estado" (BRASIL, 2009), enfatizando a suma importância do Programa Nacional de Alimentação Escolar, para a promoção da saúde e desenvolvimento, de todos os alunos matriculados e amparados pelos Órgãos Públicos.

Segundo o artigo $4^{\circ}$ da Legislação que dispõe sobre o atendimento da alimentação escolar aos alunos da educação básica,

“O PNAE tem por objetivo contribuir para o crescimento e o desenvolvimento biopsicossocial, a aprendizagem, o rendimento escolar e a formação de hábitos alimentares saudáveis dos alunos, por meio de ações de educação alimentar e nutricional e da oferta de refeições que cubram as suas necessidades nutricionais durante o período letivo". (BRASIL, LEI № 11.947, 2009)

Segundo o artigo 4o e seus incisos, no Capítulo II da Resolução № 26 (2013), são atendidos pelo PNAE os discentes matriculados na educação básica das redes públicas federal, estadual, distrital e municipal, onde são consideradas instituições conveniadas: as entidades filantrópicas, inclusive as de educação especial e confessionais; e as entidades comunitárias, conveniadas com o poder público. Os repasses financeiros são avaliados de acordo com o Censo Escolar do ano anterior, realizado pelo INEP/MEC (Instituto Nacional de Estudos e Pesquisas Educacionais Anísio Teixeira do Ministério da Educação).

O PNAE estabeleceu regras na qualidade e segurança alimentar, sendo fiscalizado por profissional nutricionista habilitado, que deverá assumir a responsabilidade técnica do Programa, respeitando as diretrizes, previstas nas Lei $n^{\circ}$ 11.947/2009 e em legislações especificas como a Resolução no 26/ 17 de junho 2013 e suas alterações.

Segundo os incisos I, II e III do Artigo 12 da Resolução CD/FNDE no26 (2013), compete ao RT - Nutricionista responsável pelas escolas de uma mesma localidade, acompanhar o estado nutricional do estudante, elaborar e acompanhar o cardápio do âmbito escolar, coordenar e orientar ações de EAN (Educação Alimentar e Nutricional).

Segundo o Artigo 38o da Resolução CD/FNDE no26 (2013), que estabelece as normas de repasse financeiro do FNDE para as escolas, onde delibera o recurso financeiro para aquisição dos gêneros alimentícios. Define o valor repassado de acordo a idade e escolaridade do aluno, a localização de sua instituição, sempre baseado no Censo Escolar do ano anterior. (BRASIL, Resolução CD/FNDE/MEC № 1, 2017)

Com isto, estabelece que a fiscalização do FNDE utilizando a ferramenta do Censo Escolar, proporcionou a viabilização de novos repasses e correções nas legislações estabelecidas, já que os gêneros alimentícios permitidos e controlados pela sua composição nutricional, devem compor um cardápio saudável e variado, e o repasse destinado especificamente ao estabelecimento do cardápio, tem objetivo de promover a saúde 
dos assistidos pelo programa.

Porém o PNAE, não só regulamenta os repasses e os agentes responsáveis da alimentação escolar, como também regulariza as normas de promoção de alimentação saudável, por meio de proibições e restrições decorrentes da Seção I Art.22 e Art.23 da Resolução CD/FNDE no26 (2013), é proibido a aquisição e distribuição de alimentos ultra processados, semiprontos e considerados não saudáveis, segundo o Guia Alimentar Brasileiro (2014) nos âmbitos escolares assistidos no PNAE.

A Seção II da Resolução CD/FNDE no26 (2013) conta com os Artigos que fomentam a alimentação escolar, por meio do planejamento de cardápio, número de refeições, tamanho das porções, seu aporte nutricional e sua aceitabilidade, baseando sempre no aluno assistido pelo programa, onde regulariza em seu Art. 14 que a elaboração dos cardápios devem ocorrer apenas pela profissional nutricionista responsável técnico pelo PNAE, respeitando as necessidades nutricional de cada faixa etária, definindo o horário de distribuição das refeições, porcionando adequadamente os nutrientes nas respectivas preparações, respeitando sempre as tradições e culturas regionais e preservando a segurança e sustentabilidade alimentar.

Sempre com a finalidade de promover a saúde dos assistidos, os cardápios devem suprir os nutrientes considerados prioritários para o programa (calorias, carboidratos, proteínas, lipídeos, além dos micronutrientes como cálcio, ferro, vitamina A), os incisos da Seção II da Resolução CD/FNDE no26 (2013), definem que deve atender, em média, às necessidades nutricionais por refeição oferecida:

No mínimo, 20\% (vinte por cento), quando oferecida 1 refeição aos alunos em período parcial, e 30\% quando localizadas em comunidades indígenas e localizadas em áreas remanescentes de quilombos;

No mínimo, 30\% (trinta por cento), quando ofertadas 2 ou mais refeições, aos alunos matriculados na educação básica, em período parcial;

No mínimo, 70\% (setenta por cento) das necessidades nutricionais dos alunos matriculados na educação básica, incluindo as localizadas em comunidades indígenas e em áreas remanescentes de quilombos, quando em quando em período integral.

O Art. 16 da mesma Seção II, da Resolução CD/FNDE no26 (2013), também regulamenta, que para as preparações diárias da alimentação escolar, adequa-se à apenas $10 \%$ do VCT de toda a refeição sejam proveniente de açúcar simples adicionado; que 15 a 30\% seja de gorduras totais; indicando no máximo $10 \%$ seja de gordura saturada, e 1\% (se possível eliminar), de gordura trans; no máximo $1200 \mathrm{mg}, 400 \mathrm{mg}$ ou $600 \mathrm{mg}$ de sódio per capita, variando de acordo ao período do aluno presente na escola; e finalizando define sobre a oferta de doces que fica limitada a 2 porções por semana 110 kcal por porção oferecida.

Sendo assim entende-se que o PNAE trouxe inúmeros benefícios a alimentação escolar, promovendo alimentação saudável e adequada dos alunos assistidos, onde a Segurança Alimentar é baseada no planejamento de cardápio e nas necessidades nutricionais de acordo ao grupo-alvo, respeitando sempre suas tradições culturais e regionais, verificando a aceitabilidade das preparações, com a intenção de deter uma dieta rica em açúcares e gorduras, e promover hábitos alimentares saudáveis.

O PNAE também é responsável por assegurar o repasse de verba correto advindo do FNDE, onde utiliza de inúmeras ferramentas legais de fiscalização, por meio de seus conselhos e colegiados, pretende sempre atualizar seus padrões para assistir seus beneficiados de forma correta e segura.

\subsection{DESPERDÍCIO DE ALIMENTOS}

No gerenciamento de uma Unidade de Alimentação e Nutrição (UAN), o desperdício é um fator de grande relevância. 0 desperdício de alimentos na cadeia alimentar tem causas econômicas, políticas, culturais e tecnológicas, que abrangem as principais etapas da cadeia de movimentação: produção, transporte, comercialização, sistema de embalagem e armazenamento (CASTRO, 2002).

$\mathrm{O}$ controle do desperdício deve ser monitorado também durante o pré-preparo dos alimentos. Na otimização das técnicas envolvidas nesta etapa, deve-se levar em conta critérios econômicos (RIBEIRO, 2003), utilizando o fator de correção, que é um índice que determina a relação entre o peso bruto (alimento in natura) e o peso líquido (alimento depois de limpo e preparado para utilização), denotando assim o percentual de perdas dos alimentos (KIMURA, 1998). Cada serviço de alimentação deve estabelecer sua tabela de fator de correção de acordo

com o tipo de alimento que adquire para maior segurança a respeito das quantidades a comprar, 
permitindo diagnosticar algum tipo de desperdício no momento do preparo desses alimentos (ORNELLAS, 2001).

Segundo Silva \& Teixeira (2007), o desperdício ocorre também quando não há planejamento adequado do volume de refeições a ser preparado. 0 número de comensais, o cardápio do dia e até mesmo a estação climática, devem ser considerados antes de ser definida a quantidade de alimento a ser preparada, a fim de evitar sobras. Mas, se a sobra de alimentos for inevitável, devem-se seguir rigorosamente alguns critérios técnicos, de forma a poder aproveitá-las seguramente.

Um aspecto importante que contribui para agravar a disponibilidade mundial de alimentos é o elevado padrão de perdas, especialmente nas etapas de distribuição alimentar, que subtrai do esforço produtivo parcela considerável da produção alimentar. Estudos técnicos indicam que é expressivo o desperdício em todas as fases da produção até o consumo, podendo atingir a cifra de $25 \%$ da produção global de alimentos até 2050 (NELLEMANN et al., 2009).

Definem-se sobras limpas como alimentos prontos que não foram distribuídos, sendo que a avaliação diária destas é uma medida utilizada no planejamento da quantidade produzida e permite inferências quanto à qualidade e aceitabilidade do cardápio. 0 excedente de alimentos distribuídos não é considerado sobra, e sim resto (ESPERANÇA, 1999).

As sobras limpas que forem encaminhadas para congelamento devem atingir temperaturas em torno de $6^{\circ} \mathrm{C}$. Alimentos congelados na faixa de -5 a $-10^{\circ} \mathrm{C}$ podem permanecer por até 20 dias armazenados (ABERC, 2003).

Para Abreu, Spinelli e Zanardi (2003) o desperdício de alimentos é sinônimo de falta de qualidade e deve ser evitado por meio de um planejamento adequado, a fim de que não existam excessos de produção e consequentes sobras.

Segundo Maciel (1997) os treinamentos aos funcionários são de suma importância para o desempenho de qualquer tarefa, pois de modo geral, os manipuladores, ao serem admitidos não possuem qualquer treinamento na área de alimentação e nutrição.

Para Andreotti et al. (2003) é indiscutível que os programas de treinamento específicos para manipuladores de alimentos são o meio mais recomendável e eficaz para transmitir conhecimentos e promover mudanças de atitudes.

Conforme Almeida, Nunes e Andrade (2007) cada serviço deve estabelecer sua tabela de Fator de correção de acordo com o tipo de alimento que adquire.

0 indicador de desperdício chamado Fator de Correção (FC) é definido como a relação entre o peso do alimento bruto, ou seja, na forma como foi adquirido, com cascas, talos, sementes, e o peso do alimento líquido, após passar por processo de limpeza. É um indicador que determina a quantidade exata de alimento que foi descartada e que deve ser empregado no planejamento quantitativo de um cardápio e consequentemente, no seu valor nutricional. (LEMOS; BOTELHO \& AKUTSU, 2011)

Segundo Augustini et al. (2008) medidas como campanhas direcionadas aos clientes para que controlem seus restos e os conscientizem de que eles fazem parte do processo de redução do desperdício, são medidas que podem ajudar na redução dos restos de alimentos.

O desperdício pode envolver os alimentos que não foram utilizados, preparações prontas que não chegam a ser distribuídas e ainda os alimentos que sobram nos pratos dos clientes(RICARTE et al, 2005), sendo definido a que o desperdício de alimentos pode estar em qualquer etapa da produção.

O termo "Banco de Alimentos" é geralmente definido por suas funções. Formalmente, o Ministério do Desenvolvimento Social e Combate à Fome (MDS) define, os bancos de alimentos como "uma iniciativa de abastecimento e segurança alimentar que tem como objetivos a redução do desperdício de alimentos, o aproveitamento integral dos alimentos e a promoção de hábitos alimentares saudáveis, contribuindo diretamente para a diminuição da fome de populações vulneráveis, assistidas ou não por entidades assistenciais" (BRASIL, 2007). Mediando intervenções aplicáveis e de baixo custo que alcancem a comunidade.

Evitar o desperdício também significa aumentar a rentabilidade da UAN, pois os restos alimentares trazem em si uma parcela dos custos de cada etapa da produção: custos de matéria- prima, tempo e energia, da mão-de-obra e dos equipamentos envolvidos (CORRÊA et al, 2006) 
A gestão de uma cozinha industrial envolve serviços, produção de alimentos, comensais e fornecedores, e dentro deste contexto surge a necessidade do respeito e preservação dos recursos naturais, que representa uma obrigação mundial. Experiências aplicadas demonstram a redução significativa dos custos fixos quando são desenvolvidos trabalhos para redução no consumo de água, energia elétrica, geração de lixo e coleta seletiva. A busca de um serviço de alimentação autossustentável foi o grande desafio das próximas gerações em prol da preservação do planeta. (MONTEIRO \& BRUNA, 2004).

A forma que se podem caracterizar estes desperdícios ou perdas são inúmeros. Conceitualmente perda ou desperdício é alguma mudança na viabilidade, comestibilidade, salubridade ou qualidade do alimento que o impeça de ser consumido por pessoas, podendo ser igual ao produto colhido menos o produto consumido (FILHO, 1996).

Em uma UAN (Unidade de Alimentação e Nutrição), de acordo com Teixeira (2000) o desperdício é proveniente da sobra de alimentos (alimentos preparados e não distribuídos) e restos (alimentos distribuídos e não consumidos) (BRADACZ, 2006).

Dentro do custo mensal de uma UAN (Unidade de Alimentação e Nutrição), estão incluídos os custos das sobras, portanto, espera-se que os restos produzidos pelos serviços não ultrapassem $5 \%$ da produção de alimentos, o que os classifica na condição de ótimos. Aqueles serviços cujo desperdício de alimentos varia entre 5\% e 10\% são classificados como bons e na faixa regular estão os serviços que perdem entre $10 \%$ e $15 \%$. As perdas alimentares que superam 15\% da produção representam um indicativo de péssimo desempenho do serviço (NONINO-BORGES et al, 2006).

O FNDE estabelece no Anexo VII da RESOLUÇÃO/CD/FNDE № 38 (2009), que a avaliação de restos ou Resto Ingestão, é um método que se baseia na obtenção dos pesos referentes à refeição rejeitada e à refeição distribuída. Definindo o índice de aceitabilidade da preparação oferecida, onde este índice de deve ser de, no mínimo, 90\%. Quando a preparação tem índices de consumo inferior a 90\%, este tópico é utilizado como critério de exclusão da preparação do respectivo cardápio.

\subsection{SUSTENTABILIDADE ALIMENTAR}

A discussão sobre alimentação e sustentabilidade se inicia com a questão se será possível a terra alimentar nove bilhões de habitantes, previstos para viver no planeta em 2050 (CONTE, BOFF, 2013) sem degradá-la de modo irreversível e com dieta alimentar que contribua para a sustentabilidade, ao mesmo tempo que garanta a saúde e o bem-estar das pessoas.

O fornecimento de um alimento seguro ao consumidor envolve o conhecimento e uso de manipulação adequada, seguindo os princípios de Boas Práticas de Fabricação (BPF). As BPFs englobam os princípios e procedimentos fundamentais necessários à produção de alimentos com qualidade desejável. É importante se utilizarem práticas de higiene, em que medidas sanitárias devem ser seguidas e mantidas pelos estabelecimentos, as quais devem ser sempre aplicadas e registradas, sendo pré-requisitos para outros sistemas, em especial, a análise de perigos e pontos críticos de controle, o APPCC. (LEVINGER, 2005)

Segundo o Plano de Ação da Cimeira Mundial de Alimentação (1996), "existe segurança alimentar, quando as pessoas têm, a todo o momento, acesso físico e econômico a alimentos seguros, nutritivos e suficientes para satisfazer as suas necessidades dietéticas e preferências alimentares, a fim de levarem uma vida ativa e sã. A este respeito é necessária uma ação concertada, a todos os níveis." Assim, a responsabilidade dos Estados nacionais seria assegurar esse direito e fazê-lo em obrigatória articulação com a sociedade civil, cada parte cumprindo suas atribuições específicas (VALENTE,2002).

Autores como Azevedo e Rigon (2005) e Navolar (2007) têm explorado em seus trabalhos a relação entre a Agroecologia e a Agricultura Familiar Orgânica e a perspectiva da promoção da saúde e da qualidade de vida dos produtores de alimentos produzidos de forma sustentável.

Segundo Cassol e Schneider (2015), a interação entre as formas de produzir e comercializar e os modos de consumir e alimentar são cruciais para desenvolver práticas sustentáveis, tanto de produção quanto de consumo.

Maluf et al. (2015) discutem o papel dos modelos agrícolas na promoção da saúde e apresentam a importância socioeconômica e ambiental da agricultura familiar e seu potencial para contribuir para o que denominam “Agricultura Sensível à Nutrição". Esse conceito orienta- se pela perspectiva dos Determinantes 
Sociais da Saúde e considera que a promoção da alimentação saudável, e com ela a garantia de segurança alimentar e nutricional, derivará de sistemas alimentares mais justos socialmente e ambientalmente sustentáveis.

Há um processo produtivo alimentar, crescentemente globalizado e dominante, com incontáveis e complexas ramificações e implicações sobre a sustentabilidade, a cultura, a sociedade, a economia e, mais importante, sobre a saúde e o bem-estar humano. "O superconsumo de alimentos não saudáveis se dá às custas da resiliência do planeta" (THE LANCET, 2016).

Percebe-se, assim, que uma visão ampliada de alimentação saudável e sustentável envolve saberes e práticas de diversos atores e campos do conhecimento que se relacionam com a alimentação e o sistema alimentar. Dessa forma, torna-se importante compreender não só o que se come, mas também as formas de produção (modelos de agricultura e pecuária) e de acesso aos alimentos (políticas de abastecimento e comercialização, em diferentes modalidades) e os aspectos da comensalidade, ou seja, os modos de comer de indivíduos e coletividades. (MONTEIRO et al., 2015)

\subsection{PANC'S E PARTES NÃO CONVENCIONAIS DE ALIMENTOS CONVENCIONAIS}

As Plantas Alimentícias Não Convencionais (PANC) estão entre as fontes dealimentos que se desenvolvem em ambientes naturais sem a necessidade de insumos e da derrubada de novas áreas (BRESSAN ET AL., 2011).

0 consumo das PANCs pode ser estratégia para manter a diversificação alimentar, estimulando a manutenção da floresta. Se realizado de maneira sustentável, pode ser considerada uma forma de utilização com baixo impacto na agricultura, associada à conservação ambiental (KINUPP, 2007).

As PANCs estão presentes em determinadas comunidades ou regiões, onde ainda exercem influência na alimentação de populações tradicionais, porém passaram a ter expressão econômica e social reduzidas, perdendo espaço para outros produtos (BRASIL, 2010).

No Brasil, diversas PANCs são utilizadas para consumo alimentar de muitas famílias, sendo as mesmas consumidas in natura, refogadas, em formas de doces, cocadas, dentre outros; porém, ainda são poucos os estudos sobre o uso destas plantas (BARREIRA, 2015).

\subsection{APROVEITAMENTO INTEGRAL DE ALIMENTOS}

A temática do aproveitamento integral de hortaliças constitui um foco chave para o empreendimento de práticas educativas ambientais, que sob o prisma da sustentabilidade, venham a articular qualidade de vida com conservação ambiental. (STEUER, Et al., 2013)

Também conhecida como alimentação alternativa, Santos (2001) define como um estímulo de propiciar na alimentação dos brasileiros, pelo consumo de partes não convencionais de alimentos tradicionais e não tradicionais, já que são bastante nutritivos e acessíveis.

Pesquisas mostram que são desperdiçados $30 \%$ dos alimentos comprados (cascas, talos, folhas e sementes de verduras, legumes e frutas), por falta de informação sobre o valor nutricional e a forma correta de preparo. (PIROZZI, 2007)

Santos e Cintra (2015) defendem que o aproveitamento integral das partes não convencionais de alimentos convencionais, seja aplicado como ferramenta da sustentabilidade alimentar e ambiental, já que possibilita reduzir os resíduos orgânicos, ampliando a utilização de recursos naturais, levando a melhoria os repasses financeiros para alimentação, enriquecendo as refeições com nutrientes e alimentos variados.

Belik (2012), apoia o uso do "aproveitamento de alimentos não utilizados", como solução eficaz para os problemas relacionados a fome, pois segundo ele, tanto os produtores, quanto os consumidores se beneficiam, já que a utilização correta do alimento desde a comercialização até o consumo, de forma segura geraria a sustentabilidade alimentar e consequentemente a redução do desperdício.

Como o homem necessita, de qualquer modo, de uma alimentação sadia, rica em nutrientes, isto pode ser alcançado com partes de alimentos que normalmente são desprezadas. (GONDIM, 2005)

Gondim (2005), ainda descreve os métodos da utilização da ferramenta de aproveitamento integral de alimentos, afirmando que são advindas de partes não muito convencionalmente utilizadas, mas que são comestíveis e muito nutritivas, por meio das cascas, talos, folhas, entrecascas, sementes. Demonstrando 
inovações, já que possibilita a elaboração de novas preparações, como, por exemplo, sucos, tortas, geleias, farinhas, bolos, entre outras preparações.

As partes não convencionais dos vegetais analisados podem ser consideradas como fontes alternativas de nutrientes, auxiliando no alcance das necessidades nutricionais, assim como suas partes convencionais, colaborando para a redução do desperdício alimentar, melhora do estado de saúde e qualidade de vida dos indivíduos. (MONTEIRO, 2009)

Storck (2013) defende que, através da identificação da composição nutricional, é possível aprimorar o uso nas elaborações, preparações e porcionamento.

As análises químicas mostraram que as cascas das frutas apresentam, em geral, teores de nutrientes maiores do que os das suas respectivas partes comestíveis. Desta forma, as cascas das frutas analisadas podem ser consideradas como fonte alternativa de nutrientes, evitando o desperdício de alimentos. (GONDIM, 2005)

\subsection{ACEITABILIDADE DAS PREPARAÇÕES}

A Resolução № 26 de 17 de junho de 2013 define Teste de Aceitabilidade como, o conjunto de procedimentos metodológicos, cientificamente reconhecidos, destinados a medir o índice de aceitabilidade da alimentação oferecida aos escolares.

Entre os métodos sensoriais de aceitação recomendados para o PNAE, o Método Sensorial Afetivo representa a preferência e aprovação do consumidor.

Os métodos afetivos representam a opinião do consumidor e avaliam o quanto o consumidor gosta ou desgosta do produto". (AUST, 1987 apud ISAAC, Et al., 2012)

Dentro desta metodologia é disponibilizado dois tipos de testes para serem utilizados, segundo o CECANE (2017), o teste de preferência, onde avalia o grau de preferência de um produto, ou, o teste de aceitação que avalia a aceitação de um produto de acordo ao gosto do provador e sua avaliação singular.

A indicação prossegue pelo conselho, pretendendo para facilitar a aplicação do teste de aceitabilidade, emprega-se a Escala Hedônica.

O Instituto Adolfo Lutz (2008) define que os testes de aceitação devem utilizar uma escala do ideal de procedimento, nesta escala o indivíduo expressa como está sua preferência em relação a intensidade do produto consumido. Podendo conter de 1 a 5 pontos, sendo opostos, como por exemplo: "muito fraco", "desgostei", "gostei", "muito forte", "nem gostei nem desgostei" e no centro da escala o termo "ideal", porém sua representação de intensidade não se delimita somente aos termos, aplicando-se também figuras e números.

A escala hedônica (facial e verbal), instrumento validado, o qual consiste na avaliação de um produto - no caso, o cardápio - a partir de uma escala gradativa, com pontos que representam psicologicamente a aceitação, de um grupo escolar. (SOUZA, 2007)

O Manual para Aplicação dos Testes de Aceitabilidade do CECANE (2017), ainda propõe que as escalas sejam definidas pela faixa etária e escolaridade, orientando modelos mais lúdicos e interativos para públicos mais jovens, e em públicos mais maduros o uso de termos e valores de intensidade. Orienta também que para uma amostra válida, a escala hedônica deve ter cada grupo definido mínimo de $100 \mathrm{ou}$ mais provadores. A sugestão é selecionar $20 \%$ a mais de estudantes do que o proposto, evitando que um número significativo de ausentes reduziria a confiabilidade do teste.

Definida a importância deste teste na alimentação escolar, foi determinado como atribuições do Nutricionista RT do PNAE, regulamentado pelo Capítulo I Art. 3 o da Resolução CFN № 465/2010,

VII - Planejar, coordenar e supervisionar a aplicação de testes de aceitabilidade, sempre que ocorrer no cardápio a introdução de alimento novo ou quaisquer outras alterações inovadoras, no que diz respeito ao preparo, ou para avaliar a aceitação dos cardápios praticados frequentemente. Para tanto, devem ser observados parâmetros técnicos, científicos e sensoriais reconhecidos, estabelecidos em normativa do Programa. 0 registro se dará no Relatório Anual de Gestão do PNAE, conforme estabelecido pelo FNDE. (BRASIL/CFN, 2010) 
A Resolução № 26, então dispõe sobre o atendimento da alimentação escolar aos alunos da educação básica, no âmbito do Programa Nacional de Alimentação Escolar - PNAE. Compete no Capítulo V da Seção II no Art. 17, que a Entidade Executora deverá aplicar o teste de aceitabilidade aos alunos sempre que inserir no cardápio algum alimento ou preparação nova, ou quando houver quaisquer outras alterações inovadoras, sejam elas no preparo ou elaboração. Estabelece também que a Responsável Técnica Nutricionista deve planejar e coordenar os testes de aceitabilidade, além de realizar relatório da ação proposta e avaliar o resultado, sendo que o índice de aceitabilidade deve ser de, no mínimo, 90\% para Resto Ingestão e de 85\% para Escala Hedônica.

Por conta da obrigatoriedade do teste de aceitabilidade nas escolas assistidas pelo PNAE que propõem inovações e modificações do cardápio, o FNDE buscou padronizar em Manual Para Aplicação dos Testes de Aceitabilidade (2017), regulamentado pelo Ministério da Educação e o FNDE, dentro do Programa Nacional de Alimentação Escolar (PNAE), adequando as normas de acordo as legislações vigentes, revisado e atualizado em 2017, pelo CECANE/ UFRGS.

\section{METODOLOGIA}

O projeto contou com pesquisa bibliográfica, buscando enriquecer a fundamentação teórica, segundo Lima e Mioto (2007), a pesquisa bibliográfica contribui com elementos que auxiliam análises futuras dos dados obtidos, e comparação com os dados científicos já estabelecidos.

Foi utilizado o método de pesquisa descritiva tipo transversal, que foi responsável pelo o levantamento quantitativo do projeto, "o estudo descritivo é utilizado quando a intenção do pesquisador é conhecer determinada comunidade, suas características e valores". (OLIVEIRA, 2011)

Utilizando a ferramenta do Censo Escolar de Minas Gerais - 2018, também utilizada pelo PNAE e regulamentada pela RESOLUÇÃ̃O № 26 de 17 de junho de 2013, pretende-se levantar os dados dos grupos amostral e das instituições assistidas.

O método central foi o de Intervenção, pois contou com a aplicação de novas técnicas e procedimentos, procurando obter ação transformadora entre a instituição e a sociedade.

Dentro desta abordagem, Mendes, Pezzato e Sacardo (2016), estimula a Pesquisa-Intervenção, pois permite a quebra dos paradigmas tradicionais, envolvendo a participação técnica e política, daqueles que serão atingidos ou envolvidos pelas ações. Sendo uma ação que respeita as habilidades dos pesquisadores, a disponibilidade e atenção da instituição atendida, e das experiências e características do alvo. Portanto, a intervenção permite sensibilidade, aproximando o científico da realidade assistida, permitindo escuta e abertura com a comunidade, por meio do respeito e confiança.

Foi similarmente utilizadas intervenções educativas de conscientização do desperdício de alimentos e do reaproveitamento integral de alimentos, com as Manipuladoras de Alimentos de cada turno escolar, pois, "Só com a conscientização, através da Educação Nutricional, é que se pode reverter o quadro alimentar atual do Brasil". (SESC, 2003)

Contou também com a realização e aplicação do Teste de Aceitabilidade, pois contou com modificações inovadoras e sustentáveis, nas técnicas de preparo das refeições e sugestão de inserção de novas preparações ao cardápio do âmbito escolar. A preparação foi realizada pelas pesquisadoras, seguindo a ficha técnica de preparação. Percorrendo todas as etapas, de pré-preparo, produção e pós-produção, todas seguindo o manual das Boas Práticas.

0 teste foi aplicado aos alunos das escolas, seus procedimentos acontecerão no ambiente escolar, acontecerá seguindo a regulamentação do Manual Para Aplicação Dos Testes De Aceitabilidade revisado pelo CECANE (2017), e da Resolução CD/FNDE no 26/2013 no Programa Nacional de Alimentação Escolar (PNAE), a fim de garantir o controle de qualidade dos alimentos ofertados na alimentação escolar, buscando inovação e sustentabilidade alimentar.

Os métodos afetivos representam a opinião do consumidor e avaliam o quanto o consumidor gosta ou desgosta do produto. (AUST, 1987 apud ISAAC, Et al.,2012)

A aceitação foi avaliada através da Escala Hedônica Facial, com Provadores Não- Treinados, Grupo Amostral de 100 alunos (com 20\%, de margem de segurança no recrutamento), de idade entre 6 a 10 anos (1음 ao ano do Ensino Fundamental) e de 10 a 14 anos (5 ao 9o ano do Ensino Fundamental) na Escola Estadual Adelaide Bias Fortes, no município de Barbacena - MG. 
Foi utilizado o Modelo indicada pelo CECANE (2017), de ficha de Escala Hedônica Facial, ilustrado na Fig. 1, para teste em escolares de 1o ao 5o ano; e ficha de Escala Hedônica Verbal, ilustrado na Fig. 2, para teste em escolares a partir do 60 ano. Exprimindo de maneira mais lúdica, utilizando figuras (rostinhos) ou termos para indicar a preferência e satisfação do provador. As fichas foram impressas e entregues de acordo a faixa etária de cada grupo aplicado. Seu resultado foi avaliado pelo número de respostas para cada expressão, calculando a percentagem das mesmas, sendo que se a amostra apresentar uma percentagem maior ou igual a 85\% nas expressões "gostei" e "adorei", a preparação/alimento testado foi aceito.

Figura 4 - Modelo de ficha de escala hedônica facial, utilizada para escolares de $1^{\circ}$ ao 5o ano.

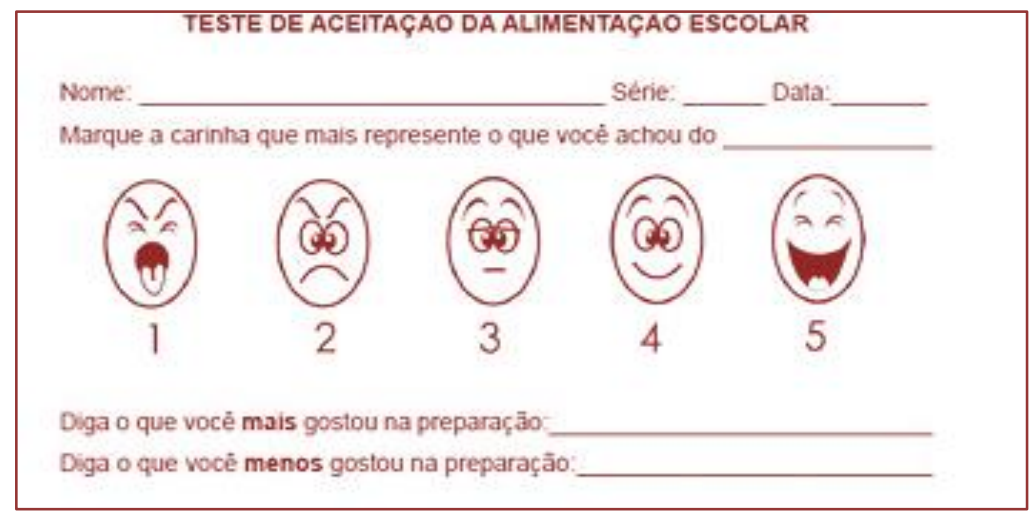

Fonte: CECANE (2017)

Figura 5 - Modelo de ficha de escala hedônica verbal, utilizada para escolares a partir do 6ํano.

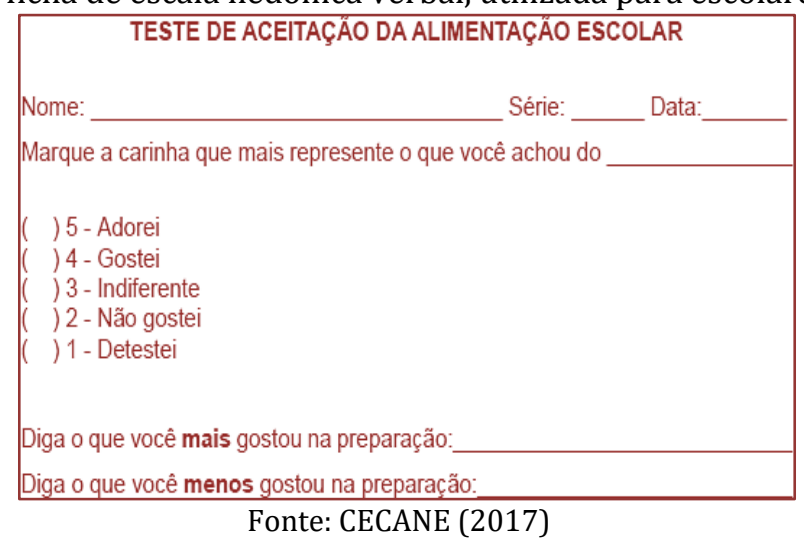

0 teste de aceitabilidade foi realizado uma vez, podendo ser aplicado novamente em caso de rejeição ou modificações nas quantidades de ingredientes e métodos de preparo, tendo intervalo mínimo de 30 dias entre os procedimentos. 0 teste de aceitabilidade somente foi aplicado sob a autorização e entrega do TCLE assinado pelos responsáveis legais de cada aluno.

A equipe contou com duas pesquisadoras, um orientador, um colaborador voluntário interno, dois colaboradores das instituições externas e a coordenação e colaboração da Nutricionista: Josélia Pricila de Paula (CRN:12704) Responsável Técnica do PNAE, no município de Barbacena SER 3o.

\section{RESULTADO E DISCUSSÃO}

0 projeto de extensão foi iniciado em julho de 2019. As atividades realizadas foram de coleta dos dados do censo escolar, apuração de dados nutricionais e fator de correção dos alimentos destacados, teste de aceitabilidade, palestra e capacitação profissional das manipuladoras de alimentos, apuração e comparação dos resultados obtidos.

A instituição participante foi escolhida em conjunto a indicação da Secretaria Estadual de Educação de 
Minas Gerais (3ํSEE - Barbacena), como instituição que tinha maior reclamações de alta produção de resíduos, a maioria deles sendo descartado na cozinha. 0 vínculo então foi estabelecido com a instituição, havendo total aceitação dos diretores, e colaboração de servidores para realização das atividades.

A Tabela 1 aborda a quantidade de alunos assistidos pelo PNAE na instituição estadual "E. E. Adelaide Bias Fortes" do município de Barbacena, os dados foram recolhidos em julho de 2019 a partir do Censo Escolar. o Censo Escolar é o principal instrumento de coleta de informações da educação básica e a mais importante pesquisa estatística educacional brasileira. É coordenado pelo Inep e realizado em regime de colaboração entre as secretarias estaduais e municipais de educação e com a participação de todas as escolas públicas e privadas do país. (INEP,2019)

Tabela 1 - Alunos beneficiados por grau de escolaridade com o PNAE na "Escola Estadual Adelaide Bias Fortes" do município de Barbacena no ano de 2019

\begin{tabular}{|c|c|c|c|c|c|c|c|c|c|}
\hline \multirow{3}{*}{ Nome da escola } & \multicolumn{2}{|c|}{ Fundamental } & \multicolumn{2}{|c|}{ Médio $\quad 2019$} & \multirow{2}{*}{\multicolumn{2}{|c|}{$\begin{array}{c}\text { Fundamental EJA } \\
\text { Presencial }\end{array}$}} & \multirow{3}{*}{$\begin{array}{c}\text { Médio EJA } \\
\text { Presencial } \\
\text { Parcial }\end{array}$} & \multirow[t]{3}{*}{ AEE } & \multirow[t]{3}{*}{ Total } \\
\hline & \multirow{2}{*}{ Parcial } & \multirow{2}{*}{ Integral } & \multirow{2}{*}{ Parcial } & \multirow{2}{*}{ Integral } & & & & & \\
\hline & & & & & Parcial & Integral & & & \\
\hline $\begin{array}{l}\text { Escola Estadual } \\
\text { Adelaide Bias } \\
\text { Fortes }\end{array}$ & 1230 & 98 & 0 & 0 & 0 & 0 & 0 & 24 & 1352 \\
\hline
\end{tabular}

Fonte: (INEP,2019)

A quantidade de alunos matriculados no ano de 2019 na instituição, está identificada no gráfico 1, onde demonstra a divisão de alunos por série do Ensino Fundamental Ie II. As aulas do 6o ao 9o ano ocorrem no período matutino, e as de 1 ao 5o ocorrem no período vespertino, respectivamente, considerando que 98 alunos participam do período integral (manhã e tarde).

Gráfico 1 - Alunos ativos por série do Ensino Fundamental na "Escola Estadual Adelaide Bias Fortes" do município de Barbacena no ano de 2019.

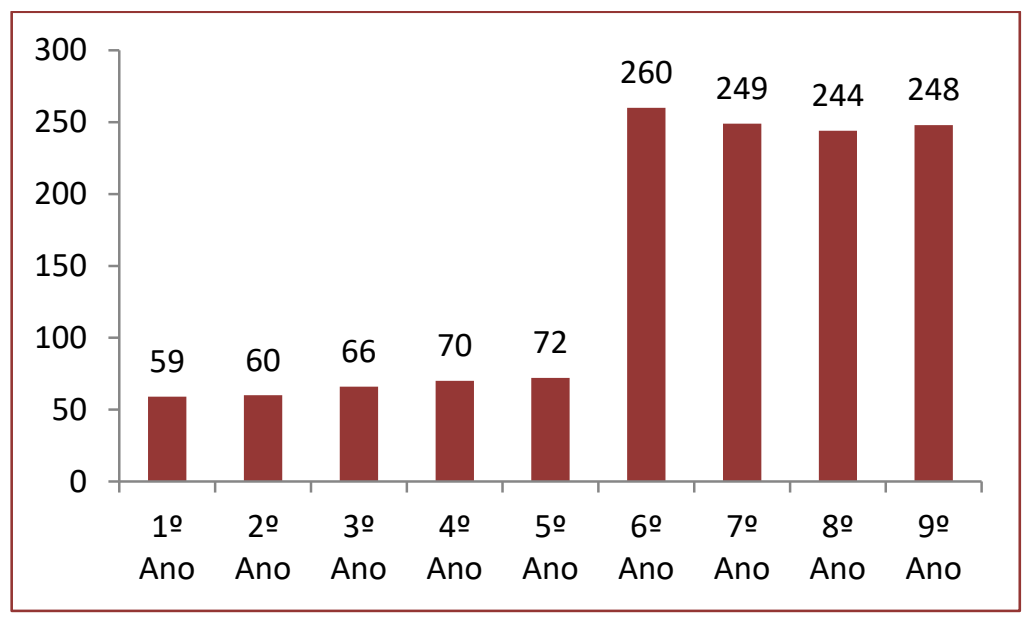

Fonte: Dados obtidos durante a pesquisa.

\section{- Teste de Aceitabilidade}

A preparação testada, descrita no Anexo I - Ficha Técnica de Preparo, foi um Bolo Integral de Laranja, com uso integral das Partes Não Convencionais de Alimentos Convencionais (PANC). A composição nutricional da preparação, segue no Anexo II.

O recrutamento dos provadores não treinados, ocorreu 25/09/2019, sendo entregue a todos os discentes da escola, o TCLE presente do Anexo III, para obtenção da assinatura dos responsáveis, englobando todas as turmas. 0 grupo amostral utilizado foi de 100 provadores, escolhidos aleatoriamente por meio de sorteio, no dia 26/09/2019, após o recolhimento do termo assinado pelos participantes selecionados, os mesmos foram enviados ao refeitório para início da análise da amostra. 
A execução do teste de aceitabilidade, exposto na fig. 4, ocorreu dentro do esperado, tendo duração de 2 horas, nas instalações da instituição "Escola Estadual Adelaide Bias Fortes", contando com equipe de duas pesquisadoras e duas colaboradoras, iniciou as 10 horas da manhã do dia 26/09/2019.

Participaram efetivamente do Teste de Aceitabilidade o total de 148 alunos (utilizando margem de erro de $20 \%$ ), assim que houve a entrada dos alunos no ambiente, foram entregues a amostra de $50 \mathrm{~g}$, acompanhando uma "ficha de escala hedônica verbal" considerando que os participantes tinham idade entre 10 a 14 anos, as informações de qual era a preparação ou sabor da amostra foram ocultadas até o fim do teste, as fichas foram preenchidas sem identificação e recolhidas ao final da atividade.

A obtenção de todos os dados, foi realizado no mesmo dia, pelas pesquisadoras, realizando a contagem de fichas e o cálculo da percentagem índice de aceitabilidade, com o auxílio do Manual Para Aplicação Dos Testes De Aceitabilidade revisado pelo CECANE (2017) que regulamenta todo o teste de aceitabilidade. Depois foi realizada sua tabulação demonstrado na tabela 2.

\section{Cálculo do Índice de Aceitabilidade = Nota obtida para a amostra x 100 \\ Nota máxima da escala utilizada}

(CECANE, 2017)

\begin{tabular}{|c|c|c|}
\hline \multicolumn{3}{|c|}{ Tabulação de notas em grupo amostral de 100 provadores } \\
\hline Índice & Quantidade de votos & Porcentagem \\
\hline Adorei & 28 & $28 \%$ \\
\hline Gostei & 63 & $63 \%$ \\
\hline Indiferente & 4 & $4 \%$ \\
\hline Não gostei & 2 & $2 \%$ \\
\hline Detestei & 2 & $2 \%$ \\
\hline
\end{tabular}

Após os cálculos realizados, foram definidos seus resultados, demonstrado no Gráfico 2.

Gráfico 2 - Resultado do Teste de Aceitabilidade da preparação "Bolo Integral de Laranja" (cascas, insumos e sementes).

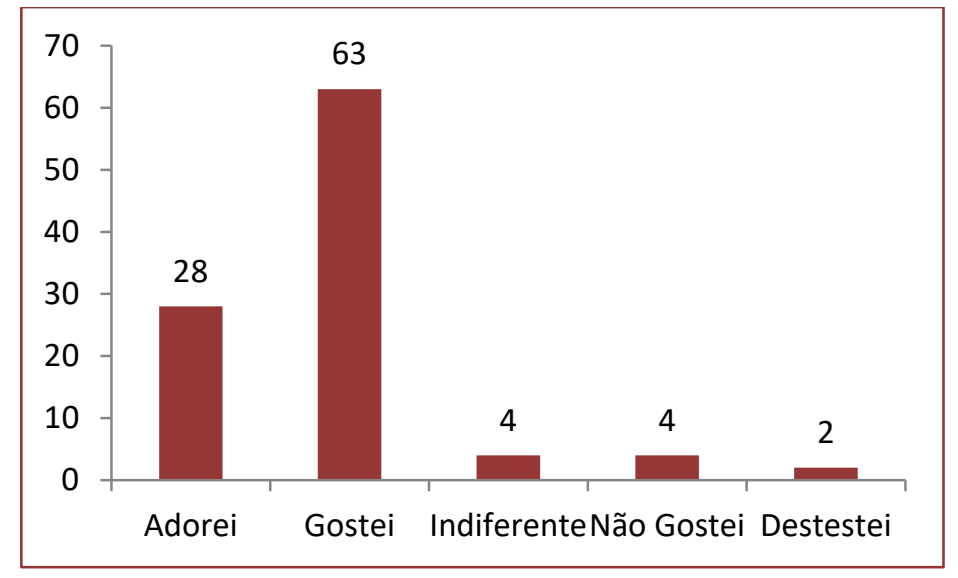

Fonte: Dados obtidos na pesquisa.

0 resultado do Teste de Aceitabilidade atingiu o total de 91\% de aceitabilidade, dos quais foram: $2 \%$ Detestei; 4\% Não Gostei; 4\% Indiferente; 63\% gostei; $28 \%$ adorei, respectivamente.

Foi possível observar com os dados obtidos, que as preparações seriam aceitas caso aderidas ao cardápio escolar, permitindo visualizar que há aceitabilidade entre os alunos. Demonstrando viabilidade do uso do aproveitamento integral para enriquecimento da alimentação, em sabor, nutrientes e sustentabilidade. Segundo Rocha (2001), é possível notar que o teste de aceitabilidade é um instrumento que contribui 
muito para o controle de desperdício no meio escolar.

Percebe-se que pelo fato de a fase escolar ser de maior socialização e independência, há melhor aceitação de novas preparações (SILVA; BASSANI \& ANTUNES, 2009). Diante disso, alguns fatores que podem favorecer respostas falso-negativas as quais delas são, idade, atividade em grupo, contato e influência da resposta entres os participantes. Porém não houve intercorrências ou diálogo durante a execução do teste. Da mesma forma foi considerada para as respostas, margem de erro de $2 \%$, tanto para mais tanto para menos.

- $\quad$ Capacitação Profissional

Uma das formas de redução dos riscos à saúde do consumidor é a adoção de boas práticas nos locais de manipulação de alimentos, reduzindo assim os riscos de DTAs. Considerando o manipulador como principal via de contaminação dos alimentos e sua importância na produção de alimentos em grande escala, a Resolução de Diretoria Colegiada (RDC) no 216 da Agência Nacional de Vigilância Sanitária (ANVISA) determina que todos os responsáveis pelas atividades de manipulação dos alimentos devem ser submetidos a curso de capacitação, abordando, no mínimo, os seguintes temas: contaminantes alimentares, DTAs, manipulação higiênica dos alimentos e Boas Práticas (GARCIA; CENTENARO, 2016). Outro fator que pode prevenir problemas de saúde é relação entre tempo e temperatura do alimento, que representa um dos mais importantes fatores dentre os que podem influir no crescimento de microorganismos em alimentos (ARTUR, 2004).

Diante dos autores pesquisados e em consonância com o resultado do teste de aceitabilidade com os alunos, foi ministrada uma capacitação profissionais para 25 manipuladoras de alimentos da rede escolar estadual do município de Barbacena, escolhidas juntamente a SEE. As instituições com servidoras ativas participantes foram: "E.E. Professor Soares Ferreira"; "E.E Maria do Rosário"; "E.E. Gabriela Ribeiro Andrade"; "E.E Adelaide Bias Fortes"; “E. E. Embaixador José Bonifácio”; "E.E Estadual Dr. Teobaldo Tolendal"; "E.

\section{E. São Miguel”; “E. E. Senhora das Dores”; “EFAFEM” “E. E. Alberto Vieira”.}

Esse curso ocorreu em parceria com o SENAC - MG - Barbacena, que contêm em sua grade do curso de Tecnólogo de Gastronomia, um Workshop sobre "Aproveitamento Integral de Alimentos", ministrado pela Nutricionista Chef. Josiane Aparecida de Andrade, que é docente vinculada da instituição.

Durante a capacitação foi ministrada uma palestra de conscientização sobre sustentabilidade alimentar e instrução sobre as BPF's. Com início do Workshop, a docente esclareceu a importância dos descascamento e cortes que reduzem a produção de resíduos em uma UAN, além de produção de receitas sustentáveis utilizando integralmente as PANC. Após os ensinamentos das receitas, houve um coffee break e roda de conversa, onde as manipuladoras de alimentos puderam tirar todas às dúvidas com as palestrantes.

Assim, a capacitação dos manipuladores é uma estratégia preconizada para melhorar a qualidade do serviços e produtos produzidos em âmbito escolar e nutrição, e tem fundamental importância para a garantia da segurança nutricional, ao evitar que sejam disseminadas práticas incorretas de higiene de alimentos, manipulação e exposição prolongada dos alimentos a temperaturas inadequadas e consequente aumento de resíduos nas etapas produção.

Composição das Preparações Sustentáveis

A preparação estudada, foi destacada pelo seu principal ingrediente, a laranja. Considerado um ingrediente muito utilizado pela população.

"A laranja fica em segundo lugar de frutas mais consumidas, com 5,44 $\mathrm{kg} /$ pessoa/ano. 0 crescimento da produção da fruta ajudou para um maior consumo. As frutas que são mais consumidas em lares brasileiros são a banana, laranja, melancia e maçã por serem frutas mais populares, relativamente baratas frente às demais, disponíveis durante praticamente todo o ano e encontradas na maioria dos estabelecimentos. São frutas sensorialmente aceitáveis e acessíveis a todas as classes de renda"(GALINDO, 2014)

0 fator de correção também foi um fator presente na escolha da preparação. Araújo et al (2007) define que para avaliação o desperdício de alimentos, utiliza-se o indicador de partes comestíveis, também conhecido como fator de correção. Expresso pela relação entre o peso bruto (PB) e o peso líquido do alimento (PL), é utilizado para determinar a quantidade de alimento a ser realmente utilizado, considerando que perdas podem ocorrer durante o pré-preparo e na preparação. 
A laranja é considerada um alimento com perda massiva de produto, já que na maioria das vezes são descartados seu bagaço, semente, entrecasca e casca. Segundo Anjos (2012) seu Fator de Correção se encontra entre 1,39 - 2,13 a cada $100 \mathrm{~g}$ da fruta. Considerando que o menor fator de correção $(1,39)$, indica que foi consumida a fruta fresca, sem a casca, mas com bagaço e insumos. Já o maior fator de correção $(2,13)$ considera que é utilizado apenas o suco da fruta, descartando todas as outras partes.

Durante a preparação foi aferido o peso da laranja sem nenhuma parte retirada (PB), com o peso de 137g, e após a retirada do insumo central dos gomos (partes brancas) (PL) foi aferida peso de 129g, calculando seu fator de correção entre 1,05 - 1,06. Comparado a literatura, conseguimos avaliar que a redução de resíduos é comprovada mediante fator de perdas do alimento.

Foi realizada também a comparação da composição nutricional das Partes Não Convencionais de Alimentos Convencionais (PANC), utilizadas na preparação, a qual foi distribuída no teste de aceitabilidade, "Bolo Integral de Laranja", destacado no apêndice A.

Podemos observar que autores que obtiveram a composição centesimal de nutrientes como Storck (2013) e Raquel \& Rosa (2014), que analisou os macronutrientes (Energia, carboidratos, proteínas e lipídeos) além das cinzas e umidade presentes nas PANC. A análise da laranja que foi a fruta utilizada na preparação do teste, demonstrou maior percentual de carboidratos (17,96\%), e após comparação entre os dados da TACO e os autores Storck (2013) e Raquel \& Rosa (2014), a quantidade de Fibra Alimentar Total nas cascas e insumos teve aumento considerável $(44,57 \%)$, e comparando com a análise de Raquel \& Rosa (2014) a vitamina C também tem um aumento quando utilizada as cascas e insumos (7,03\%).

A comparação entre as tabelas do IBGE (2008-2009), TACO (2011), a composição do PNAE, presente no anexo II, e as autoras Raquel \& Rosa (2014), demonstra diante dos minerais (Ca, Mg, P, Fe, Na, K, Zn, Se) confrontados, a observação do cálcio, magnésio, zinco e fósforo que tiveram considerado aumento 805\%, $26,9 \%, 457,14 \%$ e $35 \%$, respectivamente. Considerando que os demais minerais como $\mathrm{Fe}, \mathrm{Na}, \mathrm{K}$ e $\mathrm{Se}$ mantiveram seus valores próximos ou não haviam dados na literatura para comparação.

Também foram confrontadas a composição nutricional da preparação pronta, do "Bolo Integral de Laranja", a partir dos dados comparados com a TACO (2011) e Storck (2013) considerando 100g de amostra, podemos observar que em energia, carboidratos e fibra alimentar total, tem aumento de $6,22 \%$, $27.12 \%$ e 44,57\%, respectivamente. E considerando lipídeos e proteínas, tem redução de $23,18 \%$ e 7,78\%, respectivamente.

Monteiro (2009), afirma que após análise em seu estudo, que todas as partes não convencionais apresentaram teores de fibras, vitamina $\mathrm{C}$ e minerais $\mathrm{Fe}$, $\mathrm{Ca}$ e $\mathrm{K}$ próximos ou superiores às suas partes convencionais.

Podemos afirmar que o aproveitamento integral de alimentos, utilizando as PANC, valoriza as diretrizes que o PNAE prega, promover saúde e desenvolvimento dos assistidos, a partir de uma alimentação saudável e sustentável. Os resíduos de frutas e hortaliças são, geralmente, desprezados pela indústria e poderiam ser utilizados como fontes alternativas de nutrientes, com o objetivo de aumentar o valor nutritivo da dieta de populações carentes, bem como solucionar deficiências dietéticas do excesso alimentar. (ESPÍNDOLA, 1987)

\section{CONSIDERAÇÕES FINAIS}

O presente artigo teve como objetivo discutir as políticas propostas pelo PNAE e as possíveis formas de reduzir o desperdício gerado pela alimentação escolar. Foram analisados artigos de periódicos diferentes, selecionados pelas palavras-chave relacionadas ao assunto, bem como pelos resumos e problemas de pesquisas. Apesar de a alimentação escolar ser o principal objetivo do programa, a pesquisa relacionou a importância da capacitação e a redução do desperdício com o uso da sustentabilidade.

Com isso, conclui-se que com a implementação da pesquisa, espera-se incentivar o aproveitamento integral de alimentos, com a adesão de preparações sustentáveis, como uma alternativa de baixo custo. Operando as ferramentas do PNAE no fortalecimento de uma alimentação saudável e consciente. Podemos perceber que vários fatores foram considerados mediante aos dados coletados, como: dificuldades financeiras das instituições, o sabor das preparações e a adequação dos cardápios aos hábitos alimentares dos escolares, devendo ser investigados em estudos futuros, demonstrando quais intervenções devem ser aplicadas para uma promoção autêntica de uma alimentação escolar consciente e saudável. 


\section{REFERÊNCIAS}

[1] Aberc - Associação Brasileira das Empresas de Refeições Coletivas. Manual de práticas de elaboração e serviço de refeições para coletividades. 8.ed. São Paulo: ABERC, 2003. 120p.

[2] Abreu, E. S.; Spinelli, M. G. N.; Zanardi, A. M. P. Gestão de Unidades de Alimentação e Nutrição: um modo de fazer. São Paulo: Editora Metha; 2003.

[3] Albuquerque, U.P.; Andrade, L.D.H.C. Conhecimento botânico tradicional e conservação em uma área de caatinga no Estado de Pernambuco, Nordeste do Brasil. Acta Botânica Brasílica, v.16, n.3, p.273-85, 2002.

[4] Almeida, D. T.; nunes, I. L.; Andrade, L. L. Técnica Dietética I: Aula Prática de Mensuração de Alimentos. 2007.

[5] Andreotti, Adriana et al. Importância do treinamento para manipuladores de alimentos em relação a higiene pessoal. Inic. Cien. v. 5, n. 1, p. 29-33. 2003.

[6] Anjos, M. C. R. Relação de Fatores de Correção e índice de conversão (cocção) de alimentos. Universidade Federal do Paraná, 2012.

[7] Arruda, G. A. Análise de perigos em pontos críticos de controle no SND. In: Fernandes, A. T.; Fernandes, M. 0. V.; Ribeiro Filho, N. (Orgs.). Infecção hospitalar e suas interfaces na área de saúde. São Paulo: Atheneu, 2000.

[8] Artur, P. O. Aplicação do binómio tempo/temperatura em alimentos. Trabalho de Conclusão de Curso. Brasília. 2004.

[9] Augustini, et al. Avaliação do índice de resto-ingesta e sobras em unidade de alimentação e nutrição (UAN) de uma empresa metalúrgica na cidade de Piracicaba/SP, 2008. Rev. Simbio-Logias. v. 1, n. 1, 2008.

[10] Aust, L. B. et al. The descriptive analysis of skin care products by a trained panel of judges. J. Soc. Cosmet. Chem, v. 38, p. 443-449, 1987.

[11] Azevedo, E.; Rigon, S. A. Sistema alimentar com base na sustentabilidade. In: Taddei, J. A. A. C. et al. (Org). Nutrição em saúde pública. Rio de Janeiro: Editora Rubio, 2010.

[12] Barbosa, R. X.; Holland, N.; Damasceno, K. S. F. S. C. Análise dos perigos e pontos críticos de controle durante o preparo da alface servida no restaurante universitário da UFRN. Revista Higiene Alimentar, São Paulo, v. 18, n. 126127, p. 36-42, 2004.

[13] Barreira, T.F. et al . Diversidade e equitabilidade de Plantas Alimentícias Não Convencionais na zona rural de Viçosa, Minas Gerais, Brasil. Rev. bras. Plantas med., Botucatu , v. 17, n. 4, supl. 2, p. 964-974, 2015.

[14] Belik, W., Cunha, A. R. A. de A.; Costa, L. A. Crise dos alimentos e estratégias para a redução do desperdício no Contexto de uma política de segurança alimentar e nutricional no Brasil. Planejamento e Políticas públicas, n. 38, 2012.

[15] Bradacz, D.C. Modelo de Gestão da Qualidade para o Controle de Desperdício de Alimentos em Unidades de Alimentação e Nutrição. 2006.

[16] Brasil, F. (17 de junho de 2013). Resolução Cd/Fnde № 26, DE 17 de Junho DE 2013. Dispõe

[17] sobre o atendimento da alimentação escolar aos alunos da educação básica no âmbito do Programa Nacional de Alimentação Escolar - PNAE, pp. 1-32.

[18] . (11 de novembro de 2009). Constituição Federal (Redação dada pela Emenda Constitucional no 59, de 2009). Artigo 208. pp. Seção I - Educação.

[19] . (16 de junho de 2009). Lei № 11.947, de 16 de Junho. Dispõe sobre o atendimento da alimentação escolar e do Programa Dinheiro Direto na Escola aos alunos da educação básica. p. 13.

[20] . (8 de fevereiro de 2017). Resolução CD/Fnde/Mec № 1, de 8 de fevereiro de 2017. Altera o valor per capita para oferta da alimentação escolar do Programa de Alimentação Escolar - PNAE. pp. 19 - Seção 1.

[21] . Agência Nacional de Vigilância Sanitária. Resolução - RDC no 216, de 15 set. 2004.

[22] Brasil. Manual de hortaliças não convencionais / Ministério da Agricultura, Pecuária e Abastecimento. Brasília: Mapa, 2010. 92p

[23] . MEC. Instituto Nacional de Estudos e Pesquisas Educacionais (Inep). Sinopse Estatística da Educação Pública. [Online]. Brasília: Inep, 2019. Disponível em: http://inep.gov.br/censo-escolar. Acesso em: ago de 2019.

[24] . Ministério do Desenvolvimento Social e Combate à Fome (MDS). Bancos de alimentos. 2007

[25] Bressan, R.A. et al. Stress-adapted extremophiles provide energy without interference with food production. Food Security, v.3, n.1, p.93-105, 2011.

[26] Cassol, A.; Schneider, S. Produção e consumo de alimentos: novas redes e atores. Lua Nova: Revista de Cultura e Política, São Paulo, n.95, maio-ago 2015.

[27] Castro, F. T. Restaurantes do tipo self-service: análise dos aspectos sanitários e dos manipuladores de estabelecimentos localizados nos shoppings centers da cidade do Rio de Janeiro/ RJ. 2007. 105 f. 
[28] Dissertação (Mestrado em Tecnologia dos Alimentos) - Universidade Federal Rural do Rio de Janeiro, Rio de Janeiro, 2007.

[29] Castro, M.H.C.A. Fatores determinantes de desperdício de alimentos no Brasil: Diagnóstico da situação. 2002. 93p. Monografia (Especialização em Gestão de Qualidade em Serviços de Alimentação) - Universidade Estadual do Ceará, Fortaleza, 2002.

[30] Cecane. Manual para aplicação dos testes de aceitabilidade no PNAE. Brasília. Fnde, 2017.

[31] Conte, I. I.; Boff, L. A. As crises mundiais e a produção de alimentos no Brasil. Acta Scientiarum: Human and Social Sciences, v.35, n.1, p.49-59, 2013.

[32] Corrêa, T.A.F.; Soares, F.B.S.; Almeida, F.Q.A. Índice de resto-ingestão antes e durante a campanha contra o desperdício, em uma Unidade de Alimentação e Nutrição. Revista Higiene Alimentar, São Paulo, v.21 n.140, p.64-73, 2006.

[33] Crepaldi, I.C. et al. Composição nutricional do fruto de licuri (Syagrus coronata (Martius) Beccari). Revista Brasileira de Botânica, v.24, n.2, p.155-59, 2001

[34] Esperança, L.M.B. Estudo comparativo do desperdício alimentar observado em hospitais público e privado. Cadernos (Centro Universitário São Camilo), São Paulo, v. 5, n. 1, p. 68-69, jan./jun. 1999.

[35] Fernández, M. E. L.; Torres, A. C.; Selva, M. C.; Rodríguez, F. S. Cómo educar en higiene de los

[36] alimentos. Revista Cubana de Alimentación y Nutrición, La Habana, v. 12, n. 1, p. 51-54, 1998.

[37] Filho, J.V.C. Transporte de produtos agrícolas sobre a questão de perdas. Revista da economia e Sociologia Rural. Vol 39. N3 e 4.pg. 173-199. 1996.

[38] Galindo, C. O. Análise sensorial de produtos elaborados a base de partes não convencionais de frutas. 2014. 47 f. Trabalho de Conclusão de Curso (Tecnologia em Alimentos) - Universidade Tecnológica Federal do Paraná. Londrina, 2014.

[39] Góes J. A. et al. Capacitação dos manipuladores de alimentos e a qualidade da alimentação servida.

[40] Higiene Alimentar, São Paulo: v.15, n.82, p. 20-22. Mar. 2001.

[41] Góes, J. A. W.; Santos, J. M.; Veloso, I. S. Capacitação dos manipuladores de alimentos e a qualidade da alimentação servida. Higiene Alimentar, São Paulo, v.15, n. 82, p.20-22, mar. 2001.

[42] Gondim, J. A. M., et al. Composição centesimal e de minerais em cascas de frutas. Ciênc. Tecnol. Aliment.

[43] Campinas, v. 25, n. 4, p. 825-827, Dez. 2005.

[44] Guimarães, K. A. S. Ações educativas para a promoção da saúde e da segurança do trabalho em restaurantes comerciais. 2006. 190 f. Dissertação (Mestrado em Biociências e Saúde) - Fundação Oswaldo Cruz, Rio de Janeiro, 2006.

[45] Instituto Adolfo Lutz. Métodos físico-químicos para análise de alimentos. 1a Edição Digital. Secretaria de Estado da Saúde. São Paulo, 2008.

[46] Instituto Akatu. Descobrindo o consumidor consciente: uma nova visão da realidade brasileira. São Paulo: Instituto Akatu, 2004.

[47] Isaac, V. L. B. et al. Análise sensorial como ferramenta útil no desenvolvimento de cosméticos. Revista de Ciências Farmacêuticas Básica e Aplicada, p. 479-488, 2012.

[48] Kimura, A.Y. Planejamento e administração de custos em restaurantes industriais. São Paulo: Fazendo Arte, 1998. $312 p$

[49] Kinupp, V.F. Plantas alimentícias não-convencionais da região metropolitana de Porto Alegre, RS. 2007.

[50] Kroth, DC. Programa Nacional de Alimentação Escolar: Uma política pública saudável. Cien Saude Colet. Mar. 2019.

[51] Lemos, A. G; Botelho, R. BA; Akutsu, R. C. CA. Determinação do fator de correção das hortaliças folhosas comercializadas em Brasília. Hortic. Bras. Brasília, v. 29, n. 2, p. 231-236, June 2011.

[52] Levinger, B. School feeding, school reform, and food security: connecting the dots. Food Nutrition Bulletin, v.26, p.170-178, 2005.

[53] Lima, T. C. S. de; Mioto, R. C. Tamaso. Procedimentos metodológicos na construção do conhecimento científico: a pesquisa bibliográfica. Revista Katálysis, v. 10, 2007.

[54] Maciel, G. C. Treinamento: um desafio para o nutricionista. Higiene Alimentar, São Paulo, v.11, n.51, p. 7-8. Set/out 1997.

[55] Maluf, R. S. et al. Nutrition-sensitive agriculture and the promotion of food and nutrition sovereignty and security in Brazil. Ciênc. Saúde Coletiva, v.20, n.8, p.2303- 12, 2015.

[56] Mendes, R.; Pezzato, L. M.; Sacardo, D. P. Pesquisa-intervenção em promoção da saúde: desafios 
metodológicos de pesquisar "com”. Ciência \& Saúde Coletiva, v. 21, p. 1737-1746, 2016.

[57] Ministério do Desenvolvimento Social E Combate À Fome (MDS). Bancos de alimentos:

[58] roteiro para implantação. Brasília, 2007.

[59] Miranda, T. M; Hanazaki, N. Conhecimento e uso de recursos vegetais de restinga por comunidades das ilhas do Cardoso (SP) e de Santa Catarina (SC), Brasil. Acta Botânica Brasílica. v. 22, n.1, p. 203-205. 2008.

[60] Monteiro, B. A. Valor nutricional de partes convencionais e não convencionais de frutas e hortaliças. Dissertação (mestrado) - Universidade Estadual Paulista, Faculdade de Ciências Agronômicas de Botucatu, 2009.

[61] Monteiro, C. A. et al. Dietary guidelines to nourish humanity and the planet in the twenty-first century. A blueprint from Brazil. Public Health Nutrition, v.18, n.13, p.2311-22, 2015.

[62] Monteiro, R.Z; Bruna, G.C. Projetos para atualização de espaços destinados a serviços profissionais de alimentação. Caderno de Pós-graduação em Arquitetura e Urbanismo - Mackenzie, São Paulo, v. 4, n.1, p. 31-46, 2004.

[63] Navolar, T. S. Agricultura familiar ecológica enquanto ação promotora da saúde. 2007. Monografia (Especialização em Saúde Pública) - Universidade Federal de Santa Catarina, Florianópolis. 2007.

[64] Nellemann, C. et al. (Ed.). The Environmental Food Crisis: the environment's role in averting future food crises - a UNEP rapid response assessment. United Nations Environment Programme, GRID-Arendal, 2009.

[65] Nonino-Borges, C. B. Desperdício de alimentos intra-hospitalar. Revista de Nutrição, Campinas, 19(3):349356, maio/jun., 2006.

[66] Oliveira, M. F. Metodologia científica: um manual para a realização de pesquisas em Administração. Universidade Federal de Goiás. Catalão-GO, 2011.

[67] Organização Mundial de Saúde- OMS. Métodos de vigilância sanitária e gestão para manipuladores de alimento. Informe de uma reunião de consulta da OMS. Genebra, 2002.

[68] Ornelas, L. H. Técnica dietética: seleção e preparo de alimentos. 8 ed. São Paulo: Atheneu, 2007. 276p.

[69] Pilla, M.A.C.; Amorozo, M.C. \& Furlan, A. Obtenção e uso das plantas medicinais no distrito de Martim Francisco, município de Mogi-Mirim, São Paulo. Acta Botanica Brasilica 20(4): 789-802. 2006.

[70] Pirozzi, D.C.Z. Comparação da qualidade bioquímica de vegetais, cultivados de modo convencional e não convencional. Tese (Doutorado) - Instituto de Biociências, Unesp - Universidade Estadual Paulista, Botucatu. 2007.

[71] Praxedes, P. C. G. Aspectos da qualidade higiênico-sanitária de alimentos consumidos e comercializados na cidade de São Remo. 2003. 120 f. Dissertação (Mestrado em Epidemiologia Experimental e Aplicada ao Controle das Zoonoses) - Universidade de São Paulo, São Paulo, 2003.

[72] Ribeiro, C.S.G.R. Análise de Perdas em Unidades de Alimentação e Nutrição (UANs) industriais: estudo de caso em Restaurantes Industriais. 2003. 145p. Dissertação (Mestrado em Engenharia de Produção) - Universidade Federal de Santa Catarina, Florianópolis, 2003.

[73] Ricarte, M. P. R.; Fé, M.A.B.M.; Santos, I.H.V.S.; et al. Avaliação do desperdício de alimentos em uma unidade de alimentação e nutrição institucional em Fortaleza. CE. Saber Científico, Porto Velho, v.1, n.1, p. 158-175, 2005.

[74] Santos, B. R. C., Cintra, P. Partes usualmente não consumidas dos alimentos: vantagens e fatores antinutricionais. Interbio. ISSN-1981-3775, v. 9, p. 52-64. Dourado - MS. 2015.

[75] Santos, L. A. S., Et al. Uso e percepções da alimentação alternativa no estado da Bahia: um estudo preliminar.

[76] Rev. Nutr., Campinas, v. 14, supl. p. 35-40, 2001. ed. São Paulo: Varela, 2001. 385 p.

[77] Sesc, Mesa Brasil. Banco de alimentos e colheita urbana: aproveitamento integral dos alimentos. Rio de Janeiro: Sesc/DN, v. 45, 2003.

[78] Silva JR, E. A. da. Manual de controle higiênico sanitário em alimentos. 2001.

[79] Silva JR., E.A.; Teixeira, R.P.A. Manual de procedimentos para utilização de sobras alimentares: roteiro para implantação. Brasília, 2007.

[80] Souza, L. F. Avaliação de ponto de corte para índice de aceitabilidade de produtos alimentícios e preparações no âmbito do Programa Nacional de Alimentação Escolar: uma metanálise. Brasília, 2007.

[81] Steuer, I. R. et al. O aproveitamento integral de hortaliças como estratégia de educação para a sustentabilidade nas comunidades do semiárido Pernambucano. XIII Jornada de Ensino, Pesquisa e Extensão-JEPEX, 2013.

[82] Storck, Cátia R. et al. Folhas, talos, cascas e sementes de vegetais: composição nutricional, aproveitamento na alimentação e analise sensorial de preparações. Ciência Rural, Santa Maria, v.43, n.3, p.537-543, mar, 2013.

[83] The Lancet. Comentário. Acting in the Anthopocene - The EAT Lancet Commission, n.387. 2016.

[84] Valente, F. L. S. Direito humano à alimentação adequada: desafios e conquistas. Cortez Editora, São Paulo, 


\section{Capítulo 15}

\section{Fator motivacional para o engajamento dos atores sociais atuarem no contexto da sustentabilidade}

\section{Nathali Vieira da Silva \\ Ramiro Guedes do Carmo \\ Bárbara Oliveira de Morais \\ Adalberto Oliveira Brito}

Resumo: 0 desenvolvimento sustentável possui amplos contextos que são tradicionalmente categorizados em ambiental, econômico e social. Este tem recebido crescente atenção como um dos potenciais meios de mudança para conduzir a um mundo mais seguro e mais humano. 0 objetivo deste estudo é o de identificar fatores que motivam os indivíduos a se engajarem e se manterem participantes em movimentos sociais que abordem a temática da sustentabilidade. 0 presente trabalho se caracteriza como uma pesquisa exploratória, descritiva e subjetiva, que se utilizou da coleta de dados quali-quantitativa, por meio de um questionário estruturado em uma plataforma Survey, aplicado durante o Fórum Brasil ODS 2019. Os dados sugerem que os entrevistados atentam para a dimensão social da sustentabilidade como aprimoramento individual e transformação coletiva por meio de engajamento social e estímulo à ações que fomentem o alcance de um mudo sustentável.

Palavras-chave: Mobilização Social, Práticas sustentáveis; Meio ambiente e Educação. 


\section{INTRODUÇÃO}

Mediante os amplos contextos do desenvolvimento sustentável, a dimensão social tem recebido crescente atenção, visto que a maioria das ações movidas no início dos debates em prol da temática sustentável aborda o conceito de fauna e flora, herança deixada pela ecologia, minorando a presença do homem como fator determinante nesse cenário e a atenção na importância da relação consigo mesmo, que por sua vez reflete em sua interconexão com o meio. Frente a complexidade da compreensão sobre as mudanças causadas pela relação entre homem - meio ambiente e a improbabilidade de mudar uma realidade até então "desconhecida", iniciam-se numerosas atuações dedicadas a estimular os cidadãos à reflexão sobre as ações danosas ao meio em que vivem e a implantação de ações remediadoras e fomentadoras para o alcance de uma realidade "equilibrada" e igualitária para todos, o chamado desenvolvimento socioeconômico sustentável.

Os discursos do desenvolvimento sustentável abordam os estilos de vida concentrados na interação do indivíduo com o meio e não fazem menção a relação consigo mesmo, com o próximo e ambos com o meio. Esta questão transcende aos conflitos inter-relacionais, estando centrada no contexto "intra-relacional", composto de um universo individual e de seus contextos racionais, emocionais e afetivos constituídos por relações sociais, retratando que o homem está afetivamente presente no mundo e sua existência constitui um fio contínuo de sentimentos (GIDDENS, 1991; LE BRETON, 2009; VELHO, 1978).

Neste sentido o trabalho realizado durante o evento do Fórum Brasil ODS 2019, ocorrido em 28 e 29 de Junho de 2019, tem por objetivo principal identificar quais fatores contribuem para o engajamento dos atores sociais a desempenhar ações coletivas e/ou individuais em prol da sustentabilidade. Deste modo, a presente pesquisa visa apresentar as respostas colhidas referentes as seguintes questões: i) 0 entendimento dos entrevistados quanto a definição de sustentabilidade e ii) Quais são os maiores desafios para alcança-la, iii) Se eles participam de algum movimento (social / empresarial /outros) que trabalhe com a temática da sustentabilidade, iv) Como essa participação acontece, v) 0 que estimulou a participação nesse movimento, vi) 0 que mantém o envolvimento e comprometimento na participação desse movimento, vii) Quais mudanças ocorreram após seu engajamento com a temática da sustentabilidade e viii) Se o entrevistado é membro do MOVIMENTO ODS (Objetivos do Desenvolvimento Sustentável).

O Movimento ODS Nacional deriva do Movimento Nacional pela Cidadania e Solidariedade / Nós Podemos (MNCS) que é um movimento apartidário, ecumênico e plural da nação brasileira, integrado por organizações e voluntários que representam os diversos segmentos da sociedade e possui a missão de promover e articular ações para o alcance dos Objetivos do Desenvolvimento Sustentável (ODS) da Agenda 2030.

\section{METODOLOGIA}

O presente estudo se caracteriza como uma pesquisa exploratória, descritiva e subjetiva, por meio da coleta de dados quali-quantitativa, com a utilização de questionário digital estruturado em uma plataforma Survey e aplicado durante o Fórum Brasil ODS 2019, evento que busca estimular o debate e o intercâmbio de conhecimento acerca dos Objetivos de Desenvolvimento Sustentável no Brasil.

O universo da pesquisa é composto por 27 entrevistados que participaram do Fórum Brasil ODS 2019 e dos movimentos sociais envolvidos direta e indiretamente com o evento.

O público desta pesquisa foi selecionado para aplicação do questionário por critério de participação direta ou indireta no Fórum Brasil ODS 2019, bem como acessibilidade a ferramenta utilizada. Foram elaboradas 19 perguntas, das quais 08 são abertas e 11 fechadas. As respostas são identificadas da letra "R" seguida do número do respondente.

\section{RESULTADOS E DISCUSSÃO}

A análise de dados foi obtida por meio da aplicação de 27 questionários respondidos em um universo 74\% feminino e 26\% masculino, residentes nos Estados de Amapá, Ceará, Espirito Santos, Pará, Rio de Janeiro, Roraima, Santa Catarina, São Paulo e Sergipe.

Quando solicitado a definição de Sustentabilidade em uma frase, os entrevistados apresentaram diversas respostas, conforme exposto a seguir: 
- R6: "Garantir o equilíbrio econômico, social e ambiental para que o desenvolvimento seja possível com o equilíbrio dessas 3 dimensões".

- R9: "Proteção ao meio com desenvolvimento econômico e social".

- R15:" Um conjunto de ideias, estratégias e demais atitudes ecologicamente corretas, 4 economicamente viáveis, socialmente justas e culturalmente diversas".

Sobre os maiores desafios para alcançar a sustentabilidade, dentre as considerações dos entrevistados destaco as respostas:

- R7: "Educação, interesse político, mobilização da sociedade".

- R17: "Sentimento de Pertencimento, Participação e Comprometimento".

- R22: "Alinhar a sustentabilidade as práticas diárias; saber como disseminar a consciência sustentável e deixar de consumir industrializados".

Dentre os entrevistados 93\% participa de algum movimento social, empresarial ou outros que trabalham com a temática da sustentabilidade e $7 \%$ não participa. Entre os participantes $56 \%$ atua de forma presencial, $30 \%$ participa em sua maioria de forma presencial e pouco digital, $7 \%$ participa de forma mais digital do que presencial e 7\% de outras maneiras não descritas na pesquisa.

Na questão "O que te estimulou a participar desse movimento?", diferentes respostas foram apresentadas. Sendo selecionados os trechos expostos a seguir:

- R5: "A oportunidade de influenciar e ser influenciado".

- R15: "Ser agente de transformação e contribuir por um mundo melhor".

- R20: "O interesse por fazer alguma coisa e não apenas assistir e reclamar dos governantes, queria fazer parte de algum movimento que me impulsionasse a ser um ser humano melhor".

Sobre os fatores que mantém o envolvimento e comprometimento dos participantes nos movimentos sobre a sustentabilidade foram declaradas respostas variadas como:

- R2: "A união de pessoas engajadas em um único objetivo".

- R14: "O aprendizado, a rede de relacionamento, conhecer pessoas de etnias, costumes e regiões diferentes.".

- R21: "O engajamento e integração de pessoas se unindo para melhorarmos o nosso ambiente, a união e solidariedade".

Quando questionado sobre quais mudanças ocorreram após o engajamento com a temática da sustentabilidade os participantes apresentaram algumas respostas como:

- R12: "Novo olhar sobre meio ambiente".

- R6: "Desconstrução de um modelo mental de que a sustentabilidade era pautada 5 somente na dimensão ambiental".

- R20: "A principal mudança é quanto ao egoísmo, me achava alguém totalmente desapegada e vi que nada verdade não somos assim, somos todos em maioria egoístas, primeiro eu, mas na realidade a sustentabilidade é exatamente um exercício de não pensar só em você, mas sim na coletividade, é importante entender que a realização de práticas sustentáveis é louvável, mas antes disso é preciso ser sustentável de forma introspectiva, entendendo que o verdadeiro sentido de sustentabilidade está em valorizar o social, pois sozinho é possível mudar o seu dia a dia, mas se você não move outras pessoas pela causa as suas ações vão carecer de eficiência e não é possível mover um estado, um país ou o mundo sem eficiência de ação!".

No que tange a participação no Movimento ODS em âmbito nacional 85\% dos entrevistados são membros e $15 \%$ não são.

\section{CONSIDERAÇÕES FINAIS}

Os dados analisados demonstram que apesar da definição da maioria dos entrevistados apresentarem sustentabilidade composto pelo tripé ambiental, econômico e social, nota-se o despertar da dimensão social na sustentabilidade para além das determinações de justiça social. 
Relata-se sobre atuação tanto individual quanto coletiva como essencial para reflexão sobre o significado de sustentabilidade para cada ator social e suas transformações ao longo do tempo e espaço por ele habitado e vivenciado. As expressões descritas demostram o desejo de aprimoramento individual e transformação coletiva por meio de engajamento, comunicação e influencia social referentes as ações realizadas para alcance de um mudo sustentável.

\section{REFERÊNCIAS}

[1] GIDDENS, Anthony. As Consequências da modernidade. São Paulo: UNESP, 1991.

[2] LE BRETON, David. As paixões ordinárias: antropologia das emoções. Petrópolis: Vozes, 2009.

[3] O Movimento Nacional ODS Nós Podemos. Nossa causa. 2019. Disponível em: <https://movimentoods.org.br>. Acesso em 20 Jun. 2019.

[4] VELHO, Gilberto. Observando o familiar. In: Individualismo e cultura: notas para uma antropologia da sociedade contemporânea. 1ํEd. Rio de Janeiro: Zahar, 1978. 


\section{Capítulo 16}

\section{O Método SICOGEA como Cálculo de Sustentabilidade para Condomínios}

\section{Lorena Simões do Vale \\ Juliana Freitas Guedes Rêgo \\ Karina Lima Oliveira \\ Zoraia da Silva Assunção}

Resumo: Este trabalho tem por objetivo aprimorar os conhecimentos em contabilidade ambiental na gestão de condomínios, desenvolvendo um cálculo de sustentabilidade nos moldes do método estabelecido pelo Sistema Contábil Gerencial Ambiental (SICOGEA). Para tanto, foi formulada uma folha de verificação voltada para a realidade condominial que possibilita a extração de resultados sobre a cultura ambiental do condomínio. Deste modo, o método SICOGEA foi adaptado e aplicado em um condomínios residencial horizontal na cidade de Feira de Santana, Estado da Bahia, nos meses de abril, maio e junho de 2019, para verificar se pode ser mensurado e apurado o índice do quão sustentável em termos ambientais ele é. Ao final do estudo, o índice de sustentabilidade do condomínio de $62,38 \%$ comprova que, além de cumprir a legislação existente, há uma busca em valorizar o meio ambiente, mas ainda há o que melhorar na sua gestão ambiental. 0 resultado da pesquisa aponta com clareza a possibilidade de aplicação do SICOGEA para condomínios.

Palavras-chave: Condomínios, Sustentabilidade, SICOGEA 


\section{INTRODUÇÃO}

Um condomínio, por conceito, seja residencial ou comercial refere-se a posse/propriedade exercida simultaneamente por uma ou mais pessoas. Então, este instituto espelha a sociedade onde está inserido, utilizando de regras e normas que regulam as relações sociais, administrativas e até financeira.

Neste âmbito, se observa a preocupação da sociedade com conceitos como o desenvolvimento sustentável, bem como a utilização de métodos ambientais de valoração. Um destes métodos é o Sistema Contábil Gerencial Ambiental (SICOGEA) para calcular a sustentabilidade ambiental no setor empresarial. 0 SICOGEA é uma ferramenta de gestão ambiental, com ênfase na contabilidade e controladoria ambiental, com a finalidade de gerar informações ao gestor sobre os impactos das ações da empresa sobre o meio ambiente (Pfitscher, 2004).

Neste sentido, neste artigo sera desenvolvido uma verificação sobre a possibilidade de instituir critérios que calcule a sustentabilidade ambiental de um condomínio residencial com amparo no método SICOGEA.

No Brasil, as pessoas almejam por segurança, lazer e privacidade. Devido à isto, a busca por moradias em condomínios fechados só faz crescer nos últimos 30 anos. Diversos modelos de condomínios foram criados, como os condomínios horizontais e verticais, condomínios clube com grande infraestrutura de lazer, a fim de atender às necessidades específicas da população brasileira que pode pagar por esta opção de moradia.

Como os condomínios residenciais brasileiros agrupam um grande número de pessoas a preocupação ambiental precisa ser prioridade. Sendo assim, questiona-se: É possível desenvolver, através do método SICOGEA, um padrão de aplicação às diversas modalidades de condomínios? A aplicação do método SICOGEA em condomínios agrega resultados importantes na gestão sustentável dos recursos?

A hipótese adotada é que o SICOGEA adaptado para condomínios pode ser útil do ponto de vista da gestão ambiental e da valorização das ações de cultura ambiental nos condomínios. Uma vez que o método já foi aplicado em outros segmentos diferentes do empresarial (Muza, Silveira e Pfitscher, 2014).

0 estudo utilizará como referencial teórico o conceito de meio ambiente presente da Constituição Federal Brasileira, de 1988, legislações e políticas públicas ambientais brasileiras, preceitos contábeis do SICOGEA e as prerrogativas organizacionais dos condomínios residenciais brasileiros.

\section{MATERIAL E MÉTODOS}

0 método SICOGEA foi adaptado e aplicado em um condomínio horizontal de classe média, com 210 casas e aproximadamente 630 pessoas, no bairro Papagaio, na cidade de Feira de Santana, Estado da Bahia, nos meses de abril, maio e junho de 2019. o condomínio conta com uma área de lazer que inclui piscina, churrasqueira e salão de festas, funcionários terceirizados, um síndico que é morador, e contrata os serviços de uma empresa administradora de condomínios.

Também foi avaliado se o condomínio está de acordo com as Leis ambientais brasileiras e se possui planos e metas que visem aperfeiçoar e melhorar a sustentabilidade ambiental. Além disto, foi observado como a consciência na defesa do meio ambiente é fomentada entre os moradores.

0 percentual de sustentabilidade foi avaliado por uma folha de verificação, que representa a terceira etapa da primeira fase do SICOGEA, contendo perguntas com base em seis critérios: 1) Legitimidade Documental (verifica se há formalização do condomínio e existência de regras de convivência adequadas ao equilíbrio ambiental), 2) Fornecedores de Produtos e Serviços Contratados (avalia a opção por fornecedores e produtos engajados com o meio ambiente), 3) Serviços Essenciais (avalia o consumo de energia, água, geração e destinação de resíduos), 4) Administração do Condomínio (verifica a capacitação e disponibilidade financeira para investimentos em gestão ambiental), 5) Responsabilidade Social (analisa a relação com a sociedade e sustentabilidade financeira), 6) Recursos Humanos (observa a valorização da legislação trabalhista e dos funcionários e a aplicação de normas de segurança e medicina do trabalho).

Foi estabelecido no primeiro critério oito perguntas, no segundo critério sete perguntas, no terceiro critério 12 perguntas, no quarto critério 11 perguntas, no quinto critério seis perguntas e no sexto critério sete perguntas. 0 que totaliza 51 perguntas. Cada pergunta possui três opções de resposta para o pesquisador: A (adequado), D (deficitário) e N/A (não se aplica) (ROSA et al, 2008). Há também um espaço para que observações julgadas necessárias sejam feitas como, por exemplo, a situação do condomínio ainda não implementar coleta seletiva, mas que possui perspectivas futuras para tal. 
A fórmula de cálculo da sustentabilidade ambiental é a seguinte (Bacelo et al, 2012):

QA (total adequados) $\mathrm{x} 100$

$\overline{\text { QT (total dos itens) - QN/A (total não se aplica) }}$

A prioridade dos critérios é estabelecida do menor para o maior percentual obtido com a equação acima. 0 percentual obtido com a equação pode ser analisado de acordo com os seguintes critérios da Tabela 1:

Tabela 1 Critérios da Sustentabilidade Ambiental

\begin{tabular}{|l|l|l|}
\multicolumn{1}{c|}{ Resultado } & \multicolumn{1}{c|}{$\begin{array}{c}\text { Sustentabilidade } \\
\text { Ambiental }\end{array}$} & $\begin{array}{c}\text { Desempenho: controle, incentivo, } \\
\text { estratégia }\end{array}$ \\
\hline Inferior a $20 \%$ & Péssimo & Pode estar causando grande impacto \\
\hline Entre $20,1 \%$ a $40,0 \%$ & Fraco & $\begin{array}{l}\text { Pode estar causando danos, mas surgem } \\
\text { poucas iniciativas }\end{array}$ \\
\hline Entre $40,1 \%$ a $60,0 \%$ & Regular & Atende somente a legislação \\
\hline Entre $60,1 \%$ a $80 \%$ & Bom & $\begin{array}{l}\text { Além da legislação, busca valorizar o } \\
\text { meio ambiente }\end{array}$ \\
\hline Superior a $80 \%$ & Ótimo & Alta valorização ambiental \\
\hline
\end{tabular}

\section{RESULTADOS E DISCUSSÃO}

A partir da análise dos dados o condomínio atingiu 62,38\% de sustentabilidade ambiental, o que permite classificar a sustentabilidade ambiental como boa. Ou seja, além do cumprimento da legislação há uma busca pela valorização do meio ambiente. Lembrando que as principais legislações brasileiras sobre o tema dizem respeito a Política Nacional de Meio Ambiente, de 1981, ao artigo 225 da Constituição Federal e a Política Nacional de Resíduos Sólidos, de 2010.

o critério Legitimidade Documental atingiu 100\% de sustentabilidade ambiental, o que significa a sexta e última ordem de prioridade de intervenções ambientais no condomínio. Neste critério, considerado como ótimo, é muito importante os registros que coprovam a existência e a regularidade das normas do condomínio. Percebe-se o pensamento ambiental na criação de algumas regras que limitam o uso dos recursos essenciais como energia, ao regular o uso da quadra esportiva, e água, ao regular o uso da piscina. O condomínio, quando possui sua capacidade postulatória plena, pode cobrar o cumprimento de suas normas aos seus condôminos e estas normas, desde que sejam registradas, tornam-se oponíveis e terceiros.

O critério Serviços Essenciais atingiu 70\% de sustentabilidade ambiental, o que significa a quinta e penúltima ordem de prioridade de intervenções ambientais no condomínio. Neste critério, considerado como bom, uma vez que após a parte legal e gerencial, são os serviços mais relevantes para o condomínio, ligados, inclusive, as concessionárias de serviços públicos e/ou secretaria municipal de serviços públicos. Assim, verificou-se a relação do condomínio com o consume de água, luz e coleta de lixo. Em todos os serviços essenciais existe algum tipo de procedimento sustentável. No entanto, o condomínio precisa melhorar e planejar medidas para aproveitamento da água da chuva, bem como investor em energia solar.

O critério Fornecedores de Produtos e Serviços Contratados atingiu 57,14\% de sustentabilidade ambiental, o que significa a quarta ordem de prioridade de intervenções ambientais no condomínio. Neste critério, considerado como regular, trata-se de toda contratação e prestação de serviços além das essenciais. Os quesitos respondidos demonstraram atenção às especialidades, aquisição de produtos recicláveis e biodegradáveis e utilização de equipamentos de proteção individual. A deficiência, neste caso, está relacionada à formação técnica dos prestadores de serviços, ao selo e certificação dos contratados. 
O critério Recursos Humanos atingiu 57,14\% de sustentabilidade ambiental, o que significa a Terceira ordem de prioridade de intervenções ambientais no condomínio. Neste critério, considerado como regular, os colaboradores somam e auxiliam no que já está definido na organização ecológica do condomínio. As adequações estão relacionadas ao compromisso dos trabalhadores com projetos ambientais e também com o cuidado com a saúde e segurança dos mesmos, uma vez que estar bem de saúde e apto ao trabalho demonstra respeito a este recurso natural do condomínio. No entanto, as deficiências estão relacionadas a projetos de curso e capacitação aos funcionários na esfera ambiental.

O critério Responsabilidade Social atingiu 50\% de sustentabilidade ambiental, o que significa a segunda ordem de prioridade de intervenções ambientais no condomínio. Neste critério, considerado como regular, foi avaliado o quanto o condomínio interage socialmente com seus condôminos e região que ocupa. Foram verificadas algumas campanhas de uso adequado de água e luz e, também, descarte adequado de entulho de obras. Viu-se como deficitário, principalmente, a interação com a localidade vizinha.

O critério Administração do Condomínio atingiu 40\% de sustentabilidade ambiental, o que significa a primeira ordem de prioridade de intervenções ambientais no condomínio, considerado como fraco, atingiu o percentual mais baixo. Neste critério, o corpo diretivo do condomínio é quem vai definir as diretrizes e cobrar as adequações necessárias. A maior deficiência pautada foi no âmbito da contabilidade ambiental, verificada na entrevista como algo desconhecido.

A sustentabilidade ambiental média do condomínio foi de $62,38 \%$, o que comprova que além de cumprir a legislação existente, o condomínio busca valorizar o meio ambiente. Contudo, também demonstra que o condomínio tem muito o que melhorar na sua gestão ambiental. Grande parte das incoformidades dizem respeito ao critério Administração do Condomínio, pois todos os quesitos sobre contabilidade ambiental foram classificados como deficitários.

Desta forma, fica evidenciado como é recente o olhar para a gestão sustentável para os condomínios. A despeito da sustentabilidade ambiental fraca do critério Administração do Condomínio, não se pode tirar o mérito daqueles que estão à frente da gestão do condomínio. Uma vez que, por conta dos mesmos, os outros critérios atingiram sustentabilidades ambientais superiors à referência regular.

A preocupação da gestão condominial em valorizar o ecologicamente correto peca, principalmente, no fornecimento dos relatórios gerenciais da contabilidade ambiental. Esta situação pode ser corrigida facilmente, se, a partir de agora, for levado em consideração o produto desta pesquisa.

\section{CONCLUSÃO}

A partir do estudo realizado conclui-se que o objetivo foi alcançado, visto que os critérios propostos para o método parcial SICOGEA tiveram a aplicação adequada para condomínios.

Com isto, este estudo pode ser realizado em diversos outros condomínios para que seja mensurada a sua sustentabilidade ambiental. 0 intuito é que, a partir dos resultados sobre a sustentabilidade ambiental sejam tomadas decisões visando melhorias ambientais assertivas.

Com a aplicação do SICOGEA, na sua forma parcial, extrai-se também o vies de cultura ambiental praticada no condomínio. Percebe-se, portanto, um grande benefício ao grupo submetido a pesquisa, pois o seu resultado poderá fomenter uma mudança comportamental nos indivíduos que repercutirá na sociedade local.

O método SICOGEA, em sua forma parcial, é muito adequado para a mensuração da sustentabilidade dos condomínios residenciais. Ele pode ser aplicado periodicamente para diagnostico e sugestões de melhorias através de planos de gestão ambiental elaborados com base em suas informações. Pfitscher (2004) sugere, por exemplo, planos resumidos de gestão ambiental com base na ferramenta 5W2H (What? Why? Where? When? Who? How? How Much?), o que é muito interessante porque é simples e prático e pode ser aplicado além do ambiente empresarial. Contudo, as possibilidades de elaboração de um plano de gestão ambiental são inúmeras, a exemplo de Brasil (2006) e Gomes, Fittipaldi e Mol (2014), cabendo ao gestor condominial utilizar o que for mais conveniente para o cenário pesquisado. 


\section{REFERÊNCIAS}

[1] Bacelo, J., Uhlmann, V.O, Pfitscher, E. D., Souza, M. M. De. Sustentabilidade Ambiental em Condomínios: Utilização do Método SICOGEA para Avaliar os Aspectos e Impactos Ambientais em um Condomínio Residencial, Revista Catarinense da Ciência Contábil, v 11, p 72-83, 2012.

[2] Brasil. Política Nacional de Meio Ambiente, 1981. Disponível em:

<http://www.planalto.gov.br/ccivil_03/Leis/L6938.htm>. Acesso em: 27 out 2019.

[3] Brasil. Artigo 225 da Constituição Federal, 1988. Disponível em: <https://www.senado.leg.br/atividade/const/con1988/con1988_26.06.2019/art_225_.asp>. Acesso em: 27 out 2019.

[4] Brasil. Política Nacional de Resíduos Sólidos, 2010. Disponível em: <http://www.planalto.gov.br/ccivil_03/_ato2007-2010/2010/lei/112305.htm>. Acesso em: 27 out 2019.

[5] Brasil. Procedimentos para a Elaboração do Plano de Gestão Ambiental Rural, 2006. Disponível em: <https://www.mma.gov.br/estruturas/sds_gestar/_arquivos/99_publicacao09122008035815.pdf>. Acesso em: 27 out 2019 .

[6] Freitas, K. E. P., Pfitscher, E. D., Belan, A. B. Análise de Acessibilidade: Aplicação Parcial do Modelo SICOGEA em um Centro de Ensino de uma Instituição Federal de Ensino, Revista de Gestão Ambiental e Sustentabilidade, v 5, p $120-134,2016$.

[7] Gomes, C. J., Fittipaldi, D. V., MOL, M. P. G. Proposta de um Modelo de Gestão Ambiental para Setores Administrativos de Organizações, 2014. Disponível em: <http://www.engema.org.br/XVIENGEMA/437.pdf>. Acesso em: 20 out 2019.

[8] Muza, T.N.; Silveira, M.L.G.; Pfitscher, E.D. Aplicação do Sistema Contábil Gerencial Ambiental (SICOGEA) em uma Instituição Federal de Ensino e Tecnologia. Anais Congresso UFSC de Controladoria e Finanças e Iniciação Científica em Contabilidade. Florianópolis, 2014.

[9] Pfitscher, E. D., Gestão e Sustentabilidade Através da Contabilidade Ambiental: Estudo de Caso na Cadeia Produtiva de Arroz Ecológico, 2004. Disponível em: <https://core.ac.uk/download/pdf/30368422.pdf>. Acesso em: 20 out 2019

[10] Rosa, F. S. da, Pfitscher, E. D., Steiger, M. M., Nunes, J. P. De O., Silva, G. J. da. A Implantação do SICOGEA -Sistema Contábil Gerencial Ambiental em um Hospital, 2008. Disponível em:

<http://nemac.paginas.ufsc.br/files/2012/11/marciannigestao.pdf>. Acesso em: 20 out 2019. 


\title{
Capítulo 17
}

\section{Sistema de captação de água proveniente dos ares condicionados do IFPI - Campus Floriano}

\author{
Mateus dos Santos Correia \\ Danyel Lima Matos Granzotti, \\ Lara Denise Alves de Vasconcelos \\ Isadora Rodrigues Rocha \\ Uesllei Sousa Reis
}

Resumo: A água é um recurso natural finito que está se esgotando em consequência do seu mau uso e desperdício. 0 aproveitamento das águas que são desperdiçadas é a solução mais simples e barata para preservar água potável. Preocupado com o desperdício de água e o desenvolvimento sustentável, o IFPI Campus Floriano resolveu implantar um projeto para captar a água proveniente dos aparelhos de arescondicionados, podendo ser utilizada para outros fins, como a manutenção dos jardins do campus. Foi realizado um estudo de viabilidade do projeto, contemplando 18 máquinas interligadas por 8 drenos, além de duas saídas de água dos bebedouros. Calculou-se que esses drenos poderiam captar cerca de 120 mil litros de água por ano. Após isso determinou-se como seria a execução do projeto. Dentre os materiais necessários, estavam canos e joelhos PVC, conexão de caixa d'água, caixa de gordura, caixas de passagem de esgoto, caixa d'água de 3.000 litros, kit de bomba solar, microcontroladores e componentes eletrônicos. A compra dos materiais foi realizada com recursos financeiros provenientes do EDITAL PIBEX № 101/2017 - PROEX/IFPI Edital de Extensão, totalizando um gasto de $\mathrm{R} \$ 3.794,86$. 0 projeto teve início em dezembro de 2017, sendo finalizada sua montagem em maio de 2018. 0 sistema vem sendo acompanhado e consegue encher a caixa d'água (reservatório) em 8 dias. Concluiu-se que o sistema é eficiente no que diz respeito à captação e economia de água. Além dos ganhos ambientais, houve uma melhora no ensino-aprendizagem dos alunos envolvidos e teve impacto positivo na consciência ambiental da comunidade.

Palavras-Chave: Água; Captação; Ares-Condicionados. 


\section{INTRODUÇÃO}

A água é o recurso mais importante utilizado pelos seres humanos, fonte de vida, a presença desse elemento no planeta é imprescindível para a sobrevivência dos seres vivos. Apesar de estar presente em $75 \%$ da superfície terrestre, apenas 3\% são de água doce, por essa razão a preocupação para a preservação da mesma tornou-se maior. Dessa forma, projetos que visam manter a qualidade e quantidade desse recurso estão presentes no mundo inteiro. De acordo com o PROJETO ÁGUA (1998 apud PAZ, 2000, p. 467), ao comparar a disponibilidade de recursos hídricos com a população que deles dependem, o Brasil deixa de ser o país com maior abundância em água potável e passa ao vigésimo terceiro no planeta. Segundo Fortes et al. (2015) o aproveitamento das águas que seriam desperdiçadas se caracteriza por ser uma das soluções mais baratas e simples para preservar a água potável. Nesse contexto, foi pensado o projeto de captação da água proveniente dos ares condicionados, como forma de reduzir o consumo e dar a mesma um uso devido. 0 projeto desenvolvido estimula o estudo por parte dos alunos, professores, técnicos e terceirizados com ênfase no desenvolvimento sustentável, além do envolvimento da comunidade externa ao Instituto Federal, que poderá levar essa idéia para seus ambientes de convivência. A água captada é aproveitada principalmente nos processos de limpeza, lavagem dos veículos e manutenção dos jardins. Sendo assim, é possível afirmar que a implantação do sistema de captação causa um impacto positivo no que tange a redução do uso de água potável e também no consumo de energia elétrica.

\subsection{BJETIVO GERAL}

Expor e caracterizar o processo de instalação do sistema de captação de água proveniente dos arescondicionados do IFPI Campus Floriano.

\subsection{OBJETIVOS ESPECÍFICOS}

- Descrever e detalhar as etapas do projeto

- Coletar dados relacionados ao volume de água produzido pelos aparelhos de ar-condicionado inclusos no sistema.

- Analisar os resultados já obtidos desde a implantação do sistema.

- Difundir os foco principal do projeto por meio da sua visibilidade.

- Identificar os impactos positivos da instalação do sistema tanto para o meio ambiente como para a comunidade acadêmica.

\section{METODOLOGIA}

O IFPI Campus Floriano funciona em três turnos: manhã, tarde e noite, e está localizado em uma cidade de clima tropical, o que implica na utilização de aparelhos de ar-condicionado ligados o dia todo para o conforto de alunos e servidores. A água que é liberada através dos drenos dos condicionadores de ar, obtida devido ao processo de condensação apresentava uma destinação aleatória sem aproveitamento. Sendo assim, ela pode ser empregada em diversos processos, tais quais, limpeza, lavagem dos veículos e manutenção dos jardins. Segundo os estudos preliminares os ares-condicionados das salas de aula dos blocos "E" e " $F$ ", que totalizam 18 máquinas que interligadas por 08 drenos, poderiam captar cerca de 120.000 (cento e vinte mil) litros de água por ano, que poderiam ser usados na manutenção de jardins e limpeza do campus. A ideia inicial seria coletar a água dos drenos dos ares-condicionados, mas observouse que haviam duas saídas de bebedouros próximas as conexões dos blocos de salas de aula, "E" e "F", e que também poderiam ser adicionados ao projeto (Figura 1). 
Figura 1: Mapa preliminar do projeto. Fonte: Autores do Trabalho IFPI (2017).

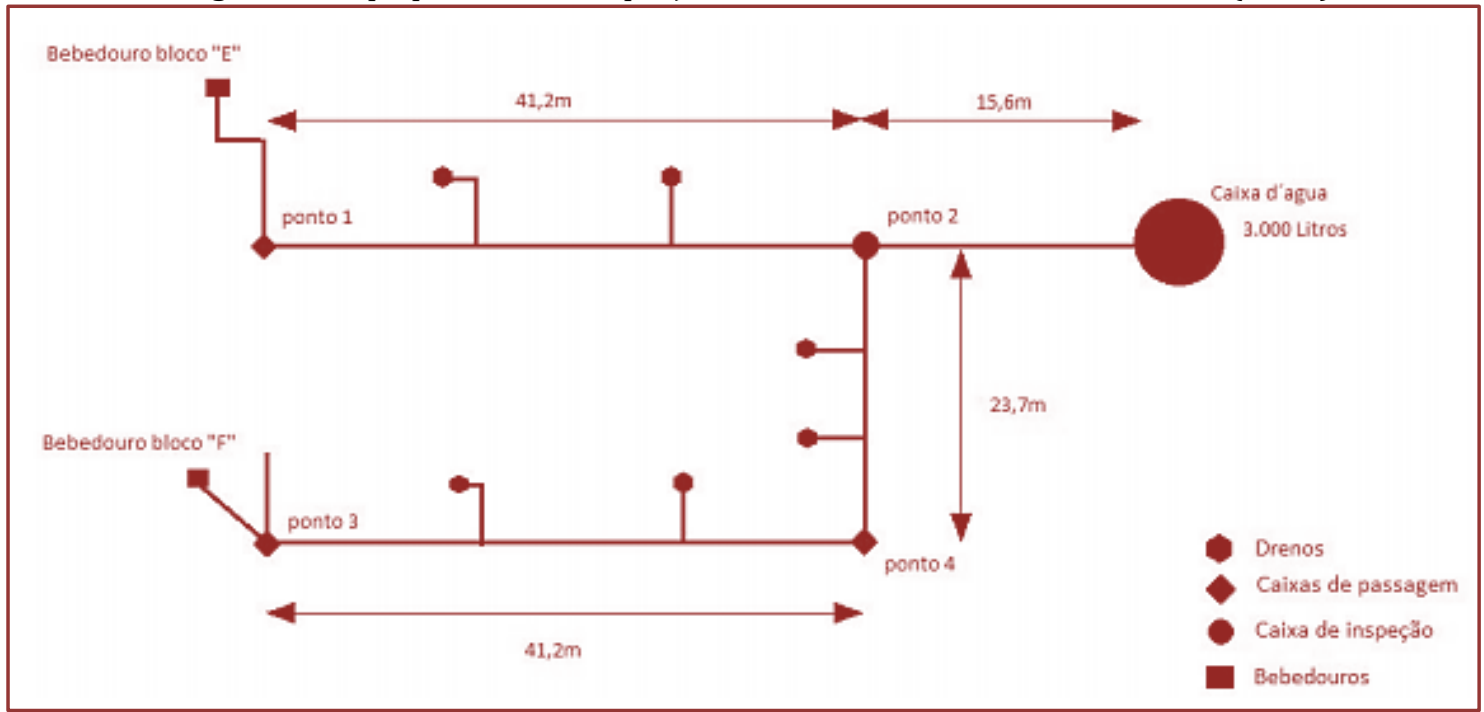

Assim que os materiais foram obtidos, iniciou-se a instalação, a compra dos materiais foi realizada com recursos financeiros provenientes do EDITAL PIBEX № 101/2017 - PROEX/IFPI - Edital de Extensão. Foram escolhidos dois blocos do campus para a implantação do sistema, que foi feita pelo coordenador, alunos bolsistas e contou com a ajuda dos servidores terceirizados do campus. No bloco mais próximo ao reservatório foi feita uma escavação com 10 centímetros de profundidade por todo o percurso da tubulação com uma extensão de 56,8 metros, da primeira caixa de inspeção até a conexão com o reservatório, logo após, sendo aterrada conforme a inclinação necessária. No outro bloco a instalação foi realizada de maneira semelhante, porém com a profundidade média de 07 centímetros e um comprimento de 64,9 metros (Figura 2). Para verificar o funcionamento do sistema testes foram realizados durante a instalação, colocando-se água na tubulação e verificando a direção e velocidade de escoamento.

Figura 2: Escavações para passagem da tubulação (A) - Passagem dos canos (B). Fonte: Sistema de Captação de Água Proveniente dos Ares-Condicionados IFPI (2017).
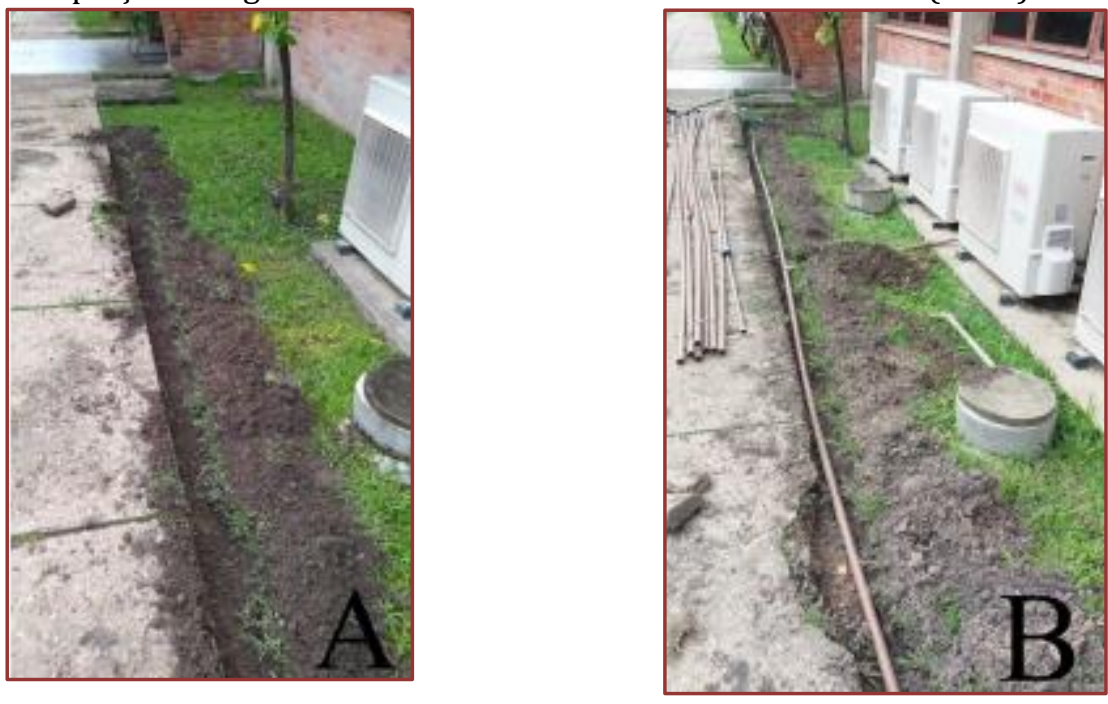

Após a instalação das caixas de passagem foi instalada a caixa de inspeção, como sua saída possuía 50 milímetros de diâmetro foi necessário uma adaptação para acoplar o cano de 32 milímetros. A função principal da caixa de inspeção é reter detritos e impurezas presentes na água por meio da decantação. 
As caixas de passagem foram adicionadas no projeto para facilitarem o acesso a tubulação para o caso de uma obstrução ou manutenção, porém as mesmas também executam a função de remover detritos. Com a fixação da tubulação foi realizada a implantação do reservatório que já em funcionamento teve calculada a quantidade de água captada. Obtivemos um total de aproximadamente 1.104 litros de água captada em três dias, com esse valor chegamos a média de 368 litros por dia, resultando no volume aproximado do reservatório, de 3.000 litros, em cerca de 8 dias de funcionamento. Buscando uma maior aplicabilidade ao projeto foi concebido um jardim próximo ao reservatório em uma área antes degradada que vem recebendo uma atenção especial, nela já foi realizada a adubação, contenção para evitar a erosão e o plantio de diversas mudas de espécies ornamentais. Posteriormente, foi acrescentada ao projeto uma bomba alimentada por energia solar, tendo como principal função irrigar parte do jardim com a água proveniente da captação, sua placa fotovoltaica possui uma potência de 95W (noventa e cinco watts) e a bomba uma vazão de 490 litros por hora. Em conjunto com o kit solar foi instalado um sistema de automação que usa como base a plataforma de prototipagem eletrônica arduino para que a bomba funcione apenas quando a irrigação for necessária, a parte física do projeto teve fim em maio de 2018. Após um período de funcionamento do projeto foi observado a necessidade de estipulação de um tempo mínimo para que seja feita a limpeza e manutenção do sistema, sendo esse de aproximadamente 03 meses para que não ocorra o acúmulo sujeira e outras impurezas.

\section{RESULTADOS}

A elaboração desse projeto resultou em uma grande economia de água potável além do surgimento de uma consciência ambiental coletiva por parte da equipe, dos que conheceram o projeto e da comunidade que frequenta o IFPI Campus Floriano. Por conta de seu alcance, outras instituições próximas também manifestaram interesse na implantação do projeto. Como exemplo podemos citar a Unidade Estadual Bucar Neto que firmou parceria com intuito de obter apoio técnico e realizar a troca de experiências na implantação do sistema próprio de captação. 0 sistema provou ser eficiente na questão de captação e economia de água e seu montante apresenta-se equivalente à somatória dos resultados esperados. Uma deficiência detectada é o tempo necessário para que ele próprio pague seus custos, como o IFPI - Campus Floriano obtém água por meio de uma bomba que a extraí de um poço no subsolo, o gasto com os recursos hídricos é menor comparando com a água fornecida pela empresa de abastecimento, a construção de um projeto como esse com um foco apenas econômico não se mostra muito eficiente nesse contexto, já que teríamos que funcionar por aproximadamente 30 anos para obter retorno do investimento. Vale ressaltar que esse fato ocorre apenas por conta do método de extração de água do campus, caso um sistema seja implantado em um local que receba água pela companhia de abastecimento e com uma captação semelhante teríamos uma economia de 1,054.81 reais ao ano. Esse cálculo é feito levando em consideração o cobrado pelo metro cúbico de água pela companhia de abastecimento local, é assim variável de uma localidade para outra. Um projeto como o apresentado melhora o ensino-aprendizagem, trabalhando de forma prática e englobando diversas áreas e temas, trata de questões ecológicas e sociais desenvolvendo uma consciência ambiental.

\section{CONCLUSÕES}

O projeto apresenta um grande potencial econômico e social, difundindo uma consciência ecológica na comunidade e diminuindo gastos de forma eficiente, utilizando um método de elaboração e aplicação simples. Sua presença estimula ações de preservação ambiental e aprimora o conhecimento sobre o tema entre aqueles que o conhecem. Futuramente esse sistema pode captar também a água da chuva e de outros pontos onde a mesma deixa de ser utilizada, aumentando seu rendimento total.

\section{REFERÊNCIAS}

[1] Paz. Recursos hídricos, agricultura irrigada e meio ambiente. Revista Brasileira de Engenharia Agrícola e Ambiental, v.4, n.3, p.465-473. Campina Grande, PB, DEAg / UFPB, 2000.

[2] Fortes, P. D. et al. Aproveitamento de água proveniente de aparelhos de ar condicionado in. Simpósio de Excelência em Gestão e Tecnologia, XII, Rio de Janeiro, RJ, 2015. 


\section{Capítulo 18}

Potencial de aproveitamento da água condensada das centrais de ar de Campus universitário

\section{Ana Taís Fernandes de Oliveira \\ Alisson Gadelha de Medeiros \\ Êmele Rádna Rodrigues do Vale \\ Maria Josicleide Felipe Guedes}

Resumo: Em face do panorama hídrico atual, através do balanço entre o consumo e a disponibilidade de água em algumas regiões, por meio deste trabalho, foi identificada uma possibilidade de uma medida sustentável dos recursos hídricos para o semiárido brasileiro. Para tanto, foi avaliado o potencial de aproveitamento da água gerada a partir das centrais de ar da Universidade Federal Rural do Semi-Árido, campus Pau dos FerrosRN. Com isso, esta pesquisa foi segmentada em duas etapas: i) diagnóstico inicial dos locais estudados, através da coleta de informações sobre o uso e ocupação dos ambientes e caracterização das máquinas condensadoras de ar; e ii) obtenção dos dados quantitativos, por meio de medições de volumes de água captada em intervalos de tempo e tabulação dos dados obtidos em planilhas eletrônicas. Os resultados de volumes de água coletados mostraram-se consideráveis para um concebível aproveitamento desses efluentes em finalidades não potáveis. A perspectiva mais otimista voltada ao aproveitamento da água condensada pelas centrais de ar ocorreu em um dos blocos de salas de aula, no qual estimou-se uma produção média de 12.470,00 L.mês'-1.

Palavras-Chave: ar-condicionado, escassez de água, recursos hídricos, sustentabilidade. 


\section{INTRODUÇÃO}

As alterações climáticas têm resultado diversos problemas ambientais, sobretudo em relação ao abastecimento de água e fornecimento de energia elétrica. Nesse contexto, o governo federal brasileiro expediu a Portaria no 23/2015 (BRASIL, 2015) estabelecendo normas de boas práticas de gestão e uso da água e da energia elétrica nos órgãos e entidades da administração pública, como forma de minimizar os impactos ambientais decorrentes dos desempenhos de suas atividades.

Dentro dessa perspectiva, observando a relevância da conservação dos recursos hídricos, algumas instituições educacionais no Brasil e no mundo desenvolveram estudos e programas voltados à essa temática. Logo, entende-se que a evolução do conceito de conservação da água constitui-se na gestão não somente da demanda, mas também da oferta. Assim, os usos menos nobres podem ser supridos por águas de qualidade inferior à potável, podendo-se aproveitar a água de chuva, residuária tratada, como também, condensada a partir de centrais de ar para limpeza de edificações, lavagem de automóveis e irrigação.

Silva et al. (2019) afirmam que o aproveitamento da água condensada por centrais de ar e o reúso de águas cinzas, ainda que pouco explorados, possuem grande aptidão para promover economia hídrica. Os autores avaliaram o potencial de reutilização de águas cinzas, aproveitamento de água pluvial e condensada a partir de centrais de ar e adoção de dispositivos hidrossanitários poupadores de água na Universidade Federal de Viçosa, em Minas Gerais. Por meio do estudo, foi assinalada a economia de água de $68,6 \%$, caso as medidas sugeridas fossem implementadas no edifício central do Departamento de Engenharia Agrícola da instituição.

Já Ferreira e Tose (2016) apresentaram um estudo de caso referente ao uso da água condensada por aparelhos de ar-condicionado para fins não potáveis no Instituto Federal de Educação, Ciência e Tecnologia do Espírito Santo, campus Santa Teresa. Por meio da pesquisa, foi apontada a produção de 172.780,72 L de água por ano letivo na instituição. Desta forma, o uso da água condensada tem assegurado a redução da dependência exclusiva das fontes tradicionais de abastecimento e, por conseguinte, economia financeira. Bem como, resulta em benefício ambiental e delineia uma boa imagem institucional.

A alternativa de aproveitamento de água condensada pelas centrais de ar pode ser aprazível, na perspectiva-ambiental, em ambientes onde esses equipamentos são utilizados em larga escala. Nesses locais, o volume de água gerado é significativo. Desta forma, o aproveitamento desse recurso provoca uma diminuição na demanda de água potável para fins menos nobres (FORTES; JARDIM; FERNANDES, 2015).

Nesse sentido, este estudo foi desenvolvido em uma instituição de ensino superior, situada em uma região onde as condicionantes ambientais se apresentam como um problema socioeconômico e ambiental, notadamente a seca e a escassez de recursos hídricos. Por meio desta pesquisa, enfatiza-se que é interessante aplicar a alternativa do aproveitamento da água gerada a partir de máquinas condensadoras de ar, do ponto de vista quantitativo, na Universidade Federal Rural do Semi-Árido (UFERSA), campus Pau dos Ferros-RN.

\section{OBJETIVO}

Avaliar o potencial quantitativo de aproveitamento da água condensada a partir de centrais de ar, para fins não potáveis, de edificações da Universidade Federal Rural do Semi-Árido, campus Pau dos Ferros-RN.

\section{METODOLOGIA}

A análise do potencial quantitativo de aproveitamento da água condensada a partir de centrais de ar da UFERSA foi segmentada em 2 etapas, conforme a Figura 1. 
Figura 1: Fluxograma da pesquisa.

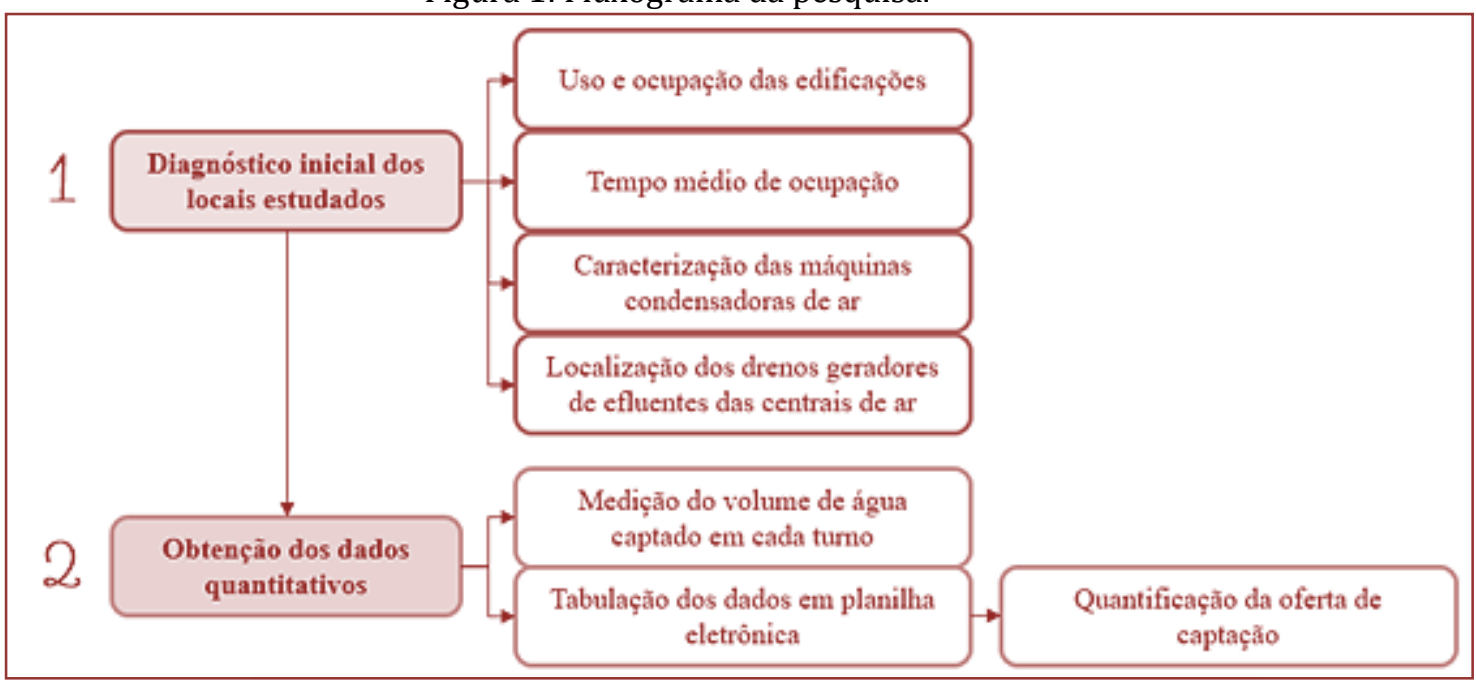

Fonte: Autoria própria (2019).

\subsection{DIAGNÓSTICO INICIAL DOS LOCAIS ESTUDADOS}

O município de Pau dos Ferros situa-se no interior do estado do Rio Grande do Norte e está totalmente inserido no Polígono das Secas, uma zona geográfica com expressivos índices de aridez e refém das constantes crises de estiagem. Além disso, o município é um importante polo econômico e universitário da região Alto Oeste potiguar, e, segundo o Censo Demográfico de 2010 - mais recente -, possuía nesse ano uma população de 27.745 habitantes (IBGE, 2010). O seu clima é muito quente e semiárido e possui temperaturas máxima, média e mínima anuais de 36,28 e $21^{\circ} \mathrm{C}$, respectivamente (IDEMA, 2008).

A Universidade Federal Rural do Semi-Árido, campus Pau dos Ferros-RN, localiza-se na BR-226, km 405, bairro São Geraldo. Atualmente, os blocos construídos e em funcionamento na UFERSA são: 3 blocos de salas de aula, 2 blocos de salas de professores, 2 blocos de laboratórios, 1 bloco administrativo, o Centro de Convivência, a Guarita e a Garagem. 0 campus possui, atualmente, 7 cursos de graduação, sendo estes: Arquitetura, Ciência e Tecnologia, Engenharias Civil, Ambiental, da Computação e de Software e Tecnologia da Informação.

Para o conhecimento do uso e ocupação dos locais estudados, aplicou-se um questionário que abrangeu informações como: horas diárias de permanência na sala; quantidade, marca e potência das máquinas condensadoras da sala; número de funcionários ou alunos que trabalham ou estudam na sala e temperatura média de funcionamento das centrais de ar.

A fim de obter os valores quantitativos desta pesquisa, verificou-se o acesso aos drenos das centrais de ar, porém, apenas alguns estavam disponíveis para coleta, de modo que os demais se encontraram enterrados, logo, inacessíveis. Portanto, a análise, coleta de informações e medições das águas oriundas das centrais de ar foram realizadas na Biblioteca (a qual, durante a realização desta pesquisa, funcionava temporariamente no Centro de Convivência), Blocos A e B de Salas de Aula, Bloco Administrativo, Bloco de Salas dos Professores e Garagem (Figura 2). Cada ponto de coleta foi monitorado e teve suas quantidades volumétricas tabuladas em planilha eletrônica durante o período de 10 semanas. Foram somadas as vazões encontradas a cada turno, gerando as médias de vazões horárias. 
Figura 2: Esquema geral da universidade com indicação dos pontos de coleta das águas condensadas nas centrais de ar.

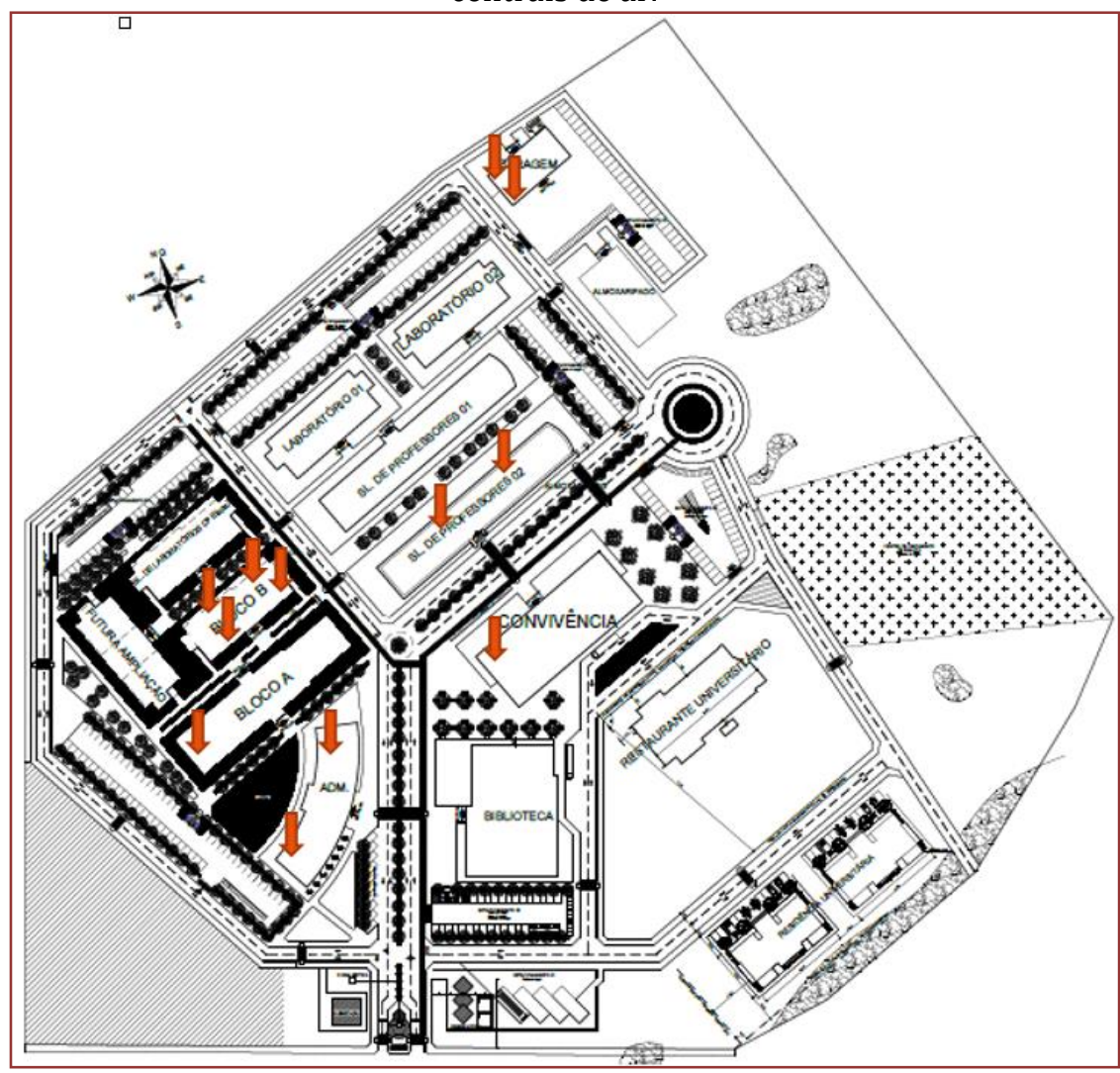

Fonte: Acervo da pesquisa (2017).

\section{RESULTADOS}

\subsection{QUANTITATIVO DO VOLUME CAPTADO}

A síntese da caracterização e tempo médio de utilização das centrais de ar analisadas no quantitativo do volume captado é apresentada na Tabela 1.

Tabela 1. Centrais de ar analisadas no quantitativo de volume de água condensada.

\begin{tabular}{|c|c|c|c|c|}
\hline Local & $\begin{array}{l}\text { Quantidade de centrais } \\
\text { de ar analisadas }\end{array}$ & $\begin{array}{l}\text { Total de centrais } \\
\text { de ar no local }\end{array}$ & $\begin{array}{l}\text { Potência } \\
\text { (BTU) }\end{array}$ & $\begin{array}{l}\text { Tempo de } \\
\text { uso }\left(\text { h.dia }^{-1}\right)\end{array}$ \\
\hline Bloco A & 2 & 20 & \multirow{3}{*}{36.000} & 12,5 \\
\hline Biblioteca & 2 & 2 & & 15,0 \\
\hline Bloco Administrativo 1 & 1 & 4 & & \multirow{3}{*}{8,0} \\
\hline Bloco Administrativo 2 & 1 & 21 & \multirow{5}{*}{12.000} & \\
\hline Garagem & 2 & 2 & & \\
\hline $\begin{array}{l}\text { Bloco de Salas dos Professores (Salas } \\
\text { 8 e 12) }\end{array}$ & 2 & 21 & & 6,0 a 8,0 \\
\hline Xerox & 1 & 1 & & 12,5 \\
\hline Bloco B (Salas 1, 6 e 8) & 6 & 18 & & 9,0 \\
\hline
\end{tabular}

Fonte: Dados da pesquisa (2017).

As vazões unitárias médias dos pontos de coleta são apresentadas na Figura 3. 
Figura 3: Vazões médias horárias de cada ponto de coleta de água condensada.

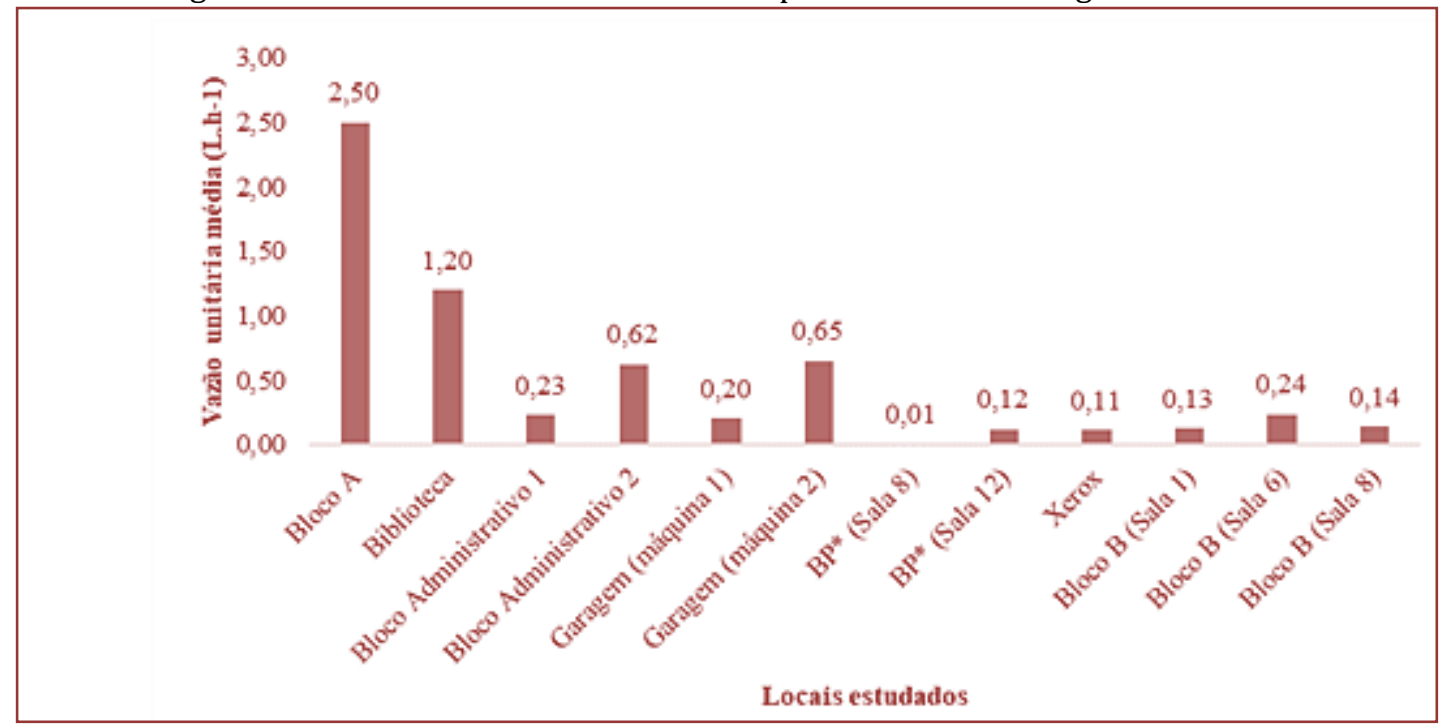

*BP: Bloco de Salas dos Professores.

Fonte: Dados da pesquisa (2017).

A partir dos dados alcançados no decorrer das 10 semanas, foi possível calcular o volume médio semanal de água condensada pelas centrais de ar (Tabela 2).

Tabela 2. Volume médio semanal de água condensada coletada. Fonte: Dados da pesquisa (2017).

\begin{tabular}{|c|c|}
\multicolumn{1}{|c}{ Local } & $\begin{array}{c}\text { Volume médio de água } \\
\text { condensada (L.semana-1) }\end{array}$ \\
\hline Bloco A & 311,75 \\
\hline Biblioteca & 149,40 \\
\hline Bloco Administrativo 1 & 14,65 \\
\hline Bloco Administrativo 2 & 39,00 \\
\hline Garagem & 53,05 \\
\hline $\begin{array}{c}\text { Bloco de Salas dos } \\
\text { Professores (Salas 8 e 12) }\end{array}$ & 8,20 \\
\hline Xerox & 7,08 \\
\hline Bloco B (Salas 1, 6 e 8) & 67,45 \\
\hline Total & 650,60 \\
\hline
\end{tabular}

Um enfoque deve ser dado ao volume de água captado no Bloco A de Salas de Aula. Ele é responsável por aproximadamente $50 \%$ da água produzida em todos os pontos analisados. E ainda, é importante salientar que, o volume de 311,75 L.semana-1 é gerado pelas máquinas de apenas 1 sala de aula, porém, esse bloco é composto por 10 salas de aula e todas possuem 2 centrais de ar com as mesmas características que as máquinas avaliadas. Logo, estima-se que as centrais de ar desse bloco produzem, em média, 12.470,00 L.mês ${ }^{-1}$.

O consumo de água nessas edificações, basicamente, é referente à manutenção e limpeza, bem como às instalações hidrossanitárias, mediante o uso e ocupação. Essas informações dão suporte ao reúso proposto: não potável. A reutilização para irrigação é outra proposta, porém, a qualidade da água captada também deve ser aferida condicionada às culturas irrigadas.

\section{CONCLUSÃO}

O projeto de aproveitamento da água condensada a partir das centrais de ar da UFERSA, campus Pau dos Ferros-RN, é viável do ponto de vista quantitativo, visto que, o volume captado é considerável para contribuir em atividades de fins não potáveis, especialmente no Bloco A. Entretanto, além da análise volumétrica, é necessário que sejam realizados outros estudos com relação à compatibilização e ao 
beneficiamento quanto ao reúso desses volumes. Ademais, as análises físico-químicas e microbiológicas são imprescindíveis para subsidiar o direcionamento da aplicação desses efluentes.

\section{REFERÊNCIAS}

[1] Brasil. Ministério do Planejamento, Desenvolvimento e Gestão. Portaria no 23, de 12 de fevereiro de 2015. Estabelece boas práticas de gestão e uso de energia elétrica e de água nos órgãos e entidades da administração pública federal direta, autárquica e fundacional e dispõe sobre o monitoramento de consumo desses bens e serviços. Brasília, DF, 2015

[2] Ferreira, E. P. Tose, M. Uso de água condensada por aparelhos de ar condicionado para fins não potáveis - um estudo de caso. Agrarian Academy, Goiânia, v. 3, n. 6, p. 99-107, 2016.

[3] Fortes, P. D.; Jardim, P. W. C. F. P. M. G.; Fernandes, J. G. Aproveitamento de água proveniente de aparelhos de ar condicionado. In: Simpósio de Excelência em Gestão e Tecnologia, Resende-RJ, 2015.

[4] Instituto Brasileiro de Geografia e Estatística (Ibge). Censo Demográfico. 2010. Disponível on-line: www.ibge.gov.br. Acesso em: 25 de julho de 2019.

[5] Instituto de Desenvolvimento Sustentável e Meio Ambiente do Rio Grande do Norte (Idema). Perfil do seu município. 2008. Disponível on-line: www.idema.rn.gov.br. Acesso em: 25 de julho de 2019.

[6] Silva, l. C. C.; Oliveira Filho, d.; silva, i. R.; pinto, a. C. V.; vaz, p. N. Water sustainability potential in a university building - case study. Sustainable cities and Society, 47, 2019. 


\section{Capítulo 19}

Avaliação da relação entre a degradação ambiental e a percepção ambiental da comunidade de alto Rio Possmoser em Santa Maria de Jetibá, ES

\section{Charles Moura Netto \\ Wanderson de Paula \\ Heitor Messias Sacht \\ Mylenna Zibell}

Resumo: Esta pesquisa teve como objetivo a avaliação da percepção ambiental de indivíduos residentes da Comunidade de Alto Rio Possmoser em Município de Santa Maria de Jetibá, localizado na região Centro-Serrana do Espírito Santo, Brasil. Foram entrevistados 386 indivíduos, entre os meses de setembro a outubro de 2017, que responderam sobre questões que abordavam a compreensão dos impactos ambientais da região; hábitos pessoais e meio ambiente. Com base na análise as respostas evidenciaram que os indivíduos da amostra estudada expoem uma boa percepção ambiental relacionado aos problemas identificados. Em contra partida, não podem ser ignoradas as chances de que parte das respostas dos entrevistados não devem mostrar realmente as ações realizadas pelos mesmos. Este estudo mostra que políticas públicas para esta região devem estar voltadas para a introdução de práticas sustentáveis no cotidiano da população.

Palavras-chave: percepção ambiental; degradação ambiental; educação ambiental; recursos naturais. 


\section{INTRODUÇÃO}

Este trabalho abordou um tema relevante para a sociedade, refere-se a degradação ambiental e sua relação com a percepção ambiental dos seres humanos. 0 homem por uma necessidade natural, sempre modificou o seu meio ambiente para sobreviver. A exploração desenfreada da natureza pode acarretar em problemas ambientais que estão ligados diretamente a problemas de saúde, conforme Dias (2000) “[...] no que diz respeito aos problemas ambientais, que são simultaneamente problemas de saúde, pois afetam os seres humanos e a sociedade em múltiplas e simultâneas escalas e dimensões[...]".

0 modo como trata-se a natureza está ligado ao nosso modo de perceber o ambiente que está em torno de nós. De acordo com Fernandes (2004), cada indivíduo percebe, reage e responde diferentemente às ações sobre o ambiente em que vive. As respostas ou manifestações daí decorrentes são resultado das percepções (individuais e coletivas), dos processos cognitivos, julgamentos e expectativas de cada pessoa.

Assim, o estudo da percepção ambiental é relevante para uma melhor compreensão da inter-relação homem e natureza, levando em conta suas expectativas, satisfações e insatisfações, julgamentos e condutas. A análise poderá fornecer subsídios à confecção de políticas públicas e servir de auxílio para ações e projetos ambientais a serem implementados na região.

Diante do exposto, este trabalho objetivou a avaliação da percepção ambiental de indivíduos residentes da Comunidade de Alto Rio Possmoser em Município de Santa Maria de Jetibá, localizado na região CentroSerrana do Espírito Santo, Brasil, verificando as percepções dos indivíduos frente às degradações identificadas na região. Que poderá ser utilizado para fornecer subsídios às ações e aos projetos de gestão e educação ambiental nessa região.

\section{MARCO TEÓRICO}

Segundo Carvalho (2008, p. 35) "Quando falamos em meio ambiente, muito frequentemente essa noção logo evoca as ideias de "natureza", "vida biológica", "vida selvagem", "flora e fauna". " Tais imagens colaboram para uma visão naturalista que influencia muito o conceito de meio ambiente disseminado na sociedade. 0 meio ambiente é definido através da Lei 6.938 (BRASIL, 1981, art. 3) como "o conjunto de condições, leis, influências e interações de ordem física, química e biológica, que permite, abriga e rege a vida em todas as suas formas."

A expressão "meio ambiente" para alguns está relacionada apenas a vegetais, animais, água, solo e ar. Daí a necessidade de se esclarecer a amplitude do significado da expressão (Kandler, 2009). A falta de esclarecimento e compreensão da expressão "meio ambiente" torna-se um problema no que diz respeito à educação ambiental. Ainda segundo Kandler (2009), o desafio já foi lançado há vários anos e por diferentes meios. Partindo de leis, instrumentos educativos e livros dotados de orientações que colaboram na formação da consciência ecológica. As ações e práticas organizadas nas escolas são diversas e voltadas basicamente à sensibilização da coletividade sobre as questões ambientais, estimulando a participação na defesa da qualidade do meio ambiente.

As atividades ligadas à conscientização da população sobre temas ambientais são importantes pois, a falta de conhecimento crítico do que é meio ambiente pode estar ligada a percepção dos indivíduos quanto ao local que estão inseridos. Segundo Palma (2005), entende-se por percepção a interação do indivíduo com seu meio. Este envolvimento dá-se através dos órgãos do sentido. Para que possamos realmente Perceber, é necessário que tenhamos algum interesse no objeto de percepção e esse interesse é baseado nos conhecimentos, na cultura, na ética, e na postura de cada um, fazendo com que cada pessoa tenha uma percepção diferenciada para o mesmo objeto.

A percepção ambiental pode ser determinada como a reflexão crítica do ambiente pelo homem, em outras palavras é o ato de perceber e viver em harmonia com o ambiente em que está inserido. De acordo com Fernandes (2004), cada indivíduo percebe, reage e responde diferentemente às ações sobre o ambiente em que vive. As respostas ou manifestações daí decorrentes são resultado das percepções (individuais e coletivas), dos processos cognitivos, julgamentos e expectativas de cada pessoa.0 estudo da percepção ambiental é importante para compreensão das relações entre o homem e o ambiente.

A Educação Ambiental aliada à Percepção Ambiental deve ter como objetivo, a transmissão de conhecimentos e a compreensão dos problemas ambientais e consequentemente provocar uma maior sensibilização das pessoas a respeito da preservação dos recursos naturais (fauna, flora, rios, matas etc.), bem como a prevenção de riscos de acidentes ambientais e correção de processos que afetam a qualidade de vida nos centros urbanos (Melazo, 2005). 
De acordo com a Lei 9.795 (Brasil, 1999, art. 1) entendem-se por educação ambiental os processos por meio dos quais o indivíduo e a coletividade constroem valores sociais, conhecimentos, habilidades, atitudes e competências voltadas para a conservação do meio ambiente, bem de uso comum do povo, essencial à sadia qualidade de vida e sua sustentabilidade.

A partir do conhecimento e compreensão dos problemas ambientais, ou seja, da degradação do meio ambiente, espera-se que a população tome consciência e procure minimizar ou evitar ações que prejudiquem o meio em que estão inseridas. Conforme a Lei 6.938 (BRASIL, 1981, art. 3) a degradação da qualidade ambiental é a alteração adversa das características do meio ambiente. A lei não especifica se tal alteração é de origem antrópica ou não portanto a degradação ambiental significa qualquer ação, originada pelo homem ou não, que venha modificar o ambiente natural.

O termo degradação ambiental frequentemente é seguido pelo termo impacto ambiental que consta na Resolução CONAMA no 001 de 1986 tendo a seguinte definição:

“Qualquer alteração das propriedades físicas, químicas ou biológicas do meio ambiente, causada por qualquer forma de matéria ou energia resultante das atividades humanas, que direta ou indiretamente afetem:

I - a saúde, a segurança e o bem-estar da população;

II - as atividades sociais e econômicas;

III - as condições estéticas e sanitárias do meio ambiente;

IV - a qualidade dos recursos ambientais."

Os impactos ambientais causados pelo homem não necessariamente precisam ser negativos. Observando a citação a cima percebemos que um impacto ambiental pode ocorrer de forma negativa ou positiva.

Realizando um levantamento dos impactos ambientais existentes em um determinado local, torna-se possível traçar metas e planejar ações a fim de garantir a qualidade de vida e a subsistência da atual e das futuras gerações. A importância de ter um diagnóstico ambiental é para de fato direcionarmos ações e projetos ambientais, assim como políticas públicas que possam ser efetivas no local de estudo. 0 diagnóstico ambiental pode ser definido como o conhecimento de todos os componentes ambientais de uma determinada área em diferentes escalas (país, estado, bacia hidrográfica, município) para a caracterização da sua qualidade ambiental (Fontanella, 2009).

Faz parte do diagnóstico ambiental elucidar as situações ambientais problemáticas basedado nas relações dos objetos e indivíduos que os constituem. Ainda segundo Fontanella (2009) a elaboração do diagnóstico ambiental envolve interpretar a situação ambiental problemática, a partir da interação e da dinâmica de seus componentes, quer relacionado aos elementos físicos e biológicos, quer aos fatores sócio-culturais. 0 diagnóstico ambiental é uma importante ferramenta na construção de políticas públicas que possuir como objetivo a melhoria da qualidade de vida da população local, se institui na forma de uma investigação de dados ambientais de uma determinada região.

Contextualizando, segundo Palma (2005), na educação ambiental, a percepção ambiental poderá ajudar na construção de metodologias para despertar nas pessoas a tomada de consciência frente aos problemas ambientais. Unindo a percepção ambiental e a educação ambiental é possível realizar trabalhos com bases locais. Isto é, saber como os indivíduos com que trabalharemos percebem o ambiente em que vivem, suas fontes de satisfações e insatisfações.

0 artigo 225 da Constituição Federal, em seu parágrafo primeiro, estabelece o caráter público do meio ambiente: "Todos têm o direito ao meio ambiente ecologicamente equilibrado, bem de uso comum do povo e essencial à sadia qualidade de vida". Determina ainda "ao Poder Público e à coletividade o dever de defendê-lo e preservá-lo para os presentes e as futuras gerações”.

Atualmente, a população sofre com os problemas que resultam de muitos anos de agressão ao ambiente, em nome do desenvolvimento. De acordo com Carvalho (2008), visão da natureza como domínio do selvagem, do ameaçador e do esteticamente desagradável estabeleceu-se sobre a crença de que o progresso humano era medido por sua capacidade de dominar e submeter o mundo natural. Tal visão, que situa o homem como o centro do universo, é chamada antropocêntrica.

Baseado nesses autores percebe-se a necessidade de mais estudos relacionados a percepção ambiental, identificar como as pessoas percebem e interagem com o meio em que estão é relevante e pode servir de base para a criação de projetos e políticas públicas ambientais efetivas na região. 


\section{METODOLOGIA}

O município de Santa Maria de Jetibá está localizado na região Centro-Serrana do Estado do Espírito Santo, com extensão territorial de $735,579 \mathrm{~km}^{2}$. Dista da capital do Estado, a cidade de Vitória, aproximadamente de $80 \mathrm{~km}$. 0 município possui uma altitude média de 706 metros está localizado na região das montanhas e por isso possui um clima com temperaturas baixas na maior parte do ano, fazendo divisa com Domingos Martins (sul), Santa Leopoldina (leste), Afonso Claudio (oeste) e Itarana e Santa Teresa (norte). A população do município foi estimada pelo IBGE em 2017 em 39.928 pessoas. Quanto a distribuição por zona de moradia, verificou-se que, no censo demográfico realizado no ano de 2010, 65,48 \% residiam na zona rural e $34,52 \%$ na zona urbana.

A economia local está diretamente ligada à agropecuária. Santa Maria de Jetibá é o segundo maior produtor de ovos do Brasil, sendo o primeiro produtor de ovos, gengibre e morango do Estado do Espirito Santo. A diversidade agrícola é rica sendo assim se cultiva várias culturas entre elas: chuchu, folhosas, beterraba, repolho e cebola, lavouras de milho, feijão, café e outros. 0 município possui ainda um grande número de indivíduos que praticam agricultura familiar.

Em relação a recursos hídricos o rio Santa Maria da Vitória nasce no município de Santa Maria de Jetibá na localidade de Alto Santa Maria, e suas águas percorrem 122 quilômetros até desaguar na Baía de Vitória. A área de drenagem da sua bacia hidrográfica é de $1844 \mathrm{~km}^{2}$ e abrange cinco municípios do Estado: Santa Maria de Jetibá, Santa Leopoldina, Cariacica, Serra e Vitória. O Rio Santa Maria da Vitória é um dos principais mananciais do Espírito Santo. Juntamente com o rio Jucu ele é responsável pelo abastecimento de água da Grande Vitória. Abastece a parte continental da capital e o município da Serra. A localização do município e da comunidade de Alto Rio Possmoser pode ser observada na Figura 1.

Figura 1: Localização da cidade de Alto Rio Possmoser, Santa Maria de Jetibá,ES.

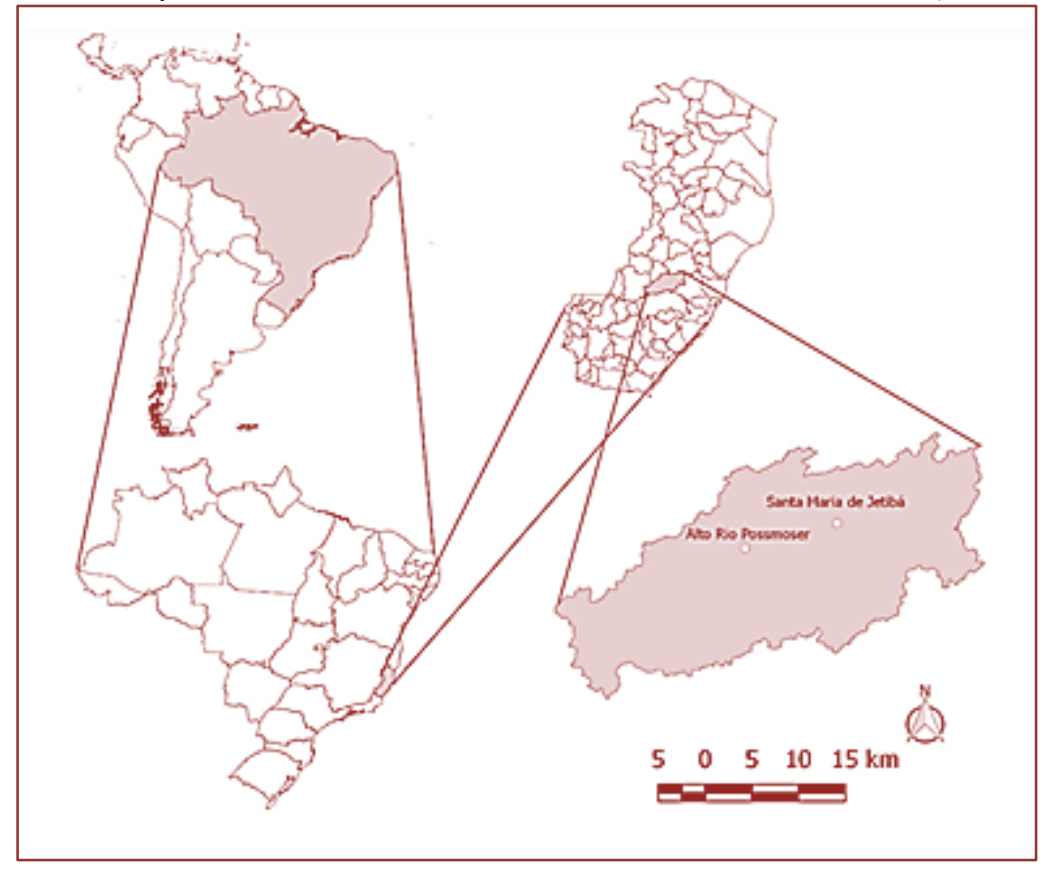

Fonte: Dos autores (2017).

A comunidade de Alto Rio Possmoser possui uma população de 1483 habitantes, em seu perímetro urbano, segundo o levantamento quantitativo populacional pelo Programa da Saúde da Família realizado em agosto de 2017. A partir da Lei Municipal № 1836/2016 ficou determinado o perímetro urbano de Alto Rio Possmoser conforme apresentado na Figura 2. 
Figura 2: Perímetro Urbano de Alto Rio Possmoser de acordo com a Lei Municipal № 1836/2016.

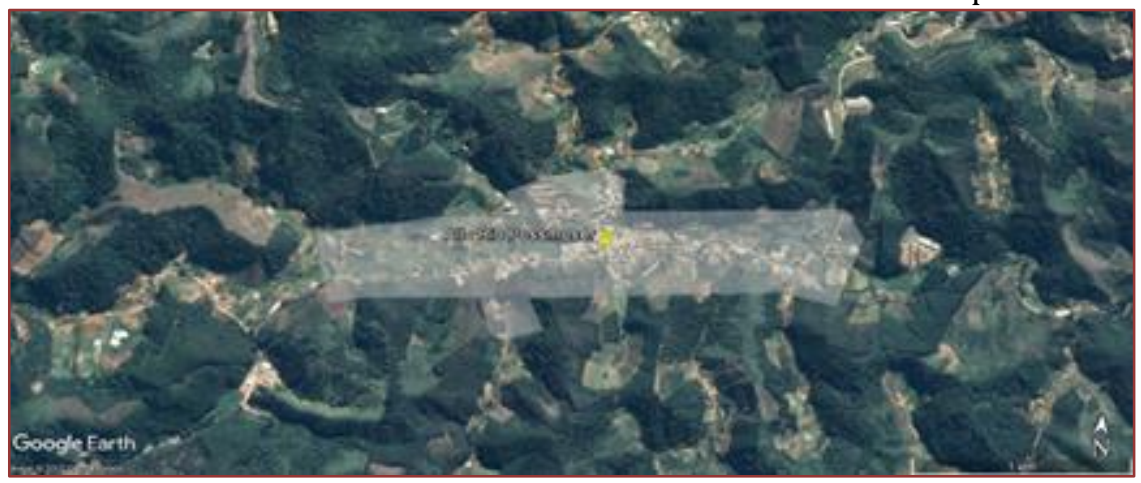

Fonte: Google Earth 2016.

Com cerca 16 km de extensão, o Rio Possmoser nasce nas coordenadas geográficas (UTM) $303645.60 \mathrm{~m}$ E/7783746.52 m S e deságua na localidade referente ás coordenadas $313472.14 \mathrm{~m} \mathrm{E/7779417.00} \mathrm{m} \mathrm{S.} \mathrm{Rio}$ Posmosser é um importante afluente do Rio Santa Maria da Vitória. A Figura 3 mostra a imagem aérea da Região de Rio Possmoser com destaque para o rio.

Figura 3: Imagem aérea da região do Rio Possmoser.

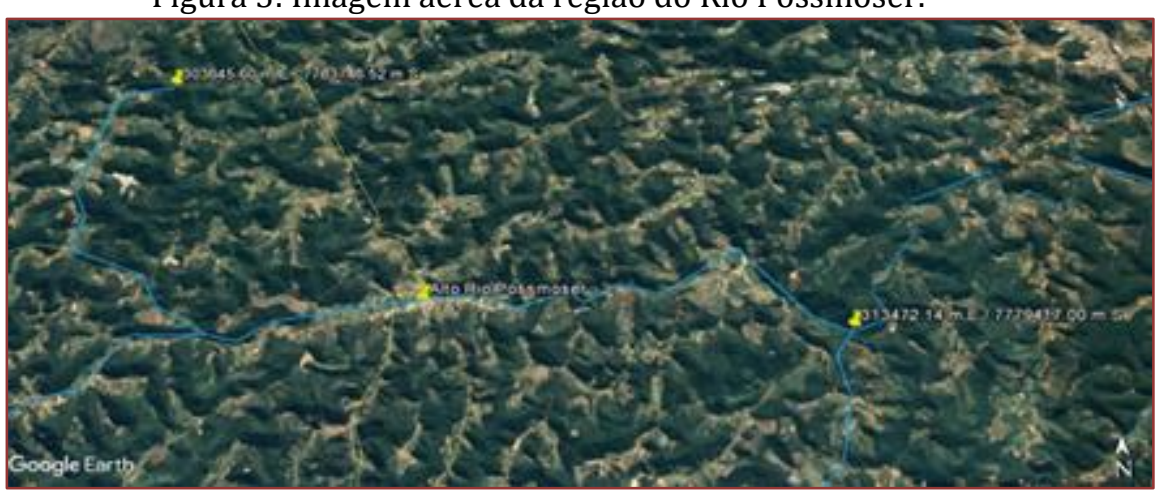

Fonte: Google Earth 2016.

Para o levantamento de campo, realizou-se visitas a região de estudo (perímetro urbano de Alto Rio Possmoser), onde foram evidenciados alguns casos de degradação ambiental, destes locais foram obtidas as coordenadas geográficas conforme demosntrado na Figura 4.

Figura 4: Imagem aérea de Alto Rio Possmoser com os casos de degradação identificados.

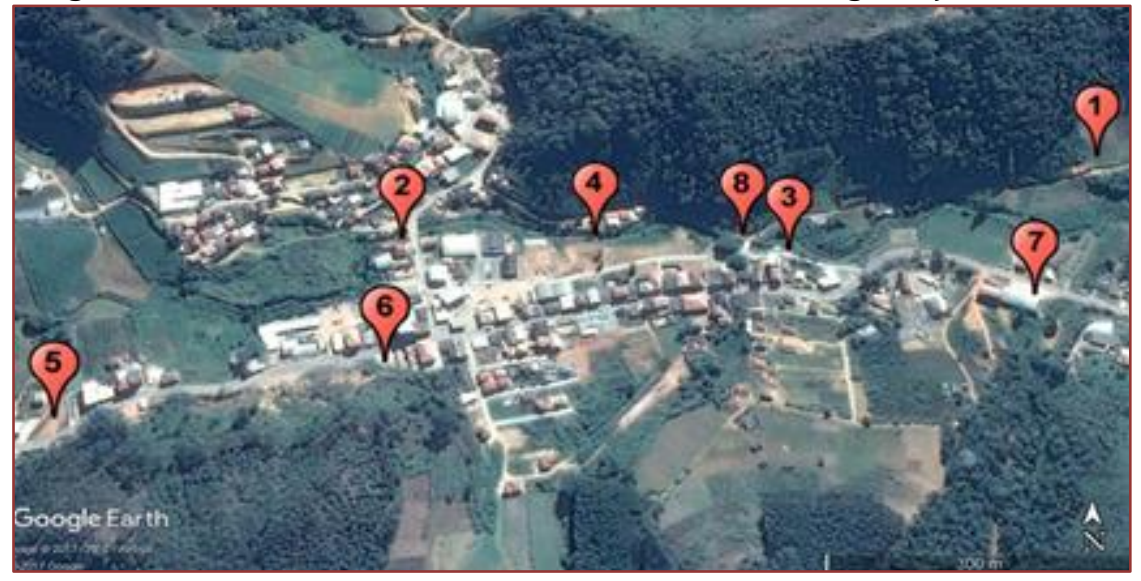

Fonte: Google Earth 2016. 
Os casos de degradação identificados na imagem foram enumerados e listados na Tabela 1 . As coordenadas geográficas foram coletadas a partir do Google Earth.

Tabela 1: Casos de degradação ambiental identificados no perímetro urbano da comunidade de Alto Rio Possmoser em Santa Maria de Jetibá/ES.

\begin{tabular}{|c|c|c|}
\hline Número & Identificação & $\begin{array}{c}\text { Coordenadas geográficas } \\
\text { (UTM) }\end{array}$ \\
\hline 1 & $\begin{array}{c}\text { Mau uso do solo ( cultivo em área de } \\
\text { declividade acentuada }\end{array}$ & $\begin{array}{l}308261.93 \mathrm{~m} \mathrm{E} \\
7780176.84 \mathrm{~m} \mathrm{~S}\end{array}$ \\
\hline 2 & $\begin{array}{l}\text { Edificações ambientalmente } \\
\text { inadequadas }\end{array}$ & $\begin{array}{l}307463.51 \mathrm{~m} \mathrm{E} \\
7780059.23 \mathrm{~m} \mathrm{~S}\end{array}$ \\
\hline 3 & $\begin{array}{l}\text { Descarte inadequado de resíduos da } \\
\text { construção civil }\end{array}$ & $\begin{array}{l}307903.74 \mathrm{~m} \mathrm{E} \\
7780045.00 \mathrm{~m} \mathrm{~S}\end{array}$ \\
\hline 4 & $\begin{array}{l}\text { Lançamento direto de efluentes } \\
\text { domésticos }\end{array}$ & $\begin{array}{l}307684.07 \mathrm{~m} \mathrm{E} \\
7780063.51 \mathrm{~m} \mathrm{~S}\end{array}$ \\
\hline 5 & Supressão de mata ciliar & $\begin{array}{l}307107.51 \mathrm{~m} \mathrm{E} \\
7779815.58 \mathrm{~m} \mathrm{~S}\end{array}$ \\
\hline 6 & Disposição inadequada de lixo & $\begin{array}{l}307457.38 \mathrm{~m} \mathrm{E} \\
7779889.50 \mathrm{~m} \mathrm{~S}\end{array}$ \\
\hline 7 & Queima de lixo & $\begin{array}{l}308177.16 \mathrm{~m} \mathrm{E} \\
7779989.60 \mathrm{~m} \mathrm{~S}\end{array}$ \\
\hline 8 & $\begin{array}{l}\text { Criação de animais perto do leito do } \\
\text { rio }\end{array}$ & $\begin{array}{l}307851.08 \mathrm{~m} \mathrm{E} \\
7780064.01 \mathrm{~m} \mathrm{~S}\end{array}$ \\
\hline
\end{tabular}

Foram realizados também, registros fotográficos dos casos de degradação identificados, a fim de auxiliar na construção do questionário estruturado a ser aplicado na região. Entre eles citam-se:

- $\quad$ Mau uso do solo; (declividade)

Figura 5: Imagem de cultivo em área com declividade acentuada.

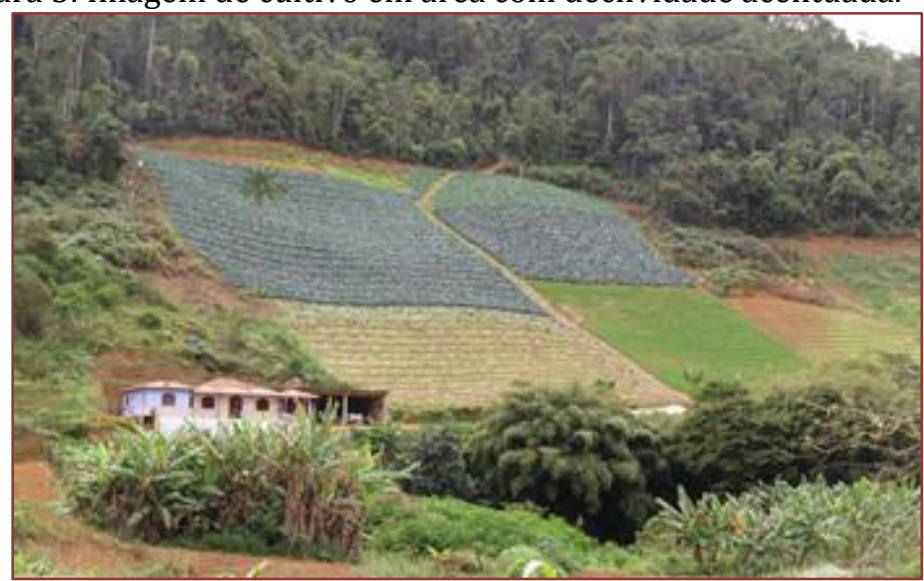

Fonte: Autoria própria. (Coordenadas em UTM 308261.93 m E 7780176.84 m S)

$\mathrm{Na}$ imagem pode ser observado o cultivo agrícola em área com declividade acentuada (superior a 45으). Tais áreas, além de importantes para a biodiversidade e para manutenção e recarga de aquíferos que vão abastecer as nascentes, são em geral áreas frágeis e sujeitas a desbarrancamentos e deslizamentos de solo ou rochas, principalmente quando desmatadas e degradadas ambientalmente (Schäffer, 2011, p. 15).

- $\quad$ Edificações ambientalmente inadequadas ás margens do Rio Possmoser (Figura 6). 
Figura 6: Imagem de residências ás margens do rio

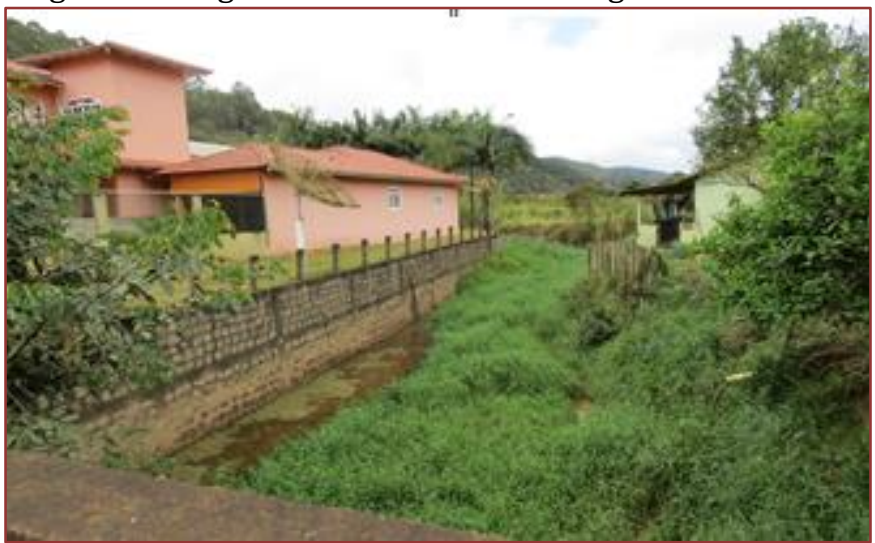

Fonte: Autoria própria. (Coordenadas em UTM 307463.51 m E 7780059.23 m S).

De acordo com o Art. 4o da lei № 12.651 (Brasil, 2012), considera-se Área de Preservação Permanente, em zonas rurais ou urbanas, as faixas marginais de qualquer curso d'água natural. No caso apresentado na Figura anterior, deve-se preservar 30 (trinta) metros, pois o curso d'água corresponde a menos de 10 (dez) metros de largura.

- Disposição e descarte inadequado de resíduos da construção civil.

Figura 7: Imagem da disposição de entulho próximo ao Rio Possmoser.

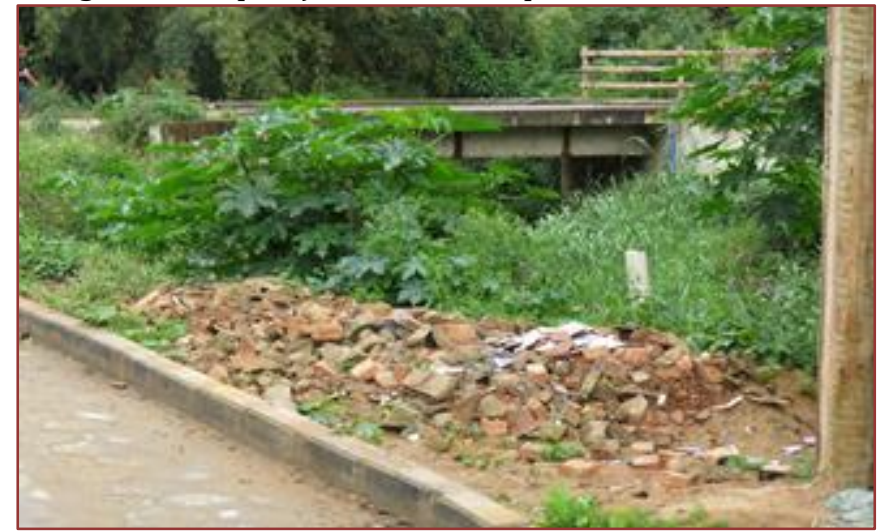

Fonte: Autoria própria. (Coordenadas em UTM 307903.74 m E 7780045.00 m S)

De acordo com a Resolução CONAMA № 307/2002, os resíduos da construção civil não poderão ser dispostos em aterros de resíduos domiciliares, em áreas de "bota fora", em encostas, corpos d’água, lotes vagos e em áreas protegidas por Lei. Na área de estudo, foram identificadas disposições de entulho em lotes vagos e nas proximidades da margem do Rio Possmoser, conforme mostra a imagem abaixo. Uma vez que os resíduos da construção civil possuem grande potencial de reciclagem, esta seria uma alternativa para evitar tal forma de degradação.

- $\quad$ Lançamento de efluentes domésticos sem tratamento no rio. 
Figura 8: Lançamento direto de efluentes domésticos no Rio Possmoser.
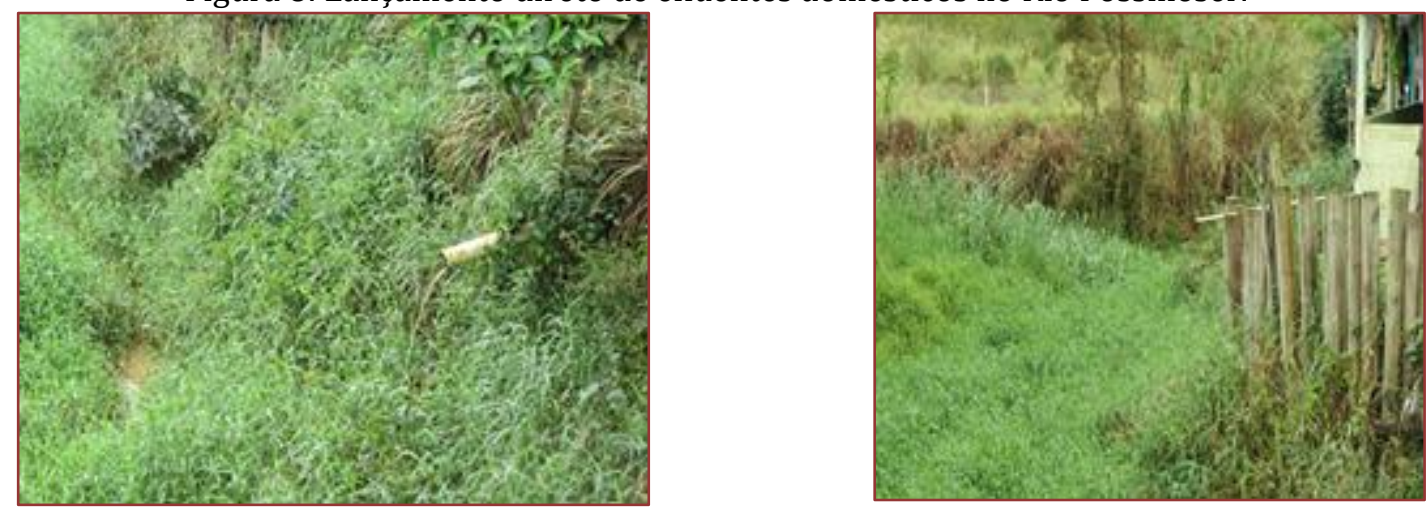

Fonte: Autoria própria. (Coordenadas em UTM 307684.07 m E 7780063.51 m S).

A matéria orgânica é o principal problema de poluição dos corpos d'água, por ser o alimento dos microrganismos que utilizam oxigênio dissolvido (OD) para degradá-la, reduzindo a concentração de OD. A dimensão do impacto causado depende da carga poluidora (DBO) do esgoto e da capacidade do corpo receptor de restabelecer o equilíbrio no meio aquático (Santos e Athayde Junior, 2008, p. 22).

Ainda, de acordo com SANTOS et al. "Diversos organismos podem ser encontrados nos esgotos. Os principais grupos capazes de causar doenças nos homens e nos animais são as bactérias, os vírus, os protozoários e os helmintos, que trazem riscos à saúde das pessoas. [...] A origem desses organismos patogênicos é predominantemente humana, refletindo diretamente o nível de saúde e as condições de saneamento básico da comunidade. A quantidade de agentes patogênicos presentes no esgoto é bastante variável e depende, entre outros fatores, das condições socioeconômicas e sanitárias da população. Os principais parâmetros empregados para a avaliação do potencial do esgoto como contaminador das águas são os coliformes termotolerantes e os ovos de helmintos".

As cidades que crescem sem controle e planejamento, principalmente sem redes de esgoto, podem sofrer com este tipo de problema. Uma vez que não existe rede de esgoto os habitantes acabam por destinar os efluentes domésticos em outros locais, estes lugares podem ser responsáveis pelas proliferação de vetores e ocasionar doenças para a população.

- $\quad$ Supressão de mata ciliar do Rio Possmoser.

Figura 9: Supressão da mata ciliar.

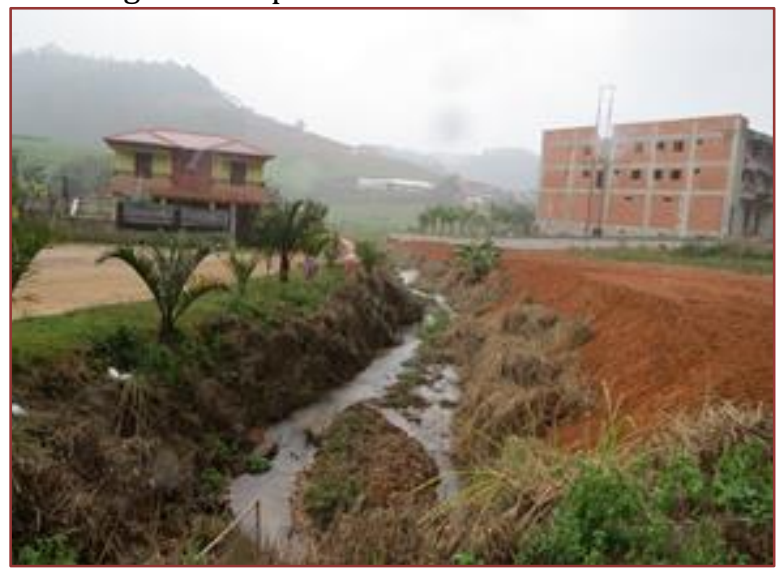

Fonte: Autoria própria. (Coordenadas em UTM 307107.51 m E 7779815.58 m S). 
Dentre os fatores que interferem diretamente sobre o volume e qualidade da água disponível no Brasil, merece destaque a destruição da vegetação existente nas margens e entorno das nascentes e dos cursos de água promovida por razões e objetivos diversos (Chaves, 2009). 0 solo exposto pode vir a interferir da qualidade do recurso hídrico, pois em época de enchente poderá ocorrer o carreamento de sedimentos.

A Mata Ciliar é um tipo de cobertura vegetal que se localiza às margens dos cursos hírdricos. 0 nome "ciliar" é dado por estarem cercando as águas, e serem tão importantes para a sua conservação quanto são os cílios para os nossos olhos. Além disso as matas ciliares conservadas diminuem os problemas de erosão do solo e mantem a qualidade das águas dos rios e lagos.

As Matas Ciliares são importantes por apresentarem um conjunto de funções ecológicas extremamente relevantes para a qualidade de vida, especialmente, das populações humanas locais e da bacia hidrográfica, sendo fundamentais para a conservação da diversidade de animais e plantas nativas da região, tanto terrestres como aquáticos. As Matas Ciliares influenciam na qualidade da água, na regulação do regime hídrico, na estabilização de margens do rio, na redução do assoreamento da calha do rio e são influenciadas pelas inundações, pelo aporte de nutrientes e pelos ecossistemas aquáticos que elas margeiam (Castro, 2012, p. 7).

- Disposição inadequada e queima de lixo.

Figura 10: Área com disposição inadequada de resíduos e queima de lixo.
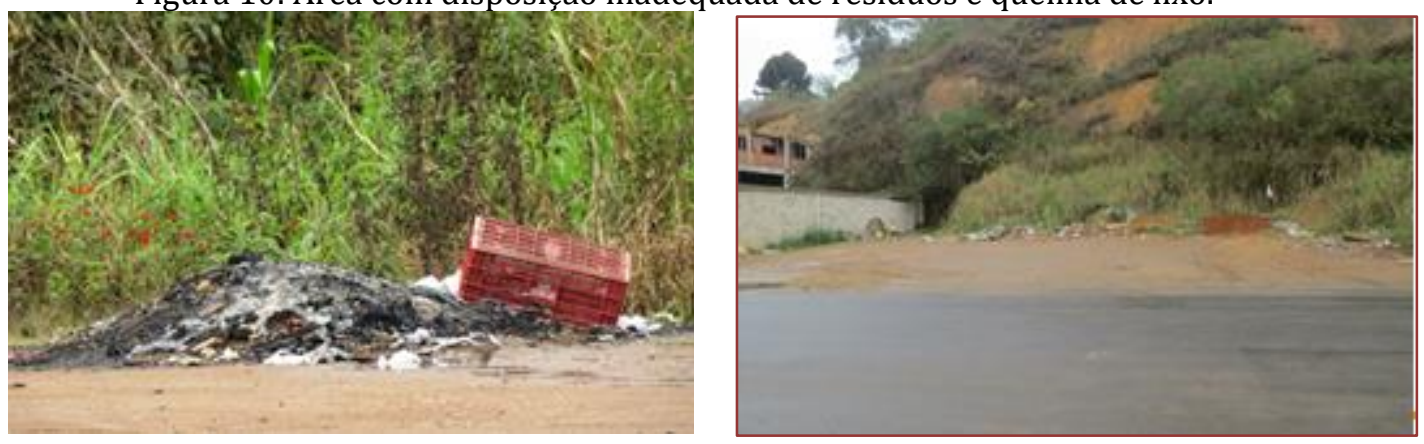

Fonte: Autoria própria. (Coordenadas em UTM 308177.16 m E 7779989.60 m S e 307457.38 m E 7779889.50 m S, respectivamente)

A Figura 10 demonstra a destinação final inadequada para resíduos domésticos. Quando o lixo é disposto de forma inadequada, em lixões a céu aberto, por exemplo, os problemas sanitários e ambientais são inevitáveis. Isso porque estes locais tornam-se propícios para a atração de animais que acabam por se constituírem em vetores de diversas doenças, especialmente para as populações que vivem da catação, uma prática comum nestes locais. Além do mais, são responsáveis pela poluição do ar, quando ocorre a queima dos resíduos, do solo e das águas superficiais e subterrâneas (Ribeiro, 2010, p. 11)

Ainda de acordo com Ribeiro (2010, p. 19) várias doenças podem ser transmitidas quando não há coleta e disposição adequada do lixo. Os mecanismos de transmissão são complexos e ainda não totalmente compreendidos. Como fator indireto, o lixo tem grande importância na transmissão de doenças através, por exemplo, de vetores que nele encontram alimento, abrigo e condições adequadas para proliferação. São muitas as doenças relacionadas ao acúmulo de lixo e a sua falta de tratamento.

- $\quad$ Criação de animais e cultivo ás margens do rio 
Figura 11: Curral de bovinos ao lado do rio.

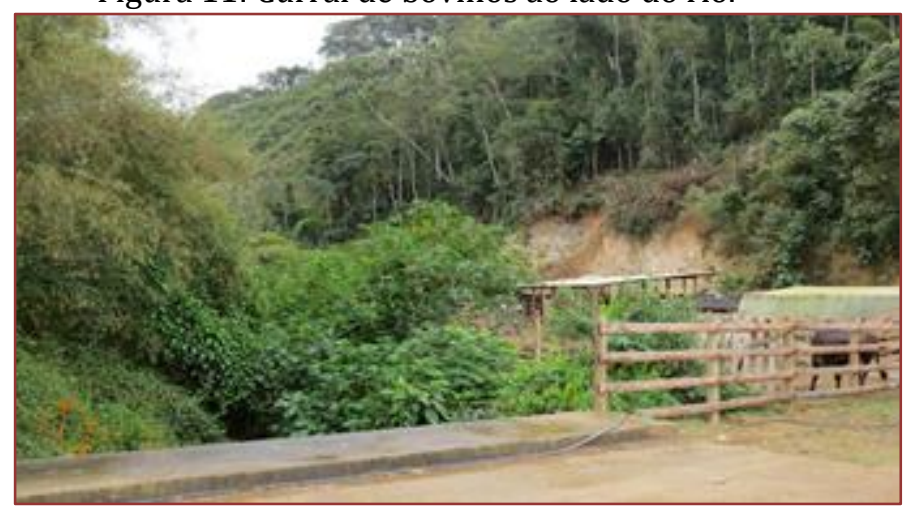

Fonte: Autoria própria. (Coordenadas em UTM 307851.08 m E 7780064.01 m S).

A Figura 11 comprova a existência de curral de bovinos próximo ao rio. A criação de animais próximo a cursos hídricos pode prejudicar a qualidade da água através de contaminação pelas fezes dos animais e também pode afetar as características naturais da área. E como se encontra em área de preservação permanente por estar próxima ao rio, de acordo com o Art. 4o da lei № 12.651/2012, deveria ser preservado total de 30 (trinta) metros de distância, pois o curso d'água corresponde a menos de 10 (dez) metros de largura.

Realizou-se o levantamento dos pontos de degradação da localidade estudade e posteriormente foi realizado o cálculo da amostra para as entrevistas. 0 tipo de amostra utilizada nesta pesquisa é a amostra aleatória ou probabilística que é constituída por $\mathrm{n}$ unidades retiradas ao acaso da população. Em outras palavras, a amostra aleatória é obtida por sorteio. Logo, toda unidade da população tem probabilidade conhecida de pertencer à amostra, de acordo com Vieira (2011, pag.5).

Fórmula para calcular o tamanho da amostra:

Equação 1.

$$
n=\frac{N \cdot z^{2} \cdot p \cdot(1-p)}{(N-1) e^{2}+z^{2} \cdot p \cdot(1-p)}
$$

Em que: $n=$ amostra; $N=$ população (1483 habitantes); $z=1,96$ (para nível de confiança de 95\%); $p=$ proporção $(0,5)$ e $e=$ margem de erro $(0,05)$.

Empregando a fórmula foi obtido um $\mathrm{n}=385,37$. Portanto a amostra necessária para a elaboração dos dados foi de 386 pessoas.

\section{RESULTADOS}

Após a elaboração do questionário foram entrevistados 386 indivíduos. A aplicação das perguntas foi realizada entre os meses de setembro e outubro de $2017 \mathrm{em}$ forma de abordagens diretas aos moradores. Aos entrevistados, na abordagem foi garantido o anonimato na divulgação dos resultados desta pesquisa e a participação não envolveria custos financeiros e nenhum tipo de dano aos participantes.

A análise preliminar dos dados obtidos a partir da aplicação do questionário aos 386 indivíduos residentes da comunidade de Alto Rio Possmoser revelou que 199 (51,554\%) indivíduos eram do sexo feminino e 187 (48,446\%) indivíduos eram do sexo masculino, indicando participação muito similar de ambos os sexos no estudo. Esta amostra foi composta de indivíduos com idade mediana de 35 a 82 anos.

Os dados obtidos através das respostas dos moradores foram reunidos e analisados em uma planilha eletrônica. Na análise bivariada, foi empregado o teste Qui-Quadrado para tendência para comparar proporções. Para um valor de $\mathrm{P}<0,05$ (teste bicaudal) foi considerado estatisticamente significante. 
Tabela 2: Resultados obtidos através de diferentes itens abordads no questionário em relação à faixa etária da amostra estudada ( $\mathrm{n}=386)$ na comunidade de Alto Rio Possmoser em Santa Maria de Jetibá/ES.

\begin{tabular}{|c|c|c|c|c|c|c|}
\hline \multirow[t]{2}{*}{ Questão } & \multicolumn{5}{|c|}{ Faixa Etária (Anos) } & \multirow{2}{*}{$\begin{array}{c}\text { Análise } \\
\text { Bivariada Valor- } \\
\text { P }\end{array}$} \\
\hline & n $(\%)$ & $16-25$ & $26-45$ & $46-60$ & $>60$ & \\
\hline \multicolumn{7}{|c|}{ Considera que existe descarte irregular de lixo na cidade? } \\
\hline Sim & $\begin{array}{c}273 \\
(70,7)\end{array}$ & $\begin{array}{c}105 \\
(27,20)\end{array}$ & $\begin{array}{c}146 \\
(37,82)\end{array}$ & $17(4,4)$ & $\begin{array}{c}5 \\
(1,29)\end{array}$ & \multirow{2}{*}{0,00015} \\
\hline Não & $113(29,3)$ & $23(5,9)$ & $69(17,87)$ & $\begin{array}{c}11 \\
(2,84)\end{array}$ & $\begin{array}{c}10 \\
(2,59)\end{array}$ & \\
\hline \multicolumn{7}{|c|}{ Considera um problema criar animais perto do leito do rio? } \\
\hline Sim & $\begin{array}{c}272 \\
(70,46)\end{array}$ & $99(25,64)$ & $\begin{array}{c}152 \\
(39,37)\end{array}$ & $\begin{array}{c}11 \\
(2,84)\end{array}$ & $\begin{array}{c}10 \\
(2,59)\end{array}$ & \multirow{2}{*}{0,00108} \\
\hline Não & $\begin{array}{c}114 \\
(29,54)\end{array}$ & $29(7,51)$ & $63(16,32)$ & $17(4,4)$ & $\begin{array}{c}5 \\
(1,29)\end{array}$ & \\
\hline \multicolumn{7}{|c|}{ Considera um problema o cultivo agrícola em áreas de declividade acentuada? } \\
\hline Sim & $\begin{array}{c}182 \\
(47,15)\end{array}$ & $58(15,02)$ & $\begin{array}{c}108 \\
(27,97)\end{array}$ & $\begin{array}{c}14 \\
(3,62)\end{array}$ & $\begin{array}{c}2 \\
(0,51)\end{array}$ & \multirow{2}{*}{0,04668} \\
\hline Não & $\begin{array}{c}204 \\
(52,84)\end{array}$ & $70(18,13)$ & $\begin{array}{c}107 \\
(27,72)\end{array}$ & $\begin{array}{c}14 \\
(3,62)\end{array}$ & $\begin{array}{c}13 \\
(3,36)\end{array}$ & \\
\hline \multicolumn{7}{|c|}{ Considera que existem edificações ambientalmente inadequadas? } \\
\hline Sim & $\begin{array}{c}294 \\
(76,16)\end{array}$ & $\begin{array}{c}104 \\
(26,94)\end{array}$ & $\begin{array}{c}168 \\
(43,52)\end{array}$ & $\begin{array}{c}16 \\
(4,14)\end{array}$ & $\begin{array}{c}6 \\
(1,55)\end{array}$ & \multirow{2}{*}{0,00032} \\
\hline Não & $92(23,83)$ & $24(6,21)$ & $47(12,17)$ & $12(3,1)$ & $\begin{array}{c}9 \\
(2,33)\end{array}$ & \\
\hline \multicolumn{7}{|c|}{ Considera a mata ciliar importante? } \\
\hline Sim & $\begin{array}{c}357 \\
(92,48)\end{array}$ & $\begin{array}{c}121 \\
(31,34)\end{array}$ & $\begin{array}{c}197 \\
(51,03)\end{array}$ & $\begin{array}{c}25 \\
(8,74)\end{array}$ & $\begin{array}{c}14 \\
(3,62)\end{array}$ & \multirow{2}{*}{0,69875} \\
\hline Não & $29(7,52)$ & $7(1,81)$ & $18(4,66)$ & $3(0,77)$ & $\begin{array}{c}1 \\
(0,25)\end{array}$ & \\
\hline \multicolumn{7}{|c|}{ Contribui com o meio ambiente de alguma forma no cotidiano? } \\
\hline Sim & $\begin{array}{c}331 \\
(85,75)\end{array}$ & $\begin{array}{c}109 \\
(28,23)\end{array}$ & $\begin{array}{c}191 \\
(49,48)\end{array}$ & $\begin{array}{c}22 \\
(5,69)\end{array}$ & $\begin{array}{c}9 \\
(2,33)\end{array}$ & \multirow{2}{*}{0,01171} \\
\hline Não & $55(14,25)$ & $19(4,92)$ & $24(6,21)$ & $6(1,55)$ & $\begin{array}{c}6 \\
(1,55)\end{array}$ & \\
\hline \multicolumn{7}{|c|}{ Você se considera o responsável pelo meio ambiente? } \\
\hline Sim & $\begin{array}{c}371 \\
(96,11)\end{array}$ & $\begin{array}{c}127 \\
(32,90)\end{array}$ & $\begin{array}{c}204 \\
(52,84)\end{array}$ & $\begin{array}{c}26 \\
(6,73)\end{array}$ & $\begin{array}{c}14 \\
(3,62)\end{array}$ & \multirow{2}{*}{0,15355} \\
\hline Não & $15(3,88)$ & $1(0,25)$ & $11(2,84)$ & $2(0,51)$ & $\begin{array}{c}1 \\
(0,25)\end{array}$ & \\
\hline
\end{tabular}


(Continuação)

Tabela 2: Resultados obtidos através de diferentes itens abordads no questionário em relação à faixa etária da amostra estudada ( $\mathrm{n}=386)$ na comunidade de Alto Rio Possmoser em Santa Maria de Jetibá/ES.

\begin{tabular}{|c|c|c|c|c|c|c|}
\hline \multicolumn{7}{|c|}{ Sabe o que são Áreas de Preservação Permanente (APP’s)? } \\
\hline Sim & $\begin{array}{c}154 \\
(39,89)\end{array}$ & $42(10,88)$ & $96(24,87)$ & $12(3,1)$ & $\begin{array}{c}4 \\
(1,03)\end{array}$ & \multirow{2}{*}{0,11644} \\
\hline Não & $\begin{array}{c}232 \\
(60,10)\end{array}$ & $86(22,27)$ & $\begin{array}{c}119 \\
(30,82\end{array}$ & $\begin{array}{c}16 \\
(4,14)\end{array}$ & $\begin{array}{c}11 \\
(2,84)\end{array}$ & \\
\hline \multicolumn{7}{|c|}{0 que é meio ambiente? } \\
\hline Natureza & $69(17,87)$ & $10(2,59)$ & $39(10,10)$ & $9(2,33)$ & $\begin{array}{c}11 \\
(2,84)\end{array}$ & \multirow{4}{*}{$4,91 \mathrm{E}-17$} \\
\hline Os animais & $1(0,25)$ & $0(0)$ & $1(0,25)$ & $0(0)$ & $0(0)$ & \\
\hline As árvores & $16(4,14)$ & $0(0)$ & $8(2,07)$ & $8(2,07)$ & $0(0)$ & \\
\hline Tudo a nossa volta & $\begin{array}{c}300 \\
(77,72)\end{array}$ & $\begin{array}{c}118 \\
(30,56)\end{array}$ & $\begin{array}{c}167 \\
(43,26)\end{array}$ & $\begin{array}{c}11 \\
(2,84)\end{array}$ & $\begin{array}{c}4 \\
(1,03)\end{array}$ & \\
\hline \multicolumn{7}{|c|}{ Qual a destinação do óleo de cozinha usado? } \\
\hline Utiliza para fazer sabão & $\begin{array}{c}181 \\
(46,89)\end{array}$ & $63(16,32)$ & $97(25,12)$ & $\begin{array}{c}13 \\
(3,36)\end{array}$ & $\begin{array}{c}8 \\
(2,07)\end{array}$ & \multirow{6}{*}{0,02811} \\
\hline Joga na pia & $25(6,47)$ & $17(4,40)$ & $6(1,55)$ & $1(0,25)$ & $\begin{array}{c}1 \\
(0,25)\end{array}$ & \\
\hline Joga na terra & $69(17,87)$ & $18(4,66)$ & $43(11,13)$ & $6(1,55)$ & $\begin{array}{c}2 \\
(0,51)\end{array}$ & \\
\hline Joga no vaso & $3(0,77)$ & $1(0,25)$ & $2(0,51)$ & $0(0)$ & $0(0)$ & \\
\hline $\begin{array}{l}\text { Coloca em recipiente e joga } \\
\text { no lixo }\end{array}$ & $86(22,27)$ & $18(4,66)$ & $56(14,50)$ & $8(2,07)$ & $\begin{array}{c}4 \\
(1,03)\end{array}$ & \\
\hline Outros & $22(5,69)$ & $11(2,84)$ & $11(2,84)$ & $0(0)$ & $0(0)$ & \\
\hline \multicolumn{7}{|c|}{ Para você quem é o principal responsável pelos danos causados ao meio ambiente? } \\
\hline Prefeitura & $29(7,51)$ & $6(1,55)$ & 22 & $1(0,25)$ & $0(0)$ & \multirow{5}{*}{0,16437} \\
\hline Indústrias & $22(5,69)$ & $9(2,33)$ & $9(2,33)$ & $2(0,51)$ & $\begin{array}{c}2 \\
(0,51)\end{array}$ & \\
\hline Setor agrícola & $1(0,25)$ & $0(0)$ & $1(0,25)$ & $0(0)$ & $0(0)$ & \\
\hline Órgãos ambientais & $9(2,33)$ & $0(0)$ & $9(2,33)$ & $0(0)$ & $0(0)$ & \\
\hline Sociedade em geral & $\begin{array}{c}325 \\
(84,19)\end{array}$ & $\begin{array}{c}113 \\
(29,27)\end{array}$ & $\begin{array}{c}174 \\
(45,07)\end{array}$ & $\begin{array}{c}25 \\
(6,47)\end{array}$ & $\begin{array}{c}13 \\
(3,36)\end{array}$ & \\
\hline
\end{tabular}


(Continuação)

Tabela 2: Resultados obtidos através de diferentes itens abordads no questionário em relação à faixa etária da amostra estudada $(n=386)$ na comunidade de Alto Rio Possmoser em Santa Maria de Jetibá/ES.

\begin{tabular}{|c|c|c|c|c|c|c|}
\hline Governo municipal/ estadual & $39(10,10)$ & $8(2,07)$ & $25(6,47)$ & $5(1,29)$ & $\begin{array}{c}1 \\
(0,25)\end{array}$ & \multirow{5}{*}{0,445736} \\
\hline População em geral & $65(16,8)$ & $29(7,51)$ & $28(7,25)$ & $6(1,55)$ & $\begin{array}{c}2 \\
(0,51)\end{array}$ & \\
\hline Proprietários rurais & $2(0,51)$ & $1(0,25)$ & $1(0,25)$ & $0(0)$ & $0(0)$ & \\
\hline Órgãos ambientais & $12(3,10)$ & $5(1,29)$ & $7(1,81)$ & $0(0)$ & $0(0)$ & \\
\hline Todos acima & $\begin{array}{c}268 \\
(69,43)\end{array}$ & $85(22,02)$ & $\begin{array}{c}154 \\
(39,89)\end{array}$ & $\begin{array}{c}17 \\
(4,40)\end{array}$ & $\begin{array}{c}12 \\
(3,10)\end{array}$ & \\
\hline \multicolumn{7}{|c|}{ Você se incomoda em relação a poluição da água? } \\
\hline Não incomoda & $14(3,62)$ & $0(0)$ & $7(1,81)$ & $6(1,55)$ & $\begin{array}{c}1 \\
(0,25)\end{array}$ & \multirow{3}{*}{$6,3911 \mathrm{E}-08$} \\
\hline Incomoda & $\begin{array}{c}215 \\
(55,69)\end{array}$ & $76(19,68)$ & $\begin{array}{c}129 \\
(33,41)\end{array}$ & $5(1,29)$ & $\begin{array}{c}5 \\
(1,29)\end{array}$ & \\
\hline Incomoda muito & $\begin{array}{c}157 \\
(40,67)\end{array}$ & $52(13,47)$ & $79(20,46)$ & $17(4,4)$ & $\begin{array}{c}9 \\
(2,33)\end{array}$ & \\
\hline \multicolumn{7}{|c|}{ Qual o destino do lixo da sua residência? } \\
\hline Queima & $78(20,20)$ & $33(8,54)$ & $38(9,84)$ & $2(0,51)$ & $\begin{array}{c}5 \\
(1,29)\end{array}$ & \multirow{4}{*}{$2,1260 \mathrm{E}-06$} \\
\hline Serviço de coleta pública & $\begin{array}{c}298 \\
(77,20)\end{array}$ & $93(24,09)$ & $\begin{array}{c}175 \\
(45,33)\end{array}$ & $\begin{array}{c}21 \\
(5,44)\end{array}$ & $\begin{array}{c}9 \\
(2,33)\end{array}$ & \\
\hline Rua ou calçadas & $0(0)$ & $0(0)$ & $0(0)$ & $0(0)$ & $0(0)$ & \\
\hline Outros & $10(2,59)$ & $2(0,51)$ & $2(0,51)$ & $5(1,29)$ & $\begin{array}{c}1 \\
(0,25)\end{array}$ & \\
\hline \multicolumn{7}{|c|}{ Qual o esgotamento sanitário da sua residência? } \\
\hline Fossa Simples & $\begin{array}{c}117 \\
(30,31)\end{array}$ & $59(15,28)$ & $50(12,95)$ & $5(1,29)$ & $\begin{array}{c}3 \\
(0,77)\end{array}$ & \multirow{7}{*}{$2,6422 \mathrm{E}-24$} \\
\hline Fossa Filtro & $38(9,84)$ & $3(0,77)$ & $34(8,80)$ & $1(0,25)$ & $0(0)$ & \\
\hline Fossa Sumidouro & $8(2,07)$ & $2(0,51)$ & $3(1,55)$ & $3(0,77)$ & $0(0)$ & \\
\hline Saída direta no rio & $\begin{array}{c}120 \\
(31,08)\end{array}$ & $36(9,32)$ & $70(18,13)$ & $7(1,81)$ & $\begin{array}{c}7 \\
(1,81)\end{array}$ & \\
\hline Biodigestor & $6(1,55)$ & $0(0)$ & $1(0,25)$ & $0(0)$ & $\begin{array}{c}5 \\
(1,29)\end{array}$ & \\
\hline Rede coletora de esgoto & $69(17,87)$ & $24(6,21)$ & $36(9,32)$ & $9(2,33)$ & $0(0)$ & \\
\hline Não sabe ou não respondeu & $28(7,25)$ & $4(1,03)$ & $21(5,44)$ & $3(0,77)$ & $0(0)$ & \\
\hline
\end{tabular}




\section{(Continuação)}

Tabela 2: Resultados obtidos através de diferentes itens abordads no questionário em relação à faixa etária da amostra estudada $(n=386)$ na comunidade de Alto Rio Possmoser em Santa Maria de Jetibá/ES.

\begin{tabular}{|c|c|c|c|c|c|c|}
\hline \multicolumn{7}{|c|}{ Qual o abastecimento de água da sua residência? } \\
\hline Poço & $\begin{array}{c}138 \\
(35,75)\end{array}$ & $49(12,69)$ & $73(18,91)$ & $8(2,07)$ & $\begin{array}{c}8 \\
(2,07)\end{array}$ & \multirow{4}{*}{$3,3535 \mathrm{E}-05$} \\
\hline Nascente & $60(15,54)$ & $17(4,4)$ & $37(9,58)$ & $5(1,29)$ & $\begin{array}{c}1 \\
(0,25)\end{array}$ & \\
\hline Rio & $3(0,77)$ & $0(0)$ & $1(0,25)$ & $0(0)$ & $\begin{array}{c}2 \\
(0,51)\end{array}$ & \\
\hline Cesan & $\begin{array}{c}185 \\
(47,92)\end{array}$ & $62(16,06)$ & $\begin{array}{c}104 \\
(26,94)\end{array}$ & $\begin{array}{c}15 \\
(3,88)\end{array}$ & $\begin{array}{c}4 \\
(1,03)\end{array}$ & \\
\hline
\end{tabular}

Fonte: Autoria Própria (2017).

Ao analisar as respostas obtidas sobre a problemática de cultivos agrícolas em área de declividade acentuada percebeu-se que do ponto de vista estatístico essas proporções são diferentes, existindo diferença entre as concepções por faixa etária $(\mathrm{P}=0,04668)$. De acordo com o Valor de p, as proporções das repostas são diferentes nas faixas etarias, mas a maior parte $(52,84 \%)$ não considera um problema esse tipo de cultivo, levando em conta que a área de estudo está localizada em região montanhosa, muitos dos entrevistados pode ser que praticam o cultivo agrícola nessas áreas com declividade. Para os dados obtidos a respeito da percepção da existência de edificações ambientalmente inadequadas, foi obtido um $\mathrm{P}$ valor=0,00032, assim podemos concluir que há diferença entre as respostas por faixa etária, sendo considerado estatisticamente significativo.

Uma associação estatística significante foi observada nas respostas sobre o lançamento de efluentes domésticos, para um valor de $\mathrm{P}=2,6422 \mathrm{E}-24$. Com relação a importância da mata ciliar foi obtido um $\mathrm{P}$ valor de 0,69875, observada associação estatística não significativa. A maioria dos entrevistados, de diferentes faixas etárias, afirmaram que a mata ciliar é importante. No entanto, foram evidenciados casos de supressão da vegetação. Sobre a disposição inadequada de lixo, o P valor foi de 0,00015 , existindo diferença entre as concepções e faixa etária. Sendo este dado estatisticamente significativo.

Para a criação de animais perto do leito do rio, os dados obtidos através da aplicação do questionário são estatisticamente significantes $(\mathrm{P}=0,00108)$,

Quando relacionadas as perguntas sobre o incomodo da poluição da água onde muitos indivíduos responderam que se incomodam $(55,69 \%)$ ou se incomodam muito $(40,67 \%)$ com a pergunta sobre qual é o esgotamento sanitário da sua residência temos uma contradição, pois 31,08\% dos entrevistados disse que em suas residências há lançamento de efluentes sanitários direto no rio mesmo com o número alto de pessoas que se incomodam com a poluição da água.

\section{CONSIDERAÇÕES FINAIS}

É importante ressaltar que o Rio Possmosser é um afluente do Rio Santa Maria da Vitória que é um dos principais mananciais do Espírito Santo. Abastece a parte continental da capital Vitória e o município da Serra. Muitos dos impactos ambientais encontrados na Comunidade de Alto Rio Possmosser pode aflingir diretamente na disponibilidade qualitativa e quantitativa de água da região. Destaca-se também a importância do curso hídrico para a região visto que grande parte da economia local é baseada agricultura familiar e na agropecuária.

A aplicação do questionário possibilitou uma análise da percepção ambiental da população desta localidade com intuito de fornecer subsídios para a elaboração de políticas públicas voltadas para as áreas de planejamento urbano, projetos de educação ambiental direcionados aos problemas ambientais identificados nesta pesquisa. 
Os resultados da pesquisa mostraram que os indivíduos da amostra estudada expoem uma boa percepção ambiental relacionado aos problemas identificados. Por outro lado, não podem ser ignoradas as chances de que parte das respostas dos entrevistados não devem mostrar realmente as ações realizadas pelos mesmos, pois uma porção dos indivíduos preferem negar a sua condição, dando uma falsa resposta, porque consideram estas atitudes incorretas.

\section{REFERÊNCIAS}

[1] Brasil, Lei 6.938, de 31 de agosto de 1981. Dispõe sobre a Política Nacional do Meio Ambiente, seus fins e mecanismos de formulação e aplicação, e dá outras providências. Disponível em:< www.planalto.gov.br/ccivil_03/leis/L6938.htm >. Acesso em: 10 abr. 2017.

[2] Brasil, Lei № 12.651, de 25 de maio de 2012. Disponível

em<http://www.planalto.gov.br/ccivil_03/_ato2011-2014/2012/lei/l12651.htm>. Acesso em 12 de setembro 2017.

[3] Brasil, Lei № 9.795, de 27 de abril de 1999. Disponível

em<http://www.planalto.gov.br/ccivil_03/leis/L9795.htm>. Acesso em 12 de setembro 2017.

[4] Brasil, Leis et al. Resolução CONAMA no 001, de 23 janeiro de 1986, Dispõe sobre as diretrizes gerais para uso e implementação de Avaliação de Impacto Ambiental. Diário Oficial, 1986.

[5] Carvalho, I. C. M. Educação Ambiental: a formação do sujeito ecológico. 4. Ed. - São Paulo: Cortez, 2008.

[6] Castro, D. Práticas para restauração da mata ciliar. Org: Dilton de Castro, p. 2012, 2012.

[7] Chaves, A. Importância da Mata Ciliar (Legislação) na Proteção dos Cursos Hídricos, alternativas para sua viabilização em pequenas propriedades rurais. Seminário apresentado na disciplina "manejo e conservação do solo e da água, v. 1, p. 1-19, 2009.

[8] Dias, G. F. Educação Ambiental: Princípios e Práticas. 6 ed. São Paulo: Gaia, 2000.

[9] Fernandes, Roosevelt S. et al. Uso da percepção ambiental como instrumento de gestão em aplicações ligadas às áreas educacional, social e ambiental. Encontro Nacional de Pós-Graduação e Pesquisa em Ambiente e Sociedade, v. 2, p. 1-15, 2004.

[10] Fontanella, Alexsandra, et al. "Diagnóstico ambiental da bacia hidrográfica do rio da ilha, Taquara, Rio Grande do Sul, Brasil." Revista Brasileira de Biociências 7.1 (2009).

[11] IBGE - Instituto Brasileiro De Geografia E Estatística. PAS - Pesquisa Anual De Serviços, 2006. [online] disponível na internet via www url: https://cidades.ibge.gov.br/brasil/es/santa-maria-de-jetiba/panorama.

[12] Kandler, R. Educação Ambiental: Horta escolar, uma experiência em educação. Ágora : revista de divulgação científica v. 16, n. 2(A), Número Especial: I Seminário Integrado de Pesquisa e Extensão Universitária Melazo, Guilherme Coelho. Percepção ambiental e educação ambiental: uma reflexão sobre as relações interpessoais e ambientais no espaço urbano. Olhares \& Trilhas, 2005.

[13] №, Resolução CONAMA. "001, de 23 de janeiro de 1986." Publicado no DOU de 17.2 (2015): 86.

[14] №, Resolução CONAMA. 307 de 05 de julho de 2002. Dispõe sobre Gestão dos Resíduos da Construção Civil, 2002.

[15] Prefeitura Municipal de Santa Maria de Jetibá. Lei Municipal № 1836/2016. Disponível em:<http://www.legislacaocompilada.com.br/santamaria/Arquivo/～Documents/legislacao/L/L18362016.pdf> Acesso em: 20 de setembro de 2017.

[16] Ribeiro, Júlia Werneck. Saneamento básico e sua relação com o meio ambiente e a saúde pública. Juiz de Fora, MG. 2010. Disponível em< http://www.ufjf.br/analiseambiental/files/2009/11/TCCSaneamentoeSa\%C3\%BAde.pdf>. Acesso em 12 de setembro 2017.

[17] Santos, André Bezerra; Athayde Junior, Gilson Barbosa. Esgotamento sanitário: qualidade da água e controle da poluição: guia do profissional em treinamento: nível 2. Secretaria Nacional de Saneamento Ambiental. Salvador: ReCESA, 2008.

[18] Schäffer, Wigold Bertoldo - Áreas de Preservação Permanente e Unidades de Conservação \& Áreas de Risco. 0 que uma coisa tem a ver com a outra? Relatório de Inspeção da área atingida pela tragédia das chuvas na Região Serrana do Rio de Janeiro / Wigold Bertoldo Schäffer... [et al.]. - Brasília: MMA, 2011. 96 p. : il. color. ; 29 cm. + mapas. (Série Biodiversidade, 41)

[19] Vieira, Sônia. Introdução À Bioestatística [recurso eletrônico]. Elsevier Brasil, 2011.

[20] Palma I. R. Análise da percepção ambiental como instrumento ao planejamento da educação ambiental. Dissertação para obtenção de título de mestre em engenharia. Universidade Federal do Rio Grande do Sul, 2005. 


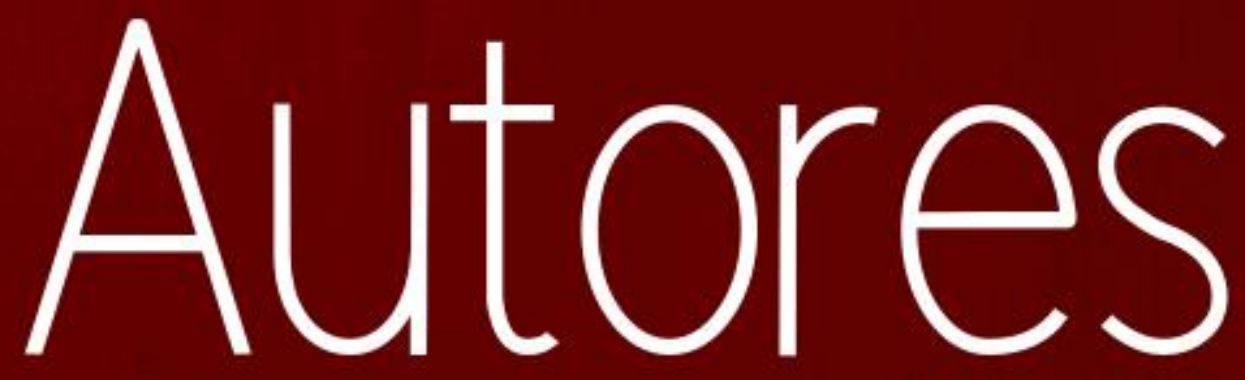




\section{ADALBERTO OLIVEIRA BRITO}

Administrador Público pela UFF. Especialista em Gestão Pública pela UFSJ, Especialista em Gestão Pública Municipal pela UFF e Mestrando no Programa de Pós-Graduação em Administração pela UFF. Aperfeiçoado em Empreendedorismo e Inovação pela UFF. Atualmente está em fase de conclusão dos curso de Graduação em Direito pela FND/UFRJ e das Pós-Graduações Lato Sensu em Finanças pela UFF, Gestão Pública das Organizações de Saúde pela UFF, Projetos Sociais Formulação e Monitoramento pela UFMG.

\section{ADRIANA MONTEIRO DA COSTA}

Técnica em Química pela Fundação Municipal de Ensino Profissionalizante de Sete Lagoas (FUMEP, 1994); Graduada em Geografia pela Fundação Educacional Monsenhor Messias (2001), especialista em Solos e Meio Ambiente pela Universidade Federal de Lavras (2003), Mestre em Agronomia Solos, pela Universidade Federal de Uberlândia (2005), Doutora em Ciência do Solo pela Universidade Federal de Lavras (2008) e Pós-doutorado (2009) em Sistemas Agrossilvipastoris pela Embrapa Milho e Sorgo e Pós-Doutorado (2015) pela Embrapa Milho e Sorgo. Atua nas áreas de Pedologia, Levantamento e Classificação de solos e Física do Solo com ênfase em Indicadores de sustentabilidade em Agroecossistemas (ISA) e Interação Solos e Recursos Hídricos. É Professora Associada I de Pedologia do Departamento de Geografia, Instituto de Geociências, da Universidade Federal de Minas Gerais, do Programa de Pós-graduação em Geografia - Análise Ambiental e do Programa de Modelagem e Análises de Sistemas Ambientais, do Departamento de Cartografia. Coordena o Laboratório de Solos e Meio Ambiente IGC/UFMG, o Núcleo de referência ISZA e o Grupo de Estudos Integrado de Solos e Sustentabilidade, orientando alunos de Doutorado, Mestrado, Graduação e Iniciação científica. Sub-coordenadora do Programa de Pós-graduação em Geografia da UFMG.

\section{ALICE SALES FABIANO DE ALMEIDA}

Graduanda do curso de bacharelado em Engenharia Ambiental pela Universidade Federal de São Carlos (UFSCar). Tem experiência na área de Engenharia Sanitária, com ênfase em Engenharia Sanitária e Química Analítica. Graduação em Engenharia Ambiental. (2017) - Universidade Federal de São Carlos, UFSCar, São Carlos, Brasil

\section{ALISSON GADELHA DE MEDEIROS}

Possui Graduação em Engenharia Civil pela Universidade Federal Rural do Semi-Árido (2014), Mestrado em Engenharia Civil pela Universidade Federal do Rio Grande do Norte (2015) e Doutorado em Manejo de Solo e Água pela Universidade Federal Rural do Semi-Árido (2019), com ênfase na produção de concretos sustentáveis a partir de substituições parciais simultâneas de resíduos em materiais convencionais, referente à linha de impactos ambientais. Atualmente, é Professor do Magistério Superior efetivo, Adjunto - Classe C, da Universidade Federal Rural do Semi-Árido.

\section{ANA CLÁUDIA PIMENTEL DE OLIVEIRA}

Licenciatura em Ciências Biológicas pela Celso Lisboa (1990), Mestrado em Biotecnologia Vegetal pela UFRJ (1998), Doutorado em Biotecnologia Vegetal pela UFRJ (2003), Pós-DOC no Instituto de Biofísica - UFRJ (2011): "Métodos alternativos de tratamento de água para a remoção de cianobactérias e cianotoxinas". Atuou como analista ambiental no Instituto Estadual do Meio Ambiente (INEA) de 2003 a 2017. Professora Pesquisadora e Coordenadora de Pesquisa, Extensão e Pós-Graduação da Universidade Castelo Branco (UCB). Experiência na área Ambiental, Ecologia, Microbiologia com ênfase em Cultivo e Fisiologia de Cianobactérias, Tratamentos para a remoção de cianobactérias e cianotoxinas, Monitoramento e Manejo de ecossistemas hídricos. 


\section{ANA TAÍS FERNANDES DE OLIVEIRA}

Possui Graduação em Engenharia Civil pela Universidade Federal Rural do Semi-Árido (2017). Atualmente é pós-graduanda em Master BIM: Ferramenta de Gestão e Projeto pelo Instituto de Pós-Graduação (IPOG) e Mestranda em Arquitetura, Projetos e Meio Ambiente pela Universidade Federal do Rio Grande do Norte (UFRN). Atuação na concepção de projetos civis em BIM residenciais, comerciais e industriais para processos de licenciamento.

\section{BÁRBARA OLIVEIRA DE MORAIS}

Gestora de RH e Contadora pela UNESA e Administradora Pública pela UFF. Especialista em Gestão Pública pela UFSJ, Especialista em Gestão Pública Municipal pela UFJF e Mestranda no Programa de Pós-Graduação em Práticas em Desenvolvimento Sustentável pela UFRRJ. Aperfeiçoada em Empreendedorismo e Inovação pela UFF e em Implementação da Política Nacional de Promoção da Saúde: Programa Academia da Saúde pela UFSC. Atualmente está em fase de conclusão dos cursos de Pós-Graduação Lato Sensu em Finanças pela UFF, Gestão Pública das Organizações de Saúde pela UFF, Projetos Sociais Formulação e Monitoramento pela UFMG. Possui experiência em Gestão de Negócios, com vasta atuação na área comercial. Na área acadêmica possui publicações nos últimos anos em periódicos e congressos de relevância, tal como atuação em cursos técnicos e de qualificação profissional.

\section{BRENDA SILVA DOS SANTOS}

Aluna do $7^{\circ}$ ano do Ensino Fundamental do Colégio Militar do Recife; Medalha de trabalho destaque da Feira de Ciências do Colégio Militar do Recife - SNCT2019

\section{BRENO CANTADORI}

Graduado no curso de Bacharelado Interdisciplinar em Ciência e Tecnologia, da UNIFAL Universidade Federal de Alfenas, campus Poços de Caldas. Atualmente cursa graduação em Engenharia de Minas, da UNIFAL. É bolsista do Programa de Extensão do Cursinho Saberes.

\section{BRUNA OLIVEIRA BEZERRA}

Aluna do $7^{0}$ ano do Ensino Fundamental do Colégio Militar do Recife; Medalha de trabalho destaque da Feira de Ciências do Colégio Militar do Recife - SNCT2019

\section{CHARLES MOURA NETTO}

Graduações (licenciatura e Bacharelado) em Educação física pela Universidade Federal de Minas Gerais (1997) e licenciatura em Pedagogia pela Faculdade Multivix, Serra/ES (2013). Concluiu Mestrado em Engenharia Ambiental, com ênfase em Tecnologias Ambientais pela Faculdade de Aracruz (2012). Em 1998 mudou se, para Santa Maria de Jetibá /ES. Em 2007, recebeu o titulo de Cidadão Santamariense pela Câmara municipal de Vereadores e em 2011, recebeu o título de Cidadão Espírito - santense pela Assembleia Legislativa do Estado do Espirito Santo. 0 autor tem 22 anos de experiência na docência, sendo, 14 anos no ensino superior. Possui dezenas de publicações (artigos em revistas científicas, capítulos de livros e publicações em anais de congressos nacionais e internacionais) na área de Educação. É conselheiro titular do Conselho Estadual de Educação do Estado do Espirito Santo - CEE-ES. É conselheiro titular do Conselho Municipal de Educação de Santa Maria de Jetibá. Foi secretário de Educação do Município de Santa Maria de Jetibá (2013-2016). Foi da diretoria do União do Dirigentes Municipais de Educação (UNDIME), Secção Espírito Santo. É coordenador do curso de Pedagogia da Faculdade da Região Serrana (FARESE). É professor e coordena o grupo de educação ambiental da Faculdade da Região Serrana (FARESE). É membro do Comitê da Bacia do Rio Santa Maria de Vitória. Avaliador Ad Hoc do Ensino Superior pelo INEP/MEC (BASis), na área de Educação Física e Pedagogia. 


\section{DANYEL LIMA MATOS GRANZOTTI}

Atualmente é membro do grupo de pesquisa TRIP (Turma de Robótica, Inovação e Pesquisa), discente do curso técnico integrado em Eletromecânica no IFPI-Campus Floriano. Desenvolve pesquisas nas áreas de energias renováveis, domótica, estudo de matérias e recursos hídricos, possui interesse por automatização de processos e física aplicada.

\section{DOMENIQUE RAMALHO CORRÊA}

Possui Técnico em Meio Ambiente em andamento pelo Colégio Técnico da Universidade Federal Rural do Rio de Janeiro. Estágio com duração de 60 horas no viveiro florestal da UFRRJ.

\section{DOUGLAS FELIPE LUCAS}

Geógrafo (PUC Minas), Especialista em Geoprocessamento (UFMG), Mestrando em Análise e Modelagem de Sistemas Ambientais (UFMG). Atuando na área das Geotecnologias a mais de 10 anos, com experiências no setor público e privado. Interesse em experiências profissionais enriquecedoras na área de Geoprocessamento e Análise Espacial.

\section{ÊMELE RÁDNA RODRIGUES DO VALE}

Possui Ensino Médio Integrado ao Técnico em Mecânica pelo Instituto Federal de Educação, Ciência e Tecnologia do Rio Grande do Norte - IFRN (2012). É Bacharel em Ciência e Tecnologia (2017) e Engenharia Civil (2019) pela Universidade Federal Rural do Semi-Árido - UFERSA. Durante as graduações, atuou como monitora das disciplinas de Expressão Gráfica (2017-2019) e Laboratório de Química Geral (2015-2017).

\section{FABIANA DE SOUZA MOREIRA}

Graduanda do curso de bacharelado em Engenharia Ambiental pela Universidade Federal de São Carlos (UFSCar). Tem experiência na área de Engenharia Sanitária, com ênfase em Engenharia Sanitária. Graduação em Engenharia Ambiental (2017) - Universidade Federal de São Carlos, UFSCar, São Carlos, Brasil

\section{FILIPE DE SOUZA PINTO}

Graduando em Ciências Biológicas (Licenciatura) no $6^{\circ}$ período pela Universidade Castelo Branco (UCB). Atualmente é Monitor das áreas de Botânica (UCB); Estagiário de Educação Inclusiva na Secretária Municipal de Educação-SME/RJ; Professor de Biologia e Coordenador de Ciências da Natureza na ONG EDUCAFRO - Núcleo Desa. Ivone Caetano; Aluno de PIBICT em Popularização do Ensino em Geociências nas Escolas (UCB, UFRJ); Aluno de Pesquisa de Clarificação de Recursos Hídricos Utilizando Fitorremediadores (UCB). Tem experiência na área de Educação, com ênfase em Ciências e Educação Especial; e Áreas Biológicas com ênfase em Botânica e Ecologia.

\section{FLORA LIZ DOUMITH OLIVEIRA SOBRINHO}

Acadêmica do curso Bacharelado de Nutrição Instituto Federal Sudeste de Minas Gerais - Campus Barbacena. Atuante como docente no ensino médio integral integralizado na área de ciências da natureza e praticas experimentais. Pesquisadora pelo PROEX.

\section{HEITOR SACHT}

Graduado em Engenharia Ambiental e Sanitária pela Faculdade da Região Serrana, FARESE e pósgraduação em Meio Ambiente e Sustentabilidade também pela FARESE. Atua como consultor ambiental. Interessa-se por Educação Ambiental, Desenvolvimento Sustentável e Astronomia. 


\section{HYGOR ARISTIDES VICTOR ROSSONI}

Graduado em Engenharia Ambiental pela Universidade Federal de Viçosa (2005), mestre em Ciência Florestal pela mesma instituição (2007) e Doutor em Saneamento, Meio Ambiente e Recursos Hídricos pela Universidade Federal de Minas Gerais (2015). Atualmente é professor da Universidade Federal de Viçosa - Campus de Florestal. Tem experiência na área de Engenharia Sanitária e Ambiental, com ênfase em Controle da Poluição e Saneamento, atuando, principalmente, nos seguintes áreas temáticas: políticas públicas de saneamento, tratamento e reutilização de efluentes ou águas residuárias; gerenciamento de resíduos sólidos, monitoramento e controle ambiental e gerenciamento de recursos hídricos. Foi o primeiro coordenador do Curso Superior de Tecnologia em Gestão Ambiental e Diretor de Ensino da UFV - Campus de Florestal. Recentemente atua como membro do Núcleo Docente Estruturante (NDE) e Coordenador Suplente do Curso Superior de Tecnologia em Gestão Ambiental. Coordena as seguintes disciplinas: i) Controle Ambiental na Indústria; ii) Coleta e Tratamento de Águas Residuárias; iii) Gestão Ambiental; iv) Manejo e Tratamento de Poluentes; v) Ética e Atuação Profissional; vi) Qualidade da Água e Tratamento de Resíduos; vii) Sustentabilidade Ambiental e viii) Turismo e Meio Ambiente. Recentemente (2017) vem atuando como docente e orientador permanente do Programa de PósGraduação em Sustentabilidade e Tecnologia Ambiental (Mestrado Profissional) do Instituto Federal de Minas Gerais - Campus Bambuí, desenvolvendo trabalhos nas linhas de pesquisas referentes a Gestão e Planejamento Ambiental e Tecnologia Ambiental. As orientações estão sendo desenvolvidas nas seguintes áreas de interesses: i) Planejamento, Gestão e Avaliação de Políticas Públicas de Saneamento; ii) Tecnologias de Tratamentos de Águas de Abastecimento e Residuárias; e iii) Controle Ambiental em Processos Agrícolas e Industriais.

\section{ISABELA MALOSPIRITO VILLENS}

Graduanda do curso de bacharelado em Engenharia Ambiental pela Universidade Federal de São Carlos (UFSCar). Tem experiência na área de Engenharia Sanitária, com ênfase em Engenharia Sanitária. Graduação em Engenharia Ambiental (2017).

\section{ISABELLA OLIVEIRA DA SILVA}

Possui graduação em andamento de Engenharia Química (UFRRJ). As experiências consistem em: bolsa de iniciação científica pela empresa Embrapa Agrobiologia; bolsa de apoio técnico pelo CTUR (Colégio Técnico da Universidade Federal Rural do Rio de Janeiro); estágio (cargo atual) pela empresa ANP (Agência Nacional de Petróleo, Gás Natural e Biocombustíveis), e curso de língua estrangeira em Inglês Americano pela instituição particular CNA.

\section{ISADORA RODRIGUES ROCHA}

Formada no curso técnico em Meio Ambiente pelo IFPI Campus Floriano, estagiou na Agenda Ambiental Pública (A3P) da instituição e desenvolveu trabalhos acadêmicos nas áreas ambientais e de energias renováveis.

\section{JESSICA CRISTINA DE SOUZA CAETANO}

Possui Bacharelado em Geologia pela Universidade Federal de Minas Gerais (UFMG). Atualmente é discente no curso de Tecnologia em Processos Gerenciais pelo Instituto Federal de Ciência e Tecnologia de Minas Gerais (IFMG). Possui experiência profissional em mapeamento geológico e mineração. Desenvolveu diversos trabalhos como gestora ambiental e gerente de sustentabilidade em mineradoras. Apresenta amplo conhecimento da legislação ambiental e minerária brasileira. Trabalha atualmente com aplicação de polímeros como solução ambiental para tratamento de efluentes e clarificação de água, e também supressores de poeira. Interesse em projetos de pesquisa relacionados ao desenvolvimento, síntese e caracterização de polímeros de baixo impacto ambiental (sintéticos e naturais) e sua aplicação (barragens de rejeito, pilhas de minério e taludes, gel agrícola, tratamento de efluentes). 


\section{JOÃO PEDRO VALUCHE DE ANDRADE PEREIRA}

Aluno do $7^{\circ}$ ano do Ensino Fundamental do Colégio Militar do Recife, graduado Cabo; Medalha de trabalho destaque da Feira de Ciências do Colégio Militar do Recife - SNCT2019; Integrante das equipes de Futsal, Xadrez e Orientação; Integrante do Grêmio da Infantaria

\section{JOCIMARA CAMARGO DA SILVA}

Mestrando do programa de pós graduação em sistemas de infraestrutura urbana na linha de pesquisa de planejamento. Fez graduação em Química na PUC-Campinas. Realizou iniciação científica nos anos de 2017 e 2018. Realizou monitorias nas matérias de química orgânica e geometria analítica. Fez, no ano de 2018, estágio no laboratório de química forense da Polícia Federal em Campinas.

\section{JORGE LUIS RODRIGUES PANTOJA FILHO}

Cursou (e/ou cursa) os bacharelados em Engenharia Sanitária e Ambiental - Universidade Federal do Pará (UFPA) e Matemática Aplicada e Computação Científica - Universidade de São Paulo (USP). Cursou (e/ou cursa) as pós-graduações em: Statistics and Data Science - Massachusetts Institute of Technology (MIT) (MicroMasters Program). Engenharia (Hidráulica e Saneamento) - Universidade de São Paulo (USP) (Mestrado e Doutorado). Pós-Doutorado em pesquisa na área de Tratamento de Água para Abastecimento - Instituto Tecnológico de Aeronáutica (ITA). Prestou diversas consultorias na área ambiental para instituições públicas e privadas, podendo ser citado o Plano Diretor de Água e Esgoto da Região Metropolitana de Belém (PA). Atualmente é professor substituto na Universidade Federal de São Carlos (UFSCar). Tem experiência principalmente em a) tratamento biológico de efluentes líquidos e gasosos e b) tratamento de água para abastecimento.

\section{JOSÉ HENRIQUE NÓBREGA ALBUQUERQUE}

Medalha de ouro na Olimpíada Canguru, 2017; Medalha de prata na Olimpíada Brasileira de Astronomia,OBA-2019; Medalha de trabalho destaque da Feira de Ciências do CMR - SNCT2019; Integrante da legião de honra do CMR; Medalha de prata, ranking do CMR 2019

\section{JUAN DOUGLAS GUIDIO CARVALHO}

Possui curso técnico em Química e atualmente é graduando do curso de Bacharelado Interdisciplinar em Ciência e Tecnologia, da UNIFAL - Universidade Federal de Alfenas, campus Poços de Caldas.

\section{JÚLIA RINALDI DE MACEDO CORTEZ}

Discente do curso de Engenharia Ambiental (2016-2021) na Universidade Federal de São Carlos campus Lagoa do Sino.

\section{JULIANA FREITAS GUEDES RÊGO}

Doutora em Economia (UFBA) , na área de desenvolvimento econômico, mestre em Engenharia Ambiental Urbana (UFBA), na área de riscos ambientais urbanos, bacharel em Ciências Econômicas (UFBA). Atua nas áreas de desenvolvimento econômico, sustentabilidade e riscos ambientais urbanos. Tem experiência no ensino superior presencial e a distância (ead) tanto em graduação quanto em pós-graduação lato sensu. Docente do Centro Universitário Jorge Amado, docente da disciplina Gestão Ambiental do MBA em Gestão de Condomínios da Faculdade 2 de Julho. 


\section{KARINA LIMA OLIVEIRA}

Mestre em Economia (UFBA), na área de Desenvolvimento Econômicos - Economia Regional; Economia Agrícola e Agrária e dos Recursos Naturais e Doutoranda em Economia (UFBA) , na mesma área. Bacharel em Ciências Econômicas (UFBA). Atua nas áreas de desenvolvimento econômico, gestão e orçamento. Tem experiência no ensino superior presencial e a distância (ead) tanto em graduação quanto em pós-graduação lato sensu. Docente do Centro Universitário Jorge Amado. Coordenadora de Curso (MBA em Controladoria e Finanças e MBA em Gestão de Condomínios ) e docente na Graduação da Faculdade 2 de Julho.

\section{KARINE RESENDE CORRÊA FLORENTINO}

Possui técnico em meio ambiente em andamento (CTUR/UFRRJ). As experiências consistem em: projeto com bolsa de iniciação científica pelo CTUR; estágio pela empresa Acácia Amarela Produção de Mudas e Consultoria Ambiental; e curso de língua estrangeira em inglês pela instituição CNA.

\section{LARA DENISE ALVES DE VASCONCELOS}

Técnica em Eletromecânica pelo Instituto Federal do Piauí, desenvolveu projetos no âmbito de energias renováveis e meio ambiente. Foi estagiária na Agenda Ambiental da Administração Pública (A3P). Atualmente, cursa odontologia na Universidade Federal do Piauí.

\section{LAURA BUENO SILVA}

Graduada no curso de Tecnologia em Gestão Ambiental na Universidade Federal de Viçosa Campus Florestal em 2019/1. Projeto publicado em 12/2018 que visa uma estimativa do aumento da demanda hídrica do Campus UFV - Florestal com base no crescimento populacional e participação voluntária na inserção de uma horta comunitária.

\section{LEONARDO HOLANDA LIMA}

Engenheiro Ambiental e Sanitarista pela pela Universidade de Fortaleza (UNIFOR), 2019. Bolsista PAVIC/UNIFOR em 2016. Bolsista pela CAPES/CNPQ em 2017. Monitor voluntário da disciplina de Ecossistemas Marinhos e Ambientes Costeiros em 2017 e monitor voluntário pela Universidade de Fortaleza da disciplina de Geologia Aplicada a Engenharia em 2018. Foi bolsista institucional pela Universidade de Fortaleza (PROBIC/UNIFOR) e monitor de ecossistemas marinhos e ambientes costeiros 2019.1. Membro da Rede BRASPOR de Pesquisadores. Conhecimento em geoprocessamento (ArcGIS), impactos na zona costeira e análise de risco costeiro. Sócio-Diretor e fundador da empresa socioambiental Greenews. Ganhador do prêmio internacional Henri Nestlé: Substituição de candos plásticos.

\section{LORENA SIMÕES DO VALE}

Bacharela em Direito (UESC), Pós Graduada em Direito do Trabalho (UCAM), Pós Graduada em Gestão de Condomínios (Faculdade Dois de Julho). Sócia fundadora da Solutio Administração de Condomínios LTDA.

\section{LUCAS ANTÔNIO BRASIL GONÇALVES LACERDA}

Profissional com sete anos de experiência na área de meio ambiente atuando na utilização de ferramentas de geoprocessamento, modelagem de sistemas ambientais e sensoriamento remoto. Analista de geoprocessamento, pós-graduado em Geoprocessamento e Análise Espacial pela Pontifícia Universidade Católica de Minas Gerais e graduado em Geografia pela mesma instituição. Atualmente cursa Mestrado em Análise e Modelagem de Sistemas Ambientais (UFMG). 


\section{LUIS HENRIQUE NERY}

Graduado no curso de Bacharelado Interdisciplinar em Ciência e Tecnologia, da UNIFAL Universidade Federal de Alfenas, campus Poços de Caldas. Atualmente cursa graduação em Engenharia Química, da UNIFAL. É bolsista do Programa do Programa de Educação Tutorial (PET), do grupo PET Ciência.

\section{LUÍZA GONÇALVES DOS SANTOS}

Acadêmica de nutrição, Instituto Federal de educação Barbacena. Pesquisadora pelo PROEX (Próreitoria de Extensão)

\section{MARCELO ALVARES TENENWURCEL}

Cientista Socioambiental na UFMG. Mestrando em Modelagem e análise de Sistemas Ambientais (UFMG). Atua na área de geotecnologias, principalmente através de ferramentas de geoprocessamento (SIG) e técnicas de sensoriamento remoto.

\section{MÁRCIA THELMA RIOS DONATO MARINO}

Possui Graduação em Geologia pela Universidade de Fortaleza (1984) , Especialização em Aperfeiçoamento em Mapeamento Geológico pela Universidade Federal de Minas Gerais (1985), Mestrado em Geologia pela Universidade Federal do Ceará (2004) e Doutorado em Geologia pela Universidade Federal do Ceará (2014). Ex-coordenadora do curso de Especialização em Gestão Ambiental e do MBA em Perícia e Auditória Ambiental da UNIFOR. Professora Adjunto, Nível 6, da Universidade de Fortaleza dos cursos de Graduação em Engenharia Ambiental e Sanitária e Engenharia Civil. Consultora Ambiental cadastrada no IBAMA. Tem experiência na área de Geociências, atuando, principalmente, nos seguintes temas: impactos ambientais na zona costeira, morfodinâmica e ecossistemas costeiros, estudos ambientais em geral (EIA / RIMA / PCA / EVA etc) e gestão ambiental. Membro da Rede BRASPOR de pesquisadores. Participante do processo de implantação do Sistema de Gestão da Qualidade e Certificação da ISO 9001:2008 - Bureau Veritas Certification - da Universidade de Fortaleza. Editora executiva da Revista Tecnologia (UNIFOR). Membro do Comitê de Ética da Universidade de Fortaleza.

\section{MARIA JOSICLEIDE FELIPE GUEDES}

Possui graduação em Engenharia Civil (2006), mestrado em Engenharia Civil e Ambiental (2009) e doutorado em Recursos Naturais (2018), pela Universidade Federal de Campina Grande - UFCG. Atuou como Analista Ambiental/Engenheira Civil na Agência Estadual de Meio Ambiente (CPRH/PE) - 2009/2011. É professora adjunta da Universidade Federal Rural do Semi-Árido UFERSA (2011-atual). Atua na área de Recursos Hídricos e Saneamento.

\section{MARIANA BARBOSA}

Graduanda do curso de bacharelado em Engenharia Ambiental pela Universidade Federal de São Carlos (UFSCar). Tem experiência na área de Engenharia Sanitária, com ênfase em Engenharia Sanitária. Graduação em Engenharia Ambiental (2017) - Universidade Federal de São Carlos, UFSCar, São Carlos, Brasil

\section{MATEUS DOS SANTOS CORREIA}

Atualmente estagia na Agenda Ambiental da Administração Pública (A3P), é membro do grupo de pesquisa Turma de Robótica, Inovação e Pesquisa TRIP e é discente do curso de eletromecânica no IFPI Campus Floriano. Desenvolve trabalhos nas áreas ambientais e de energias renováveis, se interessa por mecânica, robótica e inovações na área da tecnologia. Segue desenvolvendo trabalhos acadêmicos com foco em questões sociais. 


\section{MATHEUS ALMEIDA DE SENA}

Aluno do 7o ano do Ensino Fundamental do Colégio Militar do Recife; Participação no Grêmio de Infantaria (CMR); Atleta de Futebol de salão, Atletismo e Orientação; Membro da Legião da Honra do CMR; Medalha de trabalho destaque da Feira de Ciências do CMR - SNCT2019

\section{MATHEUS CORDEIRO FAÇANHA}

Acadêmico de Engenharia Ambiental e Sanitária pela pela Universidade de Fortaleza (UNIFOR). Foi bolsista PAVIC/UNIFOR em 2016,2017.2 e 2018, bolsista CNPq/PIBIC em 2017.1. Foi monitor voluntário da disciplina de Ecologia Geral nos anos 2017 e 2018 e da disciplina de Ecossistemas do Semiárido no ano de 2018. Atualmente bolsista voluntário pela Universidade de Fortaleza (PAVIC/UNIFOR) e monitor voluntário das disciplinas de Geologia Aplicada à Engenharia e Ecossistemas Marinhos e Ambientes Costeiros. Membro da Rede BRASPOR de Pesquisadores. Tem conhecimento na área de Geociências, atuando, nos seguintes temas: impactos ambientais na zona costeira, morfodinâmica e ecossistemas costeiros, estudos ambientais em geral (EIA / RIMA etc) e Estudante do Grupo de Pesquisa: Estudo Integrado dos Ambientes Costeiros - GEIAC.

\section{MYLENNA ZIBELL}

Bacharel em Engenharia ambiental e sanitária pela Faculdade da Região Serrana. Pós-graduada em Gestão e educação ambiental pela Faculdade Multivix. Atua como consultora ambiental e professora (SEDU-ES). Interessa-se por Gestão Ambiental, Educação Ambiental e Desenvolvimento Sustentável.

\section{NATHALI VIEIRA DA SILVA}

Engenheira Sanitarista e Ambiental, formada pela UNIFESO e Engenheira de Segurança do Trabalho graduada pela Faculdade Silva e Souza. Mestranda no Programa de Pós-Graduação em Práticas em Desenvolvimento Sustentável pela UFRRJ. Auditora Interna de ISO 9001 (sistema de gestão da qualidade); ISO 14001 (sistema de gestão ambiental). Experiente na implementação e manutenção Sistema de Gestão Integrado (Qualidade, Segurança e Meio Ambiente), em realização de auditorias (clientes, fornecedores, órgãos de controle ambiental e certificadoras), no controle de requisitos legais, controle de qualidade, treinamentos de QSMS, controle e cumprimento de licenças, autorizações e monitoramentos ambientais, na comunicação com órgãos de controle ambiental, incluindo suporte técnico à demandas jurídicas. Gerenciamento e execução de programas de comunicação e educação ambiental. Experiente no planejamento, elaboração, execução, monitoramento e avaliação de programas e projetos de educação e comunicação social no campo de socioambiental. Sólida vivência em implementação de programas de educação ambiental e comunicação para a responsabilidade social, ambiental e empresarial.

\section{NICOLE JUNIA LEMOS CHAVES}

Graduanda no curso Tecnólogo em Gestão Ambiental na Universidade Federal de Viçosa - campus Florestal, cursou o ensino técnico em Agropecuária na mesma instituição. Realizou pesquisa sobre a resposta de crescimento do Faveiro de Wilson quanto a adubação nitrogenada, e foi bolsista no projeto de cultura e extensão: Coral UFV Florestal, cantando o amor.

\section{PAULA GUIMARÃES NEVES}

Engenheira química e mestranda em ciência e engenharia dos materiais pela Universidade Federal de Alfenas. Atuo na linha de pesquisa que envolve a síntese, caracterização e avaliação das propriedades de materiais cerâmicos para degradação de corantes. Além disso, atuo na equipe de qualidade da empresa Frooty Brasil. 


\section{PEDRO SOARES DE LIMA}

Aluno do $7^{\circ}$ ano do Ensino Fundamental do Colégio Militar do Recife, graduado como $3^{\circ}$ sgt,; Membro da Legião da Honra do Colégio Militar do Recife (CMR);

\section{RAMIRO GUEDES DO CARMO}

Mestrando no Programa de Pós-Graduação em Práticas em Desenvolvimento Sustentável pela UFRRJ. Profissional com sólido conhecimento em atividades no universo de QHSE (Saúde e Segurança, meio Ambiente e Qualidade), especialmente em Análise de Riscos, Laudos Técnicos e Higiene Ocupacional, Sistemas de Gestão Certificados e Treinamentos. Engenheiro de Segurança do Trabalho, Engenheiro Ambiental e Sanitarista, Especialista em Gestão de Riscos e Crises e Especialista e Auditor Líder em Sistemas de Gestão Certificados (ISO 9001, ISO 14001, OHSAS 18001 e ISO 45001) e Especialista em Ergonomia. Possui sólida vivência de implantação e manutenção do SGI e SGSO Offshore/ Onshore, NBR ISO 9001, NBR ISO 29001; NBR ISO 14001 e OHSAS 18001; Sólidos conhecimentos de legislação, normas técnicas de segurança do trabalho e saúde ocupacional e meio ambiente; Especialista na Elaboração e realização de avaliações ambientais quantitativas de acordo com a NR 15, ACGIH, NIOSH e ABHO dos agentes físicos, químicos e biológicos; Conhecimentos avançados em Emissão de laudos técnicos, após Inspeções de segurança em áreas de risco insalubres e /ou periculósas; Elaboração de Auditorias Internas de SGI e em Auditorias Ambientais em segmentos diversos.

\section{REGINA MARCIA LONGO}

Professora e pesquisadora em dedicação integral da Pontifícia Universidade Católica de Campinas e membro do corpo permanente de docentes dos cursos de mestrado em Sistemas de Infraestrutura Urbana (PUC-Campinas) e Sustentabilidade (PUC-Campinas). Possui graduação em Agronomia pela Universidade Estadual Paulista Júlio de Mesquita Filho (1991), mestrado em Engenharia Agrícola pela Universidade Estadual de Campinas (1994) , doutorado em Engenharia Agrícola pela Universidade Estadual de Campinas (1998), pós-doutorado pela UNESP-Jaboticabal (2003) e estagio pós doutoral pela Universidade da Califórnia-Riverside (2015).

\section{RENATA KELLY MENDES}

Professora pesquisadora em regime integral da Pontifícia Universidade Católica de Campinas e Docente Permanente do Programa de Pós Graduação em Sistemas de Infraestrutura Urbana. É colíder do Grupo de Pesquisa Quimiometria e Desenvolvimento de Sensores. Possui bacharelado em Química pela Universidade Federal de São Carlos (1999), graduação em Licenciatura em Química pela Universidade Federal de São Carlos (2002), mestrado em Química pela Universidade Federal de São Carlos (2002) e doutorado em Química pela Universidade Estadual de Campinas (2006), atuando principalmente nos seguintes temas: biossensores, eletroanalítica, nanocompósitos, análise ambiental.

\section{RODRIGO AMORIM MUNHOZ}

Graduando em Bacharelado interdisciplinar em ciência e tecnologia pela Universidade Federal de Alfenas, trabalhando na linha de pesquisa envolvendo síntese, caracterização e avaliação de propriedades de materiais cerâmicos para degradação de corantes, e síntese e caracterização de compósitos PLA- Argila refrataria com propriedades de retardância de chama.

\section{ROSANA PETINATTI DA CRUZ}

Possui graduação em Licenciatura em Química pela Universidade Federal do Rio de Janeiro (1999), mestrado em Química (Química Analítica Inorgânica) pela Pontifícia Universidade Católica do Rio de Janeiro (2002) e doutorado em Doutor em Ciência - Química pela Pontifícia Universidade Católica do Rio de Janeiro (2006). Atualmente é pesquisador e professor do Colégio Técnico da UFRRJ (CTUR). Tem experiência na área de Química, com ênfase em Química Geral e Ambiental, atuando principalmente no ensino técnico e tecnológico. 


\section{SERGIO ANDRES VILLALBA MORALES}

Engenheiro Químico (Universidad Industrial de Santander-Colômbia-2008), Mestre (UNICAMP2011) e Doutor (UNICAMP-2016) em Engenharia Química. Tenho desenvolvido projetos de pesquisa em colaboração com a indústria química e possuo 5 anos de experiência docente no ensino superior. Atualmente, sou Professor Adjunto A da Universidade Federal de Alfenas, no Campus Avançado de Poços de Caldas-MG. Desenvolvo projetos de pesquisa sobre projeto e modelagem de Biorreatores e Reatores Químicos, Cinética Química, Síntese e Caracterização de Catalisadores, Imobilização de Enzimas, Fotocatálise aplicada ao tratamento de efluentes e Reologia de produtos químicos e alimentícios.

\section{STEPHANIE OLIVEIRA NEVES}

Graduanda do curso de bacharelado em Engenharia Ambiental pela Universidade Federal de São Carlos (UFSCar). Tem experiência na área de Engenharia Sanitária, com ênfase em Engenharia Sanitária e Química Analítica. Graduação em Engenharia Ambiental (2017) - Universidade Federal de São Carlos, UFSCar, São Carlos, Brasil

\section{SUELI MARIA DOS SANTOS}

Graduada em Engenharia Ambiental e Sanitária pelo Centro Universitário de Formiga (2011). Especialização em Esp. Engenharia em Segurança do Trabalho. Centro Universitário de Lavras, UNILAVRAS, Lavras. Mestrado em Mestrado Profissional em Sustentabilidade e Tecnologia Ambiental. Instituto Federal de Minas Gerais - Campus Avançado Bambuí. Título: "Avaliação do tratamento de águas residuárias e fitorremediação do lodo provenientes do processo de produção de fogos de artifícios". Atualmente é engenheira ambiental e segurança do trabalho - Ind. Com. de Fogos Piroarte LTDA., engenheira ambiental e segurança do trabalho - Consultoria Ambiental e Segurança do Trabalho, professor da Universidade Presidente Antônio Carlos, professora da Faculdade de Filosofia, Ciências e Letras do Alto São Francisco, ambiental e segurança - IND. COM. de Fogos União LTDA e segurança e consultor ambiental - Artesanato de Fogos Pirocolor LTDA. Tem experiência na área de Engenharia Sanitária, com ênfase em Engenharia Sanitária, atuando principalmente nos seguintes temas: metais pesados, contaminantes, ambiente.

\section{SUELLEN GALVÃO MORAES}

Mestranda em Tecnologia e Gestão Ambiental do Instituto Federal de Educação, Ciência e Tecnologia do Ceará-IFCE. É graduanda em Engenharia Ambiental e Sanitária, cursando o 5o semestre na Universidade de Fortaleza. (trancado). É especialista em Gestão Ambiental pela Universidade de Fortaleza (2009). É Bacharel em Turismo pela Faculdade Integrada do Ceará - FIC (2006). Atualmente é Coordenadora do de cursos de Pós Graduação no eixo Sustentabilidade na Universidade de Fortaleza-UNIFOR.

\section{SYLMA CARVALHO MAESTRELLI}

Professora Associada, possui graduação em Engenharia de Materiais pela Universidade Federal de São Carlos, mestrado e doutorado em Ciência e Engenharia dos Materiais pela Universidade Federal de São Carlos e especialização em Engenharia Cerâmica pelo Centro Cerâmico de Bolonha Italia. Já foi professora adjunta na UESC e professora titular nas faculdades FAJ e POLICAMP, tendo nesta ultima atuado como coordenadora de curso. Desde 2009 é professora da Universidade Federal de Alfenas, campus de Poços de Caldas e desde 2010 é professora do PPGCEM da UNIFALMG campus de Poços de Caldas. As linhas de pesquisa envolvem a síntese, caracterização e avaliação de propriedades de materiais cerâmicos e nanocompósitos cerâmicos.

\section{TANIA REGINA GIRALDI}

Possui graduação em Química pela Universidade Estadual Paulista Júlio de Mesquita Filho - Unesp (2000), Mestrado em Química pela Universidade Estadual Paulista Júlio de Mesquita Filho - Unesp (2003) e Doutorado pela Universidade Federal de São Carlos - UFSCar (2007). Realizou Pós- 
Doutorado na Embrapa - Istrumentação Agropecuária (2008-2010), atuando no desenvolvimento de nanomateriais com potencialidade para aplicação em agronegócio. Atualmente é professora do Instituto de Ciência e Tecnologia da Universidade Federal de Alfenas-Campus de Poços de Caldas. É docente credenciada nos Programas de Pós-Graduação em Ciência e Engenharia de Materiais, no campus Poços de Caldas. Tem experiência na área de Química, com ênfase em Química de Materiais, atuando principalmente na síntese de semicondutores na forma de nanopartículas e filmes finos.

\section{THABATA FERNANDES PRECRIMO}

Engenheira Ambiental e Sanitarista pela Universidade de Fortaleza, 2016 (UNIFOR) e Engenheira de Segurança do Trabalho pela Pós Graduação UniAteneu, 2018. Monitora Voluntária pela Universidade de Fortaleza da disciplina Ecologia Geral, 2015.

\section{THIAGO DE OLIVEIRA CALSOLARI}

Cursou licenciatura em Física (2008) pela Universidade Estadual Paulista "Júlio de Mesquita Filho" (Unesp). Possui especialização em Metodologia do Ensino de Matemática e Física (2016) pelo Centro Universitário Internacional. Atualmente é mestrando em Ciência e Tecnologia de Materiais (2018-presente) pela UNESP e atua como técnico de laboratório na área de Física pela Universidade Federal de São Carlos, campus Lagoa do Sino, desde 2014. Seus interesses em pesquisa se concentram na área de supercondutividade de materiais, ensino de física e na área de prevenção de desastres ambientais.

\section{TIAGO LUCAS FERREIRA}

Graduado em Engenharia Civil com enfase em Meio Ambiente pela FUNEDI / UEMG (2012), Pós Graduado em Construção Civil e Obras de Infraestrutura pela UEMG (2015), Mestrando Sustentabilidade e Tecnologia Ambiental no IFMG Campus Bambuí, carreira desenvolvida como professor acadêmico e coordenador de estagio na UEMG Divinópolis, experiência adquirida lecionando aulas de orçamento de obras, mecânica dos solos e obras de terra, como engenheiro executei obras em construção pesada, construção da ETE de Nova Serrana, fiscalização de obras públicas, CAIXA Econômica Federal, trabalhando com medição, planejamento e cronograma físico financeiro. Perito judicial do TJMG na área de construção civil, meio ambiente e demarcação divisas de propriedades. Inglês intermediário, cursado A+ English na Inglaterra.

\section{TIAGO NASCIMENTO DA SILVA FARIA}

Cursa Ensino Médio Integrado ao Técnico em Meio Ambiente no Colégio Técnico da Universidade Federal Rural do Rio de Janeiro (CTUR). Compõe a equipe Mensageiros de Gaia, ganhadora dos Destaque Regional e Nacional da 9a Olímpiada Brasileira de Saúde e Meio Ambiente equipe Competição elaborada pela FIOCRUZ (2018). É co-autor na seguinte publicação: Faria, T., et allis. (2017) “Raízes Literárias VI”. Pág. 112. Ed. Talagarça. ISBN 978-85-89825-24-5.

\section{UESLLEI SOUSA REIS}

Possui graduação em Direito pela Universidade Estadual do Piauí (2014). Advogado OAB-PI no12335 (2015), Especialista em Direito Administrativo pela Universidade Cândido Mendes (2017). Atualmente é técnico laboratório área eletromecânica do Instituto Federal do Piauí e membro do Grupo de Pesquisa Turma de Robótica Inovação e Pesquisa (TRIP). Tem experiência na área de Engenharia Elétrica, com ênfase em Medidas Elétricas, Magnéticas e Eletrônicas; Instrumentação. Membro da Agenda Ambiental na Administração Pública-A3P do IFPI Campus Floriano. Responsável Técnico pelo Acompanhamento e Manutenção das Usinas Fotovoltaicas do IFPI Campus Floriano. Além de desenvolver atividades junto ao setor de licitações do Instituto Federal do Piauí - Campus Floriano. 


\section{WANDERSON DE PAULA PINTO}

Possui graduação em Matemática pela Faculdade da Região Serrana - FARESE (2010), especialização em Docência do Ensino Superior - FARESE (2011), mestrado (2013) e doutorado (2019) em Engenharia Ambiental, área de concentração Poluição do Ar, linha de pesquisa modelagem matemática e estocástica de processos atmosféricos pela Universidade Federal do Espírito Santo - UFES. Professor do departamento de Ciências Ambientais e coordenador do Núcleo Integrado de Pesquisa em Engenharia Ambiental da FARESE. Professor efetivo da EEEFM Frederico Pretti Santa Teresa, ES, Brasil. Possui experiência nas áreas de Matemática, Matemática Aplicada, Modelagem Matemática, Cálculo Diferencial e Integral, Educação Matemática, Probabilidade e Estatística aplicada, Análise de Séries Temporais com missing data, Análise Espectral de Séries Temporais, Programação em R, Poluição Atmosférica, Dispersão de Contaminantes Atmosféricos e Licenciamento Ambiental.

\section{WYLLERSON EVARISTO GOMES}

Pesquisador, pós-doutorando no Programa de Pós Graduação em Sistemas de Infraestrutura Urbana - PUC- Campinas. Possui o título de Doutor em Ciências pelo Instituto de Física "Gleb Wataghin" da Universidade Estadual de Campinas, UNICAMP (2015). Doutorado Sanduíche na Universidade de Viena, Áustria (2012/2013). É Mestre em Física pela Universidade Estadual de Campinas (2010). Bacharel em Física e em Física Biomédica pela mesma Universidade (2007). Possui interesse em Estudos Avançados Multidisciplinares em Nanociência e Nanotecnologia, nas áreas de Física, Química e Biologia. Estuda a auto-organização de agregados de moléculas anfifílicas, bem como aplicações destas estruturas em sensores ambientais.

\section{ZORAIA DA SILVA ASSUNÇÃO}

Doutora em Educação (UFRN) com a tese "Metrópole Digital: o jovem aprendiz na educação tecnológica". Graduada em Engenharia (UFBA). Engenheira da Embasa - Salvador BA. Graduada em Pedagogia (UNP). Mestre em Educação (UFRN) com a dissertação de mestrado A Internet como tecnointeração da aprendizagem. Especialista em Aprendizagem Cooperativa (UCB), Especialista em Docência do Ensino Superior (UNIPEC) , Especialista em Informática (UFPB), Especialista em Currículo: Teoria e Prática (PUC-RIO), Analista de Sistema(UFBA). 


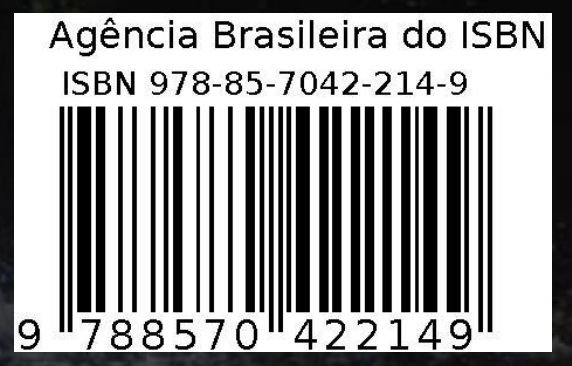

